UNIVERSIDADE DE SÃO PAULO

FACULDADE DE ECONOMIA, ADMINISTRAÇÃO E CONTABILIDADE DEPARTAMENTO DE ADMINISTRAÇÃO

PROGRAMA DE PÓS-GRADUAÇÃO EM ADMINISTRAÇÃO

Uma visão integrada sobre o nível de uso das Tecnologias da

Informação e Comunicação em escolas brasileiras

Raphael Donaire Albino

Orientador: Prof. Dr. Cesar Alexandre de Souza

SÃo PAULO

2015 
Prof. Dr. Marco Antonio Zago

Reitor da Universidade de São Paulo

Prof. Dr. Adalberto Américo Fischmann

Diretor da Faculdade de Economia, Administração e Contabilidade

Prof. Dr. Roberto Sbragia

Chefe do Departamento de Administração

Prof. Dr. Moacir de Miranda Oliveira Júnior

Coordenador do programa de Pós-Graduação em Administração 


\title{
Uma visão integrada sobre o nível de uso das Tecnologias da Informação e Comunicação em escolas brasileiras
}

\author{
Dissertação apresentada ao departamento de \\ Administração da Faculdade de Economia, \\ Administração e Ciências Contábeis da \\ Universidade de São Paulo, como avaliação para \\ obtenção do título de mestre em ciências.
}

Orientador: Prof. Dr. Cesar Alexandre de Souza

Versão Corrigida

(versão original disponível na Faculdade de Economia, Administração e Contabilidade)

\section{SÃo PAULO}



FICHA CATALOGRÁFICA

Elaborada pela Seção de Processamento Técnico do SBD/FEA/USP

Albino, Raphael Donaire

Uma visão integrada sobre o nível de uso das tecnologias da informação e comunicação em escolas brasileiras / Raphael Donaire Albino. -São Paulo, 2015.

$167 \mathrm{p}$.

Dissertação (Mestrado) - Universidade de São Paulo, 2015.

Orientador: César Alexandre de Souza.

1. Tecnologia da informação 2. Educação 3. Escolas 4. Análise multivariada 5. Modelagem de equações estruturais I. Universidade de São Paulo. Faculdade de Economia, Administração e Contabilidade. II. Título.

CDD -658.4038 
Dedico este trabalho aos meus eternos mestres e pais, Tânia e João Pedro, aos meus irmãos Daniel e João, e à minha amada e parceira incondicional, Jeniffer. 


\section{Agradecimentos}

Primeiramente gostaria de agradecer ao professor Dr. Cesar Alexandre pela oportunidade de ser seu orientando, afinal, ele foi a pessoa que me recebeu desde o momento em que me interessei a mergulhar nesta jornada acadêmica. Tenho absoluta certeza de que todo o resultado apresentado neste estudo é reflexo de sua orientação e apoio.

Agradeço ao professor Dr. Nicolau Reinhard por suas sábias contribuições. Ter a oportunidade de conviver e ser aluno de uma referência tão importante na temática Sistemas de Informação é motivo de muito orgulho para mim.

Agradeço também ao professor Dr. Wilson Yonezawa por sua participação e contribuição neste trabalho, afinal, é gratificante ter a possibilidade de contar com um mestre que pôde participar da minha formação desde minha época de graduação.

Registro também meu agradecimento para a amiga de corrida e da vida Lícia Abe por seu apoio e auxílio nesta fase da minha vida. Fico feliz de poder contar com sua amizade em todos os momentos.

Agradeço também aos colegas e amigos que fiz aqui na USP. Ao Vladi, por ganhar um amigo. Registro também um especial agradecimento à Érica Siqueira e ao Marcelo Araujo que foram duas pessoas muito importantes para que o trabalho aqui desenvolvido ganhasse forma e conteúdo.

Agradeço à minha família e meus amigos por todo o suporte, carinho, afeto e compreensão. Para minha esposa Jeniffer, fica aqui a gratidão registrada por todas as revisões e incentivos nos momentos mais complexos desta jornada. Te amo de todas as maneiras.

Um especial agradecimento ao meu pai João Pedro que, com suas importantes contribuições, pôde me apoiar mais uma vez. Serei eternamente grato à ele e a minha mãe Tânia por terem me ensinado a valorizar acima do ter, o saber.

Para finalizar, gostaria de agradecer ao CETIC.br pelo compartilhamento das valiosas bases de microdados da pesquisa TIC Educação e a todo o seu time que acompanhou esta jornada do início ao fim. Wins, Magê, Lú, Manu, Ali, Van, Tati, Fábio, Má, a energia e a amizade de vocês foram muito importantes. Ao Alexandre Barbosa, fica o agradecimento pelo estímulo ao aprendizado contínuo e pela confiança depositada. Ao Marcelo Pitta e ao Emerson Gomes, agradeço suas revisões e contribuições metodológicas, afinal, espero que saibam o quão importante foram nos momentos onde as saídas pareciam difíceis. Não posso me esquecer das minhas amigas Suzana e Isabela pelas dicas estatísticas. Fica aqui um agradecimento especial à Camila Garroux, pelo auxílio na busca do referencial teórico que sustentou este trabalho. 


\section{Resumo}

No contexto do ensino, a Tecnologia da Informação e Comunicação (TIC) assume um importante papel em termos de apoio pedagógico com o intuito de auxiliar na melhoria da estrutura básica da educação. $\mathrm{O}$ acesso a novas tecnologias traz formas diferentes de aprender e pensar, para professores, alunos e instituições de ensino.

A incorporação das tecnologias nas escolas contribui para expandir o acesso à informação atualizada e, principalmente, para promover a criação de comunidades colaborativas de aprendizagem que privilegiam a construção do conhecimento, a comunicação, a formação continuada e a gestão articulada entre as áreas administrativa e pedagógica da escola.

No Brasil, é possível observar a existência de propostas de incentivo ao uso das tecnologias digitais na educação, no entanto, é importante salientar que a ênfase das discussões recai sobre a disponibilidade de hardware e software.

Diante da importância de compreender a relação entre a tecnologia e o universo escolar, este estudo tem por objetivo avaliar o nível de uso das TICs em escolas brasileiras. Para isso, foi proposto e construído um índice que permitiu apresentar diferenças quanto ao nível de uso das escolas investigadas à luz da perspectiva regional, administrativa e de desenvolvimento humano municipal. A partir dos resultados apresentados pelas escolas, foi possível também classificá-las em baixo uso, uso moderado, uso elevado e uso muito elevado das TICs.

Como segundo enfoque de análise, através de um conjunto de variáveis utilizadas no desenvolvimento do índice, foi demonstrado que uma escola fará um maior uso das tecnologias a partir do momento em que é possível ter uma direção que suporte o uso. Além disso, torna-se importante que a escola oferte uma infraestrutura que traga a maior disponibilidade de computadores para o uso pedagógico possível, bem como ofereça aulas específicas de informática. Por fim, integrar o computador e a Internet às práticas pedagógicas, também demonstrou-se um fator importante para que haja um elevado uso das TICs.

A fim de atingir os objetivos desta pesquisa, foram utilizados os microdados da pesquisa TIC Educação, conduzida pelo Comitê Gestor da Internet no Brasil, em sua edição de 2013.

Palavras-chave: Tecnologia da Informação e Comunicação; Educação; Escolas; Uso das TICs; Análise multivariada; Modelagem de Equações Estruturais. 


\begin{abstract}
In the context of education, Information and Communication Technology (ICT) plays an important role in educational support in order to help improve the education. Access to new technologies brings different ways of learning and thinking, for teachers, students and educational institutions.

The use of ICT in schools contributes to expand access to updated information and, especially, to promote the creation of collaborative learning communities that boost the construction of knowledge, continuing education and an integrated management environment. In Brazil, it is possible to notice the existence of proposals to encourage the use of digital technologies in education, however, it is important to note that the emphasis of the discussion is on the availability of hardware and software in schools.

Given the importance in observing the dynamics of the school routine, this study aims at evaluating the level of ICT use in Brazilian schools. Because of that, it was proposed and constructed an index that allowed to differ the levels of ICT use by regional, administrative and municipal human development perspectives. From the results presented by the schools, it was also possible to classify them in low, moderate, high and very high use of ICTs.

The next step of analysis demonstrated that a school make greater use of technologies once it is possible to have leaders that support the use. In addition, it is important to school offer a good infrastructure, as well as provide information technology specific classes. Finally, integrating the computer and the Internet to pedagogical practices also proved to be an important factor to elevate the use of ICT on schools.

In order to achieve the objectives of this research, was used the micro-data of the 2013 survey ICT Education. The ICT Education survey is conducted annually by the Brazilian Internet Steering Committee (CGI).
\end{abstract}

Keywords: Information and Communication Technology; Education; schools; Use of ICTs; Multivariate Analysis; Structural Equation Modeling. 


\section{LISTA DE GRÁFICOS}

Gráfico 1- Histograma do índice de uso das TICs nas escolas..............................................93

Gráfico 2 - Histograma das dimensões do índice de uso das TICs nas escolas ......................93

Gráfico 3 - Boxplot do índice de uso das TICs nas escolas após tratamento de outliers ..........96

Gráfico 4 - Médias do índice e de suas dimensões por região ................................................98

Gráfico 5 - Médias do índice e de suas dimensões por dependência administrativa................99

Gráfico 6 - Histograma da distribuição do índice de uso das TICs por região........................103

Gráfico 7 - Histograma da distribuição do índice de uso das TICs por dependência

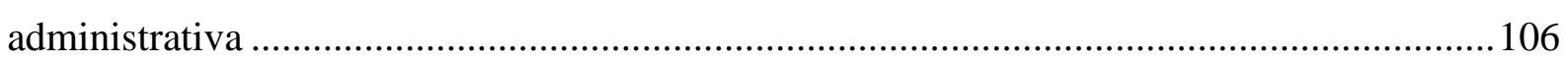

Gráfico 8 - Histograma da distribuição do índice de uso das TICs por faixa de IDH-M.......108 


\section{LISTA DE FIGURAS}

Figura 1 - Pesquisas realizadas pelo CETIC.br .7

Figura 2 - Estrutura do modelo que mostra as três dimensões de elementos interligados 40

Figura 3 - Framework de Zwicker et al. (2007) adaptado para o contexto educacional..... 41

Figura 4 - Fatores que afetam o uso das TICs pelos alunos e o desempenho escolar 43

Figura 5 - Modelo para criação do índice de uso das TICs em escolas ....................................50

Figura 6 - Passos básicos de uma lógica hipotético-dedutiva ................................................53

Figura 7 - Percentual do total de escolas da amostra por região e dependência administrativa 64

Figura 8 - Processo de desenvolvimento do índice .68

Figura 9 - Modelo de pesquisa . 84

Figura 10 - Representação gráfica da relação entre variáveis latentes em diferentes ordens ... 85

Figura 11 - Cargas fatoriais no modelo de pesquisa...... 85

Figura 12 - Análise da significância calculada por bootstrapping no modelo de pesquisa.......86

Figura 13 - Análise das cargas fatoriais no modelo derivado 87

Figura 14 - Análise da significância calculada por bootstrapping no modelo derivado .87

Figura 15 - Análise das cargas fatoriais no modelo final 90

Figura 16 - Análise da significância calculada por bootstrapping no modelo final 90

Figura 17 - Índice de uso das TICs 121 


\section{LISTA DE TABELAS}

Tabela 1 - Distribuição da amostra obtida por região 63

Tabela 2 - Distribuição da amostra obtida por dependência administrativa. 63

Tabela 3 - Matriz de correlação das variáveis da dimensão Gestão .71

Tabela 4 - Resultados da análise fatorial para a dimensão Gestão .72

Tabela 5 - Resultados da análise fatorial na dimensão Gestão pós remoção da variável p1902

Tabela 6 - Matriz de correlação das variáveis da dimensão Infraestrutura ..............................75

Tabela 7 - Resultados da análise fatorial para a dimensão Infraestrutura ................................76

Tabela 8 - Matriz de correlação das variáveis da dimensão Uso por professores e alunos .......78

Tabela 9 - Resultados da análise fatorial para a dimensão Uso por professores e alunos........ 79

Tabela 10 - Resultados da análise fatorial para todas as variáveis do modelo.........................80

Tabela 11 - Validade convergente e confiabilidade no modelo derivado ...............................89

Tabela 12 - Correlação de Pearson entre as variáveis latentes no modelo derivado ............... 89

Tabela 13 - Validade convergente e confiabilidade no modelo final .....................................91

Tabela 14 - Correlação de Pearson entre as variáveis latentes no modelo final......................91

Tabela 15 - Estatísticas descritivas dos escores fatoriais padronizados nas variáveis do índice

Tabela 16 - Escolas removidas da análise pelo desempenho na dimensão Infraestrutura .......94

Tabela 17 - Percentual de outliers identificados a partir dos indicadores que compõe a

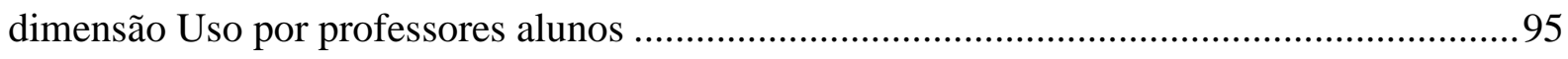

Tabela 18 - Estatísticas descritivas do índice e dimensões padronizadas ...............................96

Tabela 19 - Médias do índice e de suas dimensões por região...............................................97

Tabela 20 - Médias do índice e de suas dimensões por dependência administrativa ...............98

Tabela 21 - Médias do índice e de suas dimensões por faixa do IDH-M...............................100

Tabela 22 - P-value do teste das comparações múltiplas de Dunn para as regiões .................105

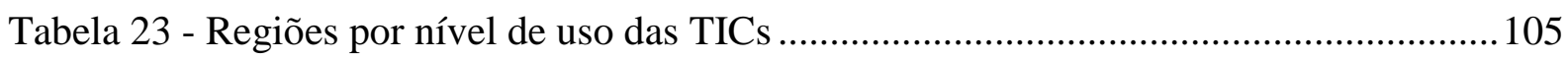

Tabela 24 - P-value do teste das comparações múltiplas de Dunn para as dependências

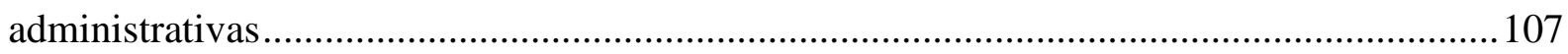

Tabela 25 - Dependências administrativas por nível de uso das TICs ..................................108

Tabela 26 - Faixa de IDH-M por nível de uso das TICs ....................................................110

Tabela 27 - Tabela de classificação do modelo logístico inicial ..........................................114

Tabela 28 - Tabela de classificação do modelo logístico final .......................................... 117 


\section{LISTA DE QUADROS}

Quadro 1 - Definição do tema de pesquisa.........................................................................

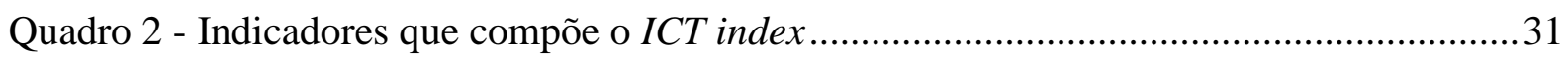

Quadro 3 - Indicadores qualitativos de uso das TICs na Educação .........................................34

Quadro 4 - Dimensões, variáveis e objetivos mensurados pelo The Use of ICT in Education 35

Quadro 5 - Dimensões, subdimensões e variáveis do modelo de pesquisa ............................. 42

Quadro 6 - Unidades de análise e variáveis mensuradas pela pesquisa TIC Educação...........47

Quadro 7 - Relacionamento entre as dimensões teóricas estudadas e os indicadores de uso das

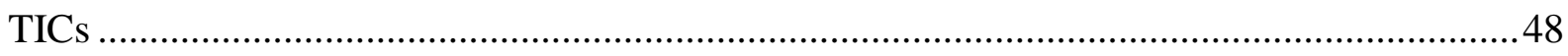

Quadro 8 - Dimensões do modelo de pesquisa .................................................................51

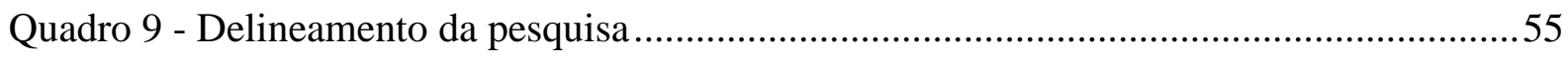

Quadro 10 - Variáveis propostas para a dimensão Gestão ...................................................58

Quadro 11 - Variáveis propostas para a dimensão Infraestrutura.........................................59

Quadro 12 - Variáveis propostas para a dimensão Uso por professores e alunos ....................60

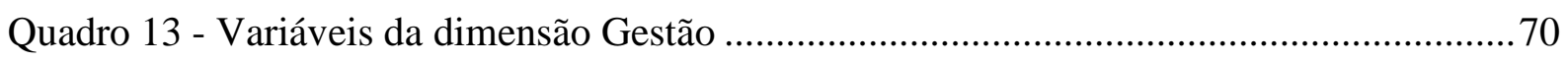

Quadro 14 - Subdimensões da dimensão Gestão .............................................................. 74

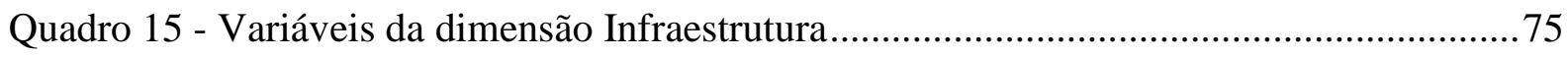

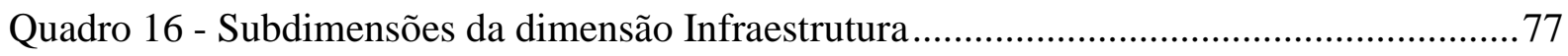

Quadro 17 - Variáveis da dimensão Uso por professores e alunos .........................................77

Quadro 18 - Subdimensões da dimensão Uso por professores e alunos ..................................79

Quadro 19 - Relação entre as dimensões, subdimensões e variáveis originadas da AFE .......81

Quadro 20 - Classificação das escolas a partir do desempenho no índice de uso das TICs ..101

Quadro 21 - Resumo dos testes estatísticos empregados como pressupostos da ANOVA....102

Quadro 22 - Teste de normalidade para as regiões ........................................................... 103

Quadro 23 - Teste de homogeneidade das variâncias entre as regiões.................................103

Quadro 24 - Estatística do teste de Kruskal-Wallis para as regiões ..................................... 104

Quadro 25 - Teste de normalidade para as dependências administrativas............................106

Quadro 26 - Teste de homogeneidade das variâncias entre as dependências administrativas106

Quadro 27 - Estatística do teste de Kruskal-Wallis para as dependências administrativas ...107

Quadro 28 - Teste de normalidade para as faixas de IDH-M ...........................................109

Quadro 29 - Teste de homogeneidade das variâncias entre as faixas de IDH-M..................109

Quadro 30 - ANOVA para a média de uso das TICs nas diferentes faixas do IDH-M .........109

Quadro 31 - Resultados do teste de Bonferroni para as faixas do IDH-M ..........................110 
Quadro 32 - Variáveis independentes do modelo logístico ................................................112

Quadro 33 - Diagnóstico de multicolinearidade................................................................. 113

Quadro 34 - R2 e -2LL dos modelos logísticos, por passos, para o modelo inicial ................113

Quadro 35 - Teste de Hosmer Lemeshow para o modelo inicial.........................................114

Quadro 36 - Modelo de regressão logística inicial .............................................................115

Quadro 37 - Diagnóstico de multicolinearidade para o modelo final ...................................116

Quadro 38 - R2 e -2LL dos modelos logísticos, por passos, para o modelo final..................116

Quadro 39 - Teste de Hosmer Lemeshow para o modelo final ............................................116

Quadro 40 - Modelo de regressão logística final..............................................................117 


\section{LISTA DE ABREVIATURAS E SIGLAS}

AF - Análise Fatorial

AFE - Análise Fatorial Confirmatória

AFE - Análise Fatorial Exploratória

ANOVA - Análise de variância

ANPAD - Associação Nacional de Pós-Graduação e Pesquisa em Administração

AVE - Análise de Variância Extraída

BYOD - Bring Your Own Device

CC - Confiabilidade Composta

CETIC.br - Centro Regional de Estudos para o Desenvolvimento da Sociedade da Informação

CGI.br - Comitê Gestor da Internet no Brasil

CIED - Centros de Informática na Educação

CR - Composite Reability

ENEM - Exame Nacional do Ensino Médio

ERP - Enterprise Resource Planning

IDH - Índice de desenvolvimento humano

IDH-M - Índice de desenvolvimento humano municipal

IDIE - Instituto para o Desenvolvimento e Inovação Educativa

IEA - International Association for the Evaluation of Educational Achievement

INEP - Instituto Nacional de Estudos e Pesquisas Educacionais Anísio Teixeira Legislação e Documentos

KMO - Kaiser-Meyer-Olkin

KS - Kolmogorov-Sminorv

MEC - Ministério da Educação

MEE - Modelagem de Equações Estruturais

OEI - Organização dos Estados Ibero-americanos para a Educação, a Ciência e a Cultura

OLPC - One Laptop per Child

PISA - Programa Internacional de Avaliação de Alunos

PLS - Partial least squares

POIE - Professor Orientador de Informática

PROINFO - Programa Nacional de Tecnologia Educacional 
PRONINFE - Programa Nacional de Informática Educativa

PROUCA - Programa Um Computador por Aluno

SAEB - Sistema de Avaliação da Educação Básica

SEED - Secretaria de Educação a Distância

TI - Tecnologia da Informação

TIC - Tecnologia da Informação e Comunicação

TICs - Tecnologias da Informação e Comunicação

UE27 - União Européia 


\section{Sumário}

1 INTRODUÇÃO - -

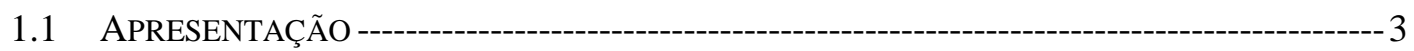

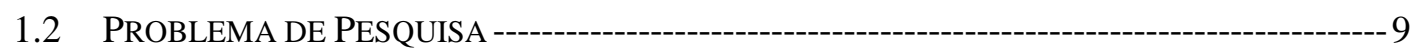

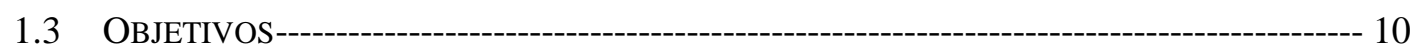

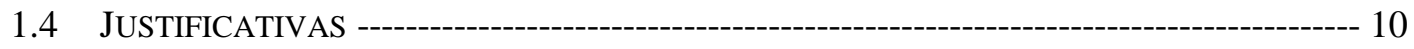

1.5 CONTRIBUIÇÃO DO ESTUDO------------------------------------------------------- 12

1.6 ESTRUTURAÇÃO-- 12

2 REFERENCIAL TEÓRICO - 13

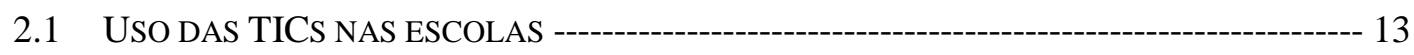

2.2 CAPITAL hUMANO E AS TICS NAS ESCOLAS --- 15

2.2.1 O uso das TICs pelos professores--.-- 16

2.2.2 O uso das TICs pelos alunos -- 17

2.2.3 O diretor e as TICs nas escolas --.-- 19

2.3 INFRAESTRUTURA TECNOLÓGICA------------------------------------------- 20

2.3.1 Infraestrutura de TI--- 20

2.3.2 Recursos computacionais no dia a dia escolar ------------------------ 22

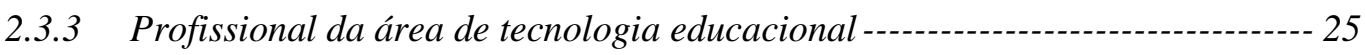

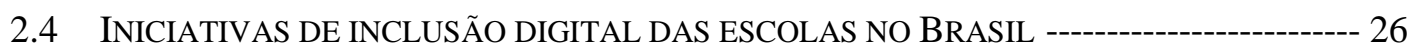

2.5 INDICADORES DE TECNOLOGIA DA INFORMAÇÃO E COMUNICAÇÃO NA EDUCAÇÃO30

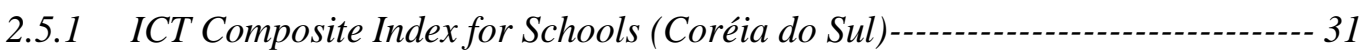

2.5.2 Indicadores qualitativos de uso das TICs na Educação (Organização dos Estados Ibero-americanos)--------------------------------------------------- 33

2.5.3 The Use of ICT in Education: a survey of schools in Europe (União Européia) 35

2.5.4 A Maturity Model for Assessing the Use of ICT in School Education---------- 37

2.5.5 Acesso e uso da Tecnologia da Informação em escolas públicas e privadas de ensino médio: o impacto nos resultados do ENEM ------------------ 41

2.5.6 Measuring ICT Use and Learning Outcomes: evidence from recent econometric studies 42

2.5.7 Pesquisa TIC Educação--- 45

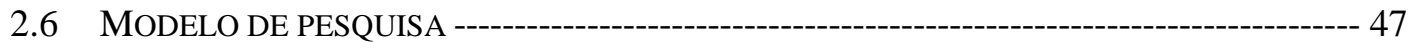

3 METODOLOGIA ------- 52

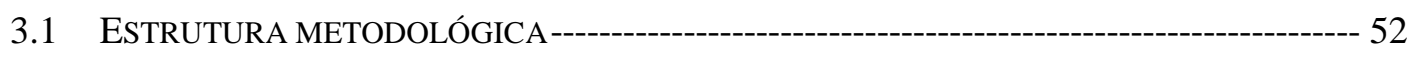

3.2 DEFINIÇÕES METODOLÓGICAS DA PESQUISA TIC EDUCAÇÃO 2013 ------------------ 55 
3.3 PROCESSO DE SELEÇÃO DAS VARIÁVEIS DO MODELO-- 57

3.4 TRATAMENTO DOS DADOS -- 61

3.5 CARACTERIZAÇÃO DA AMOSTRA OBTIDA--- 62

3.6 METOdologia DE DESENVOLVIMENTO DO ÍNDICE E DA ANÁLISE DO DADOS -------- 64

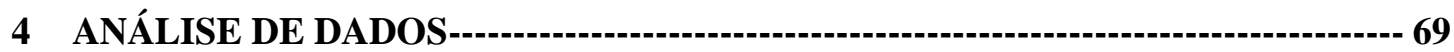

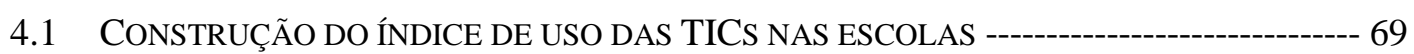

4.1.1 Definição da dimensão Gestão--- 70

4.1.2 Definição da dimensão Infraestrutura ---------------------------------- 74

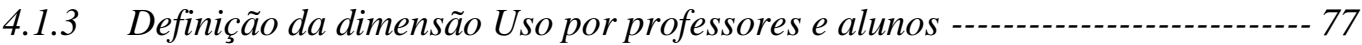

4.1.4 Análise fatorial com o conjunto de variáveis do modelo ---_-_-_-- 80

4.1.5 A aplicação da Modelagem de Equações Estruturais para o desenvolvimento do indice 81

4.2 EXPLORANDO O ÍNDICE DE USO DAS TICS NAS ESCOLAS E SUAS DIMENSÕES -------- 92

4.2.1 Estatística descritiva do índice de uso e de suas dimensões-------------------- 92

4.2.2 Transformação das variáveis e análise das escolas da amostra---------------- 96

4.2.3 Identificando diferenças no índice de uso das TICs em escolas -------------101

4.3 AVALIANDO FATORES QUE DIFERENCIAM O USO DAS TICS NAS ESCOLAS -----------111

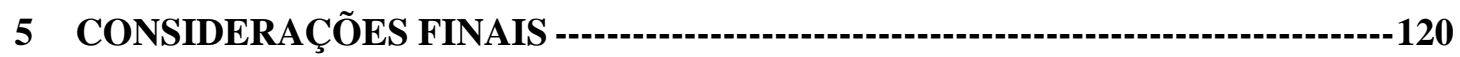

5.1 DESENVOLVIMENTO DO ÍNDICE DE USO DAS TICS EM ESCOLAS ------------------120

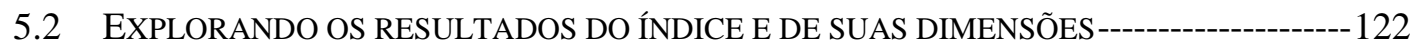

5.3 ANALISANDO FATORES QUE CONTRIBUEM PARA USO DAS TICS EM ESCOLAS-------124

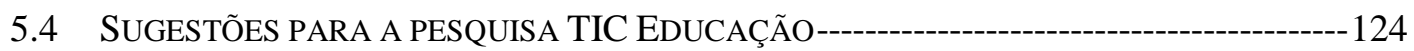

5.5 LIMITAÇÕES DA PESQUISA ---_---125

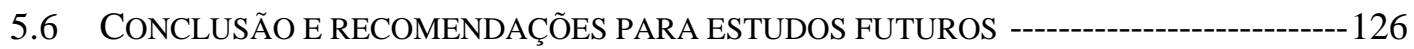

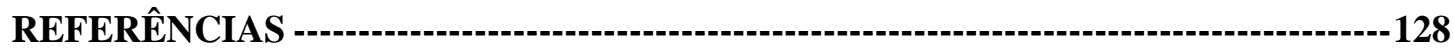

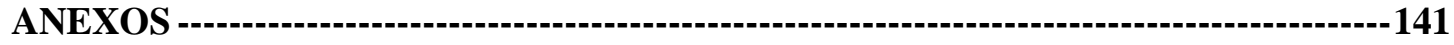

ANEXO A TIC PISA 2009: QUESTÕES UTILIZADAS NO ESTUDO DE BIAGI E LOI (2013) 141 ANEXO B DICIONÁRIO DAS VARIÁVEIS CONTIDAS NO QUESTIONÁRIO APLICADO AOS

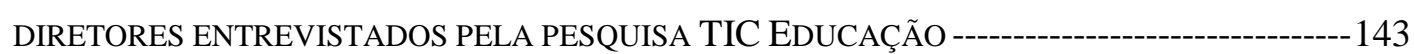

ANEXO C DICIONÁRIO DAS VARIÁVEIS CONTIDAS NO QUESTIONÁRIO APLICADO AOS COORDENADORES PEDAGÓGICOS ENTREVISTADOS PELA PESQUISA TIC EDUCAÇÃO -----159 


\section{Introdução}

\subsection{Apresentação}

A promoção do desenvolvimento humano passa, obrigatoriamente, pela oferta de uma educação de qualidade, acessível a todos e comprometida com as exigências do mundo atual. O desenvolvimento sócio econômico sustentável de uma nação está diretamente relacionado a uma educação que acompanha e impulsiona as mudanças e, ao mesmo tempo, se apropria das tecnologias disponíveis, isto é, uma educação capaz de contribuir para a inclusão social e para a construção de um saber que suporte a tarefa de imprimir as transformações necessárias para a inserção do país, de forma competitiva, no mercado mundial. Neste contexto, se torna necessária à criação de um processo educacional criativo e flexível o suficiente a fim de incorporar as novas tecnologias, colocando-as a serviço da formação de uma sociedade crítica e produtiva (SAMPAIO et al., 2005).

O problema de acesso à educação fundamental no Brasil parece ter sido resolvido nos últimos anos, haja vista que aproximadamente 98,2\% das crianças em idade escolar estão matriculadas nas escolas, conforme dados publicados pela Pesquisa Nacional por Amostras de Domicílio (IBGE, 2012). No entanto, se a questão da frequência pode ter sido resolvida, o problema da baixa qualidade do ensino ainda parece longe de sê-lo. Segundo resultados do PISA ${ }^{1}$ (OCDE, 2012), o Brasil obteve a $58^{\text {a }}$ posição no ranking de matemática, a $55^{\mathrm{a}}$ no de leitura e a $59^{\mathrm{a}}$ no de ciências entre 65 países. Mais do que esse pobre resultado relativo, a avaliação constatou que 49,2\% dos alunos brasileiros participantes não atingiram sequer o nível de leitura considerado básico, isto é, quase metade dos alunos brasileiros não conseguem estabelecer relações entre diferentes partes do texto e não conseguem compreender nuances da linguagem.

A baixa qualidade da educação no Brasil é um fator frequentemente apontado como um fundamental empecilho na solução de problemas econômicos e sociais existentes no país, como altos índices de pobreza e desigualdade de renda. Vale ressaltar que, segundo a Constituição Federal do Brasil de 1988, é dever do Estado garantir

\footnotetext{
${ }^{1}$ PISA - Programa Internacional de Avaliação de Alunos
} 
educação básica obrigatória e gratuita dos 04 (quatro) aos 17 (dezessete) anos de idade, assegurada inclusive sua oferta gratuita para todos os que a ela não tiveram acesso na idade própria (BRASIL, 2012). A Lei de Diretrizes e Bases da Educação de 1996, em seu artigo $4^{\circ}$, inciso VII, garante também oferta de educação escolar regular para jovens e adultos, com características e modalidades adequadas às suas necessidades e disponibilidades (BRASIL, 2010). É dever do Estado garantir um ensino público de qualidade, assegurando ao aluno sua permanência na escola e conclusão dos estudos.

Em um survey comparando países, Hanushek e Kimko (2000) concluem que é mais importante para o crescimento econômico a qualidade do que a quantidade de educação.

Com o objetivo de apoiar o processo de desenvolvimento de uma nação, a Tecnologia da Informação e Comunicação (TIC) tem sido colocada como uma importante aliada neste processo (KLUVER, 2000). Segundo Pozo (2004), as tecnologias estão possibilitando novas formas de distribuir socialmente o conhecimento.

$\mathrm{Na}$ tentativa de melhorar a qualidade dos insumos educacionais, uma ideia correntemente mencionada é a de aumentar o acesso dos alunos às TICs, como o computador e o acesso à Internet. Integrar informática ao processo de ensinoaprendizagem tradicional em um país emergente compensaria, de certa forma, o baixo preparo dos professores e tornaria a escola mais atrativa aos alunos (LINDEN et al., 2003).

Angrist e Lavy (2002) avaliaram o impacto do uso de computadores no auxílio ao ensino de escolas israelenses. Não só não acharam impacto nos exames de matemática e de hebreu, como também observaram efeito negativo do uso de computadores. Linden et al. (2003) argumentam que tal evidência não deve influenciar os países em desenvolvimento a abandonarem o uso de computadores nas escolas, pois o caso de Israel seria bem específico, uma vez que os alunos tratados pelo programa passaram a ter menos tempo do ensino tradicional do que o que se tem em escolas bem equipadas e com professores bem treinados.

No Brasil, Neri (2012) calculou medidas de correlações brutas e parciais entre o fato de a criança possuir acesso ao computador e Internet e o desempenho no Sistema de Avaliação da Educação Básica (Saeb). Os resultados são positivos, muito embora não representem explicitamente causalidade. Dwyer et al. (2007) compararam, usando 
dados do Saeb, alunos que tinham e não tinham acesso ao computador e evidenciou que o uso de computadores diminuiu a proficiência em português e matemática.

De forma geral, o simples acréscimo de computadores e outros equipamentos de informática traz pouco impacto sobre o desempenho dos alunos podendo, em alguns caso, trazer impacto negativo. Além disso, as TICs devem atuar de modo complementar ao ensino e não substituir totalmente o método tradicional (FIRPO; DE PIERI, 2012).

Segundo Leite e Ribeiro (2012), para que a inclusão das TICs traga impacto positivo, é necessária a união de multifatores, dentre os quais se destacam: o domínio do professor sobre as tecnologias existentes e sua utilização na prática; que a escola seja dotada de uma boa estrutura física e material, que possibilite a utilização dessas tecnologias durante as aulas; que os governos invistam em capacitação, para que o professor possa atualizar-se frente às mudanças e aos avanços tecnológicos; que o professor se mantenha motivado para aprender e inovar em sua prática pedagógica; que os currículos escolares possam integrar a utilização das novas tecnologias aos blocos de conteúdos das diversas disciplinas; dentre outros. A forma como o sistema educacional incorpora as TICs afeta diretamente a diminuição da exclusão digital existente no país.

Mesmo sendo divulgado que as TICs aumentam a motivação dos alunos e tornam o aprendizado mais eficiente (HARRISON et al., 2003) e, que as mesmas tem melhorado as competências dos alunos e professores (KIM; LEE, 2011a, 2011b), para efeito de decisões de política públicas, se faz necessária uma análise do uso efetivo das TICs nas escolas através de uma visão geral das habilidades e conhecimentos dos alunos e professores (YOUNGAE; HYESOOK, 2008 apud KIM;LEE, 2011a).

A fim de complementar esta visão, alguns indicadores estão sendo desenvolvidos para medir o nível de TIC das escolas. Tal conjunto de indicadores tem por objetivo representar o nível de todos os requisitos para o uso das tecnologias no processo de ensino-aprendizagem. Dessa maneira, o nível de uso das TICs em uma determinada escola não está restrito aos conhecimentos e habilidades sobre TIC de alunos e professores, mas também sob o corpo de gestão escolar e recursos de equipamentos da escola (SHARMA; KITCHENS, 2004).

O Brasil, por meio do Comitê Gestor da Internet no Brasil (CGI.br), vem produzindo estatísticas sobre as TICs no país através de pesquisas especializadas em diversos setores da sociedade brasileira. As pesquisas anuais sobre o uso das tecnologias de 
informação e comunicação, TIC Domicílios e TIC Empresas, são realizadas desde 2005 pelo Centro Regional de Estudos para o Desenvolvimento da Sociedade da Informação (CETIC.br) e têm o objetivo de acompanhar as mudanças ocorridas no país ao longo do tempo no que diz respeito ao acesso e uso dessas tecnologias pela população e pelas empresas brasileiras. Já a TIC Educação acompanha, desde 2010, a introdução das TICs às práticas pedagógicas de escolas públicas e privadas do Brasil. Com uma série histórica de indicadores, as pesquisas TIC do Comitê Gestor da Internet no Brasil (CGI.br) contribuem efetivamente para o debate sobre os impactos das tecnologias na sociedade brasileira entre os diversos atores dos setores público, privado e acadêmico (CGI, 2014).

Uma das missões do CGI.br é a de produzir e disseminar indicadores e estatísticas TIC de alta qualidade a fim de alimentar o governo com informações confiáveis para a elaboração de políticas públicas e também estimular a produção de trabalhos acadêmicos e científicos. Nesse sentido, o trabalho realizado pelo CETIC.br foi reconhecido em 2012 pela Organização das Nações Unidas para a Educação, a Ciência e a Cultura (Unesco) como um Centro Regional para o Desenvolvimento da Sociedade da Informação sob os auspícios da Unesco. Com a missão de contribuir para a construção de sociedades do conhecimento inclusivas, por meio das tecnologias de informação e comunicação, expandindo as atividades do CETIC.br com o objetivo de cooperar com os países da América Latina e os países africanos de língua oficial portuguesa (Palop) em atividades de capacitação em metodologias de pesquisas (CGI, 2014).

Até o presente momento, o CETIC.br realizou as pesquisas ilustradas na Figura 1. 


\section{Figura 1 - Pesquisas realizadas pelo CETIC.br}

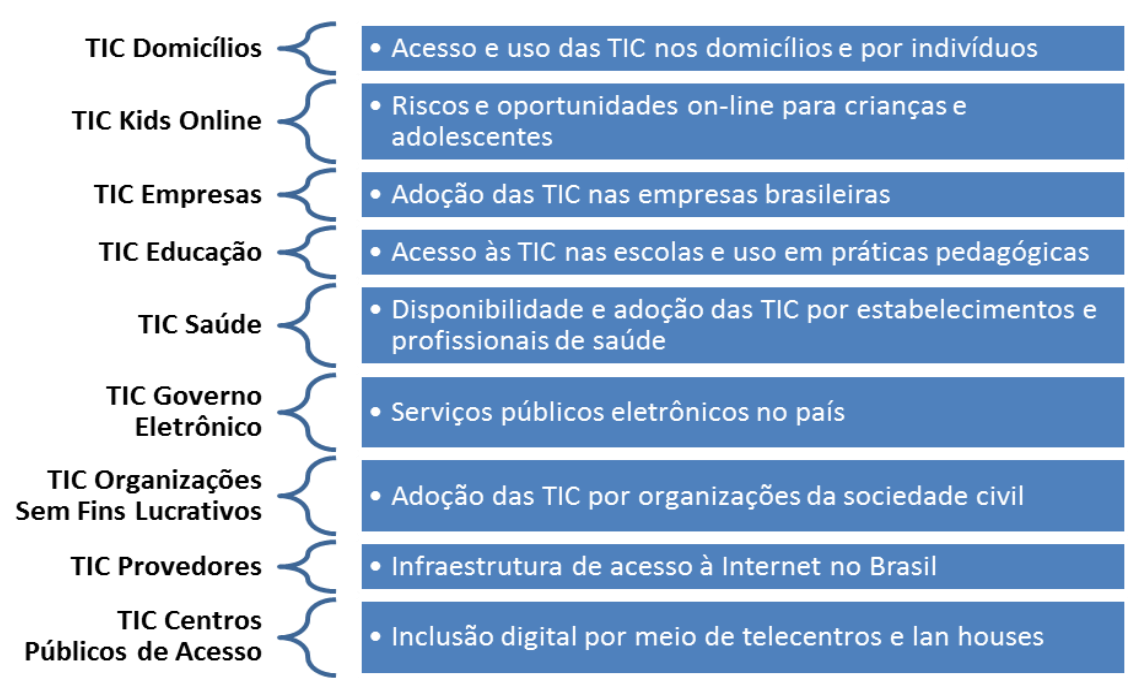

Fonte: Elaborado pelo autor

Em congruência com a importância da medição do uso das TICs no contexto escolar, o presente estudo apresentará uma análise a partir dos dados produzidos pela pesquisa TIC Educação que, segundo seu relatório metodológico (CGI, 2014), utiliza como referencial para a coleta o trabalho realizado pela International Association for the Evaluation of Educational Achievement (IEA), divulgado em duas publicações: Sites 2006 (technical report - Second information technology in education Study ${ }^{2}$ ) e Sites 2006 (user guide for the international database). Entretanto, a fim de explorar especificidades do universo brasileiro, alguns aspectos pertinentes à metodologia e ao questionário foram adaptados.

Ao longo da sua série histórica de quatro anos, os resultados da pesquisa explicitam que o desafio da integração das TICs a prática pedagógica ainda persiste. No que diz respeito à infraestrutura, o acesso às TICs está presente na maioria das escolas brasileiras. Além disso, as escolas registraram um crescimento no uso de computadores portáteis, o que aponta para um caminho de uso das TICs para além das atividades de gestão escolar ou do uso vinculado aos laboratórios de informática. O acesso à Internet também está presente na maioria das escolas públicas, mas a velocidade de conexão é uma limitação importante que impede um uso mais intensivo

\footnotetext{
${ }^{2}$ Second Information Technology in Education Study: SITES 2006 Technical Report, disponível em: http://www.iea.nl/fileadmin/user_upload/Publications/Electronic_versions/SITES_2006_Technical_Re port.pdf. Acesso em: 20/09/2014.
} 
de acordo com diretores, coordenadores pedagógicos e professores. O número de equipamentos disponíveis por aluno também é um obstáculo para o uso efetivo do computador e Internet nas atividades escolares.

É possível estabelecer uma conexão entre os resultados da pesquisa e a literatura sobre o tema. Kozma e Anderson (2002), por exemplo, afirmam que muitas escolas, nos países em desenvolvimento, utilizam computadores e tecnologias afins como ferramentas de apoio às atividades de sala de aula. Segundo a pesquisa TIC Educação (CGI, 2014), 68\% dos professores que costumam realizar projetos ou trabalhos sobre um tema durante o tempo de aula, declararam utilizar o computador e a Internet como suporte a realização das atividades.

Trindade (2010) destaca três formas de uso da tecnologia na escola, sendo elas nos fazeres do docente (uso da tecnologia, única e exclusivamente, na organização do material de trabalho do professor), nas práticas pedagógicas (oferta da tecnologia pelo docente para uso do aluno, enquanto uma ação que contribui para a aprendizagem e para a construção do seu conhecimento) e como estratégia para promover o protagonismo dos alunos (a tecnologia é ofertada pelo docente para uso do aluno, com fins de expressão, posicionamento e criação). A pesquisa TIC Educação (CGI, 2014) relata que $96 \%$ dos professores entrevistados utilizam recursos obtidos na Internet para a preparação de aulas ou atividades com alunos dentro dos fazeres docentes, $53 \%$ dos professores que costumam promover a produção de materiais pelos alunos durante o tempo de aula, utilizam computador e Internet como apoio nas práticas pedagógicas e $45 \%$ dos professores que costumam realizar a organização de atividades em grupo e trabalho colaborativo entre os alunos durante o tempo de aula utilizam computador e Internet como apoio para a promoção do aluno como protagonista do processo de ensino-aprendizagem.

Segundo Miranda (2007), equipar as escolas com computadores e laboratórios de informática representa uma parte, mas não o todo do processo de inclusão digital. Investigações em torno da inserção do computador na escola e nas salas de aula, sem alterar as práticas habituais de ensino, não tem apontado bons resultados. De acordo com a pesquisa TIC Educação (CGI, 2014), 99\% das escolas declararam possuir computador e, destas, 97\% declararam possuir acesso à Internet. Porém, apenas $30 \%$ dos coordenadores pedagógicos declararam ter o uso do computador e da Internet como parte da grade curricular da escola, $60 \%$ dos professores concordam que nas escolas falta treinamento para os alunos de como utilizar computador e Internet e, 
apenas $39 \%$ das escolas declararam desenvolver um projeto de capacitação para professores.

A literatura e os resultados da pesquisa TIC Educação sinalizam que o problema das escolas não está na disponibilidade da infraestrutura, mas sim em como articular os principais atores no processo de inclusão integral das TICs na rotina escolar.

\subsection{Problema de Pesquisa}

Dentro do contexto exposto anteriormente, para a formulação do problema de pesquisa deste trabalho, buscou-se propor uma medida de uso das TICs no contexto escolar que integre aspectos da infraestrutura de acesso (infraestrutura), das iniciativas da direção escolar (gestão) e do domínio de determinadas atividades quanto ao uso da tecnologia por professores e alunos (ensino-aprendizagem). Dessa forma, este estudo apresenta a seguinte pergunta-problema:

“Qual é o nível de uso das Tecnologias da Informação e Comunicação em escolas brasileiras?".

O uso da tecnologia neste trabalho pode ser entendido como o processo gerenciado pelo qual uma escola adota as TICs de forma integrada, buscando engajar os principais atores do processo de ensino-aprendizagem.

Portanto, neste estudo, serão consideradas inicialmente três dimensões para mensurar o índice de uso das TICs nas escolas, quais sejam: (a) Gestão, relacionada ao uso das TICs no planejamento escolar e ao apoio do corpo diretivo da escola ao uso das TICs; (b) Infraestrutura, relacionada aos recursos tangíveis de TIC dentro das escolas; (c) Uso por professores e alunos, relacionada ao uso das TICs por parte dos alunos e professores dentro do processo de ensino-aprendizagem.

O tema de pesquisa que será desenvolvido está estruturado conforme ilustrado no Quadro 1.

Quadro 1 - Definição do tema de pesquisa

\begin{tabular}{|l|l|}
\hline Campo & Tecnologia da Informação e Comunicação \\
\hline Assunto & Tecnologia da Informação e Comunicação na Educação \\
\hline Tema & Uso das TICs pelas escolas brasileiras \\
\hline Problema de pesquisa & $\begin{array}{l}\text { Qual é o nível de uso das Tecnologias da Informação e } \\
\text { Comunicação em escolas brasileiras? }\end{array}$ \\
\hline
\end{tabular}




\subsection{Objetivos}

Este trabalho tem como objetivo primário incluir aspectos relevantes a uma medida, considerando o diretor, o aluno, o professor e a infraestrutura tecnológica como importantes atores para a elaboração de um índice que servirá de apoio para gestores escolares, administradores públicos e pesquisadores interessados em medir a capacidade de uso das TICs pelas escolas.

Este trabalho visa também atingir os seguintes objetivos secundários:

1. Construir um índice para medir o nível de uso das TICs nas escolas;

2. Explorar os resultados do índice e de suas dimensões;

3. Identificar fatores que contribuam para um maior uso das TICs a partir dos resultados apresentados pelas escolas analisadas;

4. Explorar os dados da pesquisa TIC Educação de 2013, de forma que seja possível identificar variáveis e dimensões que possam ser utilizadas como comparativo a outros índices internacionais de uso.

\subsection{Justificativas}

Poucas inovações provocaram tantas mudanças em tão pouco tempo na sociedade como as tecnologias. Novas maneiras de pensar e conviver estão sendo elaboradas no mundo das telecomunicações e da informática (LÉVY, 1998).

No contexto do ensino, a TIC assume um importante papel em termos de apoio pedagógico com o intuito de auxiliar na melhoria da estrutura básica da educação. $\mathrm{O}$ acesso a novas tecnologias traz formas diferentes de aprender e pensar, para professores, alunos e escola. O desenvolvimento da sociedade depende hoje, da capacidade de gerar, transmitir, processar, armazenar e recuperar informações de forma eficiente. Por isso, a população escolar precisa ter oportunidades de acesso a esses instrumentos e adquirir capacidade para produzir e desenvolver conhecimentos utilizando as TICs (BARBOSA et al., 2004).

Wang et al. (2009), destacam que o uso das TICs pode contribuir para incrementar a aprendizagem, notadamente, quando aliada a um centro de instrução, ou laboratório de tecnologia, para o estudante. 
Diversos programas governamentais de fomento ao uso das TICs na educação, sejam eles das Secretarias Estaduais e Municipais da Educação ou do Ministério da Educação (MEC), estão levando computadores, tablets e acesso à Internet para as escolas públicas brasileiras, entretanto, a simples introdução destas tecnologias não é suficiente para garantir o uso das TICs dentro do contexto escolar e sua incorporação nos processos de ensino-aprendizagem.

Gimenez (2001) aponta que, na maioria dos casos, os computadores chegaram às escolas sem o respaldo de uma proposta que contemple os artefatos tecnológicos como recursos pedagógicos. Nos casos em que não há o envolvimento dos professores ou não lhes são fornecidos formação específica e tempo necessário para a sua inserção no processo de informatização da escola, observa-se como resultado que os professores não aprendem a lidar com tais tecnologias e muito menos como fazer uso pedagógico delas em sua rotina escolar na sala de aula ou no laboratório de informática (UNESCO, 2008a, 2008b).

Dessa forma, é preciso avançar a discussão para além da simples implementação da infraestrutura tecnológica (computadores e Internet), entendendo como as relações didático-pedagógicas acontecem com as novas tecnologias (ROSALEN; MAZZILLI, 2005).

Sob a ótica acadêmica, muito tem se produzido sobre o tema. Com o objetivo de trazer a tona a importância do estudo sobre a aplicação das TICs no cenário escolar, Bach et al. (2013) realizaram uma pesquisa bibliométrica e sociométrica dos artigos publicados nos eventos e periódicos da ANPAD e em teses e dissertações no período de 1997 a 2011. Os autores se deparam com um montante de 1.437 artigos e 573 teses e dissertações que, a partir do objetivo da pesquisa, foram sumarizados em 46 estudos para análise.

Diante do exposto, esta pesquisa se justifica, pois visa demonstrar, em nível nacional, como as escolas tem se apropriado das TICs a fim de contribuir para a discussão sobre as políticas de inclusão digital e capacitação dos docentes e alunos.

Além disso, este trabalho traz o ineditismo no sentido de aproveitar dados gerados por fontes secundárias (CGI.br) a fim de avaliar, a nível nacional, as escolas entrevistadas pela pesquisa TIC Educação. 


\subsection{Contribuição do estudo}

Espera-se que os resultados desta pesquisa auxiliem a retratar o cenário escolar brasileiro atual quanto ao uso das tecnologias da informação e comunicação. Além disso, pesquisadores da área de informática na educação, criadores e gestores de políticas públicas e, organizações de forma geral, poderão aprimorar o instrumento neste trabalho proposto e, principalmente, terão a contribuição de mais um ponto de vista, a fim de compreender as complexas relações existentes entre os processos organizacionais e de ensino-aprendizagem, para que haja o uso da tecnologia na escola.

\subsection{Estruturação}

Tendo em vista o tema central, a questão de pesquisa definidos e os objetivos estabelecidos, o desenvolvimento deste trabalho está estruturado da seguinte forma:

- Revisão da literatura: Revisão da literatura referente aos conceitos definidos como chaves neste trabalho.

- Metodologia: Escolha e estruturação do método de pesquisa, operacionalização das variáveis utilizadas para o estudo e descrição das técnicas estatísticas utilizadas para a construção do instrumento.

- Análise dos dados: Apresentação e discussão dos resultados oriundos da análise dos dados.

- Conclusões e considerações finais: Recomendações para estudos futuros e fatores limitadores da pesquisa. 


\section{Referencial teórico}

Esse capítulo tem por objetivo descrever os princípios teóricos que embasarão este trabalho, sendo assim, serão explorados os seguintes temas: (2.1) uso das TICs nas escolas; (2.2) a relação entre as TICs e os alunos, professores e diretores; (2.3) infraestrutura de TIC nas escolas; (2.4) iniciativas de inclusão digital nas escolas brasileiras; (2.5) indicadores e medidas quanto ao uso das TICs no contexto escolar; (2.6) modelo de pesquisa proposto para a construção do índice.

\section{$2.1 \quad$ Uso das TICs nas escolas}

Segundo Belloni (2009), o termo Tecnologia da Informação e Comunicação (TIC) abrange o conjunto de recursos tecnológicos que propiciam agilidade no processo de comunicação, transmissão e distribuição de informações, notícias e conhecimentos, isto é, as TICs são o resultado de três vertentes técnicas: a informática, as telecomunicações e as mídias eletrônicas. Artefatos tecnológicos como computador, televisão, aparelho de som, gravador, filmadora, câmera fotográfica, calculadora, rádio, datashow, retroprojetor, celulares, pendrives, CDs, DVDs, entre outros, são exemplos de TIC que estão presentes na vida cotidiana das pessoas (BRIGNOL, 2004).

Mesmo que alguns teóricos nomeiem a atual sociedade de "Sociedade da Informação" e que o computador, por meio do uso da Internet, seja uma ampla fonte de acesso à informação e disseminação de conhecimento, não se pode esquecer que a escola é a instituição principal, organizadora e sistematizadora dos conhecimentos quando se pensa no processo de ensino-aprendizagem. Sendo assim, o computador deve ser uma ferramenta de complementação, de aperfeiçoamento e de grande potencial de mudança na qualidade de ensino (ALTOÉ, 2005).

Valente (2008) defende que o uso inteligente do computador na escola deve existir a fim de provocar mudanças na abordagem pedagógica e não para simplesmente tornar mais eficiente a transmissão do conhecimento do professor. Sendo assim, o uso das TICs no processo de ensino-aprendizagem tem como desafio estabelecer novas alianças de cooperação com aqueles que têm algo a contribuir, constituindo uma teia nacional de comunicação, intercâmbio de informações científicas e de experiências 
pedagógicas. A função principal das TICs é a de promover a inclusão digital dos professores, pesquisadores e alunos, sendo eles próprios os sujeitos de todo o processo, além da democratização do conhecimento por meio da tecnologia (ELIA, 2008).

A tecnologia deve ser utilizada como um catalisador de uma mudança do paradigma educacional (VALENTE,1993). Um paradigma que promove a aprendizagem ao invés do ensino, que coloca o controle do processo de aprendizagem nas mãos do aprendiz e, que auxilia o professor a entender que a educação não é somente a transferência de conhecimento, mas um processo de construção do conhecimento pelo aluno (NEITZEL, 2001).

Negroponte (1995) e Papert (1994) afirmam que a inserção das TICs na educação não garante maior participação social ou desenvolvimento integral dos estudantes. Já Perrenoud (2000) afirma que, no cenário atual de inclusão das tecnologias nas escolas, as políticas de implantação ora estão sendo defendidas por propostas bem fundamentadas e coerentes, ora por divulgações mercantilistas e modistas, esvaziadas de sentido contextual. Segundo o autor, é fundamentalmente necessário realizar uma reflexão crítica e analítica sobre o uso das tecnologias na educação, de forma a entender as suas implicações nos processos de aprendizagem e na formação de competências.

A inclusão de qualquer artefato tecnológico por si só não garante a melhoria da qualidade na educação, sendo assim, as TICs buscam potencializar novas possibilidades e novas estratégias de aprendizagem para auxiliar o professor e os estudantes. Possibilidades para refletir, interagir, inventar, estimular a pesquisa e aprender a aprender, para construir novos conhecimentos. As tecnologias não mudam somente o nosso modo de pensar e agir, mas também a nossa percepção de realidade (SANTAELLA, 2003). Além disso, elas ampliam as oportunidades de aprendizagem a qualquer lugar e hora; articulam uma relação mais fluida e permanente entre estudantes e conhecimento; abrem oportunidades de aprendizagem ao longo da vida; criam comunidades de aprendizagem entre estudantes e docentes; ampliam as oportunidades de desenvolvimento profissional dos docentes; permitem a criação de novos canais de comunicação entre escola e comunidade, especialmente com os lares dos estudantes; e são poderosas ferramentas de gestão acadêmica e administrativa da escola e do sistema educacional (VALDIVIA, 2008). 
Com o objetivo de retratar discussões recentes sobre as TICs na Educação, Fu (2013) realizou uma revisão bibliográfica onde foi possível identificar autores que discorrem sobre os benefícios, as barreiras, os desafios e fatores que influenciam o uso das mesmas.

Dentro dos benefícios gerados, Fu (2013) destacou a tecnologia como uma ponte de acesso efetivo e eficiente de informações digitais aos alunos. Pela ótica do ensino, a autora cita a tecnologia como um suporte na abordagem de ensino centrada no estudante, uma aliada no desenvolvimento de um pensamento crítico e um componente importante no processo de melhoria da qualidade da aprendizagem e do ensino.

Falta de conhecimento e habilidades por parte de professores e alunos, falta de software, hardware e materiais, problemas técnicos e, dúvidas quanto aos prováveis benefícios em sala de aula, são citados como barreiras para o uso das TICs (FU, 2013).

A fim de destacar os fatores que influenciam o uso das TICs no âmbito escolar, Fu (2013) destaca autores que dividem os fatores em internos e externos. Entre os fatores externos, os mais comuns são o acesso a computadores e software, tempo insuficiente para o planejamento de curso, e apoio técnico e administrativo insuficiente. Destacam-se entre os fatores internos, a atitude dos professores, a confiança e crença na utilização das TICs.

Fu (2013) conclui que para que exista um bom uso da tecnologia dentro do contexto educacional é importante que haja um esforço de professores, alunos e diretores. Tais atores serão discutidos na seção a seguir.

\subsection{Capital humano e as TICs nas escolas}

Diante da perspectiva de que as TICs potencializam novas formas de aprendizagem, faz-se necessário expor como os professores e os alunos lidam com os novos artefatos tecnológicos, bem como o diretor pode se tornar um facilitador no processo de sua adoção pelos atores do sistema escolar. Sendo assim, esta seção apresentará uma revisão da literatura acerca do potencial uso das TICs por tais atores. 


\subsubsection{O uso das TICs pelos professores}

Fagundes et al. (2010) afirmam que o uso do computador exige, mais que nunca, um professor preparado, dinâmico e investigativo, pois as perguntas e situações que surgem na classe fogem do controle preestabelecido do currículo.

Lévy (1999) diz que a principal função do professor não pode mais ser uma difusão de conhecimentos, que agora é feita de forma mais eficaz por outros meios. Sua competência deve deslocar-se no sentido de incentivar a aprendizagem e o pensamento, isto é, o professor deve tornar-se um animador da inteligência coletiva dos grupos que estão ao seu encargo. Sua atividade será centrada no acompanhamento e na gestão das aprendizagens: o incitamento à troca dos saberes, a mediação relacional e simbólica, a pilotagem personalizada dos percursos de aprendizagem, etc. Tajra (2004) destaca que o professor deve estar aberto para as mudanças, principalmente em relação à sua nova função de facilitador e coordenador do processo de ensino-aprendizagem.

A capacitação de professores para o uso das TICs na educação, especificamente o computador como ferramenta pedagógica, é muito importante visto que, durante sua formação acadêmica, os mesmos tiveram pouco ou nenhum acesso ao uso dos recursos de informática na sala de aula (BORGES, 2008). A formação para a utilização das TICs descreve que o papel desempenhado pelo professor pode ser o de mediador entre o conhecimento teórico e o uso da tecnologia. Desse modo, o professor se coloca como um facilitador e incentivador da aprendizagem, ou seja, apresenta-se como uma ponte entre o aprendiz e sua aprendizagem, não como uma ponte estática, mas sim uma ponte ativa, que colabora para que o aprendiz alcance seus objetivos (MASETTO, 2010).

Para que o professor possa utilizar a TIC, como uma aliada pedagógica, se faz necessária uma formação ampla do educador, pois elas não envolvem somente a manipulação do computador ou de um programa especifico, mas representam um meio para auxiliá-lo a desenvolver o conhecimento sobre o conteúdo proposto e como essa máquina o integrará na execução do conhecimento (VALENTE, 2008).

Para Kenski (2013), há a necessidade de uma retomada na ação da escola e dos professores no sentido de se fazer uma revisão crítica e uma reorganização de sua realidade. Ainda hoje, a estrutura da escola orienta-se pelo modelo onde o acesso à informação do cidadão era raro, caro, difícil e demorado. Neste modelo, a formação 
do cidadão era adquirida ao longo da vida escolar, onde este acumulava conhecimentos que eram transmitidos pela escola e pelos professores para que então pudesse atuar plenamente no mundo. Sendo assim, se torna importante que o professor se desenvolva como um agente que crie mecanismos de filtragem, seleção crítica, reflexão coletiva e dialogada frente à miscelânea de possibilidades abertas pelo uso das TICs e, para que tal desenvolvimento ocorra, os professores precisam ser capacitados, pois o computador só pode ser um instrumento útil no processo de ensino-aprendizagem se o aluno, assessorado pelo professor, assumir o controle da máquina e a partir de sua criatividade, se tornar capaz de elaborar programas que atendam a seus interesses e necessidades (RIPPER,1996; TAJRA, 2004).

Dentro do contexto brasileiro, muito se tem investido, tanto pelo Ministério da Educação (MEC) quanto pelas Secretarias de Educação Municipais e Estaduais brasileiras, na formação docente para a utilização pedagógica dos recursos tecnológicos. Contudo, apesar dos investimentos realizados, pode-se perceber que o avanço tecnológico não significou exatamente uma melhoria da educação pública escolar, como era esperado (SANCHO; HERNÁNDEZ, 2006). Silva e Campos (2010) afirmam que, para que o professor auxilie na melhora da qualidade do ensino se faz necessário que o mesmo reveja os seus conceitos e a maneira de propor os desafios de aprendizagem.

\subsubsection{O uso das TICs pelos alunos}

Os alunos que se encontram em sala de aula nos dias atuais, pensam e processam as informações de forma diferente das gerações anteriores, devido às possibilidades disponíveis de interação com as tecnologias. Estes mesmos alunos passaram a vida inteira cercados e usando computadores, vídeo, telefones celulares e todos os outros brinquedos e ferramentas da era digital. Segundo Prensky (2001), tal geração é conhecida como os nativos digitais, isto é, jovens nascidos a partir da disponibilidade de informações rápidas e acessíveis na Internet.

Tomando-se a aprendizagem sob uma perspectiva construtivista, é fundamental uma interação entre o sujeito e o objeto de estudo (NITZKE et al., 2002). Sendo assim, uma nova concepção pedagógica se faz necessária, já que o processo de ensinoaprendizagem deixa de ser centrado no professor e passa a ser centrado no aluno. $\mathrm{O}$ trabalho individual, fomentado tradicionalmente, dá lugar ao trabalho em equipe, o 
qual promove o compartilhamento das ideias e experiências e a construção coletiva do conhecimento. Além disso, o aprendizado já determinado pelo professor no modelo antigo de educação é substituído pela necessidade de aprender a aprender, desenvolvendo-se, assim, habilidades para a era da informação (HEIDE; STILBONE, 2000).

Segundo Moran (2007), a escola, ao introduzir o computador como um instrumento auxiliar no processo de ensino-aprendizagem, não deve deixar que este se torne um artigo de luxo, criando assim adultos egoístas e antissociais. Ela deve buscar neste, um meio de desenvolver cidadãos mais críticos, sociais e independentes, repensando assim o seu papel frente às novas tecnologias (MORAN, 2007).

Entender a relação computador e educação é ter em vista o fato de que o computador se tornou um instrumento, uma ferramenta para a aprendizagem, desenvolvendo habilidades intelectuais e cognitivas, levando o indivíduo ao desabrochar de suas potencialidades, de sua criatividade e de sua inventividade (VALENTE, 2008).

Almeida explica que o computador é

[...] uma ferramenta tutorada pelo aluno e que lhe permite buscar informações em redes de comunicação à distância, navegar entre nós e ligações, de forma não linear, segundo seu estilo cognitivo e seu interesse momentâneo. Tais informações podem ser integradas pelo aluno em programas aplicativos, e com isso ele tem a chance de elaborar o seu conhecimento para representar a solução de uma situação problema ou a implantação de um projeto. [...] Todas essas situações levam o aluno a refletir sobre o que está sendo representado. (2000, p.19)

Em consonância ao exposto acima, Mamede-Neves et al. (2013) discorrem que o aluno já utiliza a mídia digital em seu dia a dia e a naturalizou como instrumento. Quanto às suas práticas, também pode ser considerado um usuário mediano quanto à diversidade de usos que faz em seu cotidiano: basicamente comunicação (em redes sociais, chats, mensageiros instantâneos, celular) e aplicativos para jogos e diversão. Os autores complementam dizendo que o aluno também consulta a rede como fonte de informações e questiona a escola em sua validade, como instituição formativa, e o professor como portador de verdade e autoridade, ainda que mantenha contraditoriamente uma expectativa de que a verdade do professor e a encontrada nos livros didáticos é sempre mais confiável que aquela obtida na Internet.

A literatura citada até aqui sinalizou que o aluno e o professor devem enfrentar a interação com o novo mundo que as TICs proporcionam de forma conjunta, pois, 
somente assim, será possível que haja uma revolução no processo de ensinoaprendizagem.

\subsubsection{O diretor e as TICs nas escolas}

As TICs dentro das escolas tem o potencial de contribuir no aumento do acesso à informação e podem promover a criação de comunidades de aprendizagem que privilegiam a interação, o processo de construção coletiva do conhecimento, a formação continuada e a gestão integrada entre as frentes administrativa, pedagógica e informacional da escola (ALMEIDA; RUBIM, 2004).

Uma gama de fatores afetam a integração da tecnologia na escola, no entanto, o papel de liderança do diretor é o fator mais importante para que exista uma integração bem sucedida da tecnologia com o ambiente escolar (BYROM; BINGHAM, 2001). Diretores de escolas têm uma grande responsabilidade de iniciar e promover a mudança nas escolas através da utilização das TICs e, portanto, facilitar decisões complexas sobre a integração das tecnologias no processo de ensino-aprendizagem (SCHILLER, 2003), sendo assim, os diretores devem agir como o líder que apoia a emergência de movimentos de mudança na escola e perceber nas tecnologias oportunidades para que a escola se desenvolva (ALMEIDA, 2005).

Almeida (2005) defende que o diretor é o responsável por criar condições para a utilização de tecnologias nas práticas escolares, de forma a redimensionar seus espaços, tempos e modos de aprender, ensinar, dialogar e lidar com o conhecimento. Ele procura identificar as potencialidades dos recursos disponíveis para proporcionar a abertura da escola à comunidade, integrá-la aos distintos espaços de produção do saber, fazer da escola um local de produção e socialização de conhecimentos para a melhoria da vida de sua comunidade, para a resolução de suas problemáticas, para a transformação de seu contexto e das pessoas que nele atuam. De forma complementar, Schiller (2003) cita que os diretores precisam entender as capacidades das novas tecnologias, ter uma proficiência pessoal na sua utilização, e serem capazes de promover uma cultura escolar que incentive a exploração de novas técnicas de ensino, aprendizado e gestão. Dessa forma, as escolas precisam de líderes que facilitem o processo de mudança e apoiem uma comunidade de aprendizagem para a integração tecnológica. 
Segundo Almeida e Rubim (2004), o envolvimento dos diretores na articulação dos diferentes segmentos da comunidade escolar, na liderança do processo de inserção das TICs na escola em seus âmbitos administrativo e pedagógico e, ainda, na criação de condições para a formação continuada, pode contribuir e significativamente para os processos de transformação da escola em um espaço articulador e produtor de conhecimentos compartilhados.

Assim, embasado na literatura citada nesta seção, os diretores devem se transformar em agentes ativos para que haja o uso das TICs dentro do contexto escolar.

\subsection{Infraestrutura tecnológica}

Um importante debate quanto ao uso das TICs dentro do contexto escolar diz respeito à disponibilização de uma infraestrutura de apoio tecnológico que possa ser usufruída por docentes, alunos e outros atores da escola. Esta seção explorará definições sobre a infraestrutura de TIC, o uso dos recursos computacionais no dia a dia escolar e o profissional da área de tecnologia educacional.

\subsubsection{Infraestrutura de TI}

O conceito de infraestrutura de tecnologia da informação pode ser definido como um conjunto de recursos tecnológicos que suportam a operacionalização de processos e/ou negócios correntes ou futuros (BYRD; TURNER, 2000 apud SANCHEZ; CAPPELLOZZA, 2012).

Em linhas gerais, a infraestrutura de TI de uma organização é constituída pelos ativos tecnológicos que servem de base para a construção de soluções mais específicas com as quais os usuários finais têm contato (DUNCAN, 1995 apud MORENO JUNIOR et al., 2014), tais como hardware, redes de comunicação, sistemas operacionais e aplicativos básicos para processamento de dados (BYRD; TURNER, 2000; JEFFERS et al, 2008 apud MORENO JUNIOR et al., 2014).

Além dos equipamentos e sistemas, a infraestrutura de TI de uma organização também pode ser composta de profissionais da área e conhecimentos, entre outros componentes (WEILL; BOADBENT, 1998 apud SANCHEZ; CAPPELLOZZA, 2012). 
No que diz respeito aos componentes da infraestrutura de TI, McAffe (2006) apresenta três categorias que demonstram os recursos disponíveis dentro de uma organização, a fim de fornecer suporte aos líderes no que diz respeito ao entendimento de quais tecnologias devem ser investidas e maximizadas:

1. Funcionais: compreendem sistemas que auxiliam os usuários em tarefas discretas, tais como: softwares processadores de textos e planilhas, entre outros.

2. Rede: refere-se a softwares que possibilitam a interação entre os interessados, por exemplo: gerenciadores de e-mail, mensagens instantâneas ou outros sistemas.

3. Corporativo: inclui os sistemas desenvolvidos para gerenciamento e execução de processos específicos da organização, tais como os sistemas corporativos integrados, Enterprise Resource Planning (ERP).

Ainda no que tange a definição de componentes, Schmidt et al. (2014) definem que a infraestrutura de TI de uma organização é composta por hardware (elementos da arquitetura física), software (aplicações) e redes de computadores e Internet (arquitetura de comunicação).

Em estudos mais recentes, autores têm discutido a importância em se desenvolver uma infraestrutura de TI escalável a partir da computação em nuvem. Segundo Mell e Grance (2011), computação em nuvem é um modelo que viabiliza o acesso oportuno e sob demanda a um conjunto compartilhável de recursos, permitindo uma gestão eficiente e inteligente do ecossistema de TI da organização. Segundo Chaves e Souza (2012), entre os potenciais benefícios da computação em nuvem, é possível destacar a possibilidade das organizações centrarem seus esforços em seus negócios, a redução global de gastos com TI e o grau de disponibilidade da infraestrutura.

Dentro do contexto da educação, a fim de compreender a infraestrutura de TI, o instituto de estatística da Unesco (UIS, 2009) utiliza em suas métricas dois componentes chave:

- Disponibilidade de hardware, que é medido a partir dos tipos de computadores, rede, conexão de Internet, quadros eletrônicos, etc.

- Disponibilidade de software, que é medido a partir de tipos específicos ou genéricos de aplicativos (exemplo: editores de texto), sistema de gestão de aprendizado, ferramentas de gestão administrativa, etc. 
Avaliando o contexto de oferta de infraestrutura de TI, é possível observar através do trabalho de Lopes et al. (2010) que a maioria das escolas brasileiras possui recursos materiais para fazer algum tipo de uso pedagógico do computador e, quanto maior o tamanho da escola, recursos e infraestrutura disponíveis, mais proficiente é a utilização do computador e da Internet no processo de aprendizagem. No entanto, como mostra a pesquisa TIC Educação (CGI, 2014) e, fazendo um paralelo com os componentes citados pelo UIS (2009), a quantidade de equipamentos nas escolas brasileiras ainda é um aspecto que limita o uso mais intenso das TICs no cotidiano de ensino-aprendizagem, pois o número de computadores em funcionamento dificulta o contato personalizado dos estudantes.

A fim de contribuir com a discussão sobre a infraestrutura de TI e concluir esta seção, é possível dizer que, dentro do contexto escolar, a infraestrutura de TI existe a partir de um conjunto de recursos como computador, Internet e ferramentas educacionais a fim de desenvolver um ambiente onde é possível desenhar estratégias de aprendizagem, integrar informações para uma melhor gestão da escola e criar comunidades virtuais que integrem os principais atores envolvidos na rotina escolar, isto é, pais, alunos, professores, diretores, governo e comunidade.

\subsubsection{Recursos computacionais no dia a dia escolar}

Kozma e Anderson (2002) afirmam que muitas escolas, nos países em desenvolvimento, utilizam computadores e tecnologias afins como ferramentas de apoio às atividades de sala de aula.

Seguindo a linha anteriormente citada, Thompson (2007) destaca que os estudantes do ensino fundamental e médio deveriam aprender a usar planilhas eletrônicas, editores de texto e manusear banco de dados durante a permanência na escola, da mesma maneira que eles aprendem a somar números e fazer provas, tornando-os parte do currículo normal do aluno.

Chaves (1998) enfatiza que a informática não deve entrar na escola sem que os profissionais que nela atuam, principalmente os professores, estejam convencidos de que essa tecnologia irá contribuir significativamente para o desenvolvimento do trabalho junto ao corpo discente, ajudando a promover melhor os objetivos educacionais. Dentre estes objetivos, o autor destaca a facilitação do aprendizado dos alunos, ajudando-os a se tornar pessoas autônomas e independentes, que busquem por 
si mesmas as informações e os conhecimentos de que necessitam, tendo condições de analisar e avaliar criticamente as informações encontradas, aplicando-as nas atividades práticas da vida.

A inserção dos recursos computacionais na escola, a partir do professor e da proposição de práticas docentes, tem se dado de diferentes maneiras. Trindade (2010) destaca três formas de uso de tais recursos na escola, sendo elas:

1. Nos fazeres do docente: uso da tecnologia, única e exclusivamente, na organização do material de trabalho do professor. Os recursos serviriam para a confecção de atividades e provas, a partir do editor de textos, por exemplo; para a manipulação e armazenamento de notas; para a realização de pesquisas em sites, a fim de enriquecer o conteúdo de estudo, etc.

2. Nas práticas pedagógicas: oferta da tecnologia pelo docente para uso do aluno, enquanto uma ação que contribui para a aprendizagem e para a construção do seu conhecimento. São utilizados programas e jogos digitais que contemplem o interesse dos alunos; são feitas pesquisas na web; visitas a blogs e outras páginas de Internet, etc. A tecnologia é utilizada a fim de qualificar o consumo do conhecimento já produzido socialmente.

3. Como estratégia para promover o protagonismo dos alunos: a tecnologia é ofertada pelo docente para uso do aluno, com fins de expressão, posicionamento e geração de conteúdo. Envolve a construção de blogs, participação em chats, etc. Os recursos tecnológicos são utilizados como instrumentos para a produção coletiva de conhecimento. $\mathrm{O}$ aluno passa a ser o centro do processo, e juntamente com a instituição escolar, assume o papel de autoria na produção do conhecimento social.

Mais recentemente, em decorrência do advento dos dispositivos móveis, iniciou-se uma discussão acerca das estratégias de $\mathrm{BYOD}^{3}$ nas escolas para o desenvolvimento do ensino. Segundo Alberta Education (2012), BYOD se refere a modelos de tecnologia, onde os alunos trazem um dispositivo de propriedade pessoal para a escola

\footnotetext{
${ }^{3}$ Bring Your Own Device
} 
com a finalidade de aprendizagem. MacGibbon (2012) reforça que o conceito de BYOD dentro do contexto educacional é muito simples, afinal, se o aluno já possui um dispositivo móvel em sua casa, se torna prático que ele traga o mesmo para a escola ao invés de duplicar o custo e gerar perda no tempo de aprendizado ao utilizar equipamentos TIC disponibilizados pela escola.

Martin e Ertzberger (2013) investigaram as implicações da aprendizagem móvel no sucesso e atitudes dos estudantes. Os autores identificaram que o uso de IPAD e IPOD acarretou em atitudes positivas. Rockinson-Szapkiw et al. (2013) estudaram a relação entre o formato do texto e o desempenho dos alunos que usam equipamentos móveis. Os resultados demostraram que não existe diferença de aprendizagem entre os grupos, sugerindo que os textos eletrônicos e tradicionais são equivalentes em termos de aprendizagem. López et al. (2013) da Espanha, e Mintz et al. (2012) da Inglaterra observaram que o uso adequado de plataformas de aprendizagem, nos dispositivos móveis, contribui no desenvolvimento de habilidades cognitivas em crianças com necessidades especiais. Em outro trabalho relevante alinhado às perspectivas do artigo em questão, Ozcelik e Acarturk (2011) verificaram que os dispositivos móveis, por facilitarem o acesso às informações online, aumentam o potencial de aprendizagem dos alunos.

Dentro do contexto brasileiro, Lopes et al. (2010) realizaram um estudo em 400 escolas públicas de Ensino Fundamental e Médio das capitais brasileiras com o objetivo de investigar o uso do computador e da Internet. Os autores concluíram que:

- A tecnologia deve ser integrada ao projeto pedagógico da escola, no seu monitoramento e avaliação e ao planejamento de atividades do professor;

- Apesar dos dados levantados sobre recursos e infraestrutura serem favoráveis, infraestrutura, formação de professores e problemas com acesso à Internet são apontados como os principais problemas para o uso pedagógico do computador;

- A formação oferecida não é percebida como suficiente e adequada, pois falta preparo para o uso da tecnologia centrado em ensinoaprendizagem dos conteúdos escolares;

- O número de professores que usam a tecnologia com seus alunos é ainda pequeno e este uso se dá no laboratório de informática; 
- Na maioria das escolas, as atividades que utilizam tecnologia e são realizadas com os alunos têm pouca complexidade ou usam de recursos simples.

A partir do que foi exposto até o momento, é possível concluir que o uso de ferramentas tecnologicamente mais modernas ou sofisticadas indica uma maior fluência em tecnologias e, apesar de potencializar a aprendizagem, não garantem um uso pedagógico efetivo. Por outro lado, ferramentas tecnologicamente simples podem apresentar resultados positivos quando boas estratégias pedagógicas são aplicadas.

\subsubsection{Profissional da área de tecnologia educacional}

Dentro do contexto escolar não há um consenso sobre o papel do profissional de informática, sendo assim, neste trabalho será utilizada como definição do profissional da área de tecnologia educacional, o que Lopes (2002) nomeia de coordenador do laboratório de informática. Segundo o autor, tal profissional deve ter uma formação pedagógica e uma experiência de sala de aula. Além disso, deve ser capaz de fazer uma ponte entre o potencial da ferramenta com os conceitos a serem desenvolvidos. Lopes (2002) identifica um conjunto de atributos que um profissional da área de tecnologia educacional deve ter:

- Visão abrangente dos conteúdos disciplinares e estar atento aos projetos pedagógicos das diversas áreas, verificando sua contribuição;

- Visão geral do processo e estar receptível para as devidas interferências nele;

- Visão técnica, conhecer os equipamentos e se manter informado sobre as novas atualizações;

- Conhecimento do projeto pedagógico da escola;

- Experiência de sala de aula e conhecimento de várias abordagens de aprendizagem;

- Percepção sobre as dificuldades e o potencial dos professores, para poder instigá-los e ajudá-los;

- Capacidade de mostrar para o professor que o Laboratório de Informática deve ser extensão de sua sala de aula; 
- Capacidade de pesquisar identificar e analisar softwares educativos disponíveis.

Neste contexto, um exemplo de política pública que busca atender esses atributos foi a criação do profissional Professor Orientador de Informática (POIE), criado em 1994 na rede municipal de educação da cidade de São Paulo. O objetivo foi de desenvolver um professor com habilidades pedagógicas e técnicas cuja função é

promover cursos de capacitação para seus pares; acompanhar e apoiar as atividades desenvolvidas com os professores e seus alunos no laboratório de informática, auxiliando com subsídios teóricos e práticos; garantir um trabalho integrado com as atividades desenvolvidas em sala de aula; organizar o espaço físico e horário de uso. (CENPEC, 2006 apud Dutra, 2010, p.108).

Segundo Dutra, o papel do POIE

[...] vai além daquele exercido pelos professores das disciplinas tradicionais, ao incorporar funções como a da própria organização do espaço do laboratório de informática, pois a ele cabe, inclusive, mapear os computadores que porventura não estiverem funcionando e entrar em contato com o serviço de manutenção. Mas, também, tem a função de formar outros professores e difundir o uso da tecnologia entre os membros do corpo docente. (2010, p.108).

Sendo assim, é possível concluir que, cabe aos profissionais de informática educacional, assim como aos professores em geral, lançarem um novo olhar à escola, entendendo-a como um conglomerado de novos meios de comunicação e novas tecnologias.

\subsection{Iniciativas de inclusão digital das escolas no Brasil}

Inúmeras pesquisas têm sido desenvolvidas nos últimos anos a fim de analisar o uso das tecnologias digitais no ambiente escolar. Tal cenário ocorre em decorrência da adoção de políticas públicas complexas que tem por objetivo fomentar a introdução do computador e do uso da Internet como ferramenta pedagógica em favor do aprendizado.

Maia e Barreto (2012) realizaram uma interessante contextualização histórica quanto ao uso dos computadores nas escolas brasileiras. Segundo as autoras, a informática educativa surgiu no Brasil na década de 1970 e, dentre as experiências iniciais, a que articulou a ideia de levar computadores à educação básica foi a Universidade Estadual 
de Campinas (UNICAMP), inicialmente, com a divulgação do documento denominado Introdução de Computadores nas Escolas de Segundo Grau, em 1975.

A partir dos anos 80, o computador passou a ser visto como ferramenta para auxiliar o processo de ensino-aprendizagem. Tal cultura fez com que o MEC tomasse a iniciativa de implantar dois projetos: o EDUCOM (Computadores na Educação), em 1984 e o FORMAR (formação de professores e técnicos das redes municipais e estaduais de ensino em todo Brasil), em 1986.

Segundo Moraes (1997), o primeiro projeto tinha como objetivo proceder a estudos e ações ligadas diretamente ao desenvolvimento da informática educativa no país e o segundo, tinha como foco a formação de recursos humanos para trabalhar pedagogicamente as novas ferramentas. Em 1989, foi instituído o Programa Nacional de Informática Educativa (PRONINFE) que teve por objetivo a criação dos Centros de Informática na Educação de $1^{\circ}$ e $2^{\circ}$ graus (CIED), que tinham a função de multiplicadores do emprego da informática em escolas públicas brasileiras (VALENTE, 1999 apud MAIA; BARRETO, 2012).

Em 1997 surge o PROINFO, programa implementado pelo MEC e pela Secretaria de Educação a Distância, com o propósito de informatizar a escola pública. A criação deste surgiu de uma decorrência da obrigação do poder público de diminuir as diferenças de oportunidade de formação entre os alunos do sistema público de ensino e os da escola particular, esta cada vez mais informatizada (BRASIL, 1997).

As diretrizes do PROINFO (BRASIL, 1997) apresentavam quatro objetivos macros para a implantação da tecnologia na escola pública:

1. Melhorar a qualidade do processo de ensino-aprendizagem;

2. Possibilitar a criação de uma nova ecologia cognitiva nos ambientes escolares mediante incorporação adequada das novas tecnologias da informação pelas escolas;

3. Propiciar uma educação voltada para o desenvolvimento científico e tecnológico;

4. Educar para uma cidadania global numa sociedade tecnologicamente desenvolvida.

A proposta do programa pretendia introduzir melhorias no processo de aprendizagem do indivíduo, bem como diversificar espaços de construção do conhecimento.

Passados 10 anos de sua criação, o PROINFO teve sua nomenclatura alterada para Programa Nacional de Tecnologia Educacional (PROINFO INTEGRADO). Apesar 
de manter suas bases na primeira fase do PROINFO, algumas alterações foram realizadas na nova versão do programa. O primeiro ponto é a questão da área de abrangência, deixando de ser apenas para escolas públicas urbanas e acolhendo as escolas públicas da zona rural, assim, tendo como objetivo promover o uso pedagógico das tecnologias de informação e comunicação nas escolas de educação básica das redes públicas de ensino urbanas e rurais (BRASIL, 2007). O segundo ponto é o foco no fortalecimento da formação continuada dos docentes (BRASIL, 2007).

Segundo Bielschowsky (2009), as ações desse PROINFO INTEGRADO são regidas a partir de três grandes áreas:

i) Infraestrutura TIC: disponibilização de laboratórios, com computadores conectados em rede, que serviriam de apoio pedagógico aos docentes e alunos, ainda, através da disponibilização de projetores PROINFO (computadores integrados a projetores de imagem) e dos laptops um computador por aluno (UCA).

ii) Formação continuada dos docentes e gestores escolares: desenvolvimento de propostas no formato de cursos de formação continuada, tais como, o curso de aperfeiçoamento em tecnologias educacionais e o programa Mídias na Educação.

iii) Convergência de conteúdos digitais: presentes em outras políticas públicas, tais como o canal TV Escola, o RIVED (rede internacional virtual de educação), o portal do professor e o banco internacional de objetos educacionais, no sentido de aproveitarem todos os conteúdos educacionais produzidos pelo MEC na formação continuada dos professores e gestores educacionais.

Souza e Linhares (2011) reforçam que o programa PROINFO INTEGRADO exerce um papel importante atualmente na inserção das TICs na educação brasileira, principalmente a nível básico, pois ele é o programa que tanto possibilita a inserção das tecnologias na educação, quanto proporciona a capacitação dos professores e gestores para utilizarem-se das mesmas.

Maia e Barreto (2012) complementam a discussão de inclusão digital dizendo que as ações não ficaram restritas aos laboratórios de informática educativa. Em 2005, durante o Fórum Econômico Mundial em Davos, na Suíça, foi apresentado ao governo brasileiro o projeto One Laptop per Child (OLPC). Trata-se de uma ONG 
internacional, homônima ao projeto, que objetiva proporcionar a cada estudante um computador portátil, de custo reduzido, com vistas à inclusão digital escolar. As autoras citam que em 2007 foi iniciado o pré-piloto do Programa Um Computador por Aluno em 5 escolas públicas brasileiras, sob a coordenação da Secretaria de Educação a Distância (SEED) do MEC. Com estas experiências, iniciou-se, portanto, oficialmente no Brasil o modelo de informática educativa na situação 1 para 1 , que prevê, para cada estudante, um computador (VALENTE, 2011).

Lavinas e Veiga (2013) citam que os programas desenvolvidos para a inclusão digital colocam em questão toda a estrutura da escola e a prática do ensino tal como eram conhecidas pelas famílias, discentes, docentes, gestores e a sociedade em geral. Valente e Bustamante (2009), complementam dizendo que, para que haja um impacto significativo no processo de ensino-aprendizagem e uma melhora na educação, as iniciativas de inclusão digital devem considerar tanto a infraestrutura, a política de gestão, o projeto pedagógico, a cultura escolar, quanto os fatores de caráter social e afetivo de professores e alunos.

Equipar as escolas com computadores e laboratórios de informática representa uma parte, mas não o todo do processo de inclusão digital. Investigações em torno da inserção do computador na escola e nas salas de aula, sem alterar as práticas habituais de ensino, não tem apontado bons resultados (MIRANDA, 2007). Este fato é também reforçado por Gimenez (2001), que avalia o uso de softwares educacionais em escolas públicas do $6^{\circ}$ ao $9^{\circ}$ ano em duas regiões do estado do Paraná. Ele investigou caminhos que pudessem transformar a maneira de se apresentar a matemática a partir de um ambiente computacional. O trabalho foi realizado em conjunto com os professores e o objetivo foi investigar a aplicabilidade de dois programas de computador para o domínio da aprendizagem da matemática: Cabri Géomètre e MSExcel. Ele observou que a maioria dos professores conhecia os recursos desses programas, no entanto, não sabia como usá-los. Os professores que conseguiram uma melhoria significativa no aproveitamento escolar em matemática dos seus alunos foram aqueles que buscaram definir com os estudantes os objetivos a serem atingidos, assim como os objetivos pertinentes na realização das tarefas. Esses professores vincularam o uso dos softwares ao seu planejamento pedagógico mais amplo e esse fator pareceu ser decisivo na melhoria do processo de ensino e de aprendizagem da matemática. Sendo assim, entende-se que, esse modo de utilização do computador não se encontra pronto no modelo de implantação do laboratório de informática, ele é 
parte de um mecanismo de mudança que a escola precisa pensar com base nos interesses dos seus atores, isto é, aquelas pessoas que compõem e dão significado ao cotidiano escolar, como professores, funcionários, estudantes e comunidade.

A partir da literatura exposta anteriormente é possível observar a existência de propostas de incentivo ao uso das tecnologias digitais na Educação no Brasil, no entanto, é importante salientar que a ênfase das discussões recai sobre a disponibilidade de hardware e software. Sendo assim, se tornam necessárias estratégias que complementem, através de outras dimensões de análise, a mensuração dos resultados das políticas nacionais de inclusão.

\subsection{Indicadores de Tecnologia da Informação e Comunicação na Educação}

Para o levantamento de trabalhos acadêmicos relacionados as medidas de uso das TICs na Educação, foram realizadas consultas por meio de ferramentas de busca nas bases de dados eletrônicas ISI Web of Knowledge (por sua relevância) e Google Acadêmico (por sua popularidade).

Na ISI Web of Knowledge, foram utilizados os seguintes termos no idioma inglês: "ict index for schools"; “ict indicators for education"; "ict index for education”. Já para a base Google Acadêmico, foram adotados os mesmos termos em inglês anteriormente citados, além dos seguintes termos no idioma português: "indicadores tecnologia da informação e comunicação educação"; "índice de tecnologia da informação e comunicação para escolas".

Para todas as consultas realizadas definiu-se o período de 2008 a 2013 como parâmetro, de forma a trazer contribuições recentes e relevantes para este estudo.

A partir dos resultados obtidos, os resumos dos artigos foram analisados e foram lidos, na íntegra, os 10 trabalhos mais citados e mais recentes de cada um dos termos pesquisados, a fim de destacarem-se aqueles que sustentarão o modelo de pesquisa aqui proposto. Sendo assim, a seguir serão apresentados os resumos de publicações realizadas recentemente, em culturas distintas, e que fornecerão uma referência para o desenvolvimento deste estudo. 


\subsubsection{ICT Composite Index for Schools (Coréia do Sul)}

Com objetivo de medir o nível das TICs em 4.490 escolas de ensino primário e 2.419 escolas do ensino médio na Coréia do Sul, Aoki et al. (2013) construíram um índice composto que visa medir a competência TIC das escolas, estruturando-o em um conjunto de 03 (três) componentes que foram assim denominados: Estrutura de capital humano; Infraestrutura tecnológica; e Uso efetivo das TICs. Vale ressaltar que o índice foi desenvolvido de forma a ser comparado internacionalmente, pois seguiu os padrões de coleta de dados do Instituto de Estatística da UNESCO. Os indicadores mensurados e utilizados no índice proposto pelos autores podem ser verificados em detalhes no Quadro 2.

Quadro 2 - Indicadores que compõe o ICT index

\begin{tabular}{|c|c|}
\hline Componentes do índice & Indicadores \\
\hline \multirow[t]{7}{*}{ Pessoal (7) } & 1.1 Participação do diretor em treinamentos de TIC \\
\hline & $\begin{array}{l}\text { 1.2 Participação em atividades de extensão em TIC por } \\
\text { professor (formação / associação) }\end{array}$ \\
\hline & $\begin{array}{l}\text { 1.3 Participação em treinamentos autônomos em TIC por } \\
\text { professor }\end{array}$ \\
\hline & $\begin{array}{l}1.4 \text { Percentual de professores que são responsáveis por } \\
\text { atividades relacionadas a TIC }\end{array}$ \\
\hline & $\begin{array}{l}1.5 \text { Nomeação de um diretor de TIC (percentagem de } \\
\text { escolas que declaram ter um diretor de TIC) }\end{array}$ \\
\hline & 1.6 Assistentes de TIC (escolas que têm assistentes TIC) \\
\hline & 1.7 Professores de Informática \\
\hline \multirow[t]{9}{*}{ Materiais (9) } & 2.1 Orçamento para TIC \\
\hline & 2.2 Número de computadores por estudante \\
\hline & 2.3 Equipamentos multimídia para uso em classe de aula \\
\hline & 2.4 Recursos digitais \\
\hline & 2.5 Velocidade da conexão de Internet \\
\hline & $\begin{array}{l}\text { 2.6 Acesso Web (bloqueio de conteúdos nocivos e acesso } \\
\text { para pessoas com deficiência) }\end{array}$ \\
\hline & $\begin{array}{l}2.7 \text { Compra de conteúdo e software para o ensino e } \\
\text { aprendizagem }\end{array}$ \\
\hline & 2.8 Estado da arte dos equipamentos TIC \\
\hline & 2.9 Laboratório de informática \\
\hline
\end{tabular}




\begin{tabular}{|l|l|}
\hline Uso (9) & $\begin{array}{l}\text { 3.1 Percentual de alunos que se auto diagnosticou como } \\
\text { tendo o vício em internet }\end{array}$ \\
\hline & \begin{tabular}{l} 
3.2 Construção de website escola \\
\hline 3.3 Troca de informações com os pais através do site da \\
escola
\end{tabular} \\
\hline $\begin{array}{l}\text { 3.4 Participação de estudantes em programas internos e } \\
\text { extracurriculares sobre o uso das TIC }\end{array}$ \\
\hline \begin{tabular}{l}
3.5 Educação sobre a ética e direitos autorais \\
\hline 3.6 Esforço para fazer uso de computadores e recursos de \\
TIC
\end{tabular} \\
\hline \begin{tabular}{l}
3.7 Esforço dos professores para aprender a utilizar TIC \\
\hline $\begin{array}{l}3.8 \text { Participação em programas educacionais especiais e } \\
\text { de aptidão no domínio das TIC (escolas de ensino } \\
\text { fundamental) }\end{array}$ \\
\hline $\begin{array}{l}\text { 3.9 Número de alunos que estão cursando uma disciplina } \\
\text { de informática (escola do ensino médio) }\end{array}$ \\
\hline
\end{tabular} \\
\hline Fonte: Aoki et al. (2013), tradução nossa
\end{tabular}

Para o cálculo do índice quantitativo, foram necessários cinco estágios. No primeiro estágio, foram calculados os escores brutos dos 25 indicadores distribuídos nos três componentes utilizando uma estatística descritiva. Não respostas e valores discrepantes (outliers) foram excluídos da análise.

No segundo estágio, depois de calcular o school ICT index com base nos escores brutos, foram computados escores padronizados com média 0 e um desvio padrão de 1 separadamente para as escolas do ensino fundamental e do ensino médio, pois as características dos indicadores para os grupos se mostraram diferentes.

$\mathrm{Na}$ terceira etapa, os escores padronizados foram transformados em uma distribuição com média de 50 e desvio padrão de 10.

Na quarta etapa, os índices obtidos pelos indicadores foram utilizados para calcular $o$ escore padronizado dos componentes (Estrutura de capital humano, Infraestrutura tecnológica e Uso efetivo das TICs).

Na última etapa, o ICT Composite Index foi calculado. Em outras palavras, os escores padronizados dos componentes foram calculados e, em seguida, os valores encontrados foram multiplicados pelos respectivos pesos e, finalmente, os escores dos componentes ponderados foram somados. Tal combinação dos índices dos componentes ponderados foi denominada de School ICT index. Cabe ressaltar, que os 
pesos utilizados foram determinados por um painel de 30 especialistas, entre eles professores, pesquisadores e experts em coleta de dados sobre TIC na Educação.

O cálculo do índice pode ser expresso na fórmula: ICT Composite Index for Schools $=(0,275 *$ indicadores Estrutura de capital humano $)+(0,225 *$ indicadores Infraestrutura tecnológica $)+(0,5 *$ indicadores em Uso efetivo da TIC $)$.

Através do estudo, os autores concluíram que as escolas primárias obtiveram uma melhor classificação no índice se comparadas com as escolas do ensino médio. Além disso, o componente Uso Efetivo das TICs teve um grande impacto no índice composto para os dois públicos estudados (AOKI et al., 2013).

\subsubsection{Indicadores qualitativos de uso das TICs na Educação (Organização dos Estados Ibero-americanos)}

Durante a investigação sobre fatores que possam influenciar direta ou indiretamente no uso de computadores e Internet nas escolas, foi identificado o estudo "Indicadores Qualitativos da Integração das TICs na Educação: proposições” (IDIE, 2008) do Instituto para o Desenvolvimento e Inovação Educativa (IDIE).

O IDIE foi uma iniciativa da Fundação Telefônica da Espanha em conjunto com a Organização dos Estados Ibero-americanos para a Educação, a Ciência e a Cultura (OEI). A prioridade deste estudo foi oferecer contribuições que permitam avaliar, de uma maneira próxima à escola, caminhos que conduzam ao êxito de políticas públicas de uso educacional de TIC, com ênfase na gestão escolar e nas práticas docentes (IDIE, 2008).

A concepção central da avaliação proposta pelo IDIE foi informar sobre a qualidade que se tem sobre o uso das TICs no contexto educacional e induzir o desenvolvimento de mudanças. Assim, a proposta de construção de um sistema básico de indicadores de verificação e avaliação da qualidade dos usos educacionais das TICs nas escolas tem potencial para informar e mobilizar os gestores, ao passo que o instrumento de auto avaliação deve informar e mobilizar os professores (IDIE, 2008).

Os indicadores propostos pelo IDIE são compostos de uma matriz avaliativa que visa integrar um sistema básico de avaliação de uso de TIC nas escolas. A matriz proposta colocou infraestrutura, programas e planos de ação e uso das TICs em relação às seguintes dimensões (IDIE, 2008): 
- Políticas Públicas da Educação: dados e informações que permitem contextualizar os contornos que impactam os resultados da ação educativa realizada pelas escolas (programas e financiamento).

- Escolas: dados e informações que permitem avaliar as condições de oferta e uso das TICs por alunos e professores.

- Egressos: impactos das experiências escolares com TIC na vida de exalunos.

O Quadro 3 ilustra a relação entre as dimensões e as unidades de análise infraestrutura, programas e planos de ação e uso das TICs, propostas pelo IDIE (2008).

\section{Quadro 3 - Indicadores qualitativos de uso das TICs na Educação}

\begin{tabular}{|c|c|c|c|c|}
\hline & Dimensão & Infraestrutura & $\begin{array}{l}\text { Programas } \\
\text { Planos de Ação }\end{array}$ & Uso das TICs \\
\hline 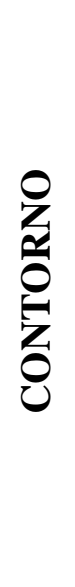 & $\begin{array}{l}\text { Políticas } \\
\text { Públicas }\end{array}$ & $\begin{array}{l}\text { Situação do país, } \\
\text { estado/província, } \\
\text { município ou } \\
\text { comunidade em } \\
\text { relação aos acessos; } \\
\text { Infraestrutura } \\
\text { disponível; } \\
\text { Orçamento da } \\
\text { educação destinado às } \\
\text { TICs. }\end{array}$ & $\begin{array}{l}\text { Programas, } \\
\text { Projetos e Planos } \\
\text { para o uso de TICs; } \\
\text { Programas de } \\
\text { avaliação e } \\
\text { acompanhamento } \\
\text { do uso de TICs; } \\
\text { Divulgação dos } \\
\text { Programas, } \\
\text { Projetos e Planos } \\
\text { em TICs. }\end{array}$ & $\begin{array}{l}\text { Programas } \\
\text { específicos de } \\
\text { formação de } \\
\text { professores e outros } \\
\text { profissionais; } \\
\text { Propostas } \\
\text { curriculares; } \\
\text { Produção e/ou } \\
\text { disponibilização de } \\
\text { conteúdos e } \\
\text { ferramentas } \\
\text { educativas. }\end{array}$ \\
\hline 仓 & Escolas & $\begin{array}{l}\text { Equipamentos; } \\
\text { Manutenção técnica. }\end{array}$ & $\begin{array}{l}\text { Projetos } \\
\text { Pedagógicos } \\
\text { Escolares; } \\
\text { Planos de Aula; } \\
\text { Registros } \\
\text { escolares. }\end{array}$ & $\begin{array}{l}\text { Condições objetivas } \\
\text { para o uso; } \\
\text { Enfoques do uso. }\end{array}$ \\
\hline 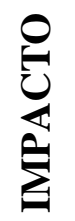 & Egressos & & & $\begin{array}{l}\text { Apropriação das } \\
\text { TICs na vida } \\
\text { cotidiana de jovens } \\
\text { e adultos. }\end{array}$ \\
\hline
\end{tabular}

Fonte: Elaborado pelo autor, com conteúdo de IDIE (2008).

Segundo o IDIE (2008), essas informações combinadas podem sugerir intervenções e investimentos capazes de gerar ou apoiar iniciativas de melhoria do trabalho pedagógico nas escolas, visando alterar positivamente a potencialidade de inserção social, econômica e política de crianças, jovens e adultos. 


\subsubsection{The Use of ICT in Education: a survey of schools in Europe (União Européia)}

Com base em mais de 190 mil respostas de estudantes, professores e diretores coletadas e analisadas durante os anos letivos de 2011 e 2012, a pesquisa The Use of ICT in Education, fornece informações detalhadas, atualizadas e confiáveis sobre o uso das TICs em escolas na Europa, desenhando um cenário onde é possível realizar uma análise da oferta de infraestrutura, do uso, da confiança e das atitudes relacionadas às TICs (Wastiau et al., 2013).

O Quadro 4 ilustra as dimensões mensuradas pelo estudo.

Quadro 4 - Dimensões, variáveis e objetivos mensurados pelo The Use of ICT in Education

\begin{tabular}{|c|c|c|}
\hline Dimensões & Variáveis & Objetivo \\
\hline $\begin{array}{l}\text { Infraestrutura de TIC } \\
\text { das escolas }\end{array}$ & $\begin{array}{l}\text { Computador de mesa; } \\
\text { Dispositivos móveis, } \\
\text { como laptops, } \\
\text { notebooks, tablets, } \\
\text { smartphones, etc.; } \\
\text { Banda larga; } \\
\text { Website da escola, } \\
\text { endereços de email, } \\
\text { ambiente virtual de } \\
\text { aprendizagem, etc.; } \\
\text { Implantação de } \\
\text { equipamentos nas salas } \\
\text { de aula, laboratórios de } \\
\text { informática, bibliotecas, } \\
\text { etc.; } \\
\text { Manutenção. }\end{array}$ & $\begin{array}{l}\text { Mensurar a infraestrutura } \\
\text { básica. }\end{array}$ \\
\hline $\begin{array}{l}\text { Acesso as TICs por } \\
\text { alunos e professores } \\
\text { nas escolas }\end{array}$ & $\begin{array}{l}\text { Anos de experiência no } \\
\text { uso das TICs na } \\
\text { escola,\% do tempo, } \\
\text { frequência. }\end{array}$ & \multirow{2}{*}{$\begin{array}{l}\text { Mensurar o acesso, a } \\
\text { frequência, a organização } \\
\text { e o contexto do uso, bem } \\
\text { como, a natureza das } \\
\text { atividades baseadas nas } \\
\text { TICs. }\end{array}$} \\
\hline $\begin{array}{l}\text { Atividades baseadas } \\
\text { nas TICs organizadas } \\
\text { por professores e } \\
\text { realizadas por alunos } \\
\text { durante as aulas }\end{array}$ & $\begin{array}{l}\text { Frequência; } \\
\text { Tipo de atividade; } \\
\text { Recursos digitais } \\
\text { utilizados. }\end{array}$ & \\
\hline
\end{tabular}




\begin{tabular}{|c|c|c|}
\hline $\begin{array}{l}\text { Declaração da } \\
\text { confiança em suas } \\
\text { competências digitais } \\
\text { por alunos e } \\
\text { professores }\end{array}$ & $\begin{array}{l}\text { Habilidades } \\
\text { operacionais, } \\
\text { habilidades de mídia } \\
\text { social, o uso seguro e } \\
\text { responsável da Internet. }\end{array}$ & $\begin{array}{l}\text { Mensurar os resultados e } \\
\text { as realizações quanto ao } \\
\text { uso das TICs. }\end{array}$ \\
\hline Treinamento & $\begin{array}{l}\text { Participação, conteúdo e } \\
\text { as modalidades. }\end{array}$ & \\
\hline $\begin{array}{l}\text { Estratégia e liderança } \\
\text { escolar }\end{array}$ & $\begin{array}{l}\text { Políticas sobre a } \\
\text { utilização das TICs no } \\
\text { ensino-aprendizagem e } \\
\text { nas disciplinas; } \\
\text { Discussão sobre a } \\
\text { utilização das TICs a } \\
\text { nível da escola como um } \\
\text { todo; } \\
\text { Tempo para os } \\
\text { professores interagirem } \\
\text { e criarem } \\
\text { relacionamento; } \\
\text { Incentivos para } \\
\text { recompensar a utilização } \\
\text { das TICs; } \\
\text { Política de inovação, etc. }\end{array}$ & $\begin{array}{l}\text { Mensurar a importância } \\
\text { da liderança no contexto } \\
\text { escolar a fim de obter a } \\
\text { adoção e o uso completo } \\
\text { das TICs dentro contexto } \\
\text { escolar. }\end{array}$ \\
\hline $\begin{array}{l}\text { Opiniões e atitudes dos } \\
\text { líderes escolares, } \\
\text { professores e alunos }\end{array}$ & $\begin{array}{lr}\text { Relevância } & \text { das TICs } \\
\text { para os diferentes } \\
\text { processos } & \text { de } \\
\text { aprendizagem; impacto } \\
\text { na aprendizagem, } \\
\text { realização e motivação. }\end{array}$ & $\begin{array}{l}\text { Mensurar o impacto das } \\
\text { TICs para o processo de } \\
\text { aprendizagem. }\end{array}$ \\
\hline
\end{tabular}

Fonte: Elaborado pelo autor, com conteúdo de Wastiau et al., 2013 (tradução nossa)

A pesquisa foi encomendada em 2011 pela Comissão Européia para avaliar, de forma generalizada, a utilização e as atitudes referentes às TICs nas escolas em 31 países (UE27, Croácia, Islândia, Noruega e Turquia).

O trabalho sobre a pesquisa foi realizado entre janeiro de 2011 e novembro de 2012 , com a coleta de dados ocorrendo no outono de 2011.

Em quatro países (Alemanha, Islândia, Países Baixos e Reino Unido), a taxa de resposta foi insuficiente, o que tornou inviável uma análise confiável dos dados, sendo assim, as conclusões do estudo não incorporam esses países.

As principais descobertas do trabalho foram:

- A falta de infraestrutura é um grande obstáculo para o uso das TICs nas escolas; 
- A utilização das TICs, medida pela pesquisa, pode não ter crescido tanto quanto se poderia esperar;

- Fornecer infraestrutura TIC na escola não gera uma garantia de confiança, uso e melhora nas atitudes de professores e alunos;

- O foco das políticas deve estar na gestão eficaz da aprendizagem, tanto quanto no fornecimento das TICs;

- Há um uso alto, mas não universalizado, das TICs nos domicílios; e

- A presença de ambientes virtuais de aprendizagem nas escolas está aumentando rapidamente.

Wastiau et al. (2013) citam que os resultados da pesquisa apontam para uma série de ações políticas, em todos os níveis, para garantir uma utilização otimizada dos recursos financeiros cada vez mais escassos. As ações citadas pelos autores são:

- Fortalecer a ação pública em níveis institucionais, locais, regionais, nacionais e europeus para impulsionar o uso das TICs na escola, de modo a reduzir a distância entre o uso fora e dentro da escola;

- Aumentar as oportunidades de desenvolvimento profissional para os professores é uma forma eficiente de aumentar a utilização das TICs no processo de ensino-aprendizagem, uma vez que ajuda a construir professores altamente confiantes e abertos;

- Apesar de ter acesso e estarem abertos em relação ao uso das TICs no processo de ensino-aprendizagem, os professores, muitas vezes se deparam com dificuldades, sendo assim, se faz necessário um apoio contínuo, não apenas técnico, mas também pedagógico; e

- Aproveitar o alto nível de uso dos telefones celulares pessoais dos alunos.

\subsubsection{A Maturity Model for Assessing the Use of ICT in School Education}

Solar et al. (2013) desenvolveram um modelo para mensurar a maturidade do uso das TICs na educação escolar. Os autores desenvolveram tal artefato com o objetivo de criar uma ferramenta que desse suporte aos gestores escolares na definição de políticas de investimento e de ações futuras no que diz respeito às TICs. 
O modelo se baseia no $\mathrm{CMMi}^{4}$ e foi estruturado em três dimensões que dão suporte ao processo educacional. São elas:

1. Critério de informação: Para satisfazer as exigências da escola, a informação deve satisfazer a critérios como efetividade, eficiência, confidencialidade, integridade, disponibilidade, legalidade e manutenção.

2. Recursos de TI: Os domínios de influência exigem que existam os recursos de Tecnologia da Informação para gerar, armazenar e disponibilizar as informações necessárias para se alcançar os objetivos da escola. Tal dimensão visa avaliar as aplicações utilizadas, o formato de armazenamento dos dados, a infraestrutura tecnológica e sua escalabilidade.

3. Domínios de alavancagem: Segundo os autores, tal dimensão é a mais importante do modelo, pois permite estabelecer os níveis de capacidade a partir das variáveis avaliadas nos domínios chave. Ao desenvolver tal estrutura de análise, os autores buscaram romper com a barreira focada tradicional e exclusivamente nas TICs, desmembrando tal dimensão em 05 unidades de análise:

a. Gestão: Fornece critérios para avaliar a capacidade da escola de articular uma visão consistente quanto as TICs. Em outras palavras, permite avaliar se a escola está alinhando TIC e estratégia organizacional na mesma direção. Os domínios chave avaliados são:

i. Gestão Escolar;

ii. Visão, estratégias e políticas;

iii. Organização e Gestão das TICs.

b. Infraestrutura: Fornece orientação sobre como a escola pode desenvolver seus recursos de multimídia a fim de desenvolver uma base para o uso das TICs. Os domínios chave avaliados são:

\footnotetext{
${ }^{4}$ O CMMI (Capability Maturity Model Integration) é um modelo de referência que define práticas necessárias para o desenvolvimento e avaliação de maturidade de software em uma organização.
} 

i. Software;
ii. Hardware;
iii. Redes;
iv. Plano de manutenção;
v. Segurança.

c. Administração: Fornece uma visão sobre a efetividade do suporte da liderança quanto as TICs na escola. Os domínios chave avaliados são:
i. Liderança e visão;
ii. Aprendizagem e ensino;
iii. Produtividade e práticas profissionais;
iv. Suporte, gestão e operação;
v. Avaliação;
vi. Questões sociais, éticas e legais.

d. Professores: Fornece uma visão sobre o uso das TICs pelos professores no processo de ensino-aprendizagem a fim de enriquecer a prática profissional e desenvolver modelos educacionais que estimulem os estudantes. Os domínios chave avaliados são:

i. Criatividade e aprendizado dos estudantes;

ii. Experiências de aprendizagem e avaliações na era digital;

iii. Trabalho e aprendizado na era digital;

iv. Responsabilidade e cidadania digital;

v. Crescimento profissional e liderança.

e. Alunos: Fornece uma visão de como as TICs podem auxiliar no processo de aprendizagem dos alunos de forma efetiva. Os domínios chave avaliados são:

i. Criatividade e inovação;

ii. Comunicação e colaboração;

iii. Pesquisa e fluência informacional;

iv. Pensamento crítico, resolução de problemas e tomada de decisão;

v. Cidadão digital; 
vi. Operações tecnológicas e conceitos.

A Figura 2 ilustra a forma como o modelo integra as dimensões acima descritas.

Figura 2 - Estrutura do modelo que mostra as três dimensões de elementos

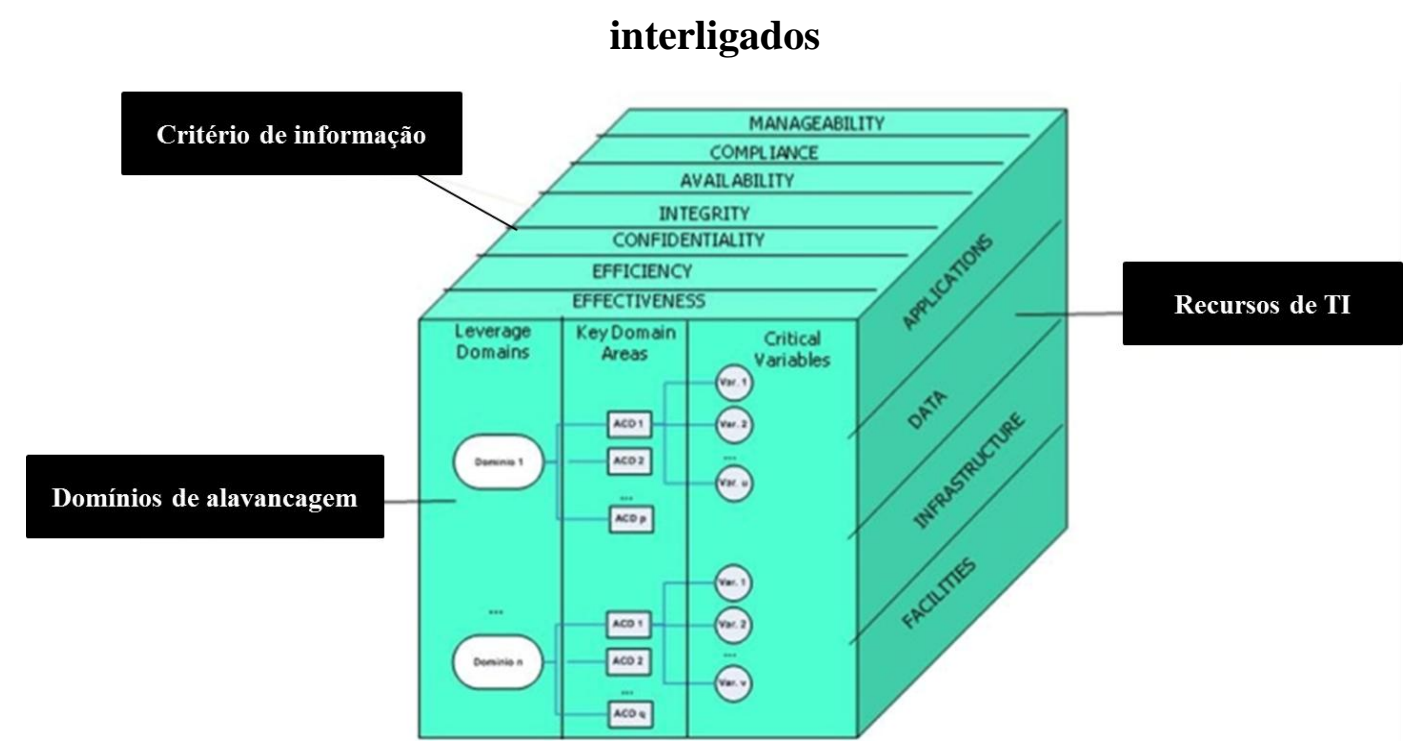

Fonte: Adaptado de Soler et al. (2013)

Para gerar os indicadores de maturidade, o modelo define capacidade como sendo a medida do estágio de cada domínio chave que contribui para suportar o desenvolvimento escolar. Para determinar a capacidade, é necessário definir um nível para cada variável chave contida no domínio. Sendo assim, para se definir o nível do domínio chave, é extraída uma média nos níveis de capacidade de cada variável chave que compõe aquele domínio. De forma generalizada, as variáveis são estruturadas em níveis categóricos que passam por iniciante, em desenvolvimento, definido, gerenciado, até alcançarem o estágio otimizado.

Os autores concluem que o modelo é um framework de referência para identificar as áreas que suportam uma estratégia de TIC, com base em normas de gestão e ensino reconhecidas internacionalmente.

Além disso, fornece uma base para a autoavaliação e melhoria de planejamento. Em termos de questões teóricas, não é apenas uma ferramenta de diagnóstico, mas também pode ser útil para orientar diretores em como avançar para melhores práticas de gestão e investimento em TIC.

Já os domínios de alavancagem permitem a realização de um processo de aprimoramento contínuo no uso das TICs a partir da criação de um roadmap que direcione a evolução da escola para estágios mais avançados do modelo. 


\subsubsection{Acesso e uso da Tecnologia da Informação em escolas públicas e privadas de ensino médio: o impacto nos resultados do ENEM}

Lobler et al. (2010) desenvolveram um modelo que buscou avaliar como a tecnologia pode impactar o desempenho em escolas de ensino médio. Tal construto é uma adaptação do trabalho de Zwicker et al. (2007), que na ocasião procurou medir os benefícios associados à adoção e ao uso adequado de TI pelas empresas.

O modelo proposto por Lobler et al.(2010) foi estruturado conforme pode ser observado na Figura 3.

Figura 3 - Framework de Zwicker et al. (2007) adaptado para o contexto educacional

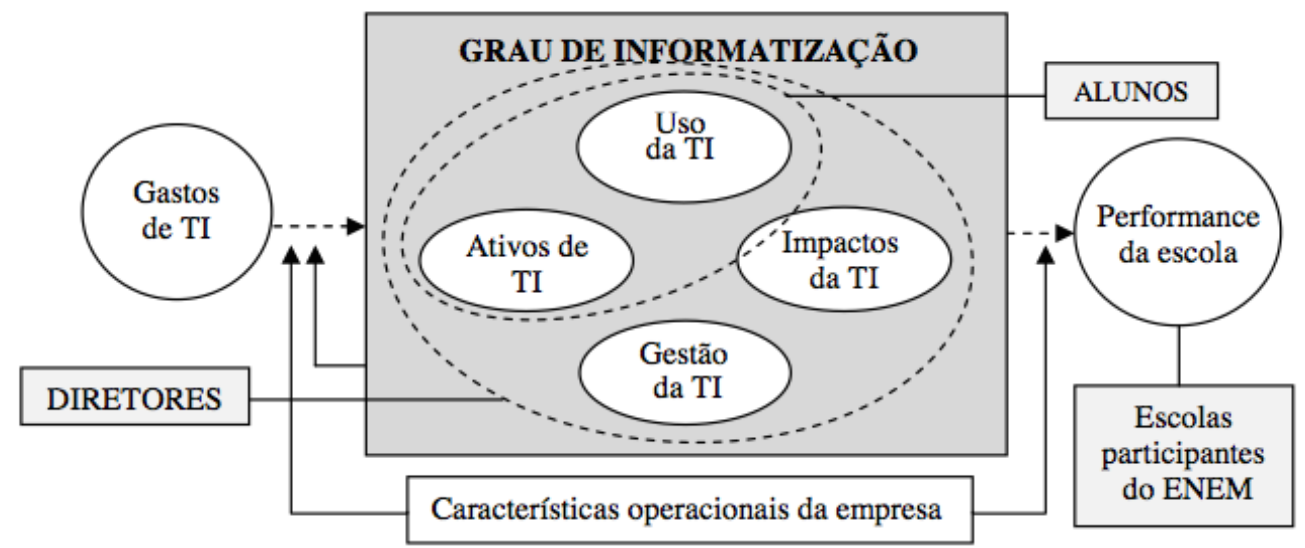

Fonte: Lobler et al. (2010)

Para a aplicação do modelo, as dimensões Gestão e Impactos da TI foram trabalhadas no instrumento de coleta de dados junto aos diretores. Já as dimensões Ativos e Uso de TI, foram abordadas junto aos alunos e diretores. A dimensão originalmente chamada de Uso Organizacional da TI, no trabalho de Zwicker et al. (2007), foi substituída por Uso de TI. Tal modificação foi realizada, pois Lobler et al. (2010) buscaram compreender a influência da TI também nos aspectos educacionais. Os dois instrumentos foram validados por um especialista da área temática do estudo, bem como por uma pedagoga especialista em orientação educacional (LOBLER et al., 2010).

As dimensões e sub dimensões utilizadas no trabalho são detalhadas no Quadro 5. 
Quadro 5 - Dimensões, subdimensões e variáveis do modelo de pesquisa

\begin{tabular}{|c|c|c|}
\hline \multicolumn{2}{|c|}{ Dimensões } & Variáveis \\
\hline \multirow[t]{2}{*}{ (1) Ativos de TI } & $\begin{array}{c}\text { Infra-estrutura } \\
\text { de } \mathrm{TI}\end{array}$ & $\begin{array}{l}\text { Conectividade interna e externa dos Sistemas de Informação e } \\
\text { serviços de infra-estrutura envolvendo indicadores do tipo } \\
\text { número de itens de TI (número de computadores, impressoras, }\end{array}$ \\
\hline & Pes & $\begin{array}{l}\text { Participação de alunos, professores e funcionários na utilização } \\
\text { e suporte das ferramentas de TI. }\end{array}$ \\
\hline \multirow[t]{2}{*}{ (2) Uso da TI } & $\begin{array}{c}\text { Para } \\
\text { Aprendizag }\end{array}$ & $\begin{array}{l}\text { Levantamento do uso dos recursos existentes na escola } \\
\text { disponíveis para os alunos (TV, vídeo, computador, etc.), do } \\
\text { laboratório de informática, da internet. Análise da opinião dos } \\
\text { alunos quanto ao uso dos recursos da TI. }\end{array}$ \\
\hline & Institucional & $\begin{array}{l}\text { âo de e-mail institucional, verificação da utilização da } \\
\text { para efetuar compras. }\end{array}$ \\
\hline (3) Gestão da TI & \multicolumn{2}{|c|}{$\begin{array}{l}\text { Indicadores sobre o número de profissionais de TI, existência ou não de uma } \\
\text { área de TI, existência ou não de um gestor das atividades de TI. Planejamento } \\
\text { para aquisição de ferramentas de TI. }\end{array}$} \\
\hline II & \multicolumn{2}{|c|}{$\begin{array}{l}\text { Percepção dos diretores sobre como a TI contribui para a melhoria dos serviços } \\
\text { em geral. Análise do grau de dependência que a escola possui com relação ao } \\
\text { uso da TI. }\end{array}$} \\
\hline
\end{tabular}

Fonte: Elaborado por Lobler et al. (2010), adaptado de Zwicker et al. (2007)

Lobler et al. (2010) concluíram que a TI tem forte impacto sobre a educação, especificamente sobre a de ensino médio. Além disso, o estudo constatou que as escolas públicas com maior desempenho no ENEM possuem acesso à TI de maneira mais ampla e incentivam seus alunos ao uso da mesma, contrastando, significativamente, com as escolas públicas de menor desempenho. As escolas com infraestrutura adequada e melhor uso dos ativos de TI nas atividades educacionais foram as que apresentaram maior desempenho no ENEM.

\subsubsection{Measuring ICT Use and Learning Outcomes: evidence from recent econometric studies}

Em consonância ao trabalho de Lobler et al. (2010), Biagi e Loi (2013) desenvolveram um estudo que buscou identificar como o tipo e a intensidade de uso das TICs se relacionavam com o desempenho escolar dos estudantes de 15 anos no exame internacional PISA ${ }^{5}$.

Sabendo da dificuldade em avaliar o impacto das TICs no processo de aprendizagem e de se buscar uma relação causal entre tais variáveis, os autores sintetizaram na Figura 4 as relações existentes entre o uso das TICs e os resultados do aprendizado. Os autores levaram em consideração a integração de níveis nos fatores micro

\footnotetext{
${ }^{5}$ Programa Internacional de Avaliação de Alunos.
} 
(características do estudante e de sua família), meso (características da escola) e macro (questões institucionais).

Figura 4 - Fatores que afetam o uso das TICs pelos alunos e o desempenho escolar

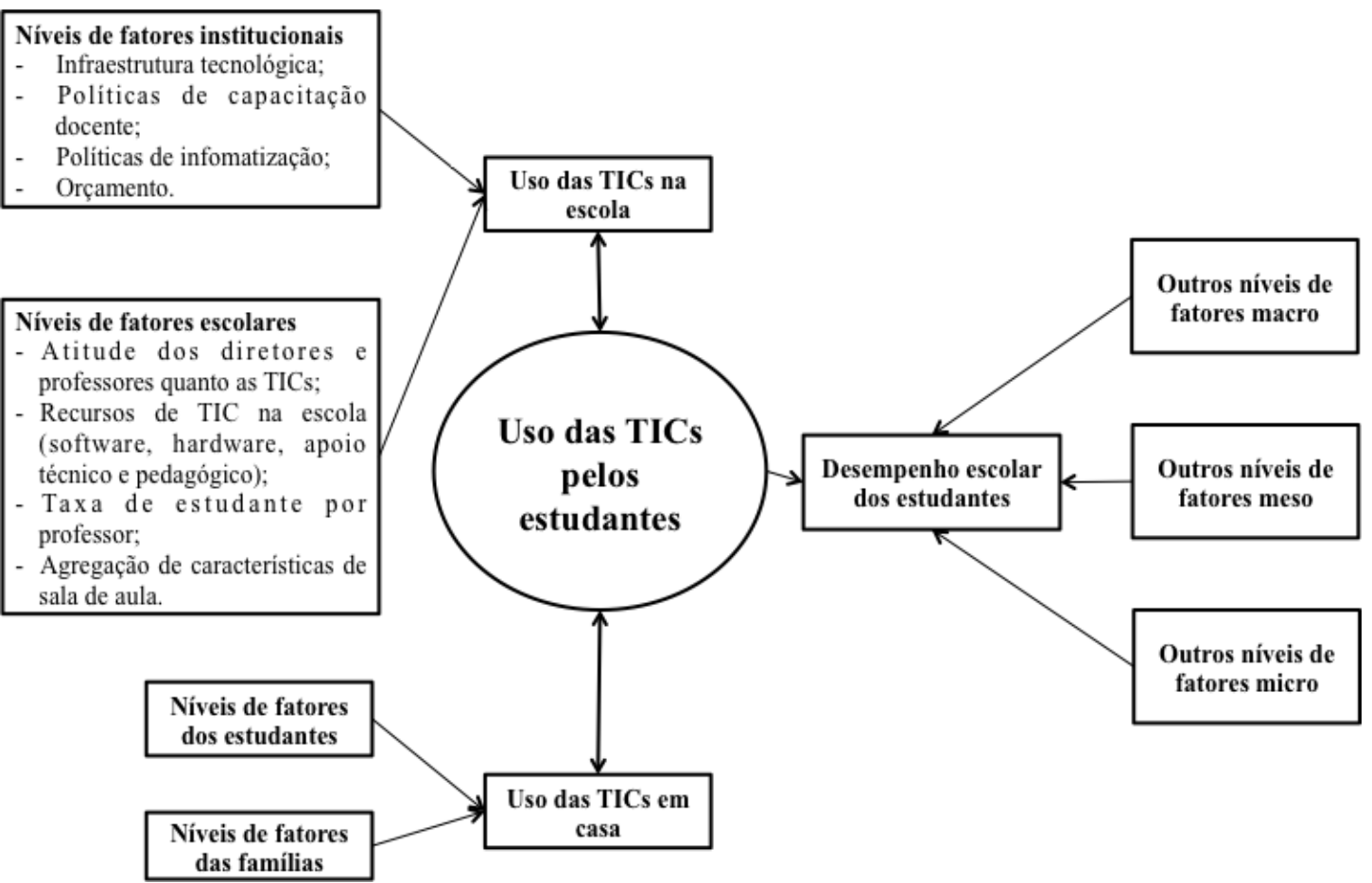

Fonte: Elaborado pelo autor, adaptado de Biagi e Loi (2013)

Para avaliar o uso das TICs pelos estudantes, foram consideradas a disponibilidade, a motivação, a intensidade, a infraestrutura e o suporte existente para tal no contexto domiciliar e escolar (BIAGI; LOI, 2013).

A avaliação do uso das TICs pelos alunos na escola foi realizada a partir de fatores institucionais e escolares.

Referente aos fatores escolares, a literatura identifica dois pontos importantes para que haja a integração das TICs nas escolas. O primeiro ponto diz respeito ao comportamento e conhecimento dos professores e diretores quanto ao uso das TICs (BRUMMELHUIS; KUIPER, 2008; LAW; CHOW, 2008; PELGRUM, 2008 apud BIAGI; LOI, 2013). O segundo ponto se refere a disponibilidade de equipamentos tecnológicos que incluem software, conectividade com a Internet e suporte pedagógico e técnico (EURYDICE, 2010 apud BIAGI; LOI, 2013).

Já com relação aos fatores institucionais, os mesmos acentuam as barreiras no nível da escola. Sem dúvida, as infraestruturas tecnológicas (por exemplo, a cobertura de 
banda larga e velocidade) afetam o acesso e utilização das TICs, tanto em casa como na escola (EUROPEAN COMMISSION, 2012 apud BIAGI; LOI, 2013).

Além disso, muitos países recomendam a utilização das TICs para o ensino, oferecendo apoio (aconselhamento e ajuda para o planejamento de aula, o ensino eficaz, gestão de sala de aula, etc.) para a integração efetiva destas ferramentas na educação (CONDIE; MUNRO, 2007 apud BIAGI; LOI, 2013).

Os países desempenham um papel central na promoção de políticas (nacionais e locais) que visem dotar os professores com conhecimentos e habilidades para integrar as TICs em suas atividades de ensino. Por fim, as definiçõos institucionais condicionam a quantidade de recursos disponíveis ao nível da escola e suas decisões de alocação de orçamento (BIAGI; LOI, 2013).

A partir da conclusão de outros autores, Biagi e Loi (2013) ressaltam a dificuldade em se encontrar uma forma única e consistente que evidencie e suporte a hipótese de um impacto positivo entre o uso das TICs em exames que visam medir o desempenho de estudantes.

Para o desenvolvimento do trabalho, Biagi e Loi (2013) consideraram os países europeus que participaram da edição de 2009 do PISA. Além disso, os autores analisaram somente as observações completas, isto é, sem dados faltantes (missigns). Para medir o uso das TICs pelos alunos na escola e em casa, foram utilizadas as respostas oriundas das questões descritas no questionário TIC PISA 2009 (disponível no anexo A). Tal conjunto de questões gerou os seguintes grupos de variáveis:

- Gaming: atividades relacionadas aos hábitos dos alunos em jogarem individualmente ou coletivamente, de forma online ou offline;

- Colaboração e comunicação: atividades relacionadas a participação dos alunos em redes sociais e comunidades digitais e, ao uso de comunicadores;

- Gestão da informação e operação tecnológica: Atividades realizadas pelos alunos para a identificação, localização, acesso, recuperação, armazenamento e organização de informações, além do uso da tecnologia e meios de comunicação para a realização de tarefas por meio de ferramentas digitais;

- Criação de conteúdo e conhecimento e resolução de problemas: Atividades realizadas pelos alunos para a integração, criação e reuso de conhecimento e conteúdo, além de atividades relacionadas ao uso de recursos para a solução de problemas. 
Biagi e Loi (2013) concluíram que atividades de uso referentes ao grupo Gaming geraram um coeficiente positivo entre os resultados dos testes do PISA e a intensidade de uso. Para os demais grupos de atividades, as medidas de intensidade tenderam a ser negativamente correlacionadas com a pontuação no teste PISA (as exceções encontradas se deram na Noruega, na Eslováquia e em Portugal). Além disso, tal efeito negativo é particularmente forte para o grupo de atividades "criação de conteúdos e conhecimentos e resolução de problemas", que parecem estar estreitamente relacionadas ao uso das TICs no currículo escolar.

\subsubsection{Pesquisa TIC Educação}

A pesquisa TIC Educação, do Comitê Gestor da Internet no Brasil (CGI.br), avalia desde 2010 a infraestrutura de TIC disponível nas escolas, a apropriação das TICs nos processos educacionais, as habilidades de professores e alunos no uso da tecnologia, as principais barreiras que impedem o seu uso pelos atores do sistema educacional bem como as motivações que levam muitos professores a integrar as TICs em suas práticas pedagógicas (CGI, 2014).

Os instrumentos de coleta da pesquisa são estruturados em módulos e serão descritos a seguir.

O módulo A trata de aspectos demográficos de cada um dos atores escolares, como sexo e idade. Também são levantados aspectos profissionais e de formação dos perfis, exceto do perfil aluno. Aos diretores, são realizadas questões sobre aspectos gerais de infraestrutura da escola e, principalmente, de infraestrutura de TIC, permitindo a construção de um retrato detalhado sobre o ambiente escolar.

$\mathrm{O}$ módulo $\mathrm{B}$ levanta o perfil dos atores escolares com relação às TICs, buscando identificar aspectos da posse e uso do computador e da Internet, tipo de computador utilizado, além da posse e uso de tecnologias móveis, com o intuito de compreender a situação de alunos, professores, coordenadores e diretores no processo de inclusão digital. Com exceção dos alunos, a pesquisa investiga a fonte de recursos para aquisição de computadores, objetivando identificar a existência e a utilização dos programas oferecidos pelo governo.

Para coordenadores pedagógicos e diretores, o módulo C levanta a utilização das TICs para atividades administrativas e de gestão da escola. Já para alunos e professores, tal 
módulo capta a percepção sobre habilidades pessoais em realizar atividades por meio do computador e da Internet.

As limitações de uso são investigadas nos módulos D para coordenador pedagógico, E para diretor e F para professor, com o intuito de compreender os fatores que se configuram como limitações para a integração das TICs dentro do contexto escolar. O módulo D, para aluno e professor, trata da capacitação específica, buscando compreender a origem do aprendizado para o uso do computador e da Internet, além de identificar a utilização dos programas do governo.

No caso dos diretores, o módulo D investiga a existência e as condições dos equipamentos e recursos das TICs nas escolas, incluindo o laboratório de informática. Para aluno e professor, as atividades em âmbito educacional e escolar são levantadas no módulo E.

Por fim, o módulo G visa compreender, junto aos professores, o uso de conteúdos digitais educacionais. O Quadro 6 sintetiza as variáveis coletadas pela pesquisa TIC Educação em cada uma das unidades de análise estudadas. 
Quadro 6 - Unidades de análise e variáveis mensuradas pela pesquisa TIC

Educação

\begin{tabular}{|c|c|}
\hline Unidade de análise & Variáveis \\
\hline \multirow{5}{*}{ Aluno } & Perfil demográfico \\
\hline & Uso do computador e Internet \\
\hline & Habilidades no uso do computador e Internet \\
\hline & Capacitação para o uso das TICs \\
\hline & Atividades escolares com suporte das TICs \\
\hline \multirow{4}{*}{ Coordenador pedagógico } & Perfil demográfico e profissional \\
\hline & Uso do computador e Internet \\
\hline & Habilidades no uso do computador e Internet \\
\hline & Barreiras para o uso das TICs \\
\hline \multirow{5}{*}{ Diretor } & Perfil demográfico e profissional \\
\hline & Uso do computador e Internet \\
\hline & $\begin{array}{l}\text { Atividades de gestão, planejamento e interação com a } \\
\text { comunidade }\end{array}$ \\
\hline & Infraestrutura das TICs na escola \\
\hline & Barreiras para o uso das TICs \\
\hline \multirow{7}{*}{ Professor } & Perfil demográfico e profissional \\
\hline & Uso do computador e Internet \\
\hline & Habilidades no uso do computador e Internet \\
\hline & Capacitação para o uso das TICs \\
\hline & Atividades escolares com suporte das TICs \\
\hline & Barreiras para o uso das TICs \\
\hline & Uso de conteúdos educacionais digitais \\
\hline
\end{tabular}

\subsection{Modelo de pesquisa}

O conceito de uso pode ser definido como o processo gerenciado pelo qual uma escola adota as TICs de forma integrada, buscando engajar os principais atores do processo de ensino-aprendizagem.

O Quadro 7 visa demonstrar o relacionamento entre as dimensões acadêmicas referenciadas na seção $2.4 \mathrm{e}$ os indicadores abordados nos trabalhos apresentados na seção 2.5. Tal relação tem por objetivo sustentar o modelo de pesquisa que será apresentado em seguida. 
Quadro 7 - Relacionamento entre as dimensões teóricas estudadas e os indicadores de uso das TICs

\begin{tabular}{|c|c|c|c|}
\hline Dimensão de estudo & Aoki et al. (2013) & IDIE (2008) & Wastiau et al. (2013) \\
\hline Professor & $\begin{array}{l}\text { Participação em atividades de extensão em TIC por } \\
\text { professor (formação/associação) e participação em } \\
\text { treinamentos autônomos em TIC por professor. }\end{array}$ & $\begin{array}{l}\text { Condições objetivas para o uso e enfoques } \\
\text { do uso. }\end{array}$ & $\begin{array}{l}\text { Anos de experiência no uso das TICs na escola e } \\
\text { frequência de uso. }\end{array}$ \\
\hline Aluno & $\begin{array}{l}\text { Participação de estudantes em programas internos e } \\
\text { extracurriculares sobre o uso das TICs e número de alunos } \\
\text { que estão cursando uma disciplina de informática (escola } \\
\text { do ensino médio). }\end{array}$ & $\begin{array}{l}\text { Apropriação das TICs na vida cotidiana de } \\
\text { jovens e adultos egressos. }\end{array}$ & $\begin{array}{l}\text { Anos de experiência no uso das TICs na escola e } \\
\text { frequência de uso. }\end{array}$ \\
\hline Infraestrutura de TI & $\begin{array}{l}\text { Número de computadores por estudante, equipamentos } \\
\text { multimídia para uso em sala de aula, recursos digitais, } \\
\text { velocidade da conexão de Internet, compra de conteúdo e } \\
\text { software para o ensino-aprendizagem, estado da arte dos } \\
\text { equipamentos TIC, controle de acesso e existência de } \\
\text { laboratório de informática. }\end{array}$ & $\begin{array}{l}\text { Infraestrutura de equipamentos } \\
\text { disponíveis. }\end{array}$ & $\begin{array}{l}\text { Computador de mesa, dispositivos móveis } \\
\text { (laptops, notebooks, tablets, smartphones, etc.), } \\
\text { banda larga, endereços de e-mail, implantação de } \\
\text { equipamentos nas salas de aula, ambiente virtual } \\
\text { de aprendizagem e laboratórios de informática. }\end{array}$ \\
\hline $\begin{array}{l}\text { Recursos } \\
\text { computacionais no dia } \\
\text { a dia escolar }\end{array}$ & $\begin{array}{l}\text { Esforço dos professores para aprender a utilizar TIC e } \\
\text { esforço para fazer uso de computadores e recursos de TIC. }\end{array}$ & $\begin{array}{l}\text { Condições objetivas para o uso e enfoques } \\
\text { do uso. }\end{array}$ & $\begin{array}{l}\text { Frequência, tipo de atividade e recursos digitais } \\
\text { usados. } \\
\text { Relevância das TICs para os diferentes processos } \\
\text { de aprendizagem. }\end{array}$ \\
\hline $\begin{array}{l}\text { Profissional da área de } \\
\text { tecnologia educacional }\end{array}$ & $\begin{array}{l}\text { Assistentes de TIC, professores de informática e } \\
\text { professores que são responsáveis por atividades } \\
\text { relacionadas a TIC. }\end{array}$ & $\begin{array}{l}\text { Manutenção dos equipamentos e } \\
\text { organização ao uso. }\end{array}$ & cor a \\
\hline Escola & $\begin{array}{l}\text { Troca de informações com os pais através do site da } \\
\text { escola, participação em programas educacionais especiais } \\
\text { e de aptidão no domínio das TICs e construção de website } \\
\text { da escola. }\end{array}$ & \multirow{2}{*}{$\begin{array}{l}\text { Ênfase no uso das TICs e no provimento } \\
\text { de condições objetivas de trabalho para } \\
\text { alunos e professores, tendo em conta as } \\
\text { concepções explicitadas nos documentos } \\
\text { escolares e declaradas por suas equipes. }\end{array}$} & \multirow{2}{*}{$\begin{array}{l}\text { Website da escola, políticas sobre a utilização das } \\
\text { TICs no ensino-aprendizagem e nas disciplinas, } \\
\text { discussão sobre a utilização das TICs no nível da } \\
\text { escola como um todo, tempo para os professores } \\
\text { interagirem e criarem relacionamento, incentivos } \\
\text { para recompensar a utilização das TICs e política } \\
\text { de inovação, etc. }\end{array}$} \\
\hline Diretor & $\begin{array}{l}\text { Participação do diretor em treinamentos de TIC e troca de } \\
\text { informações com os pais através do site da escola. }\end{array}$ & & \\
\hline $\begin{array}{l}\text { Contribuição para a } \\
\text { avaliação de políticas } \\
\text { públicas }\end{array}$ & $\begin{array}{l}\text { Medida unificada de apoio para avaliação das políticas } \\
\text { públicas de inclusão digital nas escolas da Coréia do Sul. }\end{array}$ & $\begin{array}{l}\text { Desenvolvimento de programas } \\
\text { específicos de formação de professores e } \\
\text { outros profissionais, propostas curriculares } \\
\text { e produção e/ou disponibilização de } \\
\text { conteúdos e ferramentas educativas. }\end{array}$ & $\begin{array}{l}\text { Constatação de que o fortalecimento da ação } \\
\text { pública em níveis institucionais, locais, regionais, } \\
\text { nacionais e europeus é necessário para } \\
\text { impulsionar o uso das TICs na escola, de modo a } \\
\text { reduzir a distância entre o uso fora e dentro da } \\
\text { escola. }\end{array}$ \\
\hline
\end{tabular}




\begin{tabular}{|c|c|c|c|c|}
\hline Dimensão de estudo & Solar et al. (2013) & Lobler et al. (2010) & Biagi e Loi (2013) & TIC Educação \\
\hline Professor & $\begin{array}{l}\text { Experiências de aprendizagem e avaliações } \\
\text { na era digital, responsabilidade e cidadania } \\
\text { digital e liderança. }\end{array}$ & $\begin{array}{l}\text { Participação de professores na } \\
\text { utilização das ferramentas de TI. }\end{array}$ & $\begin{array}{l}\text { Atitude dos professores } \\
\text { quanto as TIC. }\end{array}$ & $\begin{array}{l}\text { Habilidades no uso de computador e } \\
\text { Internet, capacitações para o uso das TICs, } \\
\text { barreiras para o uso das TICs e uso de } \\
\text { conteúdos educacionais digitais. }\end{array}$ \\
\hline Aluno & $\begin{array}{l}\text { Criatividade e inovação, fluência } \\
\text { informacional, pensamento crítico, resolução } \\
\text { de problemas e tomada de decisão, cidadão } \\
\text { digital e operações tecnológicas e conceitos. }\end{array}$ & $\begin{array}{l}\text { Participação de alunos na } \\
\text { utilização das ferramentas de TI. }\end{array}$ & $\begin{array}{l}\text { Hábitos de uso das TICs } \\
\text { pelos alunos em casa. }\end{array}$ & $\begin{array}{l}\text { Habilidades no uso do computador e } \\
\text { Internet, capacitação para o uso das TICs. }\end{array}$ \\
\hline Infraestrutura de TI & $\begin{array}{l}\text { Disponibilidade de software, hardware e } \\
\text { redes. }\end{array}$ & $\begin{array}{l}\text { Infraestrutura de TI e serviços de } \\
\text { infraestrutura envolvendo } \\
\text { indicadores do tipo número de } \\
\text { itens de TI, número de } \\
\text { computadores, impressoras. }\end{array}$ & $\begin{array}{l}\text { Disponibilidade de } \\
\text { equipamentos tecnológicos } \\
\text { (software, conectividade } \\
\text { com a Internet). }\end{array}$ & $\begin{array}{l}\text { Infraestrutura das TICs na escola } \\
\text { (computador, Internet e rede). }\end{array}$ \\
\hline $\begin{array}{l}\text { Recursos } \\
\text { computacionais no dia } \\
\text { a dia escolar }\end{array}$ & $\begin{array}{l}\text { Uso das TICs pelos professores e alunos no } \\
\text { processo de ensino-aprendizagem a fim de } \\
\text { desenvolver modelos educacionais que } \\
\text { estimulem os estudantes ao aprendizado. }\end{array}$ & $\begin{array}{l}\text { Participação dos alunos e } \\
\text { professores no uso dos recursos de } \\
\text { TI. }\end{array}$ & $\begin{array}{l}\text { Hábitos de uso das TICs } \\
\text { pelos alunos na escola. }\end{array}$ & $\begin{array}{l}\text { Suporte das TICs nas atividades escolares } \\
\text { dos professores e alunos. }\end{array}$ \\
\hline $\begin{array}{l}\text { Profissional da área de } \\
\text { tecnologia educacional }\end{array}$ & - & $\begin{array}{l}\text { Gestor de TI, área de TI e número } \\
\text { de profissionais de TI. }\end{array}$ & Suporte técnico. & $\begin{array}{l}\text { Assistentes de TIC, profissionais de } \\
\text { informática. }\end{array}$ \\
\hline Escola & $\begin{array}{l}\text { Capacidade da escola de articular uma visão } \\
\text { consistente quanto às TICs e disponibilidade } \\
\text { de um plano de manutenção e segurança. }\end{array}$ & Utilização de e-mail institucional. & - & $\begin{array}{l}\text { Projeto de capacitação para professores, } \\
\text { website e e-mail institucional. }\end{array}$ \\
\hline Diretor & $\begin{array}{l}\text { Suporte da liderança quanto ao uso das TICs } \\
\text { na escola. }\end{array}$ & $\begin{array}{l}\text { Planejamento de aquisições de } \\
\text { ferramentas de TI e verificação da } \\
\text { utilização da Internet para efetuar } \\
\text { compras. }\end{array}$ & $\begin{array}{l}\text { Atitude dos diretores quanto } \\
\text { as TIC. }\end{array}$ & $\begin{array}{l}\text { Atividades de gestão, planejamento e } \\
\text { interação com a comunidade. }\end{array}$ \\
\hline $\begin{array}{l}\text { Contribuição para a } \\
\text { avaliação de políticas } \\
\text { públicas }\end{array}$ & $\begin{array}{l}\text { Ferramenta de suporte aos gestores escolares } \\
\text { na definição de políticas de investimento e } \\
\text { de ações futuras no que diz respeito às TICs. }\end{array}$ & $\begin{array}{l}\text { Avaliação do impacto das TICs no } \\
\text { resultado da escola a partir de seu } \\
\text { desempenho na avaliação nacional } \\
\text { (ENEM). }\end{array}$ & $\begin{array}{l}\text { Avaliação de como tipo e a } \\
\text { intensidade de uso das TICs } \\
\text { se relacionam com o } \\
\text { desempenho escolar dos } \\
\text { estudantes de } 15 \text { anos no } \\
\text { exame internacional PISA. }\end{array}$ & $\begin{array}{l}\text { Criação de indicadores que visam apoiar a } \\
\text { avaliação do contexto brasileiro quanto a } \\
\text { oferta e a demanda de recursos tecnológicos } \\
\text { nas escolas. }\end{array}$ \\
\hline
\end{tabular}

Fonte: Elaborado pelo autor 
A partir do quadro teórico apresentado anteriormente, o modelo de pesquisa proposto neste trabalho e ilustrado na Figura 5 considerará, inicialmente, três dimensões a fim de medir o índice de uso das TICs nas escolas. São elas:

1. Gestão: dimensão que visa, no nível escolar, compreender o uso das TICs em atividades de planejamento e de comunicação, bem como, identificar ações que incentivem o uso das TICs.

2. Infraestrutura: dimensão que visa mensurar questões referentes a oferta e a disponibilidade dos recursos computacionais e de profissionais da área de tecnologia educacional.

3. Uso por professores e alunos: dimensão que visa compreender o estímulo oferecido pela escola para que haja o uso das TICs por parte dos alunos e professores dentro do processo de ensino-aprendizagem, além de identificar o suporte oferecido pelo projeto pedagógico ao uso das TICs.

Figura 5 - Modelo para criação do índice de uso das TICs em escolas

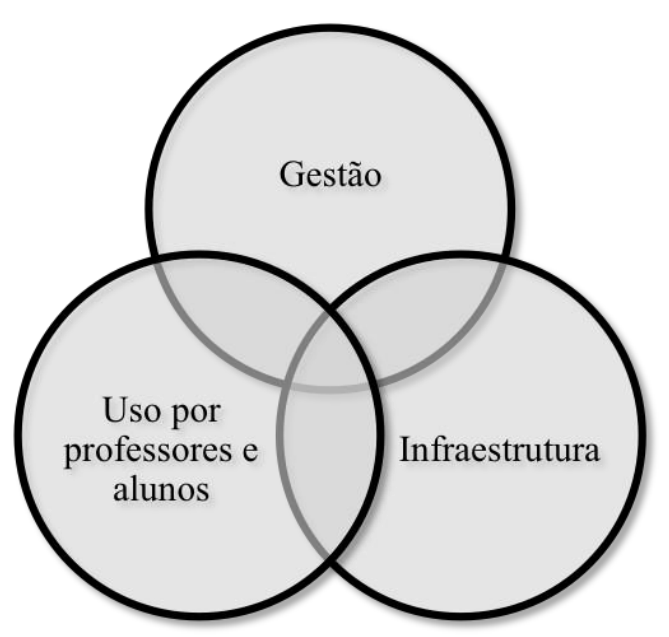

Fonte: Elaborado pelo autor

O Quadro 8 tem por objetivo descrever os indicadores que permitirão a operacionalização das dimensões propostas e apresentadas anteriormente. 
Quadro 8 - Dimensões do modelo de pesquisa

\begin{tabular}{|c|c|c|}
\hline Dimensão & Indicadores & Referências \\
\hline Gestão & $\begin{array}{l}\text { Indicadores do tipo de uso das TICs } \\
\text { para a gestão escolar; existência de } \\
\text { processo de capacitação dos } \\
\text { docentes e alunos quanto ao uso das } \\
\text { TICs. }\end{array}$ & $\begin{array}{l}\text { Dimensão Gestão da TI de } \\
\text { Lobler et al. (2010), fatores } \\
\text { escolares e institucionais de } \\
\text { Biagi e Loi (2013), dimensão } \\
\text { Estratégia e liderança escolar } \\
\text { de Wastiau et al. (2013) e } \\
\text { dimensão de alavancagem } \\
\text { Gestão de Solar } \text { et al. (2013). } \\
\end{array}$ \\
\hline $\begin{array}{l}\text { Uso por } \\
\text { professores e } \\
\text { alunos }\end{array}$ & \begin{tabular}{|l|} 
Indicadores do tipo a escola \\
integrou o computador e a Internet à \\
maioria das práticas de ensino- \\
aprendizagem; a escola começou \\
recentemente a usar o computador e \\
a Internet no processo de ensino- \\
aprendizagem dos conteúdos \\
escolares; suporte do projeto \\
pedagógico para o uso das TICs.
\end{tabular} & $\begin{array}{l}\text { Dimensões de alavancagem } \\
\text { Professores e Alunos de Solar et } \\
\text { al. (2013), enfoque do uso das } \\
\text { TICs do IDIE (2008) e } \\
\text { dimensão Uso de Aoki et al. } \\
\text { (2013). }\end{array}$ \\
\hline Infraestrutura & $\begin{array}{l}\text { Indicadores do tipo existência de } \\
\text { um responsável pela manutenção } \\
\text { das TICs na escola; a escola possui } \\
\text { professor de informática; existência } \\
\text { de um monitor no laboratório de } \\
\text { informática; uso do laboratório de } \\
\text { informática; total de computadores } \\
\text { instalados e em funcionamento. }\end{array}$ & $\begin{array}{l}\text { Dimensões de Pessoal e } \\
\text { Materiais de Aoki et al. (2013), } \\
\text { dimensão Infraestrutura de TIC } \\
\text { das escolas de Wastiau et al. } \\
\text { (2013) e dimensão de } \\
\text { alavancagem Infraestruturade } \\
\text { Solar } \text { et al. (2013). }\end{array}$ \\
\hline
\end{tabular}

Fonte: Elaborado pelo autor 


\section{Metodologia}

Esta seção descreve os caminhos que serão percorridos para o desenvolvimento deste estudo, sendo assim, serão explorados os seguintes temas: (3.1) estrutura metodológica; (3.2) definições metodológicas da pesquisa TIC Educação 2013; (3.3) procedimento de seleção das variáveis do modelo; (3.4) procedimento de tratamento dos dados; (3.5) descritivo da amostra; (3.6) plano de construção do indicador e da análise dos dados.

\subsection{Estrutura metodológica}

O presente estudo tem por escopo medir e avaliar o uso das TICs dentro do contexto escolar brasileiro. Sendo assim, os resultados aqui apresentados visam responder a seguinte pergunta-problema: qual é o nível de uso das Tecnologias da Informação e Comunicação em escolas brasileiras?

Visando responder à pergunta acima citada será realizada uma pesquisa quantitativa e exploratória com base nos microdados (dados secundários) gerados pela pesquisa TIC Educação 2013 - survey anual coordenada pelo CETIC.br - referente ao ano de 2013. Antes de descrever a estratégica metodológica aqui proposta para o trabalho, é válida a exposição do paradigma que será adotado.

Um paradigma de pesquisa está relacionado a determinadas crenças e pressupostos que temos sobre a realidade, sobre como as coisas são (ontologia) e sobre a forma como acreditamos que o conhecimento humano é construído (epistemologia). O paradigma resultante dessas crenças e pressupostos é que deverá guiar o método de pesquisa a ser adotado, isto é, a estratégia ou desenho geral de pesquisa que irá definir as técnicas de coleta e de análise dos dados a serem empregadas pelo pesquisador (CROTTY, 1998; ORLIKOWSKI e BAROUDI,1991 apud SACCOL, 2009).

Segundo Gephart (1999), existem três tipos de paradigmas de pesquisa: a) positivismo e pós-positivismo; b) interpretativismo e construtivismo; e c) teoria crítica e pósmoderna.

O paradigma positivista está fundamentado em uma ontologia realista, isto é, acredita em verdades objetivas, independentes da percepção humana. Ele considera que a realidade é composta por estruturas palpáveis, tangíveis e relativamente estáveis. 
Além disso, considera somente a existência de fatos, e não de percepções ou opiniões. Dessa forma, acredita-se que a pesquisa científica deva explicar e predizer o que irá ocorrer no mundo por buscar regularidades e relações de causa e efeito entre os elementos que o constituem. De acordo com o paradigma positivista, segue-se, em geral, uma lógica hipotético-dedutiva, isto é, a partir de um conhecimento prévio, são identificadas lacunas, questões não respondidas. Para essas questões, são geradas hipóteses, que são possíveis respostas às questões levantadas. Essas hipóteses são postas à prova, buscando-se verificar se elas são falsas ou verdadeiras. Para isso, parte-se para a coleta de dados que irão permitir testar as hipóteses. Caso as hipóteses testadas tenham sido refutadas (verificou-se a sua falsidade) elas terão que ser revistas ou reformuladas. Caso tenham sido comprovadas, poderão gerar um novo conhecimento ou uma nova teoria (SACCOL, 2009). A Figura 6 demonstra os principais passos de uma lógica hipotético-dedutiva.

\section{Figura 6 - Passos básicos de uma lógica hipotético-dedutiva}

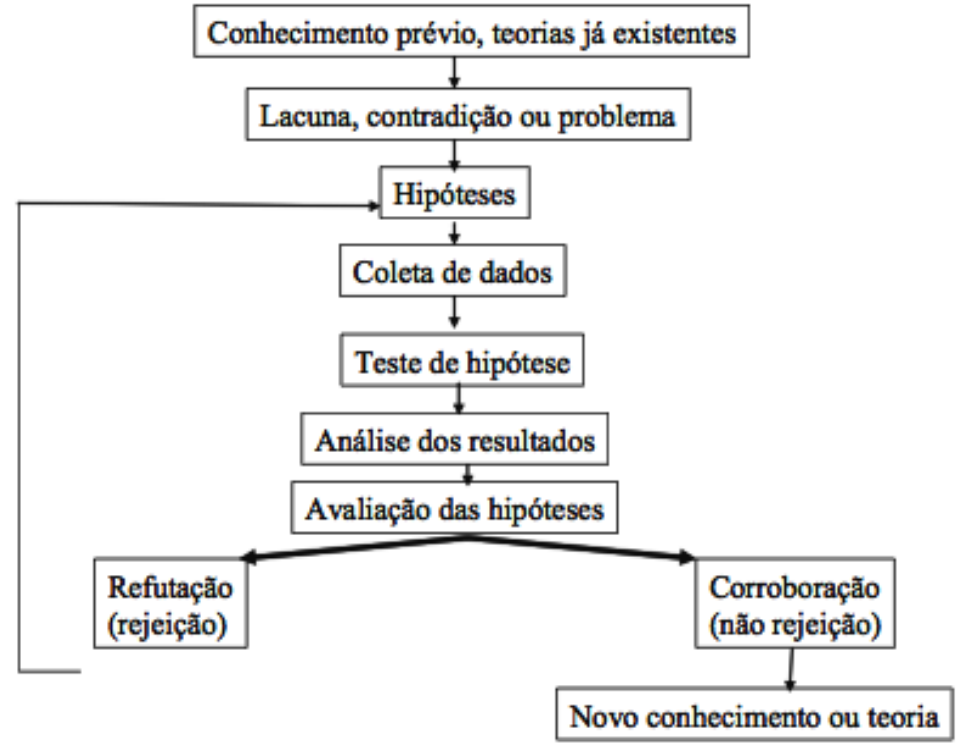

Fonte: Saccol (2009)

A presente pesquisa está apoiada no paradigma positivista, no sentido de que busca gerar um índice que comprove que escolas que possuem um conjunto de iniciativas fazem melhor uso das TICs. Para se alcançar parte do objetivo deste estudo, que visa analisar os resultados apresentados pelas escolas no índice, três hipóteses foram levantadas:

a) Há variação no nível de uso das TICs em escolas brasileiras por região; 
b) Há variação no nível de uso das TICs em escolas brasileiras por tipo de dependência administrativa.

c) Há variação no nível de uso das TICs em escolas brasileiras pelo índice de desenvolvimento humano municipal.

Com o objetivo de se familiarizar com o assunto Tecnologia da Informação e Comunicação na Educação e, a fim de se aprofundar na temática Uso das TICs pelas escolas brasileiras, foi desenvolvida uma pesquisa exploratória. Segundo Gil (2007), este tipo de pesquisa tem como objetivo proporcionar maior familiaridade com o problema, com vistas a torná-lo mais explícito ou a construir hipóteses. A grande maioria dessas pesquisas envolve: (a) levantamento bibliográfico; (b) entrevistas com pessoas que tiveram experiências práticas com o problema pesquisado; e (c) análise de exemplos que estimulem a compreensão.

A fim de compreender o conjunto de indicadores coletados pela pesquisa TIC Educação, foi necessária uma análise das tabelas estatísticas que consolidam os resultados dos dados coletados. Sendo assim, foi utilizada uma estratégia de pesquisa documental. Segundo Fonseca (2002), tal procedimento recorre a fontes mais diversificadas e dispersas, sem tratamento analítico, tais como: tabelas estatísticas, jornais, revistas, relatórios, documentos oficiais, cartas, filmes, fotografias, pinturas, tapeçarias, relatórios de empresas, vídeos de programas de televisão, etc.

À medida que este trabalho visa demonstrar o nível de uso das TICs pelas escolas brasileiras e, posteriormente, relacionar tal índice com fatores que exercem influência na adoção das TICs, é possível categorizar este estudo como uma pesquisa exploratória e descritiva.

Exploratória, pois é realizada quando a revisão da literatura revela que há temas não pesquisados e ideias vagamente relacionadas com o problema de estudo, ou seja, quando se deseja pesquisar temas com base em novas perspectivas e ampliar os estudos já existentes (SAMPIERI et al., 2006).

Já a característica descritiva justifica-se, pois de acordo com Vieira (2002) e Malhotra (2001), uma pesquisa desta natureza objetiva conhecer e interpretar a realidade, por meio da observação, descrição, classificação e interpretação de fenômenos, sem nela interferir para modificá-la.

Quanto à abordagem, este estudo categoriza-se como quantitativo. Segundo Richardson (1989), este método caracteriza-se pelo emprego da quantificação, tanto 
nas modalidades de coleta de informações, quanto no tratamento dessas através de técnicas estatísticas, desde as mais simples até as mais complexas.

Dessa forma, o delineamento desta pesquisa pode ser verificado no Quadro 9.

Quadro 9 - Delineamento da pesquisa

\begin{tabular}{|l|l|}
\hline Paradigma & Positivista \\
\hline Abordagem de pesquisa & Quantitativa \\
\hline Tipo de pesquisa & Descritiva e exploratória \\
\hline Procedimento & Pesquisa bibliográfica \\
& Pesquisa documental \\
& $\begin{array}{l}\text { Acesso a fontes secundárias } \\
\text { Tratamento estatístico de dados secundários }\end{array}$ \\
\hline
\end{tabular}

Fonte: Elaborado pelo autor

\subsection{Definições metodológicas da pesquisa TIC Educação 2013}

Para garantir que seus estudos cumpram o papel de desenhar políticas públicas, o CETIC.br conta com a participação de um grupo multissetorial de especialistas que inclui governo, organizações internacionais, pesquisadores acadêmicos e representantes de organizações sem fins lucrativos. Dessa forma, o processo de pesquisa conduzido é estruturado para favorecer a cooperação e valer-se da capacidade de análise crítica do grupo de especialistas conhecidos por sua competência em diversas áreas do conhecimento.

$\mathrm{O}$ envolvimento de tais especialistas confere legitimidade às fases críticas da produção dos dados (planejamento das amostras, coleta de dados em campo, processamento e análise), bem como cria uma garantia no rigor e na transparência dos procedimentos metodológicos e estatísticos.

Além de validar metodologias, questionários e indicadores e estabelecer diretrizes para a análise de dados, o grupo de especialistas contribui para a identificação de novas áreas de estudo e aperfeiçoamento de procedimentos metodológicos que garantam a produção de dados confiáveis.

De acordo com o relatório metodológico da pesquisa (CGI, 2014), a população alvo da pesquisa TIC Educação é composta pelas escolas públicas (estaduais e municipais) e particulares em atividade regular, localizadas em áreas urbanas do Brasil, que oferecem ensino na modalidade regular em pelo menos um dos níveis de ensino e séries: $4^{\mathrm{a}}$ série $/ 5^{\circ}$ ano do Ensino Fundamental (EF-I), $8^{\mathrm{a}}$ série $/ 9^{\circ}$ ano do Ensino Fundamental (EF-II) e $2^{\circ}$ ano do Ensino Médio (EM-2). As escolas públicas federais 
são excluídas da população alvo por possuírem um comportamento singular. Já as escolas rurais, são excluídas devido à dificuldade de acesso e às limitações de custo para realizar entrevistas presenciais em tais localidades. Também fazem parte da população alvo todos os diretores das escolas, bem como os coordenadores pedagógicos, os alunos matriculados e os professores envolvidos com as turmas dos níveis de ensino e das séries considerados na pesquisa.

A coleta dos dados da edição de 2013 foi realizada entre setembro e dezembro de 2013, por meio de entrevistas com questionários estruturados específicos para os quatro públicos abordados na pesquisa dentro do contexto escolar: alunos, professores, coordenadores pedagógicos e diretores (CGI, 2014).

O cadastro utilizado para seleção das escolas foi o Censo Escolar da Educação Básica 2011, realizado pelo Inep ${ }^{6}$.

Ainda de acordo com o relatório metodológico (CGI, 2014), a estratégia geral de amostragem da pesquisa envolveu a seleção de uma amostra de escolas em cada série de interesse. Para tanto, foi considerada como unidade primária de amostragem o agrupamento escola-série. Sendo assim, uma escola que tenha turmas na $4^{\mathrm{a}}$ e $8^{\mathrm{a}}$ séries / $5^{\circ}$ e $9^{\circ}$ anos do ensino Fundamental é incluída no cadastro para seleção da amostra do Ensino Fundamental I (EF-I) e do Ensino Fundamental II (EF-II). Dessa maneira, as escolas que possuem turmas em mais de uma série de interesse participam mais de uma vez do processo de amostragem. Visando minimizar a coincidência de seleção de uma escola nas várias séries, foi empregada amostragem sequencial de Poisson com números aleatórios gerados uma única vez para cada escola e usados para a seleção das amostras nas três séries de interesse.

Uma vez selecionadas as amostras de escolas-séries, procedeu-se à seleção das amostras das demais unidades de referência e análise de interesse (diretores, coordenadores pedagógicos, professores e alunos), isto é, o plano amostral foi implementado em etapas para selecionar as unidades de referência.

Enquanto as escolas foram selecionadas na primeira etapa, a seleção das demais unidades de referência considerou cada unidade escola-série como um conglomerado, dentro do qual foi feito o cadastramento e seleção das demais unidades de referência em campo.

\footnotetext{
${ }^{6}$ Instituto Nacional de Estudos e Pesquisas Educacionais Anísio Teixeira Legislação e Documentos
} 
Os estratos para a seleção das unidades escola-série foram definidos considerando a variável região (Nordeste, Sudeste, Sul, Norte e Centro-Oeste), dependência administrativa (pública municipal, pública estadual ou particular) e série ( $4^{\mathrm{a}}$ série $/ 5^{\circ}$ ano do Ensino Fundamental I, $8^{\mathrm{a}}$ série $/ 9^{\circ}$ ano do Ensino Fundamental II, e $2^{\circ}$ ano do Ensino Médio). Existem outras variáveis e níveis para as quais não há informações prévias adequadas nos cadastros, que também são considerados domínios de análise, exceto para os alunos, que são: faixa etária (faixa de idade em que se encontrava o respondente no dia da entrevista), renda mensal domiciliar (renda mensal de todos os membros do domicílio do respondente) e renda mensal individual (renda mensal total do respondente).

A amostra final da pesquisa TIC Educação foi composta por 994 escolas, sendo que foram entrevistados 939 diretores, 870 coordenadores pedagógicos, 1.987 professores e 9.657 alunos.

A oportunidade para o acesso à base de microdados fez parte de um convênio que vem se consolidando ao longo dos últimos quatros (04) anos entre o CETIC.br e o departamento de Administração de Empresas da Faculdade de Economia, Administração e Contabilidade da Universidade de São Paulo.

\subsection{Processo de seleção das variáveis do modelo}

Conforme descrito na seção 3.2, a estratégia geral de amostragem da pesquisa TIC Educação (CGI, 2014) envolveu a seleção de uma amostra de escolas em cada série de interesse. Para tanto, foi considerada como unidade primária de amostragem o agrupamento escola-série. A partir da seleção da escola-série, foi possível amostrar as demais unidades de análise de interesse (diretores, coordenadores pedagógicos, professores e alunos).

Em decorrência da existência da não resposta, a pesquisa não garante que existirão todas as escolas respondentes para cada um dos públicos estudados. A não possibilidade de extrapolar as observações coletadas nos microdados de cada unidade de análise para a população das escolas amostradas será relatada mais a frente como uma limitação deste estudo, no entanto, a fim de operacionalizar o índice, foram selecionadas as unidades de análise que se encontram dentro do corpo gerencial das escolas, são elas, os diretores, estes, além de compartilharem vossas opiniões quanto 
ao uso das TICs, também compartilham informações relacionadas à infraestrutura TIC das escolas, e os coordenadores pedagógicos.

Cabe ressaltar que tais unidades foram destacadas com o intuito de revelar importantes variáveis para o estudo, haja vista que, segundo Pires (2014), o coordenador pedagógico assume uma dimensão agregadora em suas ações, no intuito de articular as diversas dimensões, experiências e saberes da escola. Saberes e experiências que se evidenciam na figura dos gestores, professores, pais e alunos, entendendo assim que a coordenação pedagógica constitui-se, também, em um espaço de formação continuada dentro da escola. Neste estudo, assume-se que o coordenador pedagógico é uma figura capaz de trazer a perspectiva pedagógica quanto ao uso das TICs dentro do uso por professores e alunos. Já o diretor, segundo Byrom e Bingham (2001), é a parte interessada mais importante para que exista uma integração bem sucedida da tecnologia com o ambiente escolar.

Para que fosse possível determinar as variáveis e suas distribuições dentro de cada uma das dimensões propostas no modelo descrito na seção 2.6, foram analisados os dicionários de variáveis da pesquisa TIC Educação (CGI, 2014), que poderão ser consultados na íntegra nos anexos B (dicionário de variáveis TIC Educação diretores) e C (dicionário de variáveis TIC Educação coordenadores pedagógicos).

Para a dimensão "Gestão", foram selecionadas variáveis que explicitassem o suporte da liderança quanto ao uso das TICs na escola (SOLAR et al., 2013), atitude dos diretores quanto às TIC (BIAGI;LOI, 2013) e troca de informações entre os diretores e os pais através da Internet (AOKI et al., 2013).Tais variáveis e os respectivos tipos podem ser observados no Quadro 10.

Quadro 10 - Variáveis propostas para a dimensão Gestão

\begin{tabular}{|l|l|l|}
\hline $\begin{array}{l}\text { Código da } \\
\text { variável } \\
\text { (Unidade de } \\
\text { análise) }\end{array}$ & Variável na pesquisa TIC Educação & Tipo da variável \\
\hline $\begin{array}{l}\text { P1902 } \\
\text { (Diretor) }\end{array}$ & $\begin{array}{l}\text { O computador e a internet são } \\
\text { habitualmente utilizados pelos } \\
\text { funcionários da escola para fazer } \\
\text { orçamentos e controle de gastos? }\end{array}$ & Binário \\
\hline $\begin{array}{l}\text { P1903 } \\
\text { (Diretor) }\end{array}$ & $\begin{array}{l}\text { O computador e a internet são } \\
\text { habitualmente utilizados pelos } \\
\text { funcionários da escola para } \\
\text { comunicarem-se com os professores? }\end{array}$ & Binário \\
\hline $\begin{array}{l}\text { P1904 } \\
\text { (Diretor) }\end{array}$ & $\begin{array}{l}\text { O computador e a internet são } \\
\text { habitualmente utilizados pelos }\end{array}$ & Binário \\
\hline
\end{tabular}




\begin{tabular}{|l|l|l|}
\hline & $\begin{array}{l}\text { funcionários da escola para } \\
\text { comunicarem-se com os pais de } \\
\text { alunos? }\end{array}$ & Binário \\
\hline $\begin{array}{l}\text { P1907 } \\
\text { (Diretor) }\end{array}$ & $\begin{array}{l}\text { O computador e a Internet são } \\
\text { habitualmente utilizados pelos } \\
\text { funcionários da escola para fazer } \\
\text { cronogramas/grade de horários? }\end{array}$ & Binário \\
\hline $\begin{array}{l}\text { P1908 } \\
\text { (Diretor) }\end{array}$ & $\begin{array}{l}\text { O computador e a Internet são } \\
\text { habitualmente utilizados pelos } \\
\text { funcionários da escola para } \\
\text { administrar compromissos pessoais } \\
\text { (agenda)? }\end{array}$ & $\begin{array}{l}\text { Grau de concordância com a } \\
\text { afirmação de que nesta escola, há } \\
\text { treinamento para os alunos, de como } \\
\text { se usa computador e Internet. }\end{array}$ \\
\hline $\begin{array}{l}\text { P2903 } \\
\text { Peordenador }\end{array}$ & $\begin{array}{l}\text { Grau de concordância com a } \\
\text { afirmação de que nesta escola, há } \\
\text { treinamento para os professores, de } \\
\text { como se usa computador e Internet. }\end{array}$ & Ordinal \\
\hline $\begin{array}{l}\text { P2904 } \\
\text { (Coordenador } \\
\text { Pedagógico) }\end{array}$ &
\end{tabular}

Fonte: Elaborado pelo autor

Para a dimensão "Infraestrutura", foram selecionadas variáveis que explicitassem a infraestrutura de equipamentos disponíveis (AOKI et al., 2013; SOLAR et al., 2013; WASTIAU et al., 2013; LOBLER et al., 2010; IDIE, 2008), bem como a disponibilidade de profissionais responsáveis por atividades relacionadas às TICs dentro da escola (AOKI et al., 2013). As variáveis escolhidas da pesquisa e os respectivos tipos podem ser observados no Quadro 11.

\section{Quadro 11 - Variáveis propostas para a dimensão Infraestrutura}

\begin{tabular}{|l|l|l|}
\hline $\begin{array}{l}\text { Código da } \\
\text { variável } \\
\text { (Unidade de } \\
\text { análise) }\end{array}$ & Variável na pesquisa TIC Educação & Tipo da variável \\
\hline $\begin{array}{l}\text { P2201 } \\
\text { (Diretor) }\end{array}$ & $\begin{array}{l}\text { Esta escola conta com professor de } \\
\text { informática, que dê aulas específicas } \\
\text { de informática? }\end{array}$ & Binário \\
\hline $\begin{array}{l}\text { P26 } \\
\text { (Coordenador } \\
\text { Pedagógico) }\end{array}$ & $\begin{array}{l}\text { Esta escola proporciona aulas } \\
\text { específicas de informática, que } \\
\text { ensinem a usar computador e Internet } \\
\text { como parte da grade curricular? }\end{array}$ & Binário \\
\hline $\begin{array}{l}\text { P2705 } \\
\text { (Diretor) }\end{array}$ & $\begin{array}{l}\text { Total de computadores em } \\
\text { funcionamento da escola. }\end{array}$ & Discreta \\
\hline $\begin{array}{l}\text { P2905 } \\
\text { (Diretor) }\end{array}$ & $\begin{array}{l}\text { Total de computadores instalados e } \\
\text { funcionando que estão disponíveis } \\
\text { para uso pedagógico dos alunos. }\end{array}$ & Discreta \\
\hline $\begin{array}{l}\text { P2202 } \\
\text { (Diretor) }\end{array}$ & $\begin{array}{l}\text { Esta escola conta com monitor no } \\
\text { laboratório de informática? }\end{array}$ & Binário \\
\hline
\end{tabular}




\begin{tabular}{|l|l|l|}
\hline $\begin{array}{l}\text { P53 } \\
\text { (Diretor) }\end{array}$ & $\begin{array}{l}\text { Atualmente, o(s) laboratório(s) de } \\
\text { informática da escola está(ão) sendo } \\
\text { utilizado(s)? }\end{array}$ & Binário \\
\hline
\end{tabular}

Fonte: Elaborado pelo autor

Por fim, para a dimensão "Uso por professores e alunos", foram selecionadas variáveis que demonstrassem o suporte ofertado pela escola e pelo projeto pedagógico, para um efetivo uso das TICs no processo de ensino-aprendizagem por professores e alunos (AOKI et al., 2013; SOLAR et al., 2013; IDIE; 2008). As variáveis e seus tipos podem ser observadas no Quadro 12.

Quadro 12 - Variáveis propostas para a dimensão Uso por professores e alunos

\begin{tabular}{|l|l|l|}
\hline $\begin{array}{l}\text { Código da } \\
\text { variável } \\
\text { (Unidade de } \\
\text { análise) }\end{array}$ & Variável na pesquisa TIC Educação & Tipo da variável \\
\hline $\begin{array}{l}\text { P2901 } \\
\text { (Coordenador } \\
\text { Pedagógico) }\end{array}$ & $\begin{array}{l}\text { Grau de concordância com a } \\
\text { afirmação de que a escola integrou o } \\
\text { computador e a Internet às práticas de } \\
\text { ensino-aprendizagem. }\end{array}$ & Ordinal \\
\hline $\begin{array}{l}\text { P44 } \\
\text { (Diretor) }\end{array}$ & $\begin{array}{l}\text { A Internet da escola é utilizada pelos } \\
\text { professores em atividades de ensino- } \\
\text { aprendizagem com os alunos? }\end{array}$ & Binário \\
\hline $\begin{array}{l}\text { P2301 } \\
\text { (Coordenador } \\
\text { Pedagógico) }\end{array}$ & $\begin{array}{l}\text { O projeto pedagógico da escola } \\
\text { estimula ou requer os professores a } \\
\text { integração do uso da Internet em suas } \\
\text { práticas? }\end{array}$ & Nominal \\
\hline $\begin{array}{l}\text { P2304 } \\
\text { (Coordenador } \\
\text { Pedagógico) }\end{array}$ & $\begin{array}{l}\text { O projeto pedagógico da escola } \\
\text { estimula ou requer os professores a } \\
\text { atualização quanto ao uso de } \\
\text { computador e Internet no processo de } \\
\text { ensino-aprendizagem? }\end{array}$ & Nominal \\
\hline $\begin{array}{l}\text { P2305 } \\
\text { (Coordenador } \\
\text { Pedagógico) }\end{array}$ & $\begin{array}{l}\text { O projeto pedagógico da escola } \\
\text { estimula ou requer os professores a } \\
\text { utilização de programas de } \\
\text { computador (softwares) específicos } \\
\text { para o ensino de determinados } \\
\text { conteúdos? }\end{array}$ & Nominal \\
\hline
\end{tabular}
Fonte: Elaborado pelo autor

A partir do processo de seleção descrito acima, pretende-se operacionalizar as dimensões do índice de uso proposto como objetivo deste estudo. Na seção a seguir, serão descritos os processos de preparação dos dados que serão analisados. 


\section{$3.4 \quad$ Tratamento dos dados}

Como este trabalho visa contribuir dentro do domínio de estudos da gestão da tecnologia da informação no contexto escolar, foram extraídas variáveis dos questionários aplicados apenas no corpo diretivo/estratégico da escola, isto é, a partir das opiniões emitidas pelos diretores e coordenadores pedagógicos.

Para garantir a possibilidade da criação do índice aqui proposto, foram realizados os seguintes tratamentos nos dados:

- O primeiro procedimento adotado foi o de gerar uma base de dados unificando as variáveis dos diretores e coordenadores pedagógicos entrevistados pela pesquisa TIC Educação. Como resultado da intersecção entre as bases de dados, através de chave de identificação denominada código da escola, foi obtida uma base de microdados contendo 870 registros;

- Nas variáveis selecionadas para a geração do modelo, as observações que apresentaram respostas "Não sabe", "Não respondeu” ou "Não opinou”, bem como aquelas que não tiveram algum tipo de resposta (missing), foram removidas da base de dados de análise;

- Ainda referente as variáveis selecionadas para o modelo, para as questões originalmente coletadas em formato de escala de concordância foi realizada uma transformação das respostas a partir dos seguintes critérios:

1. Respostas marcadas como "Concorda totalmente" e "Concorda em parte" foram agrupadas em uma categoria denominada "Sim". Para efeito ilustrativo, se uma escola citou "Concordar em parte" com a afirmação "A escola integrou o computador e a Internet à maioria das práticas de ensino-aprendizagem", a mesma foi classificada com a marcação "Sim” para a variável, isto é, para efeito de análise é possível afirmar que tal escola integrou o computador e a Internet à maioria das práticas de ensino-aprendizagem.

2. Respostas marcadas como "Discorda em parte", "Discorda totalmente" e "Nessa escola isso não acontece" foram agrupadas em uma categoria denominada "Não". Para efeito ilustrativo, se uma escola citou "Nessa escola isso não acontece" para a afirmação "nesta escola, há treinamento para os professores, de como se usa computador e 
Internet", a mesma foi classificada com a marcação "Não" para a variável, isto é, para efeito de análise é possível afirmar que tal escola não oferece treinamento para professores de como se usa computador e Internet.

3. Respostas marcadas como "Não concorda, nem discorda" foram categorizadas como "Não sabe" e removidas da base de dados de análise.

- Por fim, as variáveis originalmente coletadas nas questões realizadas junto aos coordenadores pedagógicos e que solicitavam uma opinião quanto a integração das TICs no projeto pedagógico, foram realizadas as seguintes transformações:

1. As respostas marcadas na base de dados original como "requer" ou "estimula", foram agrupadas em uma categoria denominada "Sim". Para efeito ilustrativo, se um coordenador pedagógico respondeu "estimula" ou "requer" para a questão "O projeto pedagógico da escola estimula ou requer os professores a integração do uso da Internet em suas práticas?", foi considerado, para efeito de análise, que o projeto pedagógico da escola prevê a integração do uso da Internet em suas práticas.

2. Já as respostas marcadas como "Não requer, não estimula" foram categorizadas como "Não".

Após o processamento acima descrito, foi obtida uma amostra de 562 escolas que será apresentada na seção 3.5 .

\subsection{Caracterização da amostra obtida}

Com o objetivo de contextualizar as escolas que serão utilizadas nesta pesquisa, será apresentado a seguir o perfil da amostra obtida a partir das seguintes variáveis descritivas: dependência administrativa, região geográfica e existência de computadores e Internet na escola.

Em relação à distribuição das escolas por região, identifica-se uma concentração nas regiões Sul e Sudeste (45,6\%), conforme demonstrado pelos resultados da Tabela 1. 
Tabela 1 - Distribuição da amostra obtida por região

\begin{tabular}{l|l|l|l}
\hline Região & Frequência & $\begin{array}{l}\text { Percentual na } \\
\text { amostra obtida }\end{array}$ & $\begin{array}{l}\text { Percentual na } \\
\text { amostra da } \\
\text { pesquisa TIC } \\
\text { Educação }\end{array}$ \\
\hline Norte & 94 & $16,7 \%$ & $18,96 \%$ \\
\hline Nordeste & 100 & $17,8 \%$ & $22,15 \%$ \\
\hline Sudeste & 128 & $22,7 \%$ & $20,66 \%$ \\
\hline Sul & 129 & $22,9 \%$ & $20,45 \%$ \\
\hline Centro-Oeste & 111 & $19,7 \%$ & $17,78 \%$ \\
\hline
\end{tabular}

Fonte: Elaborado pelo autor

Referente à distribuição das escolas quanto ao âmbito de vossa subordinação administrativa, identifica-se um predomínio de escolas públicas (72,2\%) na amostra, conforme descrito na Tabela 2.

Tabela 2 - Distribuição da amostra obtida por dependência administrativa

\begin{tabular}{l|l|l|l}
\hline $\begin{array}{l}\text { Dependência } \\
\text { Administrativa }\end{array}$ & Frequência & Percentual & $\begin{array}{l}\text { Percentual na } \\
\text { amostra da } \\
\text { pesquisa TIC } \\
\text { Educação }\end{array}$ \\
\hline Pública Municipal & 153 & $27,2 \%$ & $29,29 \%$ \\
\hline Pública Estadual & 254 & $45,0 \%$ & $43,66 \%$ \\
\hline Particular & $156 \quad 27,8 \%$ & $27,05 \%$ \\
\hline \multicolumn{2}{|c}{ Fonte: Elaborado pelo autor }
\end{tabular}

Realizando um cruzamento entre as regiões e a dependência administrativa, é possível concluir que $75 \%$ das escolas da amostra localizadas nas regiões Norte, Sul e CentroOeste são subordinadas a uma administração pública e que, somente a região Nordeste possui um montante de escolas particulares que ultrapassa a faixa de um terço do total de escolas da região, conforme ilustrado na Figura 7. 
Figura 7 - Percentual do total de escolas da amostra por região e dependência administrativa

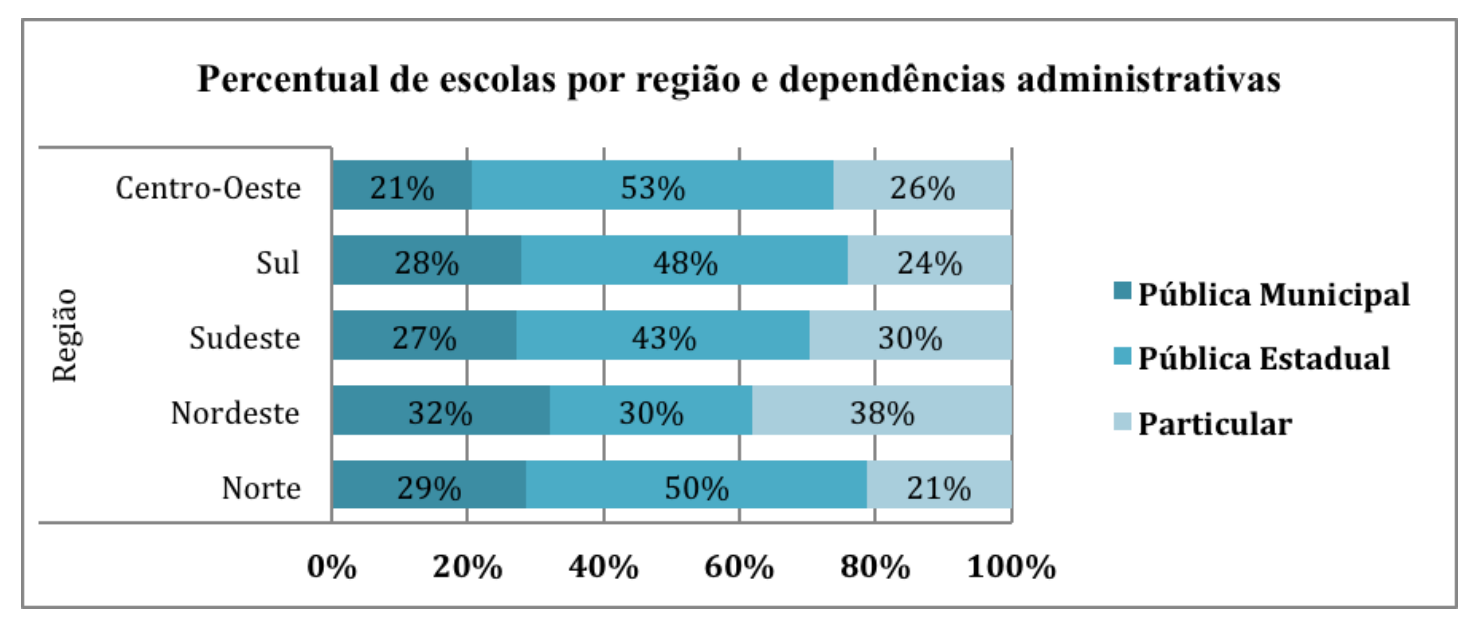

Fonte: Elaborado pelo autor

Antes de concluir a descrição do perfil da amostra, é válido comentar sobre duas medidas relacionadas à oferta de infraestrutura tecnológica dentro das escolas, isto é, se torna válida a exploração da existência de computador e acesso à Internet.

Dentro das escolas analisadas neste trabalho, $100 \%$ delas declararam possuir computador e acesso à Internet. Cabe fazer um paralelo com os dados publicados pela pesquisa TIC Educação (CGI, 2014) onde temos indicadores que afirmam um total de $99 \%$ das escolas brasileiras com computador e $97 \%$ das mesmas conectadas à Internet. Além disso, os dados aqui expostos dialogam com a observação feita por Lopes et al. (2010) quando os autores afirmaram que a maioria das escolas têm recursos materiais para fazer algum tipo de uso pedagógico do computador.

\subsection{Metodologia de desenvolvimento do índice e da análise do dados}

No caso do índice aqui proposto, a expectativa é de que ele seja uma composição de mais de um indicador que sintetize uma condição ou situação (INTERVOZES, 2010) ou, em outras palavras, um índice, composto por diferentes dimensões da realidade social sintetizadas em uma única medida (JANNUZZI, 2005). Sendo assim, a partir dos indicadores e do modelo apresentados no referencial teórico, serão construídas variáveis que permitirão o desenvolvimento de um índice denominado índice de uso das TICs nas escolas.

Conforme citado na seção 3.4, para o desenvolvimento do modelo de uso das TICs, as variáveis ordinais relacionadas ao grau de concordância e as variáveis, originalmente 
coletadas junto aos coordenadores pedagógicos, que solicitavam uma opinião quanto a integração das TICs no projeto pedagógico, foram transformadas em binárias, perdendo a qualidade mensurada no item e considerando apenas o atributo de existência. Cabe ressaltar, que os dados coletados pela pesquisa TIC Educação (CGI, 2014), não foram medidos a partir da teoria, sendo assim, as transformações aqui propostas, visam operacionalizar o constructo que é objeto deste estudo.

Com os dados tratados e transformados, foi possível aplicar as técnicas de correlação bisserial, correlação tetracórica, correlação de Pearson e análise fatorial exploratória, a fim de se investigar as dimensões planejadas no modelo teórico.

O coeficiente de correlação ponto bisserial é uma derivação do coeficiente de correlação linear de Pearson. Segundo Soares (2003), a correlação bisserial é uma medida clássica da capacidade de discriminação do item, representando o grau de correlação que cada item binário tem com o escore bruto calculado com todos os itens. Esse método é indicado quando uma das variáveis (Y) é dicotômica e a outra (X), contínua (LIRA, 2004). De acordo com Guildford (1950 apud LIRA, 2004), o coeficiente bisserial é utilizado em situações em que ambas as variáveis correlacionadas são passíveis de ser medidas como contínuas, mas, por alguma razão, uma delas foi reduzida a duas categorias.

No caso da correlação entre variáveis do tipo binária, será utilizada a correlação tetracórica que, segundo Soares (2005), mede a correlação entre os resultados dos itens de um teste. As correlações tetracóricas são usadas especificamente para estimar as correlações entre dados binários (BARTHOLOMEW et al., 2002).

Como arcabouço teórico para justificar o emprego da análise fatorial combinando dados binários e contínuos, Atkinson (1988) demonstrou que dados não contínuos são passíveis de se analisar a partir da análise fatorial, desde que a entrada para a análise, baseie-se em coeficientes de momento produto, como é o caso das matrizes de correlação tetracórica e bisserial.

Com a matriz de correlação calculada, será possível utilizá-la como entrada para a análise fatorial (AF).

Segundo Bezerra (2012), a AF busca, através da avaliação de um conjunto de variáveis, a identificação de dimensões de variabilidade comuns existentes, mas que não são observáveis diretamente.

Dentro dos tipos de AF, será empregada a variação denominada Análise Fatorial Exploratória (AFE) que, ainda segundo Bezerra (2012), não exige do pesquisador um 
conhecimento prévio da relação entre as variáveis, isto é, neste tipo de análise o pesquisador não tem certeza de que variáveis possuem uma estrutura de relacionamento, e muito menos se essa estrutura pode ser interpretada de forma coerente. Na AFE, o pesquisador analisará, entenderá e identificará uma estrutura de relacionamento entre as variáveis a partir do resultado da AF. De acordo com Figueiredo Filho e Silva Júnior (2010), a AFE geralmente é utilizada nos estágios mais embrionários da pesquisa, no sentido de literalmente explorar os dados. Nessa fase, procura-se explorar a relação entre um conjunto de variáveis, identificando padrões de correlação.

Como na AFE um modelo não é explicitamente especificado, Gosling e Gonçalves (2003) sugerem que a AFE preceda uma análise fatorial confirmatória (AFC), para que o pesquisador possa descobrir as variáveis latentes (fatores), e, suportado pelo arcabouço teórico, possa testar relações entre elas.

O método de extração dos fatores empregado para a análise fatorial foi o de análise de componentes principais (ACP). A ACP, procura explicar a estrutura de covariância da matriz de dados $(\mathrm{X})$ através de combinações lineares (Y) não correlacionadas das $\mathrm{p}$ variáveis originais (CHAVES NETO, 2002 apud LIRA, 2004). Embora $p$ componentes sejam necessárias para reproduzir a variabilidade total do sistema, frequentemente muito desta variabilidade pode ser explicada por um número pequeno, $\mathrm{k}$, de componentes principais (CHAVES NETO, 2002 apud LIRA, 2004). Neste caso, existe quase a mesma quantidade de informação nas $\mathrm{k}$ componentes que nas $\mathrm{p}$ variáveis originais. As k componentes principais podem então substituir as p variáveis originais e, o conjunto de dados originais que consiste de $\mathrm{n}$ medidas das $\mathrm{p}$ variáveis, é reduzido para um formado por $\mathrm{n}$ medidas das $\mathrm{k}$ componentes principais (CHAVES NETO, 2002 apud LIRA, 2004).

A partir dos resultados obtidos pela AFE, foi possível avaliar e atualizar os fatores (dimensões) do modelo teórico empregados no estágio de construção do índice de uso das TICs pelas escolas.

Para a construção do índice, foi utilizada a técnica denominada Modelagem de Equações Estruturais (MEE).

Para Hair Jr et al. (2010), a MEE é uma análise multivariada que combina aspectos da regressão linear múltipla e da análise de fatores comuns.

De acordo com Santos (2013), o termo MEE designa uma série de procedimentos e, ao contrário de outras técnicas multivariadas, é baseado em conceitos teóricos. É um 
método mais confirmatório do que exploratório, indicado para análises nas quais o pesquisador visa testar a validade de um modelo.

Para a aplicação da MEE, é sugerido um processo contemplando sete estágios, conforme descrito por Silva (2006):

1. Desenvolver um modelo teórico;

2. Construir um diagrama de caminhos;

3. Converter o diagrama de caminhos;

4. Escolher o tipo de matriz de entrada de dados;

5. Avaliar a identificação do modelo;

6. Avaliar as estimativas do modelo e qualidade do ajuste;

7. Interpretar e modificar o modelo.

O uso da MEE se justifica neste trabalho, pois, a partir de indicadores mensuráveis, isto é, dados originados da pesquisa TIC Educação, foi possível definir dimensões (variáveis latentes) que não poderiam ser medidas diretamente (Hair Jr et al., 2010), além disso, a partir da MEE, foi possível obter o cálculo dos escores fatorais para as variáveis latentes, assim, ao se testar o modelo, também foi possível obter diretamente o valor do nível de uso das TICs da escola e de suas dimensões, elaborado com base na consideração simultânea de todas as variáveis envolvidas e de todos os casos utilizados (SOUZA, 2004).

É válido ressaltar que, conforme demonstrado por Bistaffa (2010), é possível combinar indicadores contínuos e binários através da MEE. O autor explica em seu trabalho, que a estimação da correlação entre os indicadores utilizando as correlações especiais (correlação tetracórica, correlação policórica, correlação bisserial e correlação poliserial) e a suposição adicional de um modelo limiar relacionando os indicadores ordinais às suas contrapartes latentes, permitem que o modelo de equações estruturais seja corretamente estimado (BISTAFFA, 2010).

Objetivando explorar o índice, no passo seguinte aplicou-se uma análise para identificar fatores que influenciem um maior nível de uso das TICs pelas escolas. Sendo assim, um teste multivariado foi utilizado a fim de verificar se o apoio da gestão, a oferta de infraestrutura e a apropriação das TICs no processo de ensinoaprendizagem, diferenciam os desempenhos apresentados pelas escolas no índice de uso das TICs. A técnica utilizada foi a regressão logística que, segundo Hair Jr et al. (2010), é uma técnica de análise utilizada para aferição da probabilidade de ocorrência de um evento e para identificação das características dos elementos 
pertencentes a cada categoria estabelecida pela dicotomia da variável dependente. Ao contrário da análise discriminante, não exige a suposição da normalidade das variáveis independentes e é mais robusta quando a mesma não é atendida.

A Figura 8 tem por objetivo ilustrar as etapas do processo de desenvolvimento do índice que foram descritas anteriormente e serão melhor detalhadas na seção 4 .

\section{Figura 8 - Processo de desenvolvimento do índice}

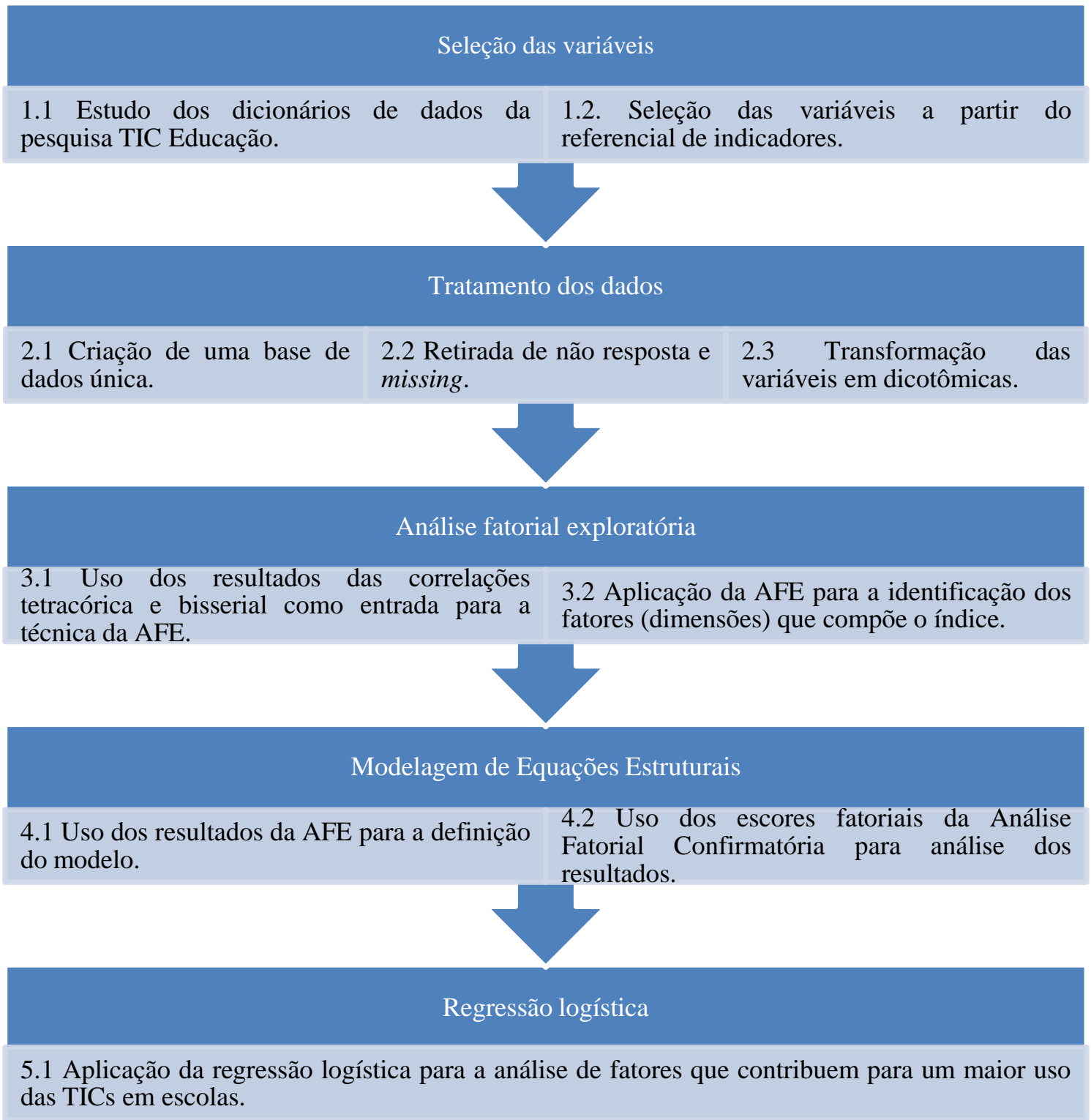

Fonte: Elaborado pelo autor 


\section{$4 \quad$ Análise de dados}

Esta seção tem por objetivo descrever os resultados das análises dos dados da presente pesquisa. Dessa maneira, a primeira seção deste capítulo descreverá os passos utilizados para o desenvolvimento do índice de uso das TICs nas escolas desde a exploração das variáveis a partir da análise fatorial exploratório, até a aplicação da técnica de modelagem de equações estruturais. Será também apresentada uma análise descritiva do índice, bem como serão detalhadas diferenças nos desempenhos apresentados pelas escolas quando analisadas por região, dependência administrativa e IDH municipal. Por fim, serão descritos na seção 4.3, fatores, baseados nos indicadores coletados pela pesquisa TIC Educação, que influenciam um uso elevado das TICs nas escolas analisadas.

\subsection{Construção do índice de uso das TICs nas escolas}

Como primeiro estágio do desenvolvimento do índice, foi realizado um estudo exploratório em cada uma das dimensões propostas no modelo teórico. Para tal, foi empregada a técnica multivariada intitulada Análise Fatorial Exploratória (AFE), a fim de validar a relação entre as variáveis propostas e, principalmente, construir uma relação de dimensões e, possíveis subdimensões (novos fatores), que descrevam o modelo de forma mais assertiva. Gosling e Gonçalves (2003) sugerem que a AFE preceda uma análise fatorial confirmatória (AFC), para que o pesquisador possa descobrir as variáveis latentes (fatores), e, suportado pelo arcabouço teórico, possa testar relações entre elas.

Sabendo que o conjunto de dados trabalhado neste estudo é uma combinação de variáveis binárias e contínuas e que a AF foi projetada para lidar com dados contínuos, pois, o modelo da $\mathrm{AF}$ assume que as variáveis observadas são métricas e não binárias, foi necessário, antes de se realizar a análise fatorial, calcular as correlações tetracóricas (no caso da correlação entre variáveis binárias) e correlações bisseriais (no caso da correlação entre variáveis contínuas e binárias). Tal preceito metodológico se baseou na demonstração feita por Atkinson (1988) onde dados não contínuos são passíveis de se analisar a partir da AF, desde que a entrada do estudo, 
baseie-se em coeficientes de momento produto, como é o caso das correlações tetracórica e bisserial.

As matrizes de correlação, que servirão como base para AF, foram calculadas por meio de uma biblioteca específica compatível com o software estatístico Stata (versão 12), que também foi utilizada em estudos recentes com dados binários por Araujo (2013) e Siqueira (2014).

\subsubsection{Definição da dimensão Gestão}

O quadro abaixo especifica as variáveis que foram destacadas da pesquisa TIC Educação e que visam descrever a dimensão proposta pelo modelo deste trabalho denominada Gestão. Os códigos listados no Quadro 13 servirão como base para a interpretação dos resultados demonstrados na sequência.

\section{Quadro 13 - Variáveis da dimensão Gestão}

\begin{tabular}{|l|l|}
\hline Código da variável & Variável na pesquisa TIC Educação \\
\hline p1902 & $\begin{array}{l}\text { O computador e a internet são habitualmente utilizados } \\
\text { pelos funcionários da escola para fazer orçamentos e } \\
\text { controle de gastos? }\end{array}$ \\
\hline p1903 & $\begin{array}{l}\text { O computador e a internet são habitualmente utilizados } \\
\text { pelos funcionários da escola para comunicarem-se com os } \\
\text { professores? }\end{array}$ \\
\hline p1904 & $\begin{array}{l}\text { O computador e a internet são habitualmente utilizados } \\
\text { pelos funcionários da escola para comunicarem-se com os } \\
\text { pais de alunos? }\end{array}$ \\
\hline p1907 & $\begin{array}{l}\text { O computador e a internet são habitualmente utilizados } \\
\text { pelos funcionários da escola para fazer cronogramas/grade } \\
\text { de horários? }\end{array}$ \\
\hline p1908 & $\begin{array}{l}\text { O computador e a internet são habitualmente utilizados } \\
\text { pelos funcionários da escola para administrar } \\
\text { compromissos pessoais (agenda)? }\end{array}$ \\
\hline p2903_bin & $\begin{array}{l}\text { Grau de concordância com a afirmação de que nesta escola, } \\
\text { há treinamento para os alunos, de como se usa computador } \\
\text { e Internet. }\end{array}$ \\
\hline p2904_bin & $\begin{array}{l}\text { Grau de concordância com a afirmação de que nesta escola, } \\
\text { há treinamento para os professores, de como se usa } \\
\text { computador e Internet. }\end{array}$ \\
\hline
\end{tabular}

Fonte: Elaborado pelo autor

Como as variáveis utilizadas nesta dimensão foram codificadas no formato binário, todas as correlações calculadas foram do tipo tetracórica (BISTAFFA, 2010). A matriz de correlação gerada pode ser observada na Tabela 3. 
Tabela 3 - Matriz de correlação das variáveis da dimensão Gestão

\begin{tabular}{l|l|l|l|l|l|l|l}
\hline & $\mathbf{p 1 9 0 2}$ & $\mathbf{p 1 9 0 3}$ & $\mathbf{p 1 9 0 4}$ & $\mathbf{p 1 9 0 7}$ & $\mathbf{p 1 9 0 8}$ & p2903_bin & p2904_bin \\
\hline p1902 & 1,00 & & & & & & \\
\hline p1903 & 0,23 & 1,00 & & & & & \\
\hline $\mathbf{p 1 9 0 4}$ & 0,08 & $\mathbf{0 , 5 2}$ & 1,00 & & & & \\
\hline p1907 & $\mathbf{0 , 4 5}$ & $\mathbf{0 , 3 3}$ & $\mathbf{0 , 4 5}$ & 1,00 & & & \\
\hline p1908 & 0,16 & $\mathbf{0 , 3 6}$ & $\mathbf{0 , 3 3}$ & $\mathbf{0 , 6 4}$ & 1,00 & & \\
\hline p2903_bin & $-0,02$ & 0,06 & 0,19 & $-0,11$ & 0,07 & 1,00 & \\
\hline p2904_bin & 0,13 & 0,15 & 0,18 & $-0,22$ & $-0,06$ & $\mathbf{0 , 6 0}$ & 1,00 \\
\hline
\end{tabular}

Segundo Araujo (2013), uma premissa essencial para aplicação AF é que os atributos analisados sejam correlacionados, pois, a variável latente (fator) representa um conjunto de variáveis altamente correlacionadas entre si e pouco correlacionadas aos atributos de diferentes fatores. Sendo assim, analisando os resultados da matriz de correlação da dimensão "Gestão" apresentada acima, foi possível identificar indícios de ajuste das variáveis para a aplicação da $\mathrm{AF}$, afinal, há um número considerável de correlações com coeficientes maiores que 0,3 .

Além da matriz de correlação, observou-se outro teste que permite avaliar se os dados originais viabilizam a utilização da AF de forma satisfatória. O teste Kaiser-MeyerOlkin (Measure of Sampling Adequacy - MSA) indica o grau de explicação dos dados a partir dos fatores encontrados na AF. Caso a estatística KMO indique um grau de explicação menor do que 0,5 , significa que os fatores encontrados na $\mathrm{AF}$ não conseguem descrever satisfatoriamente as variações dos dados originais (BEZERRA, 2012).

Para o caso da dimensão Gestão, a estatística KMO foi de 0,5043, isto é, muito próximo do limite definido como aceitável para a aplicação da AF, no entanto, como o valor ainda se encontra acima do limite mínimo, seguiu-se com a AF.

Utilizando como entrada a matriz com as respectivas correlações calculadas, foi possível processar a análise fatorial, utilizando como método de extração de fatores a análise de componentes principais.

De acordo com Bezerra (2012), a análise fatorial, com método ACP, pode ser utilizada visando procurar uma combinação linear entre as variáveis, de forma que o máximo de variância seja explicado por tal combinação.

Visando uma maior facilidade na interpretação dos fatores extraídos, aplicou-se o método de rotação ortogonal Varimax. Os métodos de rotação ortogonal visam 
produzir fatores que não estejam correlacionados entre si, sendo estes interpretados a partir de suas cargas (ARAUJO, 2013).

Como primeiro resultado da análise fatorial, dois fatores, que explicam 60,13\% da variância original, foram identificados nas variáveis da dimensão Gestão.

$\mathrm{Na}$ Tabela 4, serão apresentadas todas as variáveis consideradas na análise, junto com as cargas fatoriais as quais elas pertencem e sua comunalidade (proporção de variância explicada pelos fatores comuns, sendo que, quanto maior a comunalidade, maior será o poder de explicação daquela variável pelo fator).

Tabela 4 - Resultados da análise fatorial para a dimensão Gestão

\begin{tabular}{l|l|l|l}
\hline Variável & Fator 1 & Fator 2 & Comunalidade \\
\hline p1902 & 0,4833 & 0,0222 & $\mathbf{0 , 2 3 4 1}$ \\
\hline p1903 & 0,6704 & 0,247 & 0,5104 \\
\hline p1904 & 0,6725 & 0,3308 & 0,5641 \\
\hline p1907 & 0,8654 & $-0,238$ & 0,8051 \\
\hline p1908 & 0,7554 & $-0,047$ & 0,5726 \\
\hline p2903_bin & $-0,003$ & 0,8497 & 0,7221 \\
\hline p2904_bin & $-0,0415$ & 0,8942 & 0,8012 \\
\hline
\end{tabular}

Método de Extração: Análise de componentes principais

Rotação: Varimax.

Variância Total Explicada: $0.6013=60,13 \%$

Total de observações: 562 .

\section{Fonte: Elaborado pelo autor}

Figueiredo Filho e Silva Júnior (2010) afirmam que usualmente o valor mínimo aceitável para comunalidade é de 0,50 e que, caso o pesquisador encontre alguma comunalidade abaixo desse patamar, a variável deve ser excluída e a análise fatorial deve ser realizada novamente, sendo assim, como a variável p1902 (O computador e a internet são habitualmente utilizados pelos funcionários da escola para fazer orçamentos e controle de gastos?) apresentou comunalidade abaixo do mínimo aceitável, se fez necessária a retirada da mesma do modelo. Uma nova matriz de correlação foi calculada e a análise fatorial foi reprocessada.

O cálculo da estatística KMO para o novo conjunto de variáveis foi de 0,6012, isto é, acima dos 0,5 citados como aceitáveis para a aplicação da AF e melhor do que os 0,5043 obtidos no processamento anterior.

Seguindo com o cálculo da análise fatorial, foram extraídos, novamente, dois fatores e o percentual de explicação da variância original teve um aumento em 7,53 pontos 
percentuais, se comparado com o conjunto de variáveis anteriormente utilizado, subindo para $67,66 \%$, conforme descrito na Tabela 5.

Tabela 5 - Resultados da análise fatorial na dimensão Gestão pós remoção da variável p1902

\begin{tabular}{|c|c|c|c|}
\hline Variável & Fator 1 & Fator 2 & Comunalidade \\
\hline p1903 & 0,69 & 0,2248 & 0,5266 \\
\hline p1904 & 0,7322 & 0,3069 & 0,6303 \\
\hline p1907 & 0,8277 & $-0,2639$ & 0,7548 \\
\hline p1908 & 0,7843 & $-0,072$ & 0,6203 \\
\hline p2903_bin & 0,0329 & 0,8491 & 0,7221 \\
\hline p2904_bin & $-0,0452$ & 0,8965 & 0,8058 \\
\hline
\end{tabular}

Método de Extração: Análise de componentes principais

Rotação: Varimax.

Variância Total Explicada: $0.6766=67,66 \%$

Total de observações: 562.

Fonte: Elaborado pelo autor

Como nenhuma das variáveis demonstrou comunalidade abaixo de 0,5 , a Tabela 5 permitiu uma classificação mais precisa dos indicadores relacionados à dimensão Gestão, sendo assim, é possível concluir que:

- O Fator 1 é composto pelas variáveis p1903, p1904, p1907 e p1908.

- O Fator 2 é composto pelas variáveis p2903_bin e p2904_bin.

Diante dos resultado expostos pela AF, a dimensão Gestão foi decomposta em duas subdimensões descritas no Quadro 14. 


\section{Quadro 14 - Subdimensões da dimensão Gestão}

\begin{tabular}{|l|l|l|}
\hline \multirow{4}{*}{$\begin{array}{l}\text { Atividades de } \\
\text { comunicação e controle }\end{array}$} & p1903 & $\begin{array}{l}\text { O computador e a internet são } \\
\text { habitualmente utilizados pelos } \\
\text { funcionários da escola para comunicarem- } \\
\text { se com os professores? }\end{array}$ \\
\cline { 2 - 3 } & p1904 & $\begin{array}{l}\text { O computador e a internet são } \\
\text { habitualmente utilizados pelos } \\
\text { funcionários da escola para comunicarem- } \\
\text { se comas os pais de alunos? }\end{array}$ \\
\hline \multirow{5}{*}{ Suporte da direção ao uso } & $\begin{array}{l}\text { O computador e a internet são } \\
\text { habitualmente utilizados pelos } \\
\text { funcionários da escola para fazer } \\
\text { cronogramas/grade de horários? }\end{array}$ \\
\cline { 2 - 3 } & p1908 & $\begin{array}{l}\text { O computador e a internet são } \\
\text { habitualmente utilizados pelos } \\
\text { funcionários da escola para administrar } \\
\text { compromissos pessoais (agenda)? }\end{array}$ \\
\cline { 2 - 3 } & p2904_bin & $\begin{array}{l}\text { Grau de concordância com a afirmação de } \\
\text { que nesta escola, há treinamento para os } \\
\text { alunos, de como se usa computador e } \\
\text { Internet. }\end{array}$ \\
\hline $\begin{array}{l}\text { Grau de concordância com a afirmação de } \\
\text { que nesta escola, há treinamento para os } \\
\text { professores, de como se usa computador e } \\
\text { Internet. }\end{array}$ \\
\hline
\end{tabular}

Fonte: Elaborado pelo autor

\subsubsection{Definição da dimensão Infraestrutura}

O Quadro 15 especifica as variáveis que foram destacadas da pesquisa TIC Educação e que visam descrever a dimensão proposta pelo modelo deste trabalho denominada Infraestrutura. Os códigos listados servirão como base para a interpretação dos resultados demonstrados na sequência. 
Quadro 15 - Variáveis da dimensão Infraestrutura

\begin{tabular}{|l|l|}
\hline Código da variável & Variável na pesquisa TIC Educação \\
\hline p2201 & $\begin{array}{l}\text { Esta escola conta com professor de informática, que dê aulas } \\
\text { específicas de informática? }\end{array}$ \\
\hline p2202 & Esta escola conta com monitor no laboratório de informática? \\
\hline p26_coordenador & $\begin{array}{l}\text { Esta escola proporciona aulas específicas de informática, que } \\
\text { ensinem a usar computador e Internet como parte da grade } \\
\text { curricular? }\end{array}$ \\
\hline p2705 & Total de computadores em funcionamento da escola. \\
\hline p2905 & $\begin{array}{l}\text { Total de computadores instalados e funcionando que estão } \\
\text { disponíveis para uso pedagógico dos alunos. }\end{array}$ \\
\hline p53 & $\begin{array}{l}\text { Atualmente, o(s) laboratório(s) de informática da escola } \\
\text { está(ão) sendo utilizado(s)? }\end{array}$ \\
\hline
\end{tabular}

Fonte: Elaborado pelo autor

Como as variáveis utilizadas nesta dimensão foram codificadas no formato binário e contínuo, as correlações calculadas foram do tipo bisserial, para dados binários e dados contínuos e, tetracórica, para dados binários (BISTAFFA, 2010). Os resultados das correlações estão descritos na Tabela 6.

Tabela 6 - Matriz de correlação das variáveis da dimensão Infraestrutura

\begin{tabular}{l|l|l|l|l|l|l}
\hline & $\mathbf{p 2 2 0 1}$ & $\mathbf{p 2 2 0 2}$ & $\mathbf{p 2 6}$ _coordenador & $\mathbf{p 5 3}$ & $\mathbf{p 2 9 0 5}$ & $\mathbf{p 2 7 0 5}$ \\
\hline $\mathbf{p 2 2 0 1}$ & 1,00 & & & & & \\
\hline $\mathbf{p 2 2 0 2}$ & 0,16 & 1,00 & & & & \\
\hline $\mathbf{p 2 6}$ coordenador & $\mathbf{0 , 6 9}$ & 0,06 & 1,00 & & & \\
\hline $\mathbf{p 5 3}$ & $\mathbf{0 , 5 0}$ & $\mathbf{0 , 5 4}$ & $\mathbf{0 , 4 8}$ & 1,00 & & \\
\hline $\mathbf{p 2 9 0 5}$ & 0,24 & 0,18 & 0,27 & $\mathbf{0 , 5 6}$ & 1,00 & \\
\hline $\mathbf{p 2 7 0 5}$ & 0,21 & 0,27 & 0,25 & $\mathbf{0 , 4 8}$ & $\mathbf{0 , 9 0}$ & 1,00 \\
\hline
\end{tabular}

Fonte: Elaborado pelo autor

Analisando os resultados da matriz de correlação da dimensão Infraestrutura apresentados acima, foi possível identificar indícios de ajuste das variáveis para a aplicação da AF, afinal, há um número considerável de correlações com coeficientes maiores que 0,3 .

No que diz respeito a estatística $\mathrm{KMO}$, o conjunto de variáveis apresentou um valor de 0,5672, isto é, acima do aceitável para a aplicação da AF.

Utilizando como entrada a matriz com as respectivas correlações calculadas, foi possível realizar a análise fatorial, utilizando, assim como na dimensão Gestão, o método de extração de fatores a partir da análise de componentes principais. 
Visando uma maior facilidade na interpretação dos fatores extraídos aplicou-se, novamente, o método de rotação ortogonal Varimax.

Como resultado da análise fatorial, três fatores, que explicam $88,79 \%$ da variância original, foram identificados.

A Tabela 7 apresenta todas as variáveis consideradas na análise, junto com as cargas fatoriais as quais elas pertencem e sua comunalidade.

Tabela 7 - Resultados da análise fatorial para a dimensão Infraestrutura

\begin{tabular}{l|l|l|l|l}
\hline Variável & Fator 1 & Fator 2 & Fator 3 & Comunalidade \\
\hline p2201 & 0,0843 & 0,8991 & 0,1361 & 0,8341 \\
\hline p2202 & 0,0942 & 0,0147 & 0,9669 & 0,944 \\
\hline p26_coordenador & 0,1611 & 0,9078 & $-0,0033$ & 0,8501 \\
\hline $\mathbf{p 5 3}$ & 0,4497 & 0,4882 & 0,6083 & 0,8106 \\
\hline $\mathbf{p 2 9 0 5}$ & 0,9634 & 0,1448 & 0,0934 & 0,9578 \\
\hline $\mathbf{p 2 7 0 5}$ & 0,9496 & 0,0921 & 0,1434 & 0,9309 \\
\hline
\end{tabular}

Método de Extração: Análise de componentes principais

Rotação: Varimax

Variância Total Explicada: $0.8879=88,79 \%$

Total de observações: 562

\section{Fonte: Elaborado pelo autor}

Como nenhuma das variáveis demonstrou comunalidade abaixo de 0,5 , a Tabela 7 permitiu uma classificação mais precisa dos indicadores relacionados à dimensão Infraestrutura, sendo assim, é possível concluir que:

- O Fator 1 é composto pelas variáveis p2905 e p2705.

- O Fator 2 é composto pelas variáveis p2201 e p26_coordenador.

- O Fator 3 é composto pelas variáveis p2202 e p53.

Diante dos resultados expostos pela AF, a dimensão Infraestrutura foi decomposta em três subdimensões descritas no Quadro 16. 
Quadro 16 - Subdimensões da dimensão Infraestrutura

\begin{tabular}{|c|c|c|}
\hline \multirow[b]{2}{*}{ Apoio pedagógico da TI } & p2201 & $\begin{array}{l}\text { Esta escola conta com professor } \\
\text { de informática, que dê aulas } \\
\text { específicas de informática? }\end{array}$ \\
\hline & p26_coordenador & $\begin{array}{l}\text { Esta escola proporciona aulas } \\
\text { específicas de informática, que } \\
\text { ensinem a usar computador e } \\
\text { Internet como parte da grade } \\
\text { curricular? }\end{array}$ \\
\hline \multirow[b]{2}{*}{ Recursos computacionais } & $\mathrm{p} 2705$ & $\begin{array}{l}\text { Total de computadores em } \\
\text { funcionamento da escola. }\end{array}$ \\
\hline & p2905 & $\begin{array}{l}\text { Total de computadores instalados } \\
\text { e funcionando que estão } \\
\text { disponíveis para uso pedagógico } \\
\text { dos alunos. }\end{array}$ \\
\hline \multirow[b]{2}{*}{ Laboratório de Informática } & p2202 & $\begin{array}{l}\text { Esta escola conta com monitor no } \\
\text { laboratório de informática? }\end{array}$ \\
\hline & p53 & $\begin{array}{l}\text { Atualmente, o(s) laboratório(s) de } \\
\text { informática da escola está(ão) } \\
\text { sendo utilizado(s)? }\end{array}$ \\
\hline
\end{tabular}

Fonte: Elaborado pelo autor

\subsubsection{Definição da dimensão Uso por professores e alunos}

O Quadro 17 especifica as variáveis que foram destacadas da pesquisa TIC Educação e que visam descrever a dimensão proposta pelo modelo deste trabalho denominada Uso por professores a alunos. Os códigos listados servirão como base para a interpretação dos resultados demonstrados na sequência.

Quadro 17 - Variáveis da dimensão Uso por professores e alunos

\begin{tabular}{|l|l|}
\hline Código da variável & Variável na pesquisa TIC Educação \\
\hline p2901_bin & $\begin{array}{l}\text { Grau de concordância com a afirmação de que a escola integrou o computador } \\
\text { e a Internet às práticas de ensino-aprendizagem. }\end{array}$ \\
\hline p44 & $\begin{array}{l}\text { A Internet da escola é utilizada pelos professores em atividades de ensino- } \\
\text { aprendizagem com os alunos? }\end{array}$ \\
\hline p2301_bin & $\begin{array}{l}\text { O projeto pedagógico da escola estimula ou requer dos professores a } \\
\text { integração do uso da Internet em suas práticas? }\end{array}$ \\
\hline p2304_bin & $\begin{array}{l}\text { O projeto pedagógico da escola estimula ou requer dos professores a } \\
\text { atualização quanto ao uso de computador e Internet no processo de ensino- } \\
\text { aprendizagem? }\end{array}$ \\
\hline p2305_bin & $\begin{array}{l}\text { O projeto pedagógico da escola estimula ou requer dos professores a utilização } \\
\text { de programas de computador (softwares) específicos para o ensino de } \\
\text { determinados conteúdos? }\end{array}$ \\
\hline
\end{tabular}

Fonte: Elaborado pelo autor

Como as variáveis utilizadas nesta dimensão foram codificadas no formato binário, todas as correlações calculadas foram do tipo tetracórica (BISTAFFA, 2010). Os resultados das correlações estão demonstrados na Tabela 8 . 
Tabela 8 - Matriz de correlação das variáveis da dimensão Uso por professores e alunos

\begin{tabular}{l|l|l|l|l|l}
\hline & p2901_bin & p44 & p2301_bin & p2304_bin & p2305_bin \\
\hline p2901_bin & 1,00 & & & & \\
\hline p44 & $\mathbf{0 , 5 6}$ & 1,00 & & & \\
\hline p2301_bin & $\mathbf{0 , 4 3}$ & 0,02 & 1,00 & & \\
\hline p2304_bin & $\mathbf{0 , 3 4}$ & 0,03 & $\mathbf{0 , 7 3}$ & 1,00 & \\
\hline 22305_bin & $\mathbf{0 , 3 7}$ & 0,14 & $\mathbf{0 , 7 2}$ & $\mathbf{0 , 6 3}$ & 1,00 \\
\hline \multicolumn{6}{r}{ Fonte: Elaborado pelo autor }
\end{tabular}

Analisando os resultados da matriz de correlação da dimensão Uso por professores e alunos apresentados acima, foi possível identificar indícios de ajuste das variáveis para a aplicação da AF, afinal, há um número considerável de correlações com coeficientes maiores que 0,3 .

No que diz respeito a estatística KMO, o conjunto de variáveis apresentou um valor de 0,6749, isto é, acima do aceitável para a aplicação da AF.

Utilizando como entrada a matriz com as respectivas correlações calculadas, foi possível realizar a análise fatorial, utilizando, assim como nas dimensões anteriores, o método de extração de fatores a partir da análise de componentes principais.

Visando uma maior facilidade na interpretação dos fatores extraídos aplicou-se, novamente, o método de rotação ortogonal Varimax.

Como resultado da análise fatorial, dois fatores, que explicam $80,74 \%$ da variância original, foram identificados.

Na Tabela 9, serão apresentadas todas as variáveis consideradas na análise, junto com as cargas fatoriais as quais elas pertencem e sua comunalidade. 
Tabela 9 - Resultados da análise fatorial para a dimensão Uso por professores e alunos

\begin{tabular}{l|l|l|l}
\hline Variável & Fator 1 & Fator 2 & Comunalidade \\
\hline p2901_bin & 0,3771 & 0,8069 & 0,7933 \\
\hline p44 & $-0,0679$ & 0,9283 & 0,8663 \\
\hline p2301_bin & 0,9192 & 0,0886 & 0,8528 \\
\hline p2304_bin & 0,8814 & 0,0423 & 0,7787 \\
\hline p2305_bin & 0,8473 & 0,1669 & 0,7459 \\
\cline { 2 - 3 } & &
\end{tabular}

Método de Extração: Análise de componentes principais

Rotação: Varimax

Variância Total Explicada: $0.8074=80,74 \%$

Total de observações: 562

Fonte: Elaborado pelo autor

Como nenhuma das variáveis demonstrou comunalidade abaixo de 0,5 , a tabela descrita acima permitiu uma classificação mais precisa dos indicadores relacionados à dimensão Uso por professores e alunos, sendo assim, é possível concluir que:

- O Fator 1 é composto pelas variáveis p2901_bin e p44.

- O Fator 2 é composto pelas variáveis p2301_bin, p2304_bin e p2305_bin.

Diante dos resultado expostos pela AF, a dimensão Uso por professores e alunos foi decomposta em duas subdimensões descritas no Quadro 18.

Quadro 18 - Subdimensões da dimensão Uso por professores e alunos

\begin{tabular}{|l|l|l|}
\hline \multirow{2}{*}{$\begin{array}{l}\text { Estímulo no processo } \\
\text { de ensino- } \\
\text { aprendizagem }\end{array}$} & p2901_bin & $\begin{array}{l}\text { Grau de concordância com a afirmação de } \\
\text { que a escola integrou o computador e a } \\
\text { Internet às práticas de ensino- } \\
\text { aprendizagem. }\end{array}$ \\
\cline { 2 - 3 } Projeto pedagógico & p44 & $\begin{array}{l}\text { A Internet da escola é utilizada pelos } \\
\text { professores em atividades de ensino- } \\
\text { aprendizagem com os alunos? }\end{array}$ \\
\hline & p2301_bin & $\begin{array}{l}\text { O projeto pedagógico da escola estimula ou } \\
\text { requer dos professores a integração do uso } \\
\text { da Internet em suas práticas? }\end{array}$ \\
\cline { 2 - 3 } & p2305_bin & $\begin{array}{l}\text { O projeto pedagógico da escola estimula ou } \\
\text { requer dos professores a atualização quanto } \\
\text { ao uso de computador e Internet no } \\
\text { processo de ensino-aprendizagem? }\end{array}$ \\
\hline $\begin{array}{l}\text { O projeto pedagógico da escola estimula ou } \\
\text { requer dos professores a utilização de } \\
\text { programas de computador (softwares) } \\
\text { específicos para o ensino de determinados } \\
\text { conteúdos? }\end{array}$ \\
\hline
\end{tabular}




\subsubsection{Análise fatorial com o conjunto de variáveis do modelo}

Antes da execução da modelagem de equações estruturais (MEE), foi realizada uma análise fatorial com todas as variáveis citadas anteriormente, a fim de verificar sua adequação às subdimensões e dimensões que compõe o índice de uso proposto no modelo de pesquisa.

O cruzamento entre as variáveis p1907 (O computador e a internet são habitualmente utilizados pelos funcionários da escola para fazer cronogramas/grade de horários?) e p2301_bin (O projeto pedagógico da escola estimula ou requer dos professores a integração do uso da Internet em suas práticas?), apresentou como resultado uma situação onde não houve a existência de observações, isto é, quando ambas as respostas para as perguntas eram "não", o número de observações registrado foi zero. Para a continuidade da análise, optou-se por remover a variável p1907, pois a mesma demonstrou um número maior de baixas correlações com as outras variáveis levantadas, se comparada com a variável p2301_bin.

O valor da estatística KMO para o conjunto de variáveis foi de 0,2106 e nem todas as variáveis apresentaram comunalidade superior a 0,5 .

Tabela 10 - Resultados da análise fatorial para todas as variáveis do modelo

\begin{tabular}{|c|c|c|c|c|c|}
\hline Variável & Fator 1 & Fator 2 & Fator 3 & Fator 4 & Comunalidade \\
\hline p1903 & -0.0398 & 0.2704 & 0,1431 & 0,7258 & 0,6219 \\
\hline p1904 & 0.2067 & 0.2982 & $-0,0062$ & 0,7086 & 0,6338 \\
\hline p1908 & 0.0724 & -0.1178 & 0,0134 & 0,7491 & 0,5805 \\
\hline p2903_bin & 0.8704 & 0.0872 & 0,1841 & 0,0253 & 0,7998 \\
\hline p2904_bin & 0.4948 & 0.0374 & 0,5379 & 0,029 & 0,5364 \\
\hline p2201 & 0.7415 & 0.1958 & $-0,064$ & 0,1203 & 0,6067 \\
\hline p2202 & 0.0668 & 0.5956 & 0,1673 & $-0,1634$ & 0,4139 \\
\hline p26_coorde $\sim r$ & 0,8671 & 0,1336 & $-0,0381$ & 0,1001 & 0,7811 \\
\hline p53 & 0,4951 & 0,7558 & 0,0707 & $-0,1398$ & 0,8409 \\
\hline p2905 & 0,1159 & 0,7353 & 0,2533 & 0,3673 & 0,7531 \\
\hline p2705 & 0,0278 & 0,7888 & 0,2244 & 0,3556 & 0,7998 \\
\hline p2901_bin & 0,5759 & 0,3 & 0,4193 & $-0,0338$ & 0,5985 \\
\hline p44 & 0,4899 & 0,6024 & $-0,0621$ & 0,0591 & 0,6103 \\
\hline p2301_bin & 0,0035 & 0,0163 & 0,9121 & 0,1227 & 0,8473 \\
\hline p2304_bin & 0,0702 & 0,1584 & 0,8558 & 0,0102 & 0,7625 \\
\hline p2305_bin & 0,0581 & 0,259 & 0,7923 & $-0,0243$ & 0,6987 \\
\hline
\end{tabular}

Método de Extração: Análise de componentes principais 


\begin{tabular}{ll}
\hline Variância Total Explicada: $0.6803=68,03 \%$ \\
$\begin{array}{ll}\text { Total de observações: } 562 & \text { Fonte: Elaborado pelo autor }\end{array}$
\end{tabular}

Fonte: Elaborado pelo autor

Conforme pode ser observado na Tabela 10, como resultado, a solução fatorial produziu quatro fatores, sendo que esses explicam 68,03\% da variância original.

A solução da análise fatorial realizada por dimensões descrita nos tópicos anteriores, produziu três fatores a mais do que a solução fatorial com o conjunto completo de variáveis elencadas acima, isso se deu pelo fato de que a única subdimensão que não recebeu variáveis de outras subdimensões, foi a "Atividades de comunicação e controle".

Como a solução fatorial com o conjunto de todas as variáveis apresentou a estatística KMO menor do que 0,5 e gerou uma divisão das dimensões diferente da apresentada individualmente pela AFE, a mesma não será considerada para a aplicação da modelagem de equações estruturais. Tal decisão se sustenta pela diretriz que a distribuição inicialmente proposta das variáveis baseou-se em componentes teóricos e, em sua análise independente, demonstrou validade estatística.

\subsubsection{A aplicação da Modelagem de Equações Estruturais para o desenvolvimento do índice}

O Quadro 19 sintetiza de forma hierárquica a relação entre as dimensões, as subdimensões e as variáveis que foram derivadas da AFE descrita nas seções anteriores, que será utilizada para a geração do índice de uso das TICs nas escolas.

Quadro 19 - Relação entre as dimensões, subdimensões e variáveis originadas da

AFE

\begin{tabular}{|l|l|l|l|}
\hline Dimensão & Subdimensão & Variável & Descrição \\
\hline \multirow{2}{*}{ Gestão } & p1903 & $\begin{array}{l}\text { O computador e a internet são } \\
\text { habitualmente utilizados pelos } \\
\text { funcionários da escola para } \\
\text { comunicarem-se com os } \\
\text { professores? }\end{array}$ \\
\cline { 3 - 4 } & $\begin{array}{l}\text { Atividades de } \\
\text { comunicação } \\
\text { e controle } \\
\text { (ACC) }\end{array}$ & p1904 & $\begin{array}{l}\text { O computador e a internet são } \\
\text { habitualmente utilizados pelos } \\
\text { funcionários da escola para } \\
\text { comunicarem-se com os pais de } \\
\text { alunos? }\end{array}$ \\
\cline { 3 - 4 } & & p1907 & $\begin{array}{l}\text { O computador e a internet são } \\
\text { habitualmente utilizados pelos }\end{array}$ \\
\hline
\end{tabular}




\begin{tabular}{|c|c|c|c|}
\hline & & & $\begin{array}{l}\text { funcionários da escola para fazer } \\
\text { cronogramas/grade de horários? }\end{array}$ \\
\hline & & p1908 & $\begin{array}{l}\text { O computador e a internet são } \\
\text { habitualmente utilizados pelos } \\
\text { funcionários da escola para } \\
\text { administrar compromissos } \\
\text { pessoais (agenda)? }\end{array}$ \\
\hline & \multirow{2}{*}{$\begin{array}{l}\text { Suporte da } \\
\text { direção ao uso } \\
\text { (SDAU) }\end{array}$} & p2903_bim & $\begin{array}{l}\text { Grau de concordância com a } \\
\text { afirmação de que nesta escola, há } \\
\text { treinamento para os alunos, de } \\
\text { como se usa computador e } \\
\text { Internet. }\end{array}$ \\
\hline & & p2904_bin & $\begin{array}{l}\text { Grau de concordância com a } \\
\text { afirmação de que nesta escola, há } \\
\text { treinamento para os professores, } \\
\text { de como se usa computador e } \\
\text { Internet. }\end{array}$ \\
\hline \multirow{6}{*}{ Infraestrutura } & \multirow[b]{2}{*}{$\begin{array}{l}\text { Apoio } \\
\text { pedagógico da } \\
\text { TI (APTI) }\end{array}$} & $\mathrm{p} 2201$ & $\begin{array}{l}\text { Esta escola conta com professor } \\
\text { de informática, que dê aulas } \\
\text { específicas de informática? }\end{array}$ \\
\hline & & $\begin{array}{l}\text { p26_coorden } \\
\text { ador }\end{array}$ & $\begin{array}{l}\text { Esta escola proporciona aulas } \\
\text { específicas de informática, que } \\
\text { ensinem a usar computador e } \\
\text { Internet como parte da grade } \\
\text { curricular? }\end{array}$ \\
\hline & \multirow[b]{2}{*}{$\begin{array}{l}\text { Recursos } \\
\text { computaciona } \\
\text { is }(\mathbf{R C})\end{array}$} & $\mathrm{p} 2705$ & $\begin{array}{l}\text { Total de computadores em } \\
\text { funcionamento da escola. }\end{array}$ \\
\hline & & p2905 & $\begin{array}{l}\text { Total de computadores instalados } \\
\text { e funcionando que estão } \\
\text { disponíveis para uso pedagógico } \\
\text { dos alunos. }\end{array}$ \\
\hline & \multirow{2}{*}{$\begin{array}{l}\text { Laboratório } \\
\text { de } \\
\text { Informática } \\
\text { (LI) }\end{array}$} & p2202 & $\begin{array}{l}\text { Esta escola conta com monitor } \\
\text { no laboratório de informática? }\end{array}$ \\
\hline & & p53 & $\begin{array}{l}\text { Atualmente, o(s) laboratório(s) } \\
\text { de informática da escola está(ão) } \\
\text { sendo utilizado(s)? }\end{array}$ \\
\hline \multirow{3}{*}{$\begin{array}{l}\text { Uso por } \\
\text { professores e } \\
\text { alunos }\end{array}$} & \multirow{2}{*}{$\begin{array}{l}\text { Estímulo no } \\
\text { processo de } \\
\text { ensino- } \\
\text { aprendizagem } \\
\text { (EPEA) }\end{array}$} & p2901_bin & $\begin{array}{l}\text { Grau de concordância com a } \\
\text { afirmação de que a escola } \\
\text { integrou o computador e a } \\
\text { Internet às práticas de ensino- } \\
\text { aprendizagem. }\end{array}$ \\
\hline & & p44 & $\begin{array}{l}\text { A Internet da escola é utilizada } \\
\text { pelos professores em atividades } \\
\text { de ensino-aprendizagem com os } \\
\text { alunos? }\end{array}$ \\
\hline & $\begin{array}{l}\text { Projeto } \\
\text { pedagógico } \\
(\mathrm{PP})\end{array}$ & p2301_bin & $\begin{array}{l}\text { O projeto pedagógico da escola } \\
\text { estimula ou requer dos } \\
\text { professores a integração do uso } \\
\text { da Internet em suas práticas? }\end{array}$ \\
\hline
\end{tabular}




\begin{tabular}{|l|l|l|}
\hline \multirow{2}{*}{} & p2304_bin & $\begin{array}{l}\text { O projeto pedagógico da escola } \\
\text { estimula ou requer dos } \\
\text { professores a atualização quanto } \\
\text { ao uso de computador e Internet } \\
\text { no processo de ensino- } \\
\text { aprendizagem? }\end{array}$ \\
\cline { 2 - 3 } & p2305_bin & $\begin{array}{l}\text { O projeto pedagógico da escola } \\
\text { estimula ou requer dos } \\
\text { professores a utilização de } \\
\text { programas de computador } \\
\text { (softwares) específicos para o } \\
\text { ensino de determinados } \\
\text { conteúdos? }\end{array}$ \\
\hline
\end{tabular}

Fonte: Elaborado pelo autor

No âmbito da MEE, as dimensões, subdimensões e, o próprio índice de uso, são definidos como variáveis latentes. Segundo Hair Jr et al. (2010), as variáveis latentes são aquelas que não são observáveis diretamente, mas são mensuráveis via indicadores. Sendo assim, por ser uma estrutura que representa três níveis de relação, isto é, como o índice de uso se reflete nas dimensões, que por conseguinte se refletem nas subdimensões e que, por fim, se refletem nos indicadores, temos um modelo com variáveis latentes de primeira (subdimensões), segunda (dimensões) e terceira (índice de uso) ordem.

Para a modelagem do índice de uso TICs, foi utilizado o software SmartPLS (versão 2) e sua representação visual pode ser observada na Figura 9, na qual os indicadores (variáveis mensuradas através dos resultados da pesquisa TIC Educação) são indicados por retângulos e as variáveis latentes (variáveis não observáveis) são indicadas por círculos. 
Figura 9 - Modelo de pesquisa

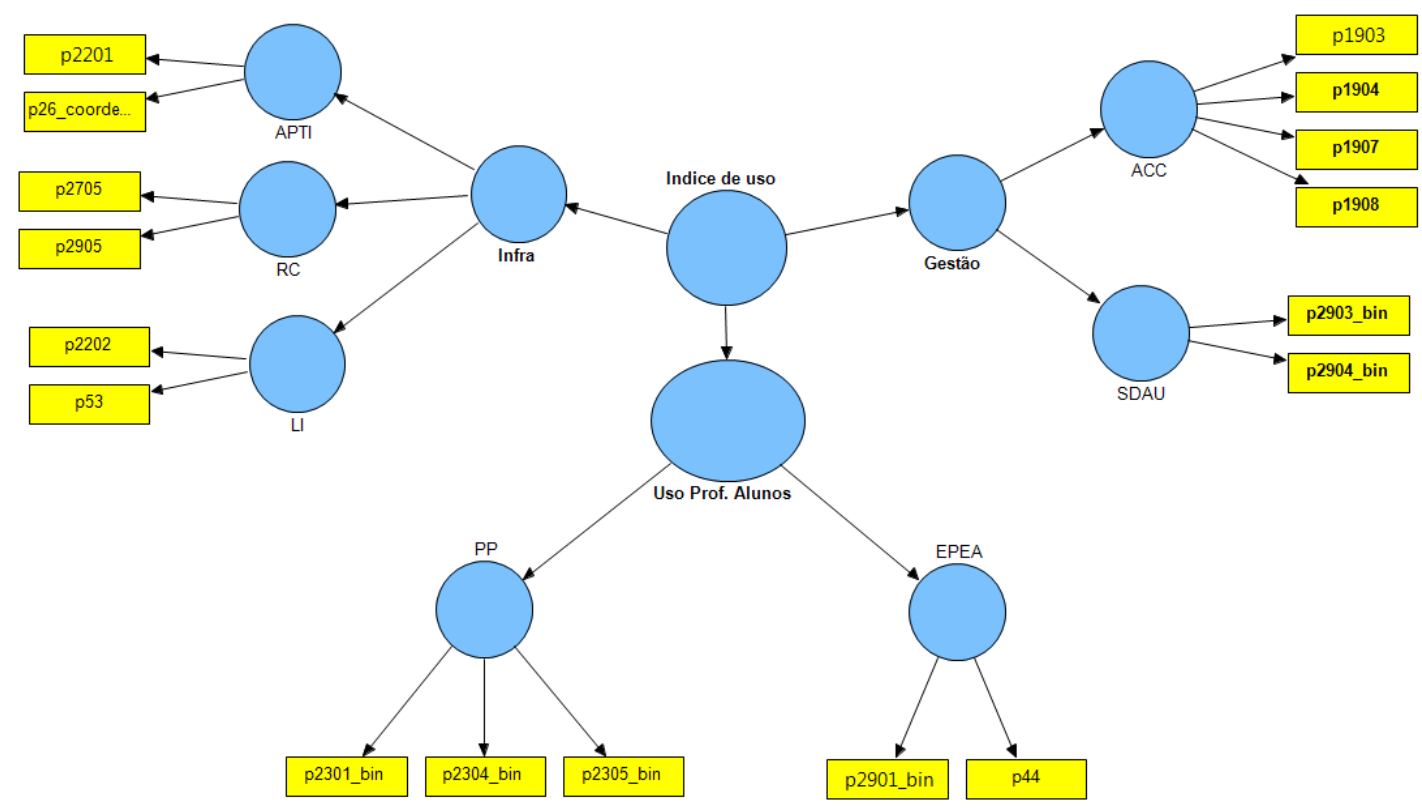

Fonte: Elaborado pelo autor, gerado pelo SmarPLS

Conforme mostra a Figura 9, o modelo proposto é um modelo de análise fatorial confirmatória (AFC), afinal, não há uma variável exógena (variáveis que causam outras variáveis, graficamente são representadas pelas setas saindo delas) que possua indicadores observados para uma variável endógena (variáveis que são causadas por outras variáveis do modelo, graficamente são representadas pelas setas chegando até elas), o que configuraria a existência de um modelo causal (SOUZA, 2004), sendo assim, a única variável exógena do modelo é o índice de uso.

Neste estudo, como método para estimação dos coeficientes de mensuração da MEE, foi utilizado o PLS (partial least squares). Conforme sintetizado por Zwicker et al. (2008), o PLS tem por objetivo ser um modelo de predição, baseado na variância, sem suposições quanto a distribuição dos dados (normalidade), capaz de lidar com alta complexidade (100 construtos e 1000 indicadores), sendo aplicado em amostras com no mínimo de 30 a 100 casos, onde as variáveis latentes são combinações lineares dos indicadores e os escores fatoriais são estimados explicitamente. Vale ressaltar que a estimação pelo método PLS gera, automaticamente, os valores para os escores fatoriais das variáveis latentes, que neste estudo serão utilizados para a sequência da análise dos resultados.

A fim de justificar a viabilidade de se aplicar MEE utilizando o método PLS para variáveis latentes de ordem $n$, Wetzels et al. (2009) citam que variáveis latentes de ordens superiores podem ser criadas a partir de uma variável latente que represente 
todos os indicadores utilizados nas variáveis latentes dos níveis inferiores, consequentemente, os indicadores são duplicados, partindo do nível de variável latente de menor ordem até o nível de variável latente de maior ordem, ou seja, os indicadores das variáveis latentes de primeira ordem são reutilizados como indicadores reflexivos das variáveis latentes de ordem superior, conforme ilustrado na Figura 10.

\section{Figura 10 - Representação gráfica da relação entre variáveis latentes em diferentes ordens}

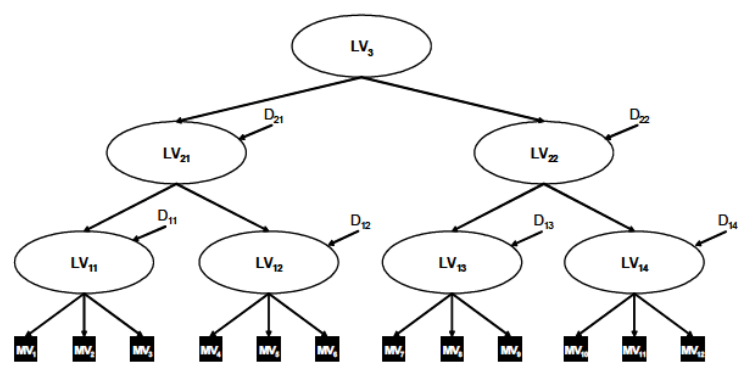

Fonte: Wetzels et al. (2009)

Justificada a aplicação da MEE através do método PLS, foi possível processar a análise fatorial confirmatória. Na Figura 11, é possível analisar o resultado das cargas fatoriais entre as variáveis latentes de primeira, segunda e terceira ordem e seus respectivos indicadores.

Figura 11 - Cargas fatoriais no modelo de pesquisa

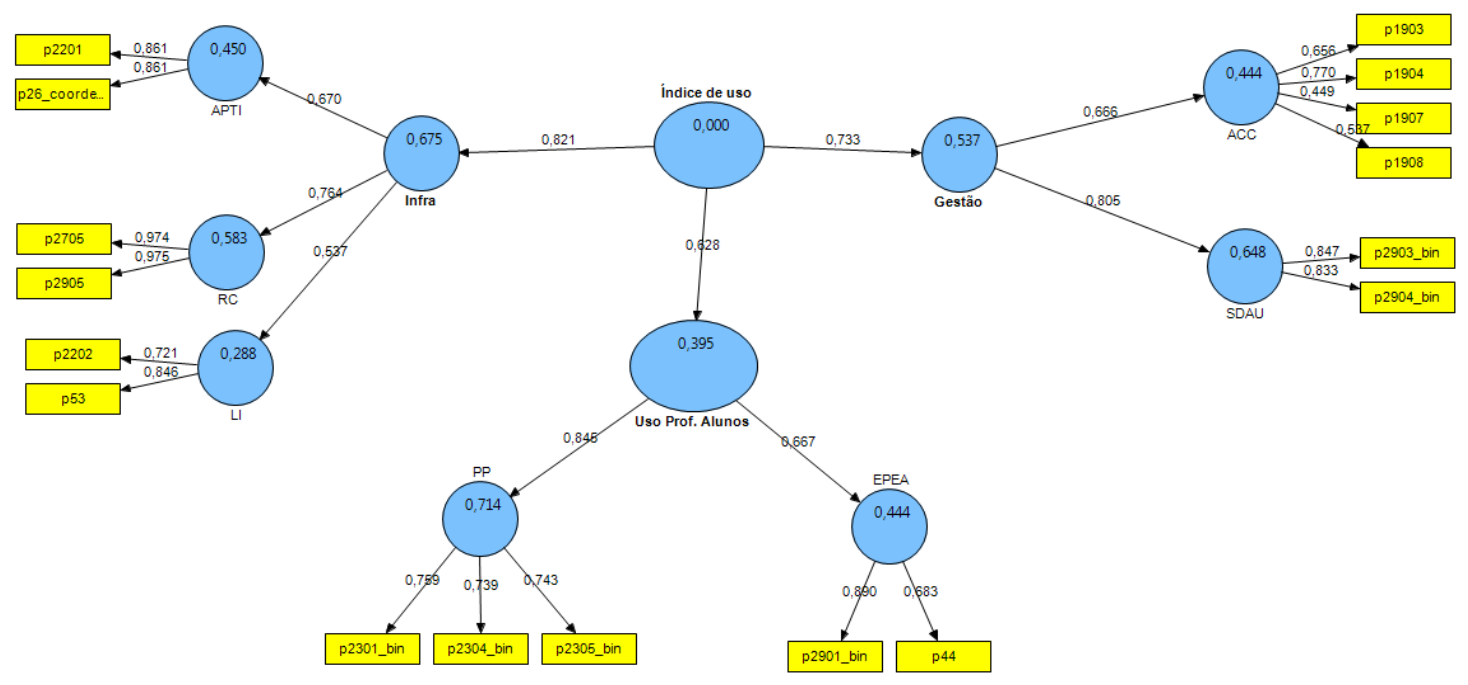

Fonte: Elaborado pelo autor, gerado pelo SmarPLS

A fim de avaliar a significância dos coeficientes extraídos, foi realizado o processo de bootstrapping. A simulação foi feita em um cenário de 562 casos (tamanho total da 
amostra) e 200 repetições. Após o processamento, foi possível identificar que todas as correlações encontradas no modelo são significantes a 95\%, isto é, todos os valores da estatística $t$ ilustrados sobre as setas na Figura 12 são maiores do 1,96.

Figura 12 - Análise da significância calculada por bootstrapping no modelo de pesquisa

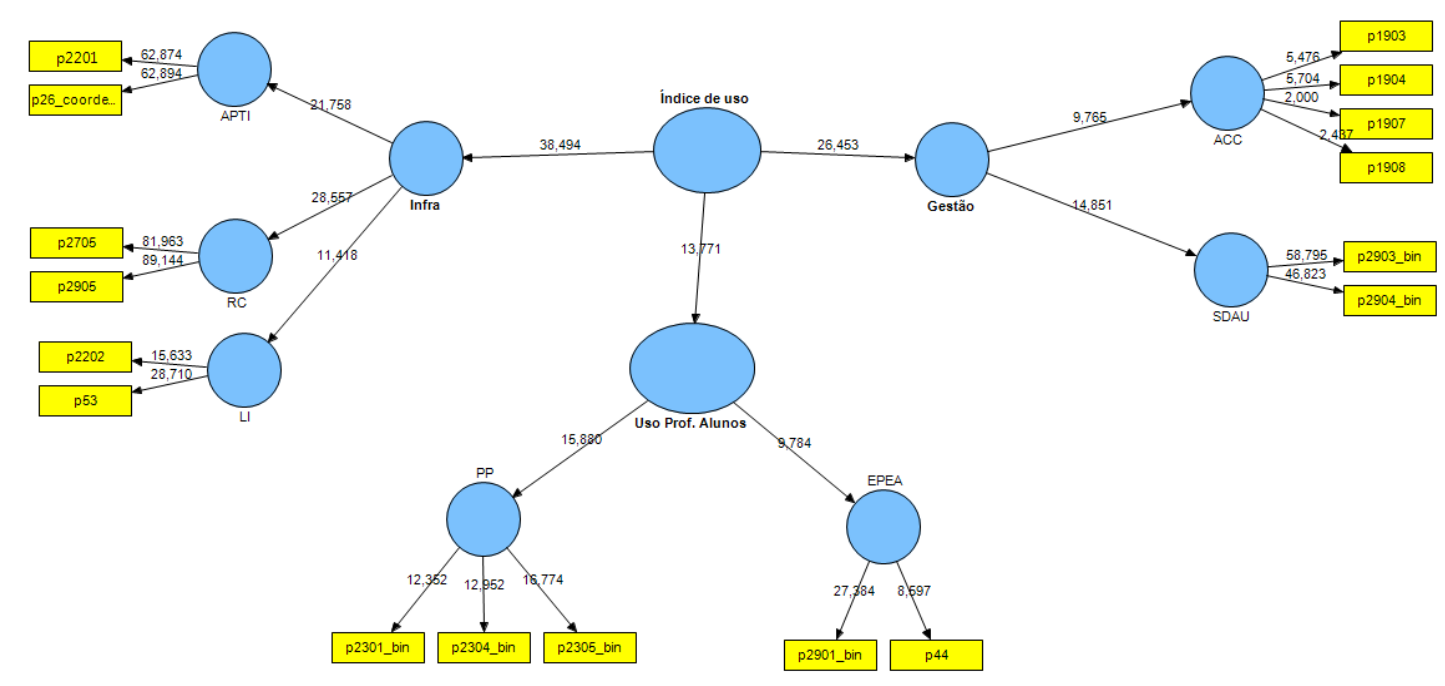

Fonte: Elaborado pelo autor, gerado pelo SmartPLS

Mesmo avaliando que os coeficientes extraídos pelo modelo demonstraram significância, foram identificados alguns indicadores que obtiveram carga fatorial menor do que 0,7. Seguindo a sugestão apresentada por Kubo e Gouvêa (2012), que para propor um modelo de significado do trabalho realizaram a exclusão de indicadores com carga fatorial inferior a 0,7, foram removidos do modelo os indicadores p1907 (carga fatorial de 0,449) e p1908 (carga fatorial de 0,537), pois ambos demonstraram baixa carga fatorial. Além disso, a subdimensão anteriormente intitulada "Atividades de comunicação e controle" (ACC) foi renomeada para "Atividades de comunicação" (AC), haja vista que os indicadores (variáveis) que se mantiveram no modelo dizem respeito às questões relacionadas à comunicação. As variáveis p44 (A Internet da escola é utilizada pelos professores em atividades de ensino-aprendizagem com os alunos?) e p1903 (O computador e a internet são habitualmente utilizados pelos funcionários da escola para comunicar-se com os professores?) não foram removidas do modelo, pois apresentaram carga fatorial aproximada de 0,7 (0,68 e 0,66, respectivamente).

Na Figura 13, é possível analisar o diagrama do novo modelo, no qual verifica-se que todos os indicadores apresentam cargas fatoriais maiores do que 0,7 . 
Figura 13 - Análise das cargas fatoriais no modelo derivado

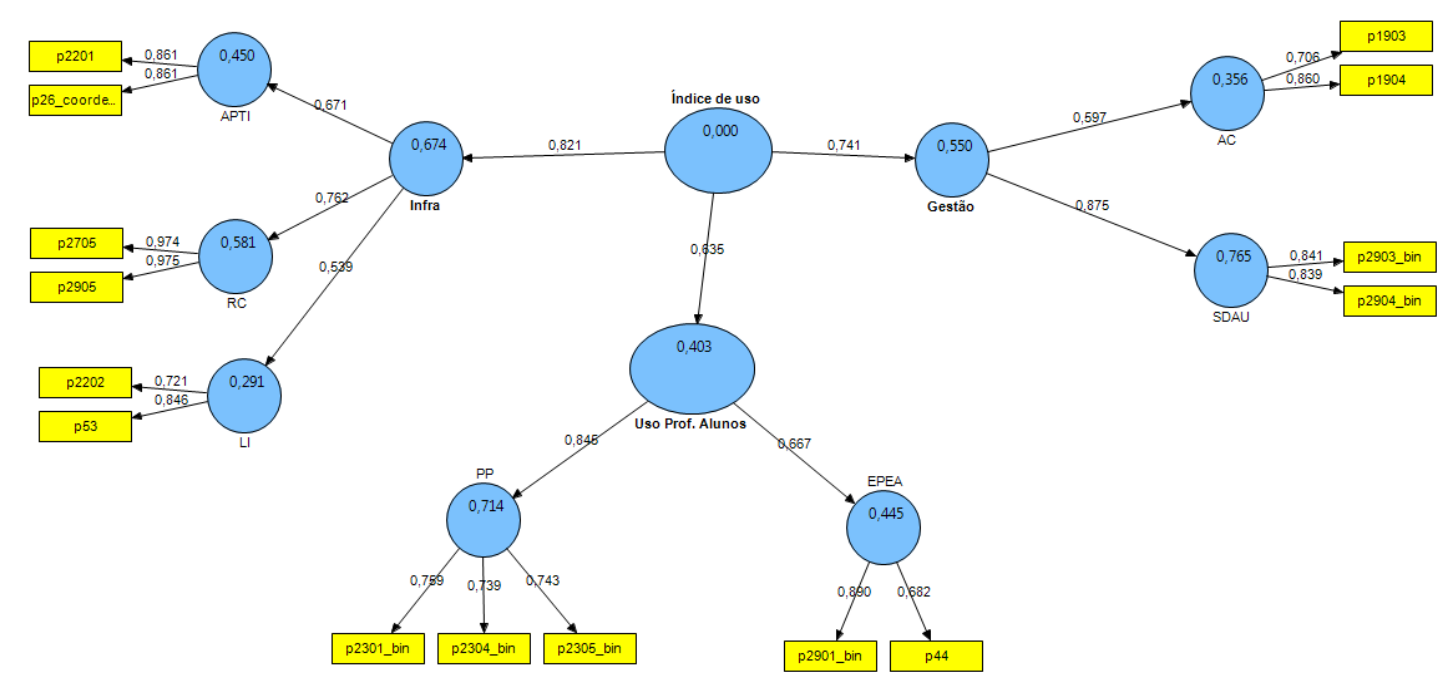

Fonte: Elaborado pelo autor, gerado pelo SmartPLS

A fim de validar a significância dos coeficientes extraídos pelo novo modelo, foi executado um novo processo de bootstraping com 562 casos (total da amostra) e 200 repetições. A partir do resultado ilustrado na Figura 14, foi possível identificar que todas as correlações encontradas no novo modelo são significantes a 99\%, isto é, todos os valores da estatística $t$ ilustrados sobre as setas na figura abaixo são maiores do 2,576. Cabe ressaltar que, no modelo anterior, foi observada uma significância a $95 \%$.

Figura 14 - Análise da significância calculada por bootstrapping no modelo derivado

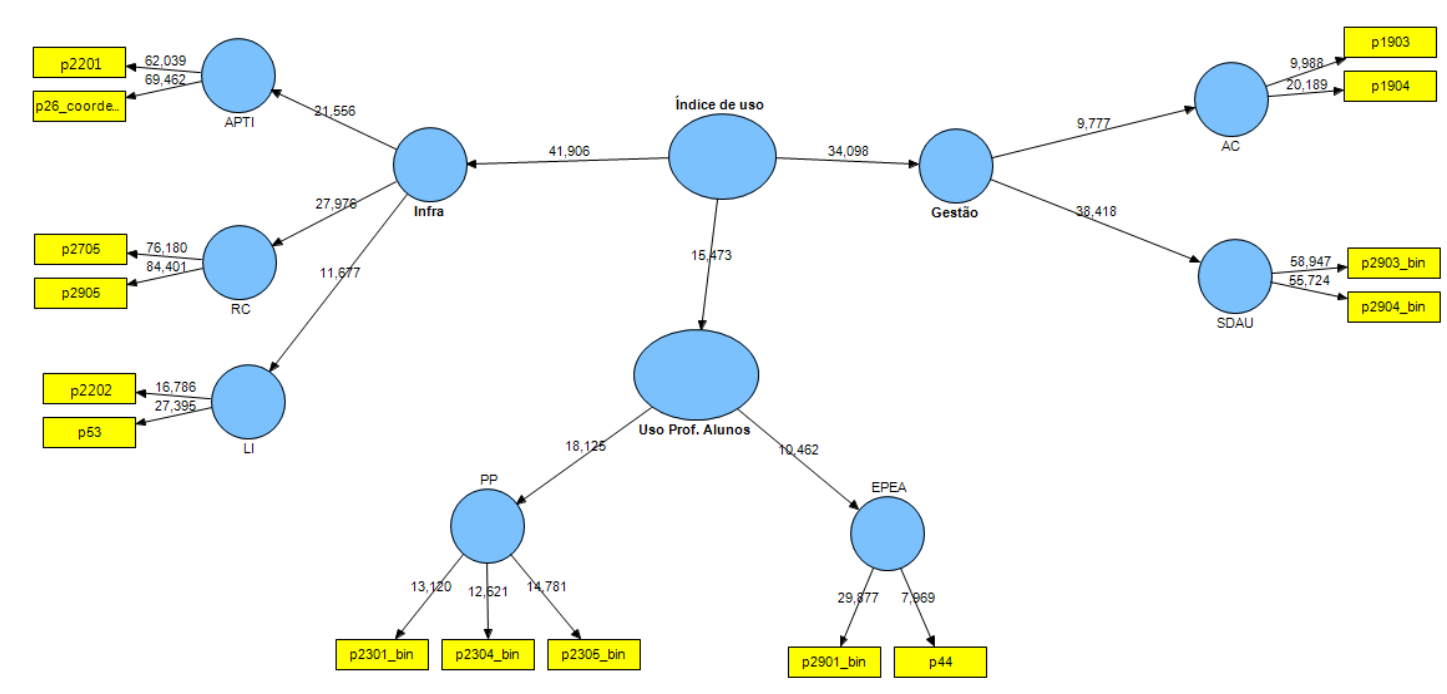


Fonte: Elaborado pelo autor, gerado pelo SmartPLS

A fim de realizar-se a validação do modelo, foram empregados os seguintes estágios de avaliação (Zwicker et al., 2008):

1. Validade convergente: a AVE (Análise de Variância Extraída) das variáveis latentes deve ser maior do que 0,5 ;

2. Validade discriminante: a correlação entre uma variável latente e as demais variáveis latentes deve ser sempre menor do que a raiz quadrada da AVE, para tornar a grandeza comparável às correlações;

3. Confiabilidade composta: a CC (Confiabilidade Composta) dos construtos deve ser igual ou superior ao valor de 0,7 .

Para os fatores de primeira ordem, os valores utilizados foram obtidos diretamente através do software SmartPLS, já para os fatores de segunda ordem, a validade e a confiabilidade foram calculadas com o auxílio de uma planilha eletrônica a partir dos coeficientes que as conectam aos seus fatores de primeira ordem. De acordo com Hair Jr et al. (2010), a AVE e a CC, descrita na fórmula abaixo como CR (Composite Reability), devem ser calculadas da seguinte maneira:

$$
\frac{A V E=\sum_{i=1}^{n} \lambda i^{2}}{n}
$$

$\mathrm{Na}$ fórmula da AVE, lambda representa as cargas fatoriais calculadas dos itens relacionados à variável latente e $\mathrm{n}$ representa o número de itens relacionados à variável.

$$
C R=\frac{\left(\sum_{i=1}^{n} \lambda y i\right)^{2}}{\left(\sum_{i=1}^{n} \lambda y i\right)^{2}+\left(\sum_{i=1}^{p} \operatorname{var}(\varepsilon i)\right)}
$$

$\mathrm{Na}$ fórmula do CR (ou CC), lambda representa as cargas fatoriais calculadas e var (ei) representa a variância devido ao erro de medição.

Descritos os pressupostos de avaliação do modelo, a seguir serão descritos os resultados da avaliação.

Fez-se a constatação da validade convergente e da confiabilidade composta por meio da Tabela 11. Nela é possível observar que a AVE para variável latente de segunda ordem Infraestrutura $(0,44)$ está demonstrando um valor abaixo do que o limite inferior estipulado de 0,5 e, o motivo aparente para tal desempenho tem relação com a carga fatorial da variável latente de primeira ordem Laboratório de Informática $(0,54)$ estar com um valor abaixo das demais variáveis que compõe a dimensão Infraestrutura, já que as subdimensões Recursos Computacionais e Apoio pedagógico 
de TI apresentam, respectivamente, cargas de 0,76 e 0,67. Para os demais construtos, o valor da AVE demonstrou-se maior do que 0,5 , sendo assim, a validade convergente é satisfeita. Quanto à confiabilidade composta, observam-se valores acima de $0,7, \mathrm{ou}$, no caso da variável latente Infraestrutura, sendo muito próximo de $0,7(0,67)$; portanto, é atendida a condição de confiabilidade de escala.

Tabela 11 - Validade convergente e confiabilidade no modelo derivado

\begin{tabular}{l|l|l|l|l|}
\hline${\text { Variáveis latentes de } \mathbf{1}^{\circ} \mathbf{2}^{\circ} \mathbf{e} \mathbf{3}^{\circ} \text { ordem }}$ & $\mathbf{C F}$ & $\mathbf{V E}$ & $\mathbf{C C}$ & $\mathbf{A V E}$ \\
\hline Gestão & 0,74 & 0,45 & 0,71 & 0,56 \\
\hline Atividades de comunicação (AC) & 0,60 & 0,64 & 0,76 & 0,62 \\
\hline Suporte da direção ao uso (SDAU) & 0,88 & 0,23 & 0,83 & 0,71 \\
\hline Infraestrutura & 0,80 & 0,35 & 0,70 & 0,44 \\
\hline Apoio pedagógico da TI (APTI) & 0,67 & 0,55 & 0,85 & 0,74 \\
\hline Recursos computacionais (RC) & 0,76 & 0,42 & 0,97 & 0,95 \\
\hline Laboratório de Informática (LI) & 0,54 & 0,71 & 0,76 & 0,62 \\
\hline Uso por professores e alunos & 0,62 & 0,61 & 0,73 & 0,58 \\
\hline Estímulo no processo de ensino-aprendizagem (EPEA) & 0,67 & 0,56 & 0,77 & 0,63 \\
\hline Projeto pedagógico (PP) & 0,85 & 0,29 & 0,79 & 0,56 \\
\hline Índice de uso TIC & - & & 0,77 & 0,53 \\
\hline
\end{tabular}

Legenda: CF: Carga fatorial; CC: Confiabilidade composta; AVE: Análise de variância extraída; VE: Variância devido ao erro de medição.

\section{Fonte: Elaborado pelo autor}

Na Tabela 12 é possível observar que todas as correlações entre as variáveis latentes de primeira ordem são menores que a raiz quadrada da AVE, representada pela diagonal destacada em negrito, sendo assim, é possível afirmar que há validade discriminante.

Tabela 12 - Correlação de Pearson entre as variáveis latentes no modelo derivado

\begin{tabular}{l|l|l|l|l|l|l|l}
\hline & AC & APTI & EPEA & LI & PP & RC & SDAU \\
\hline AC & $\mathbf{0 , 7 8 7}$ & & & & & & \\
\hline APTI & 0,168 & $\mathbf{0 , 8 6 1}$ & & & & & \\
\hline EPEA & 0,137 & 0,232 & $\mathbf{0 , 7 9 3}$ & & & & \\
\hline LI & 0,134 & 0,195 & 0,362 & $\mathbf{0 , 7 8 6}$ & & & \\
\hline PP & 0,060 & 0,046 & 0,166 & 0,125 & $\mathbf{0 , 7 4 7}$ & & \\
\hline RC & 0,155 & 0,170 & 0,103 & 0,145 & 0,076 & $\mathbf{0 , 9 7 4}$ & \\
\hline SDAU & 0,133 & 0,384 & 0,314 & 0,207 & 0,162 & 0,156 & $\mathbf{0 , 8 4 0}$ \\
\hline
\end{tabular}

Devido ao problema da validade convergente $(\mathrm{AVE}<0,5)$ demonstrado pela variável latente de segunda ordem Infraestrutura, decidiu-se analisar um modelo alternativo. Em tal modelo, a subdimensão Laboratório de Informática, construto que apresentou 
menor carga fatorial, foi removida e um novo modelo ficou definido conforme ilustrado na Figura 15.

\section{Figura 15 - Análise das cargas fatoriais no modelo final}

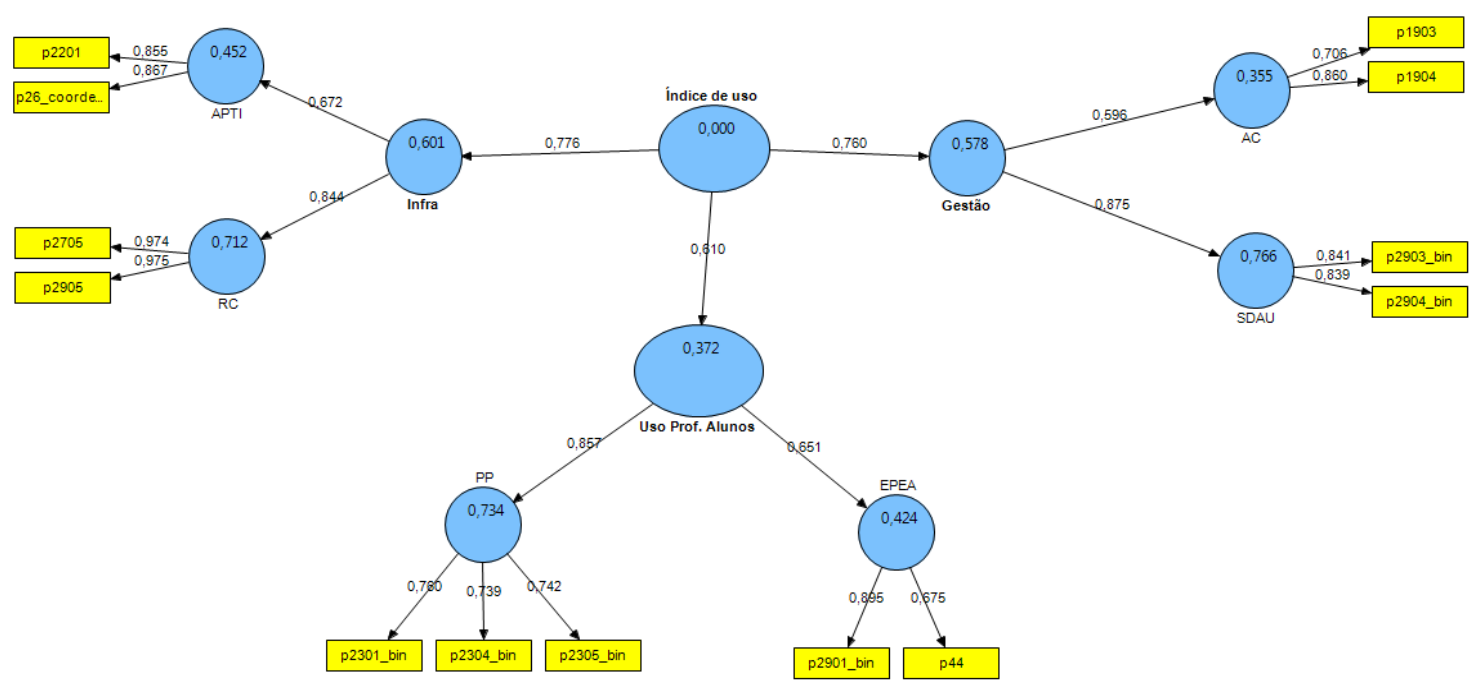

Fonte: Elaborado pelo autor, gerado pelo SmartPLS

É possível observar na figura anterior, que as cargas fatoriais para as variáveis latentes de primeira ordem continuaram acima de 0,7 .

O processo de bootstraping, ilustrado na Figura 16, também demonstrou uma significância de $99 \%$ para os coeficientes encontrados, isto é, os valores obtidos na estatística $t$, ilustrados sobre as setas na figura, são maiores do 2,576.

Figura 16 - Análise da significância calculada por bootstrapping no modelo final

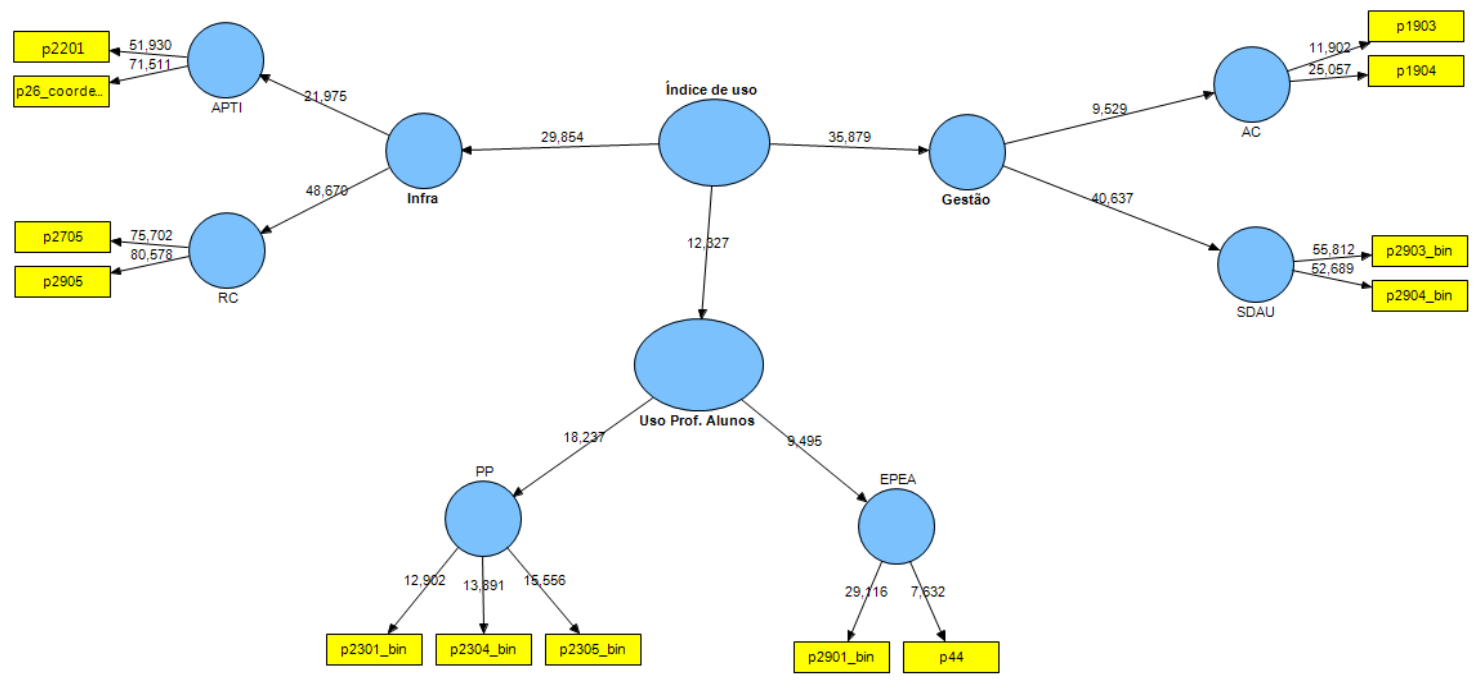

Fonte: Elaborado pelo autor, gerado pelo SmartPLS 
Conforme pode ser observado na Tabela 13, os valores de AVE indicam validade convergente para todas as variáveis do novo modelo. Os valores da confiabilidade composta são todos superiores a 0,7 ; portanto, a confiabilidade de escala também é satisfeita.

Tabela 13 - Validade convergente e confiabilidade no modelo final

\begin{tabular}{|c|c|c|c|c|}
\hline Variáveis latentes de $1^{\circ}, 2^{\circ}$ e $3^{\circ}$ ordem & $\mathbf{C F}$ & $\mathbf{V E}$ & $\mathbf{C C}$ & AVE \\
\hline Gestão & 0,74 & 0,45 & 0,71 & 0,56 \\
\hline Atividades de comunicação e controle (AC) & 0,60 & 0,64 & 0,76 & 0,62 \\
\hline Suporte da direção ao uso (SDAU) & 0,88 & 0,23 & 0,83 & 0,71 \\
\hline Infraestrutura & 0,80 & 0,35 & 0,73 & 0,58 \\
\hline Apoio pedagógico da TI (APTI) & 0,67 & 0,55 & 0,85 & 0,74 \\
\hline Recursos computacionais (RC) & 0,84 & 0,29 & 0,97 & 0,95 \\
\hline Uso por professores e alunos & 0,62 & 0,61 & 0,73 & 0,58 \\
\hline Estímulo no processo de ensino-aprendizagem (EPEA) & 0,65 & 0,58 & 0,77 & 0,63 \\
\hline Projeto pedagógico $(\mathrm{PP})$ & 0,86 & 0,27 & 0,79 & 0,56 \\
\hline Índice de uso TIC & - & & 0,77 & 0,53 \\
\hline
\end{tabular}

Legenda: CF: Carga fatorial; CC: Confiabilidade composta; AVE: Análise de variância extraída; VE: Variância devido ao erro de medição.

Fonte: Elaborado pelo autor

Também é possível verificar, a partir da Tabela 14, que as correlações entre as variáveis latentes são menores que a raiz quadrada da AVE, representada pela diagonal destacada em negrito, portanto, o modelo apresenta validade discriminante.

Tabela 14 - Correlação de Pearson entre as variáveis latentes no modelo final

\begin{tabular}{l|l|l|l|l|l|l}
\hline & AC & APTI & EPEA & PP & RC & SDAU \\
\hline AC & $\mathbf{0 , 7 8 7}$ & & & & & \\
\hline APTI & 0,169 & $\mathbf{0 , 8 6 1}$ & & & & \\
\hline EPEA & 0,137 & 0,232 & $\mathbf{0 , 7 9 3}$ & & & \\
\hline PP & 0,060 & 0,046 & 0,167 & $\mathbf{0 , 7 4 7}$ & & \\
\hline RC & 0,155 & 0,170 & 0,103 & 0,076 & $\mathbf{0 , 9 7 4}$ & \\
\hline SDAU & 0,133 & 0,386 & 0,315 & 0,162 & 0,156 & $\mathbf{0 , 8 3 9}$ \\
\hline
\end{tabular}

Fonte: Elaborado pelo autor

Como o modelo que foi apresentado anteriormente atendeu a todos os critérios de validação propostos por Zwicker et al. (2008), o mesmo será adotado como modelo final deste estudo. A subdimensão Laboratório de Informática teve que ser removida para que os critérios técnicos pudessem ser validados, no entanto, a mesma deve ser considerada em estudos futuros, afinal, tal ambiente é um local importante para a infraestrutura tecnológica da escola. Segundo Miranda (2007), equipar as escolas com computadores e laboratórios de informática representa uma parte, mas não o todo do 
processo de inclusão digital, sendo assim, o índice que será analisado nas próximas seções, demonstrará nas diferentes perspectivas apresentadas pelo modelo, o nível de uso das TICs pelas escolas.

\subsection{Explorando o índice de uso das TICs nas escolas e suas dimensões}

Após processada a AFC pelo software SmartPLS, foi possível associar, a cada observação da amostra, um escore fatorial padronizado para o índice de uso das TICs e suas dimensões.

Como primeira estratégia de análise de tais resultados, será descrita a seguir uma investigação das estatísticas básicas do índice e de suas dimensões.

\subsubsection{Estatística descritiva do índice de uso e de suas dimensões}

O primeiro passo, a fim de analisar os resultados obtidos, foi compreender de forma descritiva os valores mínimo e máximo, bem como a média e o desvio padrão, do índice de uso das TICs nas escolas e de suas dimensões. Tais resultados podem ser analisados na Tabela 15 .

Tabela 15 - Estatísticas descritivas dos escores fatoriais padronizados nas variáveis do índice

\begin{tabular}{l|l|l|l|l}
\hline Variável & Mínimo & Máximo & Média & Desvio-padrão \\
\hline Índice de uso das TICs nas escolas & $-3,35$ & 6,81 & 0,000002 & 1,000893 \\
\hline Gestão & $-2,22$ & 1,28 & 0,000013 & 1,000903 \\
\hline Infraestrutura & $-0,98$ & 11,62 & 0,000001 & 1,000891 \\
\hline Uso por professores e alunos & $-6,71$ & 0,46 & 0,000009 & 1,000892 \\
\hline
\end{tabular}

Fonte: Elaborado pelo autor, extraído do software SPSS.

A dimensão "Infraestrutura" e o "Índice de uso das TICs nas escolas”, demonstraram um escore fatorial alto para o valor máximo disponível na distribuição. Como o escore calculado foi gerado dentro de uma distribuição de média zero (0) e desvio padrão um (1), não foi calculado o coeficiente de variação, pois não seria possível avaliar o quão dispersas se encontram as distribuições, sendo assim, para compreender a frequência de ocorrência dos valores calculados, foram gerados os respectivos histogramas das variáveis ilustrados nos Gráficos 1 e 2. 


\section{Gráfico 1- Histograma do índice de uso das TICs nas escolas}

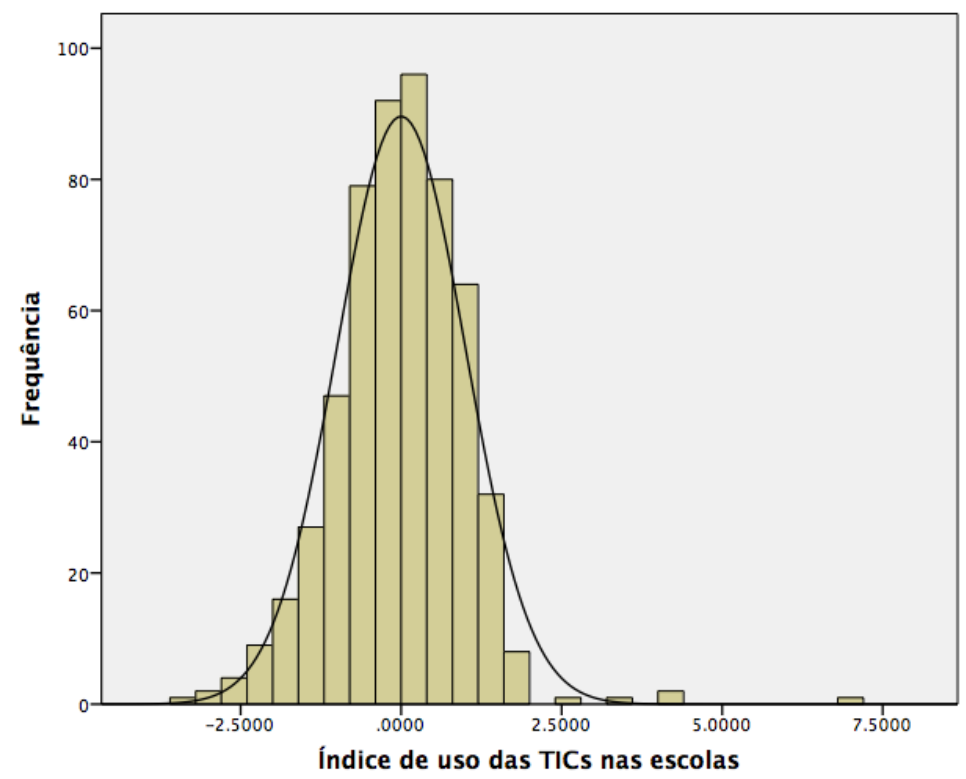

Fonte: extraído do software SPSS

Gráfico 2 - Histograma das dimensões do índice de uso das TICs nas escolas
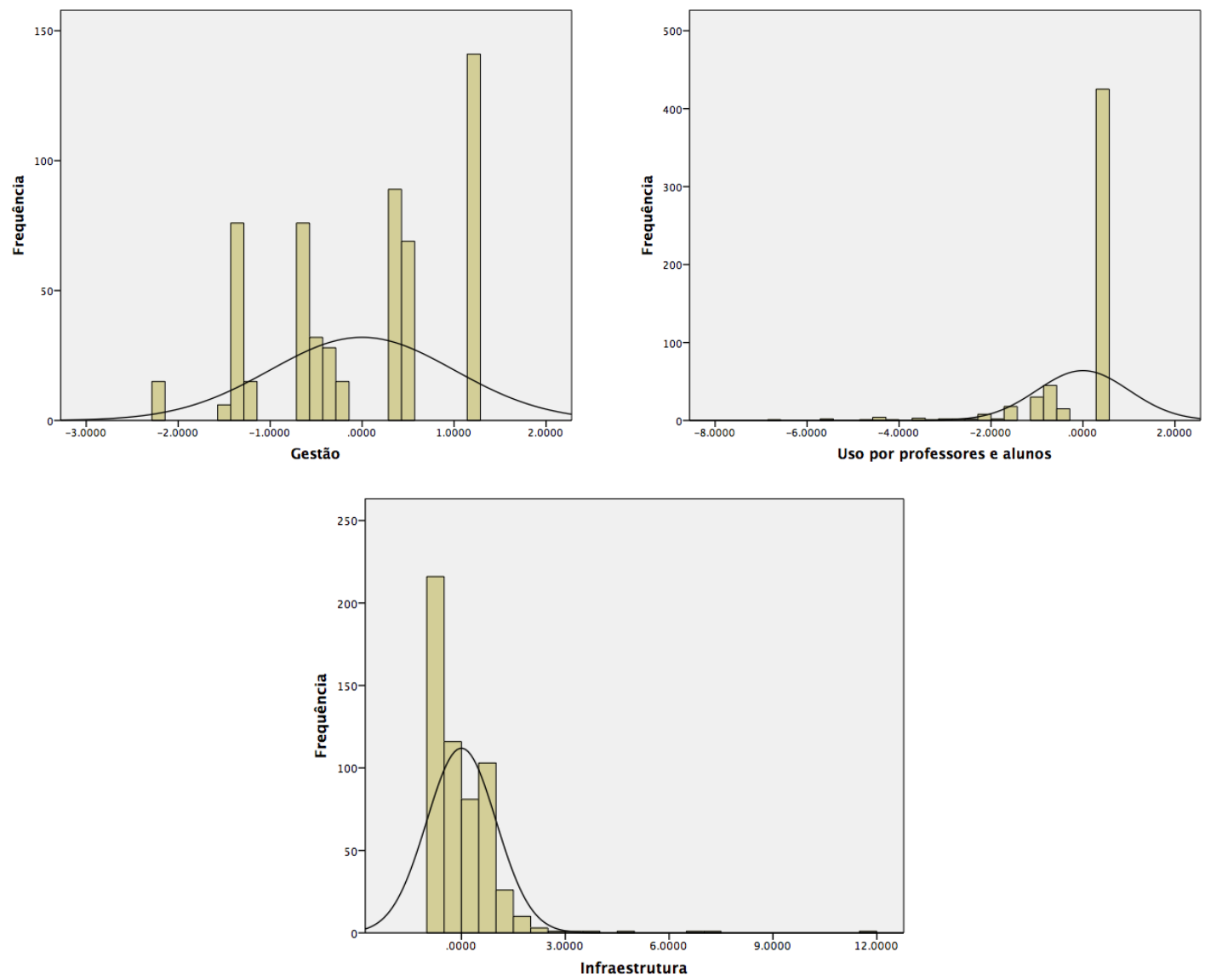

Fonte: extraído do software SPSS

A partir de uma análise das distribuições nas dimensões e no índice, é possível identificar valores que se encontram fora do limite da curva normal. 
Segundo Rodrigues e Paulo (2012), é possível se detectar observações atípicas (outliers) quando elas apresentarem um valor, em módulo, maior ou igual a três (3), sendo tais valores originados a partir de um distribuição padronizada (média zero e desvio-padrão um).

Seguindo o critério supracitado, a única distribuição que não demonstrou conter outliers, foi a distribuição da dimensão "Gestão".

Para a dimensão "Infraestrutura", foram identificadas seis (6) escolas que demonstraram escores fatoriais maiores do que três (3).

Tabela 16 - Escolas removidas da análise pelo desempenho na dimensão

Infraestrutura

\begin{tabular}{l|l|l|l|l}
\hline$\#$ & $\begin{array}{l}\text { Escore fatorial padronizado } \\
\text { para a dimensão } \\
\text { Infraestrutura sem } \\
\text { modularização }\end{array}$ & $\begin{array}{l}\text { *Proporção de } \\
\text { computadores instalados e } \\
\text { funcionando que estão } \\
\text { disponíveis para uso } \\
\text { pedagógico dos alunos. }\end{array}$ & Região & $\begin{array}{l}\text { Dependência } \\
\text { administrativa }\end{array}$ \\
\hline 1 & 11,6188 & $78,72 \%$ & Sudeste & Particular \\
\hline 2 & 7,4338 & $36,36 \%$ & Sudeste & Particular \\
\hline 3 & 6,9480 & $100 \%$ & Sul & Particular \\
\hline 4 & 4,9433 & $96,51 \%$ & Sudeste & Particular \\
\hline 5 & 3,6341 & $84,9 \%$ & Sudeste & Particular \\
\hline 6 & 3,4032 & $100 \%$ & Sul & Municipal \\
\hline $\begin{array}{l}\text { *Indicador calculado a partir da razão entre o total de computadores instalados e funcionando que estão } \\
\text { disponíveis para uso pedagógico dos alunos e o total de computadores instalados e funcionando } \\
\text { disponíveis na escola. }\end{array}$
\end{tabular}

É possível observar a partir da Tabela 16 que as escolas que obtiveram um escore fatorial alto para a dimensão "Infraestrutura" são, em sua maioria, particulares e se encontram nas regiões Sudeste e Sul do país. Além disso, todas as escolas, exceto a escola número dois (2), demonstraram disponibilizar quase que em sua totalidade os computadores instalados e funcionando disponíveis na escola, para o uso pedagógico dos alunos.

Já para a dimensão "Uso por professores e alunos", foram identificados quinze (15) casos onde os escores fatoriais, em módulo, se encontraram acima de três (3). Todas as escolas deste conjunto são públicas, sendo, cinco (5) delas municipais e dez (10) delas estaduais.

A partir dos resultados apresentados na Tabela 17, foi possível compreender as razões pelas quais tais escolas demonstraram baixo desempenho na dimensão "Uso por professores e alunos", afinal, analisando os indicadores brutos que compõe tal dimensão, apenas no indicador “A Internet da escola é utilizada pelos professores em atividades de ensino-aprendizagem com os alunos?", as escolas estimularam o uso das 
TICs por parte dos professores dentro do processo de ensino-aprendizagem, haja vista que tal indicador foi o único a obter um percentual de respostas "sim" acima de 50\% no conjunto dos outliers identificados.

Tabela 17 - Percentual de outliers identificados a partir dos indicadores que compõe a dimensão Uso por professores alunos

\begin{tabular}{l|l}
\hline Indicador & $\begin{array}{l}\text { Percentual de outliers identificados } \\
\text { que responderam "sim" para o } \\
\text { indicador }\end{array}$ \\
\hline $\begin{array}{l}\text { A Internet da escola é utilizada pelos professores em } \\
\text { atividades de ensino-aprendizagem com os alunos? }\end{array}$ & $86,70 \%$ \\
\hline $\begin{array}{l}\text { Grau de concordância com a afirmação de que a escola } \\
\text { integrou o computador e a Internet às práticas de ensino- } \\
\text { aprendizagem. }\end{array}$ & $40,00 \%$ \\
\hline $\begin{array}{l}\text { O projeto pedagógico da escola estimula ou requer dos } \\
\text { professores a integração do uso da Internet em suas práticas? }\end{array}$ & $26,70 \%$ \\
\hline $\begin{array}{l}\text { O projeto pedagógico da escola estimula ou requer dos } \\
\text { professores a atualização quanto ao uso de computador e } \\
\text { Internet no processo de ensino-aprendizagem? }\end{array}$ & $20,00 \%$ \\
\hline $\begin{array}{l}\text { O projeto pedagógico da escola estimula ou requer dos } \\
\text { professores a utilização de programas de computador } \\
\text { (softwares) específicos para o ensino de determinados } \\
\text { conteúdos? }\end{array}$ & $13,30 \%$ \\
\hline
\end{tabular}
Fonte: Eaborado pelo autor

A partir do descritivo realizado acima, foi tomada a decisão de remover da análise de escolas estudadas, as vinte e uma (21) observações identificadas como casos extremos. Vale pontuar que essas escolas poderiam ser analisadas a partir de estudos de caso, pois demonstraram desempenhos elevados, nos casos apresentados para a dimensão "Infraestrutura", e baixos, nos casos apresentados na dimensão "Uso por professores de alunos". Uma exploração in loco, permitiria avaliar em profundidade a realidade de tais instituições de ensino.

Após a remoção de tais observações, o índice de uso das TICs nas escolas não demonstrou nenhum caso de outlier, conforme pode ser constatado no gráfico de boxplot ilustrado no Gráfico 3. 
Gráfico 3 - Boxplot do índice de uso das TICs nas escolas após tratamento de outliers

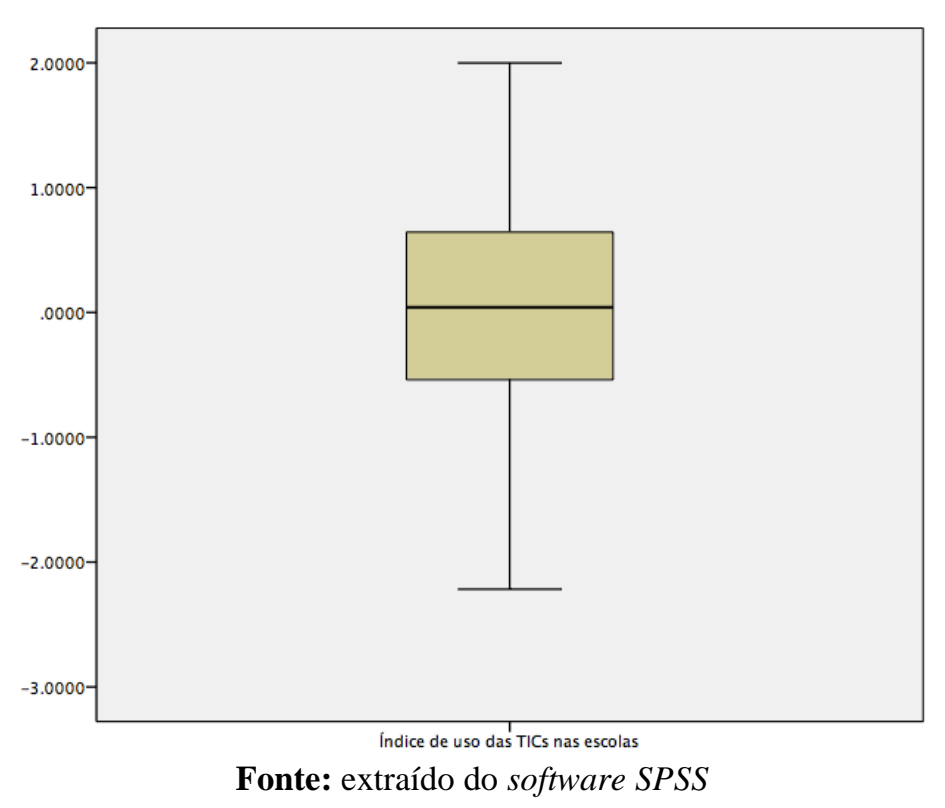

\subsubsection{Transformação das variáveis e análise das escolas da amostra}

Com o objetivo de tornar os valores obtidos mais significativos, foi realizada uma transformação de maneira que o escores fatoriais obtidos estivessem contidos no intervalo entre zero (0) e um (1).

$$
z i=\frac{x i-\min (x)}{\max (x)-\min (x)}
$$

A fórmula descrita acima considerou x como sendo o conjunto das cargas fatoriais obtidas para o índice e suas dimensões, $\min (\mathrm{x})$ como a menor e $\max (\mathrm{x})$ como a maior carga fatorial obtida para cada variável latente do modelo apresentado na seção 4.1.

Com a retirada dos outliers para a análise e a transformação das variáveis, foi possível extrair uma nova visão descritiva dos valores mínimo e máximo, bem como a média e o desvio padrão, do índice de uso das TICs nas escolas e de suas dimensões. Tais resultados podem ser analisados na Tabela 18.

Tabela 18 - Estatísticas descritivas do índice e dimensões padronizadas

\begin{tabular}{l|l|l|l|l}
\hline Variável & Total de observações & Média & Desvio Padrão & CV \\
\hline Indice de uso das TICs nas escolas & 541 & 0,5301 & 0,19849 & $37 \%$ \\
\hline Uso por professores e alunos & 541 & 0,8944 & 0,021308 & $24 \%$ \\
\hline Gestão & 541 & 0,6376 & 0,28489 & $45 \%$ \\
\hline Infraestrutura & 541 & 0,2340 & 0,17828 & $76 \%$ \\
\hline CV: Coeficiente de variação & \multicolumn{3}{|l}{}
\end{tabular}


A partir dos coeficientes de variação apresentados, é possível perceber uma alta dispersão das observações nas variáveis, isto é, os valores apresentados não se encontram próximos das médias.

Analisando as médias apresentadas pelo índice e suas dimensões, por região, a partir dos resultados descritos na Tabela 19, foi possível identificar que a única dimensão onde a dupla de regiões Sudeste-Sul não demonstrou desempenho superior às demais regiões brasileiras, foi em "Infraestrutura", pois, neste caso, a região Nordeste demonstrou maior nível médio de infraestrutura do que a região Sul.

Tabela 19 - Médias do índice e de suas dimensões por região

\begin{tabular}{|c|c|c|c|c|c|}
\hline \multirow[t]{2}{*}{ Variável } & \multicolumn{5}{|c|}{ Região } \\
\hline & Norte & Nordeste & Sudeste & Sul & Centro-Oeste \\
\hline $\begin{array}{l}\text { Indice de uso das TICs nas } \\
\text { escolas }\end{array}$ & 0,49 & 0,52 & 0,56 & 0,57 & 0,49 \\
\hline Uso por professores e alunos & 0,86 & 0,85 & 0,89 & 0,95 & 0,90 \\
\hline Gestão & 0,56 & 0,63 & 0,69 & 0,69 & 0,59 \\
\hline Infraestrutura & 0,23 & 0,25 & 0,26 & 0,24 & 0,19 \\
\hline
\end{tabular}

Fonte: Elaborado pelo autor

É possível observar no Gráfico 4, que o índice de uso e suas dimensões não demonstraram uma grande variação em suas médias, se analisados por região. A única região que se apresentou abaixo das demais, em todos quesitos, foi a região Norte. Corroborando com a constatação que o Norte é a região com menor nível médio de TIC, a pesquisa TIC Educação (CGI, 2014) descreve que apenas 47\% das escolas de tal região dispõem de energia elétrica adequada para o uso simultâneo de equipamentos elétricos. Além disso, apenas $88 \%$ das escolas do Norte que possuem computador estão conectadas à Internet (o pior desempenho entre as regiões brasileiras). 
Gráfico 4 - Médias do índice e de suas dimensões por região

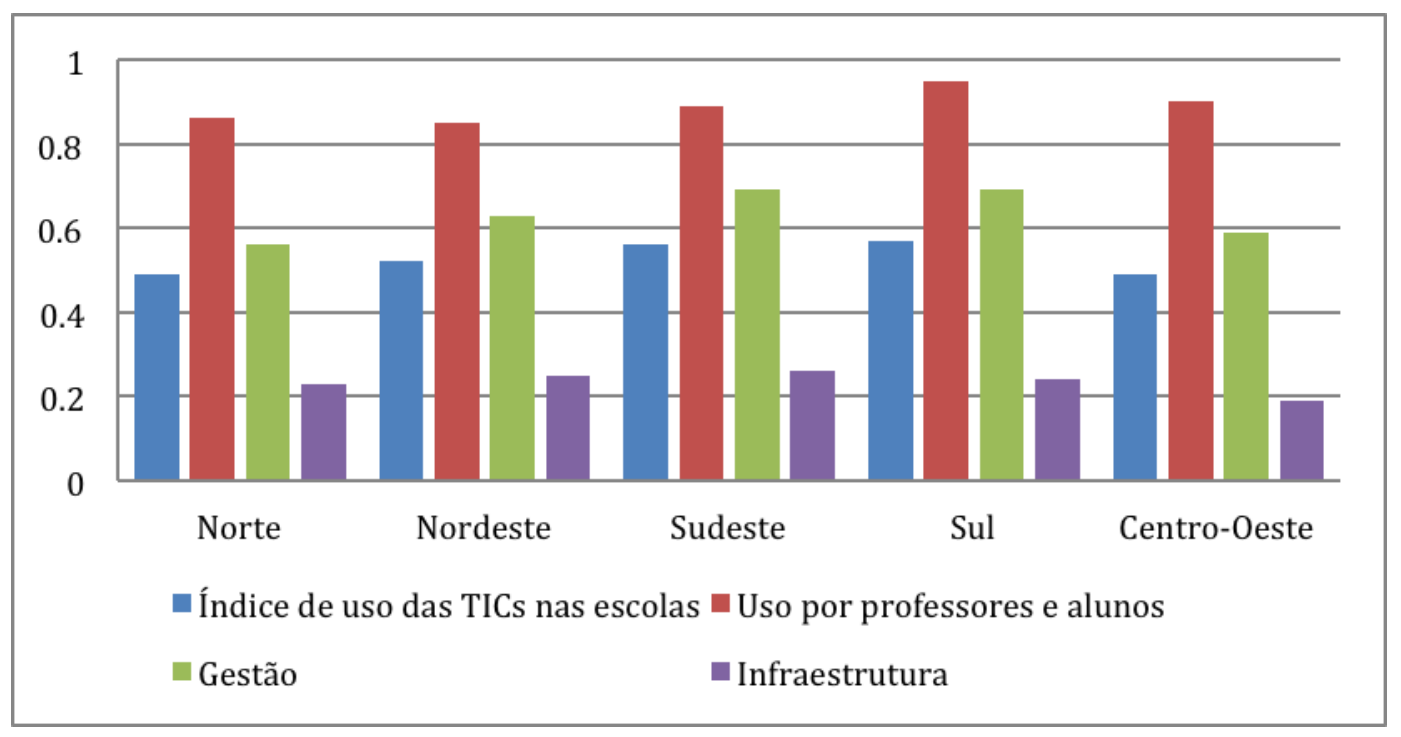

Fonte: Elaborado pelo autor

Analisando as médias apresentadas pelo índice e suas dimensões, por dependência administrativa, foi possível evidenciar melhor desempenho das escolas particulares frente às escolas municipais e estaduais, conforme descrito pela Tabela 20.

Tabela 20 - Médias do índice e de suas dimensões por dependência administrativa

\begin{tabular}{l|l|l|l}
\hline Variável & Dependência administrativa & \\
\hline & Municipal & Estadual & Particular \\
\hline Indice de uso das TICs nas escolas & 0,48 & 0,47 & 0,67 \\
\hline Uso por professores e alunos & 0,84 & 0,90 & 0,94 \\
\hline Gestão & 0,58 & 0,57 & 0,80 \\
\hline Infraestrutura & 0,20 & 0,17 & 0,37 \\
\hline
\end{tabular}

Fonte: Elaborado pelo autor

Conforme ilustrado no Gráfico 5, a única dimensão que mostrou menor diferença entre os tipos de dependência foi "Uso por professores e alunos". Complementando tal constatação, a pesquisa TIC Educação (CGI, 2014) descreve que a diferença em pontos percentuais da proporção de escolas por projeto de capacitação para professores não é grande, sendo que 30\% das escolas municipais, 40\% das escolas estaduais e $45 \%$ das escolas particulares, dizem ter projeto de capacitação para professores.

Ainda segundo a pesquisa TIC Educação (CGI, 2014), 52\% das escolas privadas possuem conexão com velocidade acima de $5 \mathrm{Mbps}$, o que significa 38 pontos percentuais a mais que a proporção das públicas. A pesquisa afirma que a velocidade de conexão à Internet apresenta-se como uma das principais limitações no âmbito da infraestrutura para as instituições públicas de ensino, pois impacta na capacidade de 
compartilhamento de informações e conteúdo de forma simultânea por diversos equipamentos e dispositivos. Cabe ressaltar, que as afirmações geradas pela pesquisa estão em total alinhamento quando observados os resultados apresentados nesta pesquisa para as médias da dimensão "Infraestrutura".

\section{Gráfico 5 - Médias do índice e de suas dimensões por dependência} administrativa

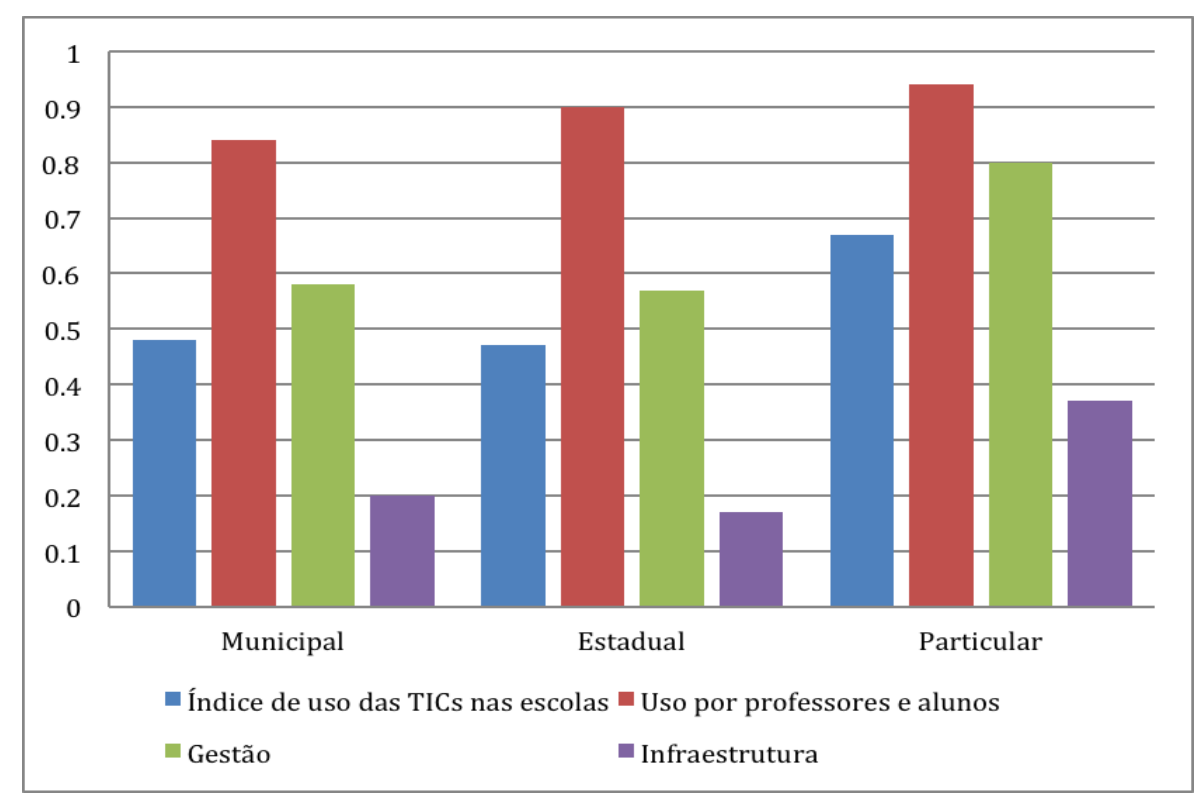

Fonte: Elaborado pelo autor

A fim de trazer uma terceira perspectiva para análise do desempenho médio no índice e de suas dimensões nas escolas da amostra, foi criada uma variável de agrupamento denominada "Faixa do IDH-M". Segundo Guimarães e Jannuzzi (2011), o IDH-M é uma versão, para os municípios, do Índice de Desenvolvimento Humano (IDH), desenvolvida, metodologicamente, pela Fundação João Pinheiro e pelo Ipea para o estudo pioneiro sobre o desenvolvimento humano nos municípios mineiros em 1996. Os autores citam que o índice foi calculado para unidades da federação, grandes regiões e Brasil, mas não é comparável ao IDH, mesmo quando esses dois índices se referem à mesma unidade geográfica e ao mesmo ano, porém, ambos os índices sintetizam as mesmas três dimensões (renda, educação e longevidade). A partir dos resultados obtidos para o IDH-M nos municípios brasileiros, disponíveis no Atlas do Desenvolvimento Humano Brasileiro (2015), foram criadas quatro (4) faixas que visaram separar os desempenhos dos munícipios no índice da seguinte maneira:

- De 0 até 0,40175: munícipios com IDH-M abaixo do percentil 25;

- Acima de 0,40175 até 0,50650: munícipios com IDH-M acima do percentil 25 até o percentil 50; 
- Acima de 0,50650 até 0,56200: munícipios com IDH-M acima do percentil 50 até o percentil 75;

- Acima de 0,56200: munícipios com IDH-M acima do percentil 75.

Mesmo reconhecendo a limitação da comparação de tal variável, afinal, o IDH-M, em sua última edição, foi calculado com dados obtidos nos censos demográficos de 1991, 2000 e 2010 e, os dados da pesquisa TIC Educação foram coletados em 2013, foi diagnosticado, a partir dos resultados apresentados na Tabela 21, que a única dimensão onde os munícipios de maior IDH-M não demonstraram desempenho médio maior se comparados com as outras faixas, foi na dimensão "Uso por professores e alunos".

Tabela 21 - Médias do índice e de suas dimensões por faixa do IDH-M

\begin{tabular}{l|l|l|l|l}
\hline Variável & \multicolumn{2}{l}{ Faixa do IDH-M } & \multicolumn{2}{l}{} \\
& De 0 até 0,40175 & $\begin{array}{l}\text { Acima de } \\
\mathbf{0 , 4 0 1 7 5} \text { até } \\
\mathbf{0 , 5 0 6 5 0}\end{array}$ & $\begin{array}{l}\text { Acima de } \\
\mathbf{0 , 5 0 6 5 0} \text { até } \\
\mathbf{0 , 5 6 2 0 0}\end{array}$ & $\begin{array}{l}\text { Acima de } \\
\mathbf{0 , 5 6 2 0 0}\end{array}$ \\
\hline $\begin{array}{l}\text { Índice de uso das } \\
\text { TICs nas escolas }\end{array}$ & 0,46 & 0,53 & 0,56 & 0,57 \\
\hline $\begin{array}{l}\text { Uso por professores } \\
\text { e alunos }\end{array}$ & 0,84 & 0,92 & 0,92 & 0,89 \\
\hline Gestão & 0,55 & 0,63 & 0,65 & 0,7 \\
\hline Infraestrutura & 0,18 & 0,22 & 0,26 & 0,27 \\
\hline
\end{tabular}

Fonte: Elaborado pelo autor

A partir dos resultados apresentados acima, é possível concluir, restringindo a extrapolação para a amostra aqui analisada, que temos um maior nível de uso das TICs no índice proposto neste trabalho e em suas dimensões, para um contexto regional Sul-Sudeste, em escolas particulares e em municípios com o IDH-M maior que 0,562 .

À luz dos resultados apresentados pelo índice de uso das TICs, torna-se possível desenvolver uma classificação, a partir de faixas criadas sobre o desempenho das escolas, para uma avaliação qualitativa. Sendo assim, de acordo com o Quadro 20, foi possível classificar as escolas da seguinte maneira. 
Quadro 20 - Classificação das escolas a partir do desempenho no índice de uso das TICs

\begin{tabular}{|l|l|l|}
\hline $\begin{array}{l}\text { Faixa do índice de uso das } \\
\text { TICs }\end{array}$ & Descrição & Classificação \\
\hline $0-0,397503$ & $\begin{array}{l}\text { Conjunto de escolas } \\
\text { abaixo do percentil 25. }\end{array}$ & Baixo uso das TICs \\
\hline $0,397503-0,535680$ & $\begin{array}{l}\text { Conjunto de escolas entre } \\
\text { o percentil 25 até o } \\
\text { percentil 50. }\end{array}$ & Uso moderado das TICs \\
\hline $0,535680-0,678611$ & $\begin{array}{l}\text { Conjunto de escolas } \\
\text { acima do percentil 50 até } \\
\text { o percentil 75. }\end{array}$ & Uso elevado das TICs \\
\hline $0,678611-1$ & $\begin{array}{l}\text { Conjunto de escolas } \\
\text { acima do percentil 75. }\end{array}$ & $\begin{array}{l}\text { Uso muito elevado das } \\
\text { TICs }\end{array}$ \\
\hline
\end{tabular}

Fonte: Elaborado pelo autor

$\mathrm{Na}$ próxima seção, serão levantadas e validadas hipóteses quanto a média do desempenho no índice de uso das TICs nas escolas, se comparadas por região geográfica, dependência administrativa ou por faixas do índice de desenvolvimento humano municipal.

\subsubsection{Identificando diferenças no índice de uso das TICs em escolas}

Como terceiro e último passo de exploração do índice, serão realizados testes estatísticos a fim de responder às seguintes hipóteses:

- Hipótese 01: Há variação no nível de uso das TICs em escolas brasileiras por região.

- Hipótese 02: Há variação no nível de uso das TICs em escolas brasileiras por tipo de dependência administrativa.

- Hipótese 03: Há variação no nível de uso das TICs em escolas brasileiras pelo índice de desenvolvimento humano municipal.

Para responder às hipóteses listadas anteriormente, será aplicada a análise da variância. Segundo Fávero et al. (2009), a ANOVA (análise de variância) representa um teste utilizado para comparar médias de mais de duas populações, buscando determinar a variabilidade da amostra. Como pressupostos, a ANOVA exige que:

- as populações possuam distribuição normal; e

- as variâncias das populações sejam iguais. 
Para a validação dos pressupostos de normalidade e de homogeneidade das variâncias entre os grupos, nas variáveis de região, de dependência administrativa e de faixa de IDH-M, serão utilizados os testes resumidos no Quadro 21. Todos os testes realizados levarão em consideração um nível de significância de 5\%.

Quadro 21 - Resumo dos testes estatísticos empregados como pressupostos da ANOVA

\begin{tabular}{|l|l|l|}
\hline Teste & Descrição & Hipótese \\
\hline Kolmogorov-Sminorv (KS) & $\begin{array}{l}\text { Teste de aderência que } \\
\text { compara a distribuição de } \\
\text { frequência acumulada de } \\
\text { um conjunto de valores } \\
\text { observados da amostra } \\
\text { com uma distribuição } \\
\text { provém de uma } \\
\text { distribuição normal. }\end{array}$ & \\
\hline Shapiro-Wilk & $\begin{array}{l}\text { Teste de normalidade que, } \\
\text { no caso de pequenas } \\
\text { amostras (n<30), é mais } \\
\text { apropriado que o KS. }\end{array}$ & $\begin{array}{l}\text { Hipótese nula: a amostra } \\
\text { provém de uma } \\
\text { distribuição normal. }\end{array}$ \\
\hline Levene & $\begin{array}{l}\text { Teste de homogeneidade } \\
\text { de variâncias exigido para } \\
\text { se comparar duas ou mais } \\
\text { populações. }\end{array}$ & $\begin{array}{l}\text { Hipótese nula: as } \\
\text { variâncias populacionais } \\
\text { são homogêneas. }\end{array}$ \\
\hline
\end{tabular}

Fonte: Elaborado pelo autor, adaptado de Fávero et al. (2009)

Ao analisar a distribuição do índice de uso das TICs por região, através dos histogramas apresentados no Gráfico 6 , é possível perceber uma concentração das escolas da região Norte à esquerda da distribuição, isto é, com nível de uso das TICs abaixo de 0,5, além das regiões Sudeste e Sul com uma elevada concentração das escolas em níveis maiores de nível de uso. 


\section{Gráfico 6 - Histograma da distribuição do índice de uso das TICs por região}

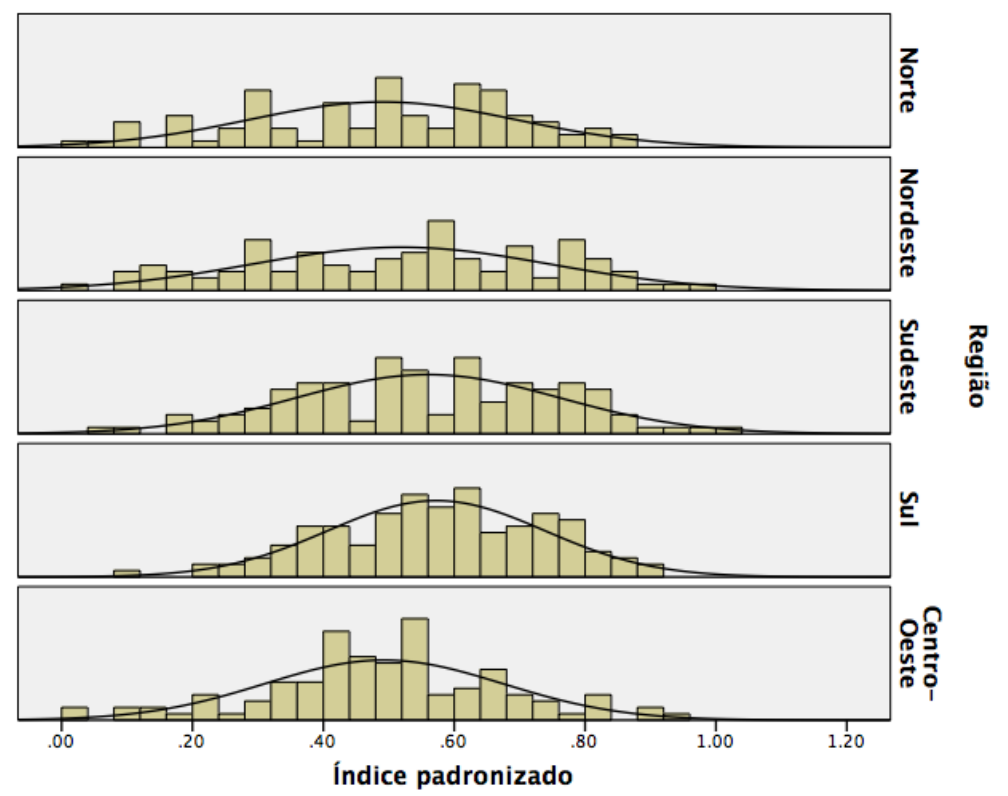

Fonte: Elaborado pelo autor, extraído do software SPSS

Os testes a fim de validar os pressupostos de normalidade para cada região e de homogeneidade das variâncias entre as regiões, são apresentados nos Quadros 22 e 23.

Quadro 22 - Teste de normalidade para as regiões

\begin{tabular}{|l|l|l|l|}
\hline & \multirow{2}{*}{ Região } & Kolmogorov-Smirnov $^{\mathbf{a}}$ & Shapiro-Wilk $^{-}$ \\
\cline { 2 - 4 } & & Sig. & Sig. \\
\hline \multirow{5}{*}{ Índice de uso das TICs } & Norte & 0,058 & 0,052 \\
\cline { 2 - 4 } & Nordeste & 0,200 & 0,069 \\
\cline { 2 - 4 } & Sudeste & 0,200 & 0,492 \\
\cline { 2 - 4 } & Sul & 0,200 & 0,316 \\
\cline { 2 - 4 } & Centro-Oeste & 0,152 & 0,308 \\
\hline
\end{tabular}

Fonte: extraído do software SPSS

\section{Quadro 23 - Teste de homogeneidade das variâncias entre as regiões}

\begin{tabular}{|l|l|l|l|}
\hline Índice de uso das TICs \\
\hline Levene Statistic & df1 & df2 & Sig. \\
\hline 4.908 & 4 & 536 & 0,001 \\
\hline
\end{tabular}

Fonte: Extraído do software SPSS

A estatística do teste apresentada no Quadro 22, para um nível de significância de 0,05, apresenta normalidade na distribuição do índice de uso das TICs para cada região (todos os valores de sig. são superiores a 0,05), no entanto, o teste de Levene demonstra que as variâncias não são homogêneas (o valor de Sig. é menor do que 0,05). Diante do cenário em que não há a possibilidade da aplicação da ANOVA, pois, um dos pressupostos da técnica foi rejeitado, buscou-se encontrar um teste não 
paramétrico (com menos hipóteses sobre os dados) para identificar a diferença do índice de uso das TICs nas regiões.

Segundo Fávero et al. (2009), o teste de Kruskal-Wallis verifica a probabilidade de $k$ amostras $(k>2)$ independentes serem provenientes da mesma população. Este teste deve ser aplicado nos casos em que a amostra for pequena e/ou os pressupostos exigidos pela ANOVA forem violados. Cabe ressaltar que a hipótese nula do teste afirma que a distribuição das $k$ amostras são iguais, sendo assim, tal teste visa rejeitar tal hipótese para afirmar que há diferença entre as amostras (FÁVERO et al., 2009). Os resultados do teste de Kruskal-Wallis para as regiões, ao nível de significância de 5\%, são ilustrados no Quadro 24.

Quadro 24 - Estatística do teste de Kruskal-Wallis para as regiões

\begin{tabular}{|l|l|}
\hline Qui-quadrado & 15,452 \\
\hline df & 4 \\
\hline Asymp. Sig. & .004 \\
\hline a. Kruskal Wallis Test \\
\hline \multicolumn{2}{|l|}{ b. Variável de agrupamento: Região } \\
\hline
\end{tabular}

Fonte: Extraído do software SPSS

De acordo com o quadro acima, a estatística do teste (sig.) é de 0,004 , como tal valor é menor do 0,05 , é possível rejeitar a hipótese nula e concluir que há diferenças nas distribuições das amostras, ou seja, há diferença no índice de uso das TICs entre as regiões.

A fim de se identificar em quais regiões as diferenças no índice são significativas, aplicou-se o teste de comparação múltipla de Dunn. Entre os testes de comparações múltiplas não paramétricos destacam-se os propostos por Steel e por Dunn, não havendo uma clara vantagem de um sobre outro (STEEL, 1960 ; DUNN; 1964 apud PONTES; CORRENTE, 2001). Para cada par de região, exemplo, região Sul e região Sudeste, é testada a hipótese nula das medianas serem iguais, neste caso, o objetivo é que seja rejeitada tal hipótese.

Os resultados do teste das comparações múltiplas de Dunn, ao nível de significância de 5\%, para cada par de região, são ilustrados na Tabela 22. 
Tabela 22 - P-value do teste das comparações múltiplas de Dunn para as regiões

\begin{tabular}{l|l|l|l|l}
\hline & Norte & Nordeste & Sudeste & Sul \\
\hline Nordeste & 1,00 & & & \\
\hline Sudeste & 0,15 & 1,00 & & \\
\hline Sul & 0,03 & 0,31 & 1,00 & \\
\hline Centro-Oeste & 1,00 & 1,00 & 0,05 & 0,01 \\
\hline
\end{tabular}

Fonte: Extraído do software Stata

As combinações regionais que apresentaram diferenças significantes quanto ao índice de uso das TICs, destacadas em negrito na tabela acima, foram: Sul e Norte; CentroOeste e Sudeste; e Centro-Oeste e Sul.

Corroborando com a ideia de que as escolas da região Sul, neste estudo analisadas, possuem nível de uso das TICs diferenciado, é possível observar na Tabela 23 que $60 \%$ das escolas da amostra que se situam nesta região, estão classificadas como aquelas que fazem uso elevado ou muito elevado das TICs. Em outra perspectiva de análise e ainda seguindo os resultados da Tabela 23, é possível observar que mais de $50 \%$ das escolas da amostra localizadas nas regiões Norte e Centro-Oeste, fazem uso moderado ou baixo das TICs.

Tabela 23 - Regiões por nível de uso das TICs

\begin{tabular}{l|l|l|l|l}
\hline Região & $\begin{array}{l}\text { Baixo uso das } \\
\text { TICs }\end{array}$ & $\begin{array}{l}\text { Uso moderado das } \\
\text { TICs }\end{array}$ & $\begin{array}{l}\text { Uso elevado das } \\
\text { TICs }\end{array}$ & $\begin{array}{l}\text { Uso muito elevado das } \\
\text { TICs }\end{array}$ \\
\hline Norte & $30,40 \%$ & $25,00 \%$ & $26,10 \%$ & $18,50 \%$ \\
\hline Nordeste & $33,70 \%$ & $13,30 \%$ & $23,50 \%$ & $29,60 \%$ \\
\hline Sudeste & $23,70 \%$ & $22,90 \%$ & $21,20 \%$ & $32,20 \%$ \\
\hline Sul & $16,80 \%$ & $23,20 \%$ & $31,20 \%$ & $28,80 \%$ \\
\hline $\begin{array}{l}\text { Centro- } \\
\text { Oeste }\end{array}$ & $23,10 \%$ & $40,70 \%$ & $22,20 \%$ & $13,90 \%$ \\
\hline
\end{tabular}

Fonte: Elaborado pelo autor

Ao analisar a distribuição do índice por dependência administrativa, através dos histogramas apresentados no Gráfico 7, é possível perceber algumas diferenças entre as distribuições, em especial, a concentração de escolas da rede particular que demonstram valores no índice acima do ponto médio de 0,5 . 
Gráfico 7 - Histograma da distribuição do índice de uso das TICs por dependência administrativa

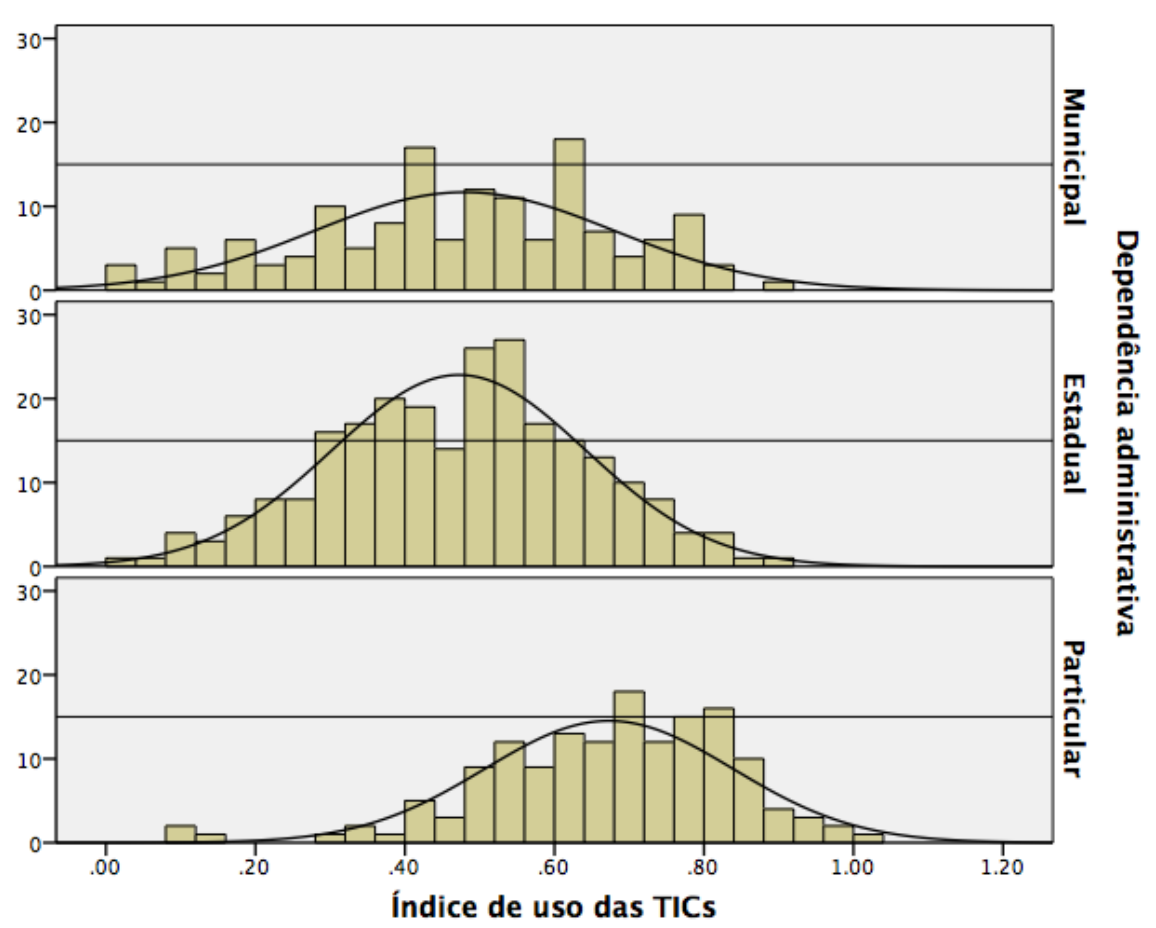

Fonte: Elaborado pelo autor, extraído do software SPSS

A fim de testar a hipótese da existência de variação no nível de uso das TICs em escolas brasileiras por tipo de dependência administrativa e de respeitar os pressupostos do teste da ANOVA, foram validadas a normalidade para cada dependência administrativa e a homogeneidade das variâncias entre as dependências, conforme apresentado nos Quadros 25 e 26, respectivamente.

Quadro 25 - Teste de normalidade para as dependências administrativas

\begin{tabular}{|c|c|c|c|}
\hline & $\begin{array}{l}\text { Dependência } \\
\text { administrativa }\end{array}$ & $\begin{array}{l}\text { Kolmogorov- } \\
\text { Smirnov }^{\text {a }}\end{array}$ & Shapiro-Wilk \\
\hline & & Sig. & Sig. \\
\hline \multirow{3}{*}{$\begin{array}{l}\text { Índice de uso das } \\
\text { TICs }\end{array}$} & Municipal & 0,200 & 0,077 \\
\hline & Estadual & 0,200 & 0,783 \\
\hline & Particular & 0,200 & 0,000 \\
\hline
\end{tabular}

Fonte: Extraído do software SPSS

Quadro 26 - Teste de homogeneidade das variâncias entre as dependências administrativas

\begin{tabular}{|l|l|l|l|}
\hline Indice de uso das TICs \\
\hline Levene Statistic & df1 & df2 & Sig. \\
\hline 4,281 & 2 & 538 & 0,014 \\
\hline
\end{tabular}
Fonte: Extraído do software SPSS


A estatística do teste de normalidade de Kolmogorov-Smirnova e Shapiro-Wilk para as dependências municipal e estadual foi superior a 0,05, no entanto, a partir do resultado apresentado no teste de Shapiro-Wilk, para as escolas particulares, não foi possível afirmar normalidade (sig. menor do que 0,05). Além disso, foi possível concluir a partir dos resultados do teste de Levene, que as variâncias apresentadas não são homogêneas (sig menor do que 0,05). Assim como foi realizado para a análise das regiões, para que seja possível investigar a existência da diferença do nível de uso das TICs por dependência administrativa, foi realizado o teste não paramétrico de Kruskal-Wallis. Os resultados do teste, ao nível de significância de 5\%, são ilustrados no Quadro 27.

\section{Quadro 27 - Estatística do teste de Kruskal-Wallis para as dependências} administrativas

\begin{tabular}{|l|l|}
\hline Qui-quadrado & 114,1962 \\
\hline df & 2 \\
\hline Sig. & 0,000 \\
\hline a. Kruskal Wallis Test \\
\hline b. Variável de agrupamento: Dependência administrativa \\
\hline
\end{tabular}

De acordo com o quadro acima, a estatística do teste de Kruskal Wallis é de 0,000, como tal valor é menor do 0,05 , é possível rejeitar a hipótese nula, o que permite concluir que há diferença nas distribuições das amostras, ou seja, há diferença no índice de uso das TICs nas diferentes dependências administrativas.

A fim de identificar em quais dependências as diferenças são significativas, aplicouse o teste Dunn. Os resultados do teste das comparações, ao nível de significância de 5\%, para cada par de dependência, são descritos na Tabela 24.

Tabela 24 - P-value do teste das comparações múltiplas de Dunn para as dependências administrativas

\begin{tabular}{l|l|l}
\hline & Municipal & Estadual \\
\hline Estadual & 0,6811 & \\
\hline Particular & 0,0000 & 0,0000 \\
\hline
\end{tabular}

Fonte: Extraído do software Stata

A partir dos resultados apresentados pelo teste de Dunn, foi possível concluir que as escolas particulares demonstraram diferenças significativas quando comparadas com as escolas municipais e estaduais.

Os resultados obtidos pelo teste podem ser também complementados a partir das informações apresentadas na Tabela 25, pois, qualitativamente, é possível observar 
que $80,10 \%$ das escolas particulares da amostra estão classificadas como fazendo uso elevado ou muito elevado das TICs. Os resultados demonstraram que, dentro das escolas analisadas, aquelas que são particulares possuem maior nível de uso das TICs.

Tabela 25 - Dependências administrativas por nível de uso das TICs

\begin{tabular}{l|l|l|l|l}
\hline $\begin{array}{l}\text { Dependência } \\
\text { administrativa }\end{array}$ & $\begin{array}{l}\text { Baixo uso das } \\
\text { TICs }\end{array}$ & $\begin{array}{l}\text { Uso moderado } \\
\text { das TICs }\end{array}$ & $\begin{array}{l}\text { Uso elevado das } \\
\text { TICs }\end{array}$ & $\begin{array}{l}\text { Uso muito elevado } \\
\text { das TICs }\end{array}$ \\
\hline Municipal & $31,30 \%$ & $29,30 \%$ & $22,40 \%$ & $17,00 \%$ \\
\hline Estadual & $34,20 \%$ & $28,40 \%$ & $25,90 \%$ & $11,50 \%$ \\
\hline Particular & $4,00 \%$ & $15,90 \%$ & $54,30 \%$ \\
\hline \multicolumn{5}{r}{ Fonte: Elaborado pelo autor }
\end{tabular}

Concluindo a análise univariada do índice de uso, ao compreender a distribuição do índice por faixa de IDH-M, através dos histogramas apresentados no Gráfico 8, é possível perceber que, conforme as faixas de IDH-M aumentam, as escolas passam a ter melhor desempenho no índice.

\section{Gráfico 8 - Histograma da distribuição do índice de uso das TICs por faixa de}

\section{IDH-M}

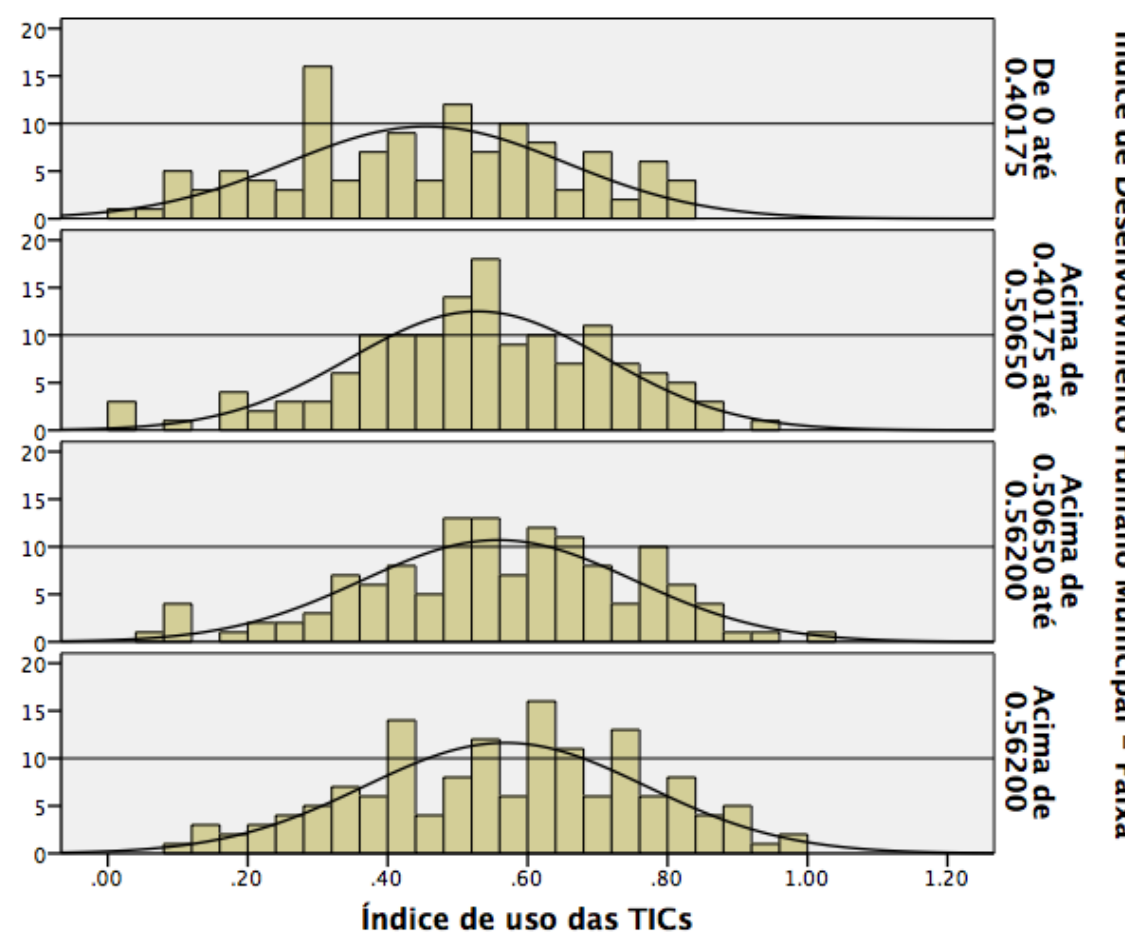

Fonte: Elaborado pelo autor, extraído do software SPSS

A fim de testar a hipótese da existência de variação no nível de uso das TICs em escolas brasileiras por faixa de IDH-M e de respeitar os pressupostos do teste da ANOVA, foram testadas a normalidade para cada faixa de IDH-M e a homogeneidade das variâncias entre as faixas, conforme descrito nos Quadros 28 e 29. 
Quadro 28 - Teste de normalidade para as faixas de IDH-M

\begin{tabular}{|c|c|c|c|}
\hline & $\begin{array}{l}\text { Índice de Desenvolvimento } \\
\text { Humano Municipal - Faixa }\end{array}$ & $\begin{array}{l}\text { Kolmogorov- } \\
\text { Smirnov }\end{array}$ & Shapiro-Wilk \\
\hline & & Sig. & Sig. \\
\hline \multirow{4}{*}{$\begin{array}{l}\text { Índice de uso } \\
\text { das TICs }\end{array}$} & De 0 até 0.40175 & 0,160 & 0,093 \\
\hline & $\begin{array}{l}\text { Acima de } 0.40175 \text { até } \\
0.50650\end{array}$ & 0,200 & 0,086 \\
\hline & $\begin{array}{l}\text { Acima de } 0.50650 \text { até } \\
0.56200\end{array}$ & 0,200 & 0,127 \\
\hline & Acima de 0.56200 & 0,200 & 0,128 \\
\hline
\end{tabular}

Quadro 29 - Teste de homogeneidade das variâncias entre as faixas de IDH-M

\begin{tabular}{|l|l|l|l|}
\hline Índice de uso das TICs \\
\hline Levene Statistic & df1 & df2 & Sig. \\
\hline 1,568 & 3 & 537 & 0,196 \\
\hline
\end{tabular}

Fonte: Extraído do software SPSS

$\mathrm{O}$ teste de normalidade para todas as faixas demonstrou-se superior a 0,05. Além disso, foi possível concluir, a partir dos resultados do teste de Levene, que as variâncias apresentadas são homogêneas (Sig. maior do que 0,05), sendo assim, os dois pressupostos necessários para a realização da ANOVA foram atendidos e, dessa forma, a técnica pôde ser aplicada.

Quadro 30 - ANOVA para a média de uso das TICs nas diferentes faixas do

IDH-M

\begin{tabular}{|l|l|l|l|l|l|}
\hline & $\begin{array}{l}\text { Soma dos } \\
\text { quadrados }\end{array}$ & Df & Valor médio & F & Sig. \\
\hline Between Groups & 0,992 & 3 & 0,331 & 8,759 & 0,000 \\
\hline Within Groups & 20,282 & 537 & 0,038 & & \\
\hline Total & 21,274 & 540 & & & \\
\hline \multicolumn{7}{|c|}{ Fonte: Extraído do software SPSS } \\
\hline
\end{tabular}

O Sig. apresentado no teste de ANOVA e descrito no Quadro 30, foi de 0,000, valor inferior a 0,05 , o que leva a rejeição da hipótese nula, concluindo que pelo menos uma das médias populacionais é diferente das demais, isto é, há diferença no índice de uso das TICs nas faixas de IDH-M analisadas.

A fim de identificar em quais faixas as diferenças no nível de uso são significativas e como foi possível aplicar a técnica de ANOVA, aplicou-se o teste de comparação múltipla de Bonferroni. Os resultados do teste das comparações, ao nível de significância de 5\%, para cada faixa de IDH-M, são ilustrados no Quadro 31. 
Quadro 31 - Resultados do teste de Bonferroni para as faixas do IDH-M

Variável dependente: Índice de uso das TICs

Teste de Bonferroni

\begin{tabular}{|l|l|l|}
\hline IDH-M- Faixa & IDH-M- Faixa & Sig. \\
\hline \multirow{4}{*}{ De 0 até 0.40175} & Acima de 0.40175 até 0.50650 & 0,014 \\
\hline & Acima de 0.50650 até 0.56200 & 0,000 \\
\cline { 2 - 3 } Acima de 0.40175 até 0.50650 & Acima de 0.56200 & 0,000 \\
\hline \multirow{3}{*}{ Acima de 0.50650 até 0.56200} & De até 0.40175 & 0,014 \\
\cline { 2 - 3 } & Acima de 0.50650 até 0.56200 & 1,000 \\
\cline { 2 - 3 } & Acima de 0.56200 & 0,514 \\
\hline \multirow{3}{*}{ Acima de 0.56200} & De 0 até 0.40175 & 0,000 \\
\cline { 2 - 3 } & Acima de 0.40175 até 0.50650 & 1,000 \\
\cline { 2 - 3 } & Acima de 0.56200 & 1,000 \\
\hline & De 0 até 0.40175 & 0,000 \\
\cline { 2 - 3 } & Acima de 0.40175 até 0.50650 & 0,514 \\
\cline { 2 - 3 } & Acima de 0.50650 até 0.56200 & 1,000 \\
\hline
\end{tabular}

Fonte: Extraído do software SPSS

A partir dos resultados apresentados pelo quadro acima, é possível concluir que as escolas localizadas na menor faixa de IDH-M (de 0 até 0.40175 ) possuem nível médio de TIC significantemente diferente se comparadas com todas as outras faixas.

Objetivando-se explorar a afirmação acima, é possível observar nos resultados apresentados na Tabela 26 que apenas $15,7 \%$ das escolas analisadas, que se encontram na menor faixa de IDH-M, demonstraram nível de uso das TICs elevado, além disso, 40,5\% demonstraram baixo nível de uso. Comparativamente, apenas $21 \%$ das escolas localizadas em munícipios com um IDH-M entre 0,40175 até 0,50650, isto é, a segunda pior faixa do IDH-M, apresentaram baixo uso das TICs, demonstrando uma diferença positiva de 19,5 pontos percentuais para o pior nível de IDH-M.

Tabela 26 - Faixa de IDH-M por nível de uso das TICs

\begin{tabular}{l|l|l|l|l}
\hline & \multicolumn{3}{|l}{ Faixa do índice de uso das TICs } \\
\hline $\begin{array}{l}\text { Índice de Desenvolvimento } \\
\text { Humano Municipal - Faixa }\end{array}$ & $\begin{array}{l}\text { Baixo uso } \\
\text { das TICs }\end{array}$ & $\begin{array}{l}\text { Uso } \\
\text { moderado } \\
\text { das TICs }\end{array}$ & $\begin{array}{l}\text { Uso elevado } \\
\text { das TICs }\end{array}$ & $\begin{array}{l}\text { Uso muito } \\
\text { elevado das } \\
\text { TICs }\end{array}$ \\
\hline De 0 até $\mathbf{0 . 4 0 1 7 5}$ & $40,50 \%$ & $21,50 \%$ & $22,30 \%$ & $15,70 \%$ \\
\hline Acima de $\mathbf{0 . 4 0 1 7 5}$ até $\mathbf{0 . 5 0 6 5 0}$ & $21,00 \%$ & $32,20 \%$ & $23,80 \%$ & $23,10 \%$ \\
\hline Acima de $\mathbf{0 . 5 0 6 5 0}$ até $\mathbf{0 . 5 6 2 0 0}$ & $19,20 \%$ & $26,20 \%$ & $25,40 \%$ & $29,20 \%$ \\
\hline Acima de $\mathbf{0 . 5 6 2 0 0}$ & $21,10 \%$ & $20,40 \%$ & $27,90 \%$ & $30,60 \%$ \\
\hline
\end{tabular}

Fonte: Elaborado pelo autor

A partir dos resultados apresentados nesta seção, foi possível comprovar diferenças do nível de uso das TICs nas escolas levantadas neste estudo a partir da perspectiva regional, administrativa e de desenvolvimento humano municipal. 
Os dados apresentaram uma discrepância quanto ao uso quando compara-se a região Sul-Sudeste com a região Centro-Oeste, bem como a região Sul com a região Norte. Além disso, foi possível comprovar uma evidente diferença entre o nível de uso das TICs entre as escolas particulares e públicas (municipais e estaduais). Por fim, foi observado que as escolas localizadas em munícipios com baixo IDH-M (entre 0 e 0,40175), apresentaram pior desempenho no nível de uso das TICs.

Na próxima seção, serão levantados fatores que podem diferenciar um maior e menor nível de uso das TICs pelas escolas analisadas.

\subsection{Avaliando fatores que diferenciam o uso das TICs nas escolas}

A partir dos indicadores coletados pela pesquisa TIC Educação, será apresentado nesta seção um conjunto de fatores que diferenciam os desempenhos apresentados pelas escolas no índice de uso das TICs. Para fins de análise, será utilizada a técnica multivariada de regressão logística.

Segundo Hair Jr et al. (2010), a regressão logística é uma técnica de análise multivariada utilizada para aferição da probabilidade de ocorrência de um evento e para identificação das características dos elementos pertencentes a cada categoria estabelecida pela dicotomia da variável dependente. Ao contrário da análise discriminante, não exige a suposição da normalidade das variáveis independentes e é mais robusta quando a mesma não é atendida.

Segundo Fávero et al. (2009), a regressão logística assume as seguintes premissas:

- Relação entre o vetor das variáveis explicativas é igual a zero;

- Valor esperado dos resíduos é igual a zero;

- Ausência de heterocedasticidade;

- Ausência de multicolinearidade.

Diferentemente da análise de regressão múltipla e da análise discriminante, a regressão logística não pressupõe normalidade dos resíduos. Isso acaba representando, quando da aplicação daquelas técnicas, uma grande limitação, uma vez que, na presença de muitas variáveis dicotômicas, este pressuposto acaba sendo violado. Além disso, a regressão logística não tem como pressuposto homogeneidade de variância (Fávero et al., 2009).

A variável dependente binária do modelo denominada "uso elevado das TICs" foi 
criada a partir das faixas apresentadas no Quadro 21, sendo assim, foram agrupadas na categoria "Sim", escolas que se enquadraram nas faixas "Uso elevado" e "Uso muito elevado". Para a categoria "Não", foram alocadas as escolas que se enquadraram nas faixas "Uso moderado" e "Baixo uso".

As variáveis independentes, aqui identificadas como fatores, são descritas no Quadro 32 e foram selecionadas a partir das dimensões desenvolvidas para o índice de uso descritas na AFE apresentada na seção 4.1. Cabe ressaltar, que o critério utilizado para a seleção baseou-se na comunalidade, isto é, foram selecionadas variáveis que demonstraram maior poder de explicação pelas dimensões desenvolvidas. A variável “Total de computadores instalados e funcionando que estão disponíveis para uso pedagógico dos alunos", foi transformada em uma variável categórica ordinal, sendo suas faixas definidas a partir dos quartis.

Quadro 32 - Variáveis independentes do modelo logístico

\begin{tabular}{|l|l|l|}
\hline Variável & Tipo & Categorias \\
\hline $\begin{array}{l}\text { A Internet da escola é utilizada pelos } \\
\text { professores em atividades de ensino- } \\
\text { aprendizagem com os alunos? }\end{array}$ & Binária & $\begin{array}{l}0=\text { "Não" } \\
1=\text { "Sim" }\end{array}$ \\
\hline $\begin{array}{l}\text { O projeto pedagógico da escola estimula ou } \\
\text { requer os professores a integração do uso da } \\
\text { Internet em suas práticas? }\end{array}$ & Binária & $\begin{array}{l}0=\text { "Não" } \\
1=\text { "Sim" }\end{array}$ \\
\hline $\begin{array}{l}\text { Grau de concordância com a afirmação de } \\
\text { que a escola integrou o computador e a } \\
\text { Internet às práticas de ensino-aprendizagem. }\end{array}$ & Binária & $\begin{array}{l}0=\text { "Não" } \\
1=\text { "Sim" }\end{array}$ \\
\hline $\begin{array}{l}\text { Total de computadores instalados e } \\
\text { funcionando que estão disponíveis para uso } \\
\text { pedagógico dos alunos. }\end{array}$ & Ordinal & $\begin{array}{l}1=\text { "Até } 14 \text { computadores" } \\
2=\text { "De } 14 \text { até } 22 \text { computadores" } \\
3=\text { "De 22 até } 34 \text { computadores" } \\
4=\text { "Mais de } 34 \text { computadores" }\end{array}$ \\
\hline $\begin{array}{l}\text { Esta escola proporciona aulas específicas de } \\
\text { informática, que ensinem a usar computador } \\
\text { e Internet como parte da grade curricular? }\end{array}$ & Binária & $\begin{array}{l}0=\text { "Não" } \\
1=\text { "Sim" }\end{array}$ \\
\hline $\begin{array}{l}\text { Grau de concordância com a afirmação de } \\
\text { que nesta escola, há treinamento para os } \\
\text { alunos, de como se usa computador e }\end{array}$ & Binária \\
$\begin{array}{l}\text { Internet. } \\
\text { Grau de concordância com a afirmação de } \\
\text { que nesta escola, há treinamento para os } \\
\text { professores, de como se usa computador e } \\
\text { Internet. }\end{array}$ & Binária & $\begin{array}{l}0=\text { "Não" } \\
1=\text { "Sim" }\end{array}$ \\
\hline
\end{tabular}

Fonte: Elaborado pelo autor

A fim de validar a ausência de multicolinearidade, serão utilizadas as estatísticas VIF (Variance Inflation Factor) e Tolerância. Segundo Fávero et al. (2009), a VIF é uma medida de quanto a variância de cada coeficiente de regressão estimado aumenta devido a multicolinearidade. Já a Tolerância, indica a proporção da variação de uma variável explicativa que independe das outas variáveis explicativas. Em geral, quando o valor da estatística VIF for acima de 10, há indícios de alta relação linear e 
problemas graves de multicolinearidade.

O Quadro 33 demonstra os resultados obtidos para as estatísticas de VIF e Tolerância. Os valores foram obtidos através do software Stata, versão 12.

Quadro 33 - Diagnóstico de multicolinearidade

\begin{tabular}{|l|l|l|}
\hline Variável & VIF & Tolerância \\
\hline p44 & 1,10 & 0,9091 \\
\hline p2301_bin & 1,02 & 0,9780 \\
\hline p2901_bin & 1,20 & 0,8367 \\
\hline p2905_faixa & 1,10 & 0,9094 \\
\hline p26_coordenador & 1,32 & 0,7591 \\
\hline p2904_bin & 1,26 & 0,7944 \\
\hline p2903_bin & 1,54 & 0,6481 \\
\hline
\end{tabular}

Fonte: Elaborado pelo autor, extraído do software Stata

A partir dos resultados apresentados acima, é possível concluir que não há alta relação linear entre as variáveis, bem como não há problemas graves de multicolinearidade, afinal, a estatística VIF apresentou valores inferiores a dez (10). Tal constatação valida a execução da regressão logística.

O modelo foi estimado a partir do método forward Wald no software SPSS. Em tal método, o software automaticamente propõe a melhor solução com a inclusão de variáveis significantes e a exclusão de variáveis não significantes (Fávero et al., 2009).

O procedimento stepwise forward Wald, com critério de entrada que o teste de Wald fosse significante a $5 \%$, precisou de sete (7) passos para convergir. A estatística -2LL variou de 498,662 do modelo sem intercepto (estágio 0) para 243,45 (estágio 7), conforme demonstrado no Quadro 34.

Quadro 34 - R2 e -2LL dos modelos logísticos, por passos, para o modelo inicial

\begin{tabular}{|l|l|l|l|}
\hline Passo & -2 Log likelihood & Cox \& Snell Nagelkerke \\
\hline 1 & 498,662 & 0,372 & 0,495 \\
\hline 2 & 406,655 & 0,470 & 0,626 \\
\hline 3 & 340,670 & 0,531 & 0,708 \\
\hline 4 & 285,223 & 0,576 & 0,769 \\
\hline 5 & 260,489 & 0,595 & 0,794 \\
\hline 6 & 246,672 & 0,606 & 0,807 \\
\hline 7 & 243,454 & 0,608 & 0,811 \\
\hline
\end{tabular}

Fonte: Elaborado pelo autor, extraído do software SPSS

A partir dos resultados apresentados acima, é possível afirmar que o poder explicativo do modelo ou pseudo-R2, foi de $81,1 \%$.

Por sua vez, o teste de Hosmer-Lemeshow apresentado no Quadro 35 e que mede a 
qualidade do ajuste de um modelo logístico a partir da correspondência entre os valores previstos e efetivos da variável dependente em decis da probabilidade estimada (Fávero et al., 2009), teve a hipótese nula rejeitada (Sig. < 0,10), sendo assim, as variáveis incluídas no modelo não contribuíram para uma grande aderência das previsões aos valores reais. Segundo Fávero et al. (2009), cabe, porém, ressaltar que a aplicabilidade deste teste é limitada, já que seus resultados são mais consistentes quando a amostra apresenta grandes dimensões.

\section{Quadro 35 - Teste de Hosmer Lemeshow para o modelo inicial}

\begin{tabular}{|l|l|l|l|}
\hline Passo & Qui-quadrado & df & Sig. \\
\hline 1 & 0,000 & 0 & \\
\hline 2 & 1,019 & 6 & 0,985 \\
\hline 3 & 12,809 & 8 & 0,119 \\
\hline 4 & 6,342 & 8 & 0,609 \\
\hline 5 & 3,456 & 8 & 0,903 \\
\hline 6 & 7,612 & 8 & 0,472 \\
\hline 7 & 17,396 & 8 & 0,026 \\
\hline \multicolumn{7}{|c|}{ Fonte: Elaborado pelo autor, extraído do software SPSS } \\
\hline
\end{tabular}

Classificando como de uso elevado as escolas com probabilidade estimada maior que 0,5, a Tabela 27 mostra que o modelo acertou 90,8\% das previsões. É possível observar que o modelo tende a acertar mais escolas que encontram-se no grupo de uso elevado das TICs (percentual de acerto de 93,3\%).

Tabela 27 - Tabela de classificação do modelo logístico inicial

\begin{tabular}{|c|c|c|c|c|}
\hline \multirow{2}{*}{\multicolumn{2}{|c|}{ Observado }} & \multicolumn{2}{|c|}{ Uso elevado das TICs } & \multirow{3}{*}{$\begin{array}{l}\text { Percentual de acerto } \\
88,2 \%\end{array}$} \\
\hline & & \multirow{2}{*}{$\frac{\text { Não }}{246}$} & \multirow{2}{*}{\begin{tabular}{|l|} 
Sim \\
25 \\
\end{tabular}} & \\
\hline Uso elevado das & Não & & & \\
\hline TICs & Sim & 25 & 245 & $93,3 \%$ \\
\hline \multicolumn{2}{|l|}{ Total } & & & $90,8 \%$ \\
\hline
\end{tabular}

Fonte: Elaborado pelo autor, extraído do software SPSS

A fim de validar a qualidade da classificação do modelo, foi realizado o teste estatístico Press' Q.

Para fins de referência, o valor da estatística qui-quadrado para um nível de significância de 0,01 com um grau de liberdade é igual a 6,63. Como Press' Q calculado do modelo $(360,23)$ é maior do que 6,63, tem-se que as previsões obtidas são significativamente melhores do que as chances ao acaso.

Ao fim de sete passos, considerando um nível de significância de 5\%, o processo forward Wald selecionou para compor o modelo as variáveis descritas no Quadro 36. 
Quadro 36 - Modelo de regressão logística inicial

\begin{tabular}{|l|l|l|l|l|}
\hline Variáveis & B & Wald & Sig. & Exp(B) \\
\hline $\begin{array}{l}\text { Na escola há treinamento para os } \\
\text { professores, de como se usa computador e } \\
\text { Internet. }\end{array}$ & 2,504 & 38,029 & 0 & 12,228 \\
\hline $\begin{array}{l}\text { Na escola há treinamento para os alunos, de } \\
\text { como se usa computador e Internet. }\end{array}$ & 3,153 & 62,264 & 0 & 23,401 \\
\hline $\begin{array}{l}\text { A Internet da escola é utilizada pelos } \\
\text { professores em atividades de ensino- } \\
\text { aprendizagem com os alunos. }\end{array}$ & 4,131 & 12,175 & 0 & 62,248 \\
\hline $\begin{array}{l}\text { A escola proporciona aulas específicas de } \\
\text { informática, que ensinem a usar computador } \\
\text { e Internet como parte da grade curricular. }\end{array}$ & 3,747 & 57,21 & 0 & 42,377 \\
\hline $\begin{array}{l}\text { O projeto pedagógico da escola estimula ou } \\
\text { requer os professores a integração do uso da } \\
\text { Internet em suas práticas. }\end{array}$ & 4,658 & 1,747 & 0,186 & 105,39 \\
\hline $\begin{array}{l}\text { A escola integrou o computador e a Internet } \\
\text { às práticas de ensino-aprendizagem. }\end{array}$ & 3,054 & 16,993 & 0 & 21,198 \\
\hline $\begin{array}{l}\text { Faixa de computadores para uso } \\
\text { pedagógico (referência = até 14 } \\
\text { computadores) }\end{array}$ & & 48,552 & 0 & \\
\hline De 14 até 22 computadores & 0,025 & 0,003 & 0,955 & 1,026 \\
\hline De 22 até 34 computadores & 1,734 & 12,372 & 0 & 5,663 \\
\hline Mais de 34 computadores & 7,76 & 92,048 & 0 & 41,655 \\
\hline Constante & 90,644 & 0 & 2344,655 \\
\hline
\end{tabular}

Fonte: Elaborado pelo autor, extraído do software SPSS

Como o modelo acima apontou, para um nível de significância de 5\%, que as variáveis "O projeto pedagógico da escola estimula ou requer os professores a integração do uso da Internet em suas práticas" e "Faixa de 14 até 22 computadores para uso pedagógico" não são significativas (Sig. > 0,05), decidiu-se retirar a primeira variável do modelo e agrupar as faixas até "14 computadores" e de "14 até 22 computadores", em uma única faixa denominada "até 22 computadores".

Após o novo processamento, é possível observar no Quadro 37 que as variáveis que se mantiveram no modelo continuaram não gerando uma relação linear entre elas, isto é, não houve problemas graves de multicolinearidade (VIF < 10). 


\section{Quadro 37 - Diagnóstico de multicolinearidade para o modelo final}

\begin{tabular}{|l|l|l|}
\hline Variável & VIF & Tolerância \\
\hline p44 & 1,1 & 0,9078 \\
\hline p2901_bin & 1,18 & 0,85 \\
\hline p2905_faixa & 1,09 & 0,9156 \\
\hline p26_coordenador & 1,32 & 0,7595 \\
\hline p2904_bin & 1,25 & 0,798 \\
\hline p2903_bin & 1,54 & 0,6504 \\
\hline
\end{tabular}

Fonte: Elaborado pelo autor, extraído do software Stata

O novo procedimento stepwise forward Wald, com critério de entrada que o teste de Wald fosse significante a 5\%, precisou de seis (6) passos para convergir. A estatística -2LL variou de 498,662 do modelo sem intercepto (estágio 0) para 243,45 (estágio 6). A partir dos resultados apresentados no Quadro 38, o novo poder explicativo do modelo ou pseudo-R2, a partir da estatística de Nagelkerke, foi de 80,7\%.

Quadro 38 - R2 e -2LL dos modelos logísticos, por passos, para o modelo final

\begin{tabular}{|l|l|l|l|}
\hline Passo & $\mathbf{- 2 ~ L o g ~ l i k e l i h o o d ~}$ & Cox \& Snell & Nagelkerke \\
\hline 1 & 498,662 & 0,372 & 0,495 \\
\hline 2 & 406,890 & 0,470 & 0,626 \\
\hline 3 & 340,691 & 0,531 & 0,708 \\
\hline 4 & 285,237 & 0,576 & 0,769 \\
\hline 5 & 260,515 & 0,595 & 0,794 \\
\hline 6 & 246,687 & 0,606 & 0,807 \\
\hline
\end{tabular}

O teste de Hosmer-Lemeshow apresentado no Quadro 39, teve a hipótese nula aceita (Sig. > 0,10), sendo assim, as variáveis incluídas no modelo contribuíram para uma grande aderência das previsões aos valores reais.

Quadro 39 - Teste de Hosmer Lemeshow para o modelo final

\begin{tabular}{|l|l|l|l|}
\hline Passo & Qui-quadrado & df & Sig. \\
\hline 1 &, 000 & 0 & 0,0 \\
\hline 2 &, 386 & 4 & 0,984 \\
\hline 3 & 13,888 & 7 & 0,053 \\
\hline 4 & 10,077 & 8 & 0,260 \\
\hline 5 & 5,215 & 8 & 0,734 \\
\hline 6 & 4,949 & 8 & 0,763 \\
\hline \multicolumn{2}{r}{ Fonte: Elaborado pelo autor, extraído do software SPSS } \\
\hline
\end{tabular}

Classificando como de uso elevado as escolas com probabilidade estimada maior que 0,5, a Tabela 28 mostra que o modelo acertou 90,6\% das previsões. É possível observar que o modelo tende a alocar mais as escolas no grupo de uso elevado das TICs (percentual de acerto de 93,3\%). 
Tabela 28 - Tabela de classificação do modelo logístico final

\begin{tabular}{|c|c|c|c|c|}
\hline \multirow{2}{*}{\multicolumn{2}{|c|}{ Observado }} & \multicolumn{2}{|c|}{ Uso elevado das TICs } & \multirow{3}{*}{$\begin{array}{l}\text { Percentual de acerto } \\
87,8 \%\end{array}$} \\
\hline & & \multirow{2}{*}{$\begin{array}{l}\text { Não } \\
246\end{array}$} & \multirow{2}{*}{\begin{tabular}{|l|} 
Sim \\
25
\end{tabular}} & \\
\hline $\begin{array}{lll}\text { Uso } & \text { elevado das }\end{array}$ & Não & & & \\
\hline TICs & Sim & 25 & 245 & $93,3 \%$ \\
\hline \multicolumn{2}{|l|}{ Total } & & & $90,6 \%$ \\
\hline
\end{tabular}

Fonte: Elaborado pelo autor, extraído do software SPSS

Como a estatística Press' Q calculada do modelo $(356,71)$ é maior do que 6,63, tem-se que as previsões obtidas pelo modelo logístico são significativamente melhores do que as chances ao acaso.

Ao fim de seis passos, considerando um nível de significância de 5\%, o processo forward Wald selecionou para compor o modelo as variáveis descritas no Quadro 40.

Quadro 40 - Modelo de regressão logística final

\begin{tabular}{|l|l|l|l|l|}
\hline Variável & B & Wald & Sig. & Exp(B) \\
\hline $\begin{array}{l}\text { Na escola há treinamento para os professores, } \\
\text { de como se usa computador e Internet. }\end{array}$ & 2,521 & 38,821 & 0 & 12,436 \\
\hline $\begin{array}{l}\text { Na escola há treinamento para os alunos, de } \\
\text { como se usa computador e Internet. }\end{array}$ & 3,114 & 61,595 & 0 & 22,511 \\
\hline $\begin{array}{l}\text { A Internet da escola é utilizada pelos } \\
\text { professores em atividades de ensino- } \\
\text { aprendizagem com os alunos }\end{array}$ & 4,048 & 11,866 & 0.00 & 57,304 \\
\hline $\begin{array}{l}\text { A escola proporciona aulas específicas de } \\
\text { informática, que ensinem a usar computador } \\
\text { e Internet como parte da grade curricular. }\end{array}$ & 3,665 & 56,9 & 0 & 39,051 \\
\hline $\begin{array}{l}\text { A escola integrou o computador e a Internet } \\
\text { às práticas de ensino-aprendizagem. }\end{array}$ & 2,986 & 16,595 & 0 & 19,806 \\
\hline $\begin{array}{l}\text { Faixa de computadores para uso } \\
\text { pedagógico (referência = até 22 } \\
\text { computadores) }\end{array}$ & & 48,472 & 0 & \\
\hline De 22 até 34 computadores & 1,727 & 15,148 & 0 & 5,626 \\
\hline Mais de 34 computadores & 3,703 & 48,157 & 0 & 40,569 \\
\hline Constante -12,386 & 55,765 & 0 & 0 \\
\hline
\end{tabular}

Fonte: Elaborado pelo autor, extraído do software SPSS

Para um nível de significância de $1 \%$, todas as variáveis e suas categorias, no caso da variável de faixa de computadores para uso pedagógico, se mostraram significantes.

De antemão, percebe-se que a variável "Internet da escola é utilizada pelos professores em atividades de ensino-aprendizagem com os alunos" é a que mais incrementa a possibilidade da escola fazer um uso elevado das TICs, afinal, ela possui maior $\operatorname{Exp}(B)$, o que significa que escolas onde a Internet é utilizada pelos professores 
no processo de ensino-aprendizagem com os alunos tem 57,304 vezes mais chances de serem classificadas como aquelas que fazem uso elevado das TICs.

Ainda de acordo com o modelo acima, escolas que oferecerem treinamento aos professores de como se usa computador e Internet, tendem a ter uso mais elevado das TICs do que quando tal tipo de treinamento não é oferecido. De fato, escolas que capacitam seus professores tem 12,436 vezes mais chances de serem classificadas no grupo de escolas com uso elevado das TICs.

Analisando a perspectiva dos alunos, escolas que oferecem treinamento para os alunos de como se usa computador e Internet tem 22,511 vezes mais chances de serem classificadas como aquelas que tem uso elevado das TICs.

Já escolas que proporcionam aulas específicas de informática, que ensinem a usar computador e Internet como parte da grade curricular, possuem 39,051 vezes mais chances de fazerem uso elevado das TICs.

Por fim, no que diz respeito a influência do número de computadores disponíveis para uso pedagógico, tem-se que, quanto maior a disponibilidade, maiores serão as chances da escola fazer uso elevado das TICs. Se comparadas com a faixa base (até 22 computadores disponíveis para uso pedagógico), escolas que tem de 22 a 34 computadores possuem 5,626 vezes mais chances de fazerem uso elevado das TICs. Escolas que possuem em sua infraestrutura mais de 34 computadores disponíveis para uso pedagógico possuem 40,569 vezes mais chances de fazerem uso elevado das TICs, se comparadas com as escolas que possuem até 22 computadores.

A equação proposta pelo modelo logístico pode ser utilizada como forma de avaliar se as escolas estão ou não fazendo uso elevado das TICs, sem a necessidade da construção do índice de uso proposto neste trabalho.

Em resumo, as constatações do modelo demonstraram integração com o referencial teórico apresentado no tópico 2, pois foi possível sustentar que uma escola fará um uso integrado das TICs a partir do momento em que é possível ter o apoio e incentivo da direção ao uso. Além disso, torna-se relevante a oferta de uma infraestrutura que traga a disponibilidade de computadores para o uso pedagógico, bem como iniciativas que propiciem uma capacitação específica em informática. Por fim, mostra-se importante a escola ter a capacidade de trazer as TICs como ferramentas de apoio ao processo de ensino-aprendizagem. Dessa forma, é possível concluir que o modelo aqui apresentado e originado dos dados da pesquisa TIC Educação, permite destacar fatores que determinam a probabilidade de uma escola fazer uso intensivo das TICs. 
Embora existam limitações inerentes às modelagens estatísticas, no sentido de serem uma abstração da realidade e de incorporarem elementos de incerteza, os resultados proporcionados pela regressão logística foram satisfatórios e podem subsidiar pesquisadores e gestores públicos a compreenderem fatores que influem positivamente no uso das TICs dentro do contexto escolar. 


\section{Considerações finais}

O presente estudo teve por objetivo desenvolver um índice que possibilitasse medir o nível de uso das TICs em escolas brasileiras. Para tanto, foram consideradas três dimensões que permitiram mensurar o uso: (a) Gestão, relacionada ao uso das TICs no planejamento escolar e no apoio ao uso das TICs por parte do corpo diretivo das escolas; (b) Infraestrutura, relacionada aos recursos tangíveis de TIC dentro das escolas; (c) Uso por professores e alunos, relacionada ao uso das TICs por parte dos alunos e professores dentro do processo de ensino-aprendizagem. Para tanto, foram utilizados os microdados da pesquisa TIC Educação 2013. A análise dos dados se deu por meio da aplicação de técnicas estatísticas descritivas (análises de frequência, testes univariados de médias, mediana) e análises multivariadas (Análise Fatorial Exploratória e Confirmatória; Modelagem de Equações Estruturais; Regressão Logística).

A seção que será exposta abaixo, tem por objetivo descrever os resultados apresentados pelo trabalho à luz de seus objetivos.

\subsection{Desenvolvimento do índice de uso das TICs em escolas}

A partir dos estudos descritos no referencial teórico deste trabalho e de um estudo aprofundado nos microdados das pesquisa TIC Educação, foi possível tratar o uso das TICs a partir de três perspectivas: Gestão, Infraestrutura e Uso por professores e alunos.

Para a dimensão "Gestão", foram selecionadas variáveis que explicitassem o suporte da liderança quanto ao uso das TICs na escola (SOLAR et al., 2013), atitude dos diretores quanto às TICs (BIAGI; LOI, 2013) e troca de informações entre os diretores e os pais através da Internet (AOKI et al., 2013).

Já para a dimensão "Infraestrutura", foram selecionadas variáveis que explicitassem a infraestrutura de equipamentos disponíveis (AOKI et al., 2013; SOLAR et al., 2013; WASTIAU et al., 2013; LOBLER et al., 2010; IDIE, 2008), bem como a disponibilidade de profissionais responsáveis por atividades relacionadas às TICs dentro da escola (AOKI et al., 2013). 
Por fim, para a dimensão "Uso por professores e alunos", foram selecionadas variáveis que demonstrassem o suporte ofertado pela escola e pelo projeto pedagógico para um efetivo uso das TICs no processo de ensino-aprendizagem por professores e alunos (AOKI et al., 2013; SOLAR et al., 2013; IDIE; 2008).

Para o desenvolvimento do índice foi aplicada uma AFE em cada uma das dimensões apontadas, a fim de se analisar individualmente as dimensões para que, em uma segunda etapa, fosse possível utilizar a MEE como ferramenta para a construção do índice.

Como resultado da AFE, foi possível perceber que as dimensões inicialmente previstas decompuseram-se em subdimensões, sendo assim, o modelo gerado na MEE tornou-se do tipo de terceira ordem, isto é, foram criados três níveis de variáveis latentes (índice, dimensões e subdimensões), conforme ilustrado na Figura 17.

Figura 17 - Índice de uso das TICs

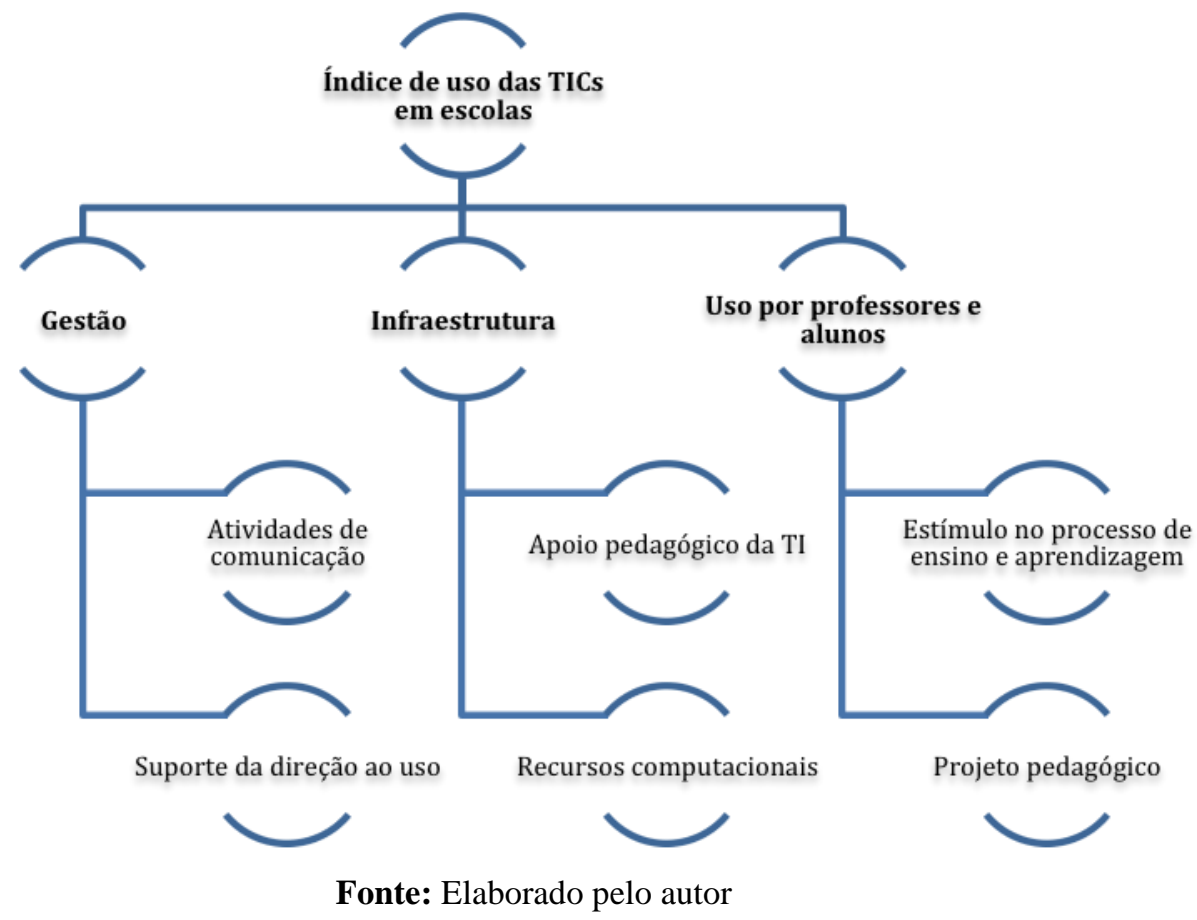

A partir dos testes de validade convergente, discriminante e confiabilidade composta, o modelo demonstrou que a subdimensão Laboratório de Informática não deveria ser levada em consideração ao se medir o nível de uso das TICs nas escolas. Mesmo sabendo que tal ambiente ainda é um importante espaço para o uso das TICs, fruto de políticas públicas que visam equipar as escolas com computadores e laboratórios de informática, a pesquisa TIC Educação (CGI, 2014) constata que outros espaços, como a própria sala de aula, têm se tornado relevantes para que haja o uso das tecnologias. 
Acredita-se que o objetivo de construção do índice tenha sido atingido, haja vista que o mesmo propôs, a partir de um único constructo, trazer a perspectiva gerencial, pedagógica e infraestrutural quanto às TICs.

Por fim, tal índice traz uma nova perspectiva quanto ao uso das tecnologias digitais na Educação no Brasil, pois complementa a ênfase que limita a avaliação do uso das tecnologias a partir da disponibilidade de hardware e software, para uma perspectiva que leva em consideração, entre outras questões, a capacitação de alunos e professores, o suporte do projeto pedagógico e o apoio pedagógico da área de TI como questões relevantes para uso efetivo das TICs.

\subsection{Explorando os resultados do índice e de suas dimensões}

Uma vez construído o índice, foi possível analisar, a partir dos escores fatoriais, dimensão por dimensão. Como primeira estratégia de análise, foram levantados casos extremos.

Analisando a perspectiva de "Infraestrutura", foram identificadas seis (6) escolas com alto desempenho na dimensão. Foi constatado que tais escolas são, em sua maioria, particulares e se encontram nas regiões Sudeste e Sul do país.

Avaliando o "Uso por professores e alunos", foram identificados quinze (15) casos de escolas com baixo desempenho em tal dimensão. Todas as escolas deste conjunto são públicas sendo, cinco (05) delas municipais e dez (10) delas estaduais.

Para fins de análise, foram removidas as vinte e uma (21) observações identificadas como casos extremos.

Após a retirada dos casos extremos, foi possível concluir, restringindo a extrapolação para a amostra analisada no trabalho, que há um intenso nível de uso das TICs no índice proposto neste trabalho e em suas dimensões, para um contexto regional SulSudeste, em escolas particulares e em municípios com o IDH-M maior que 0,562.

A partir dos resultados apresentados pelas escolas, foi possível também classificá-las em baixo uso, uso moderado, uso elevado e uso muito elevado das TICs.

De maneira geral, comprovou-se a existência da diferença do nível de uso das TICs nas escolas levantadas no estudo a partir da perspectiva regional, administrativa e de desenvolvimento humano municipal. 
As combinações regionais que apresentaram diferenças significativas quanto ao índice de uso das TICs foram: Sul e Norte; Centro-Oeste e Sudeste; e Centro-Oeste e Sul.

A partir dos resultados do estudo foi possível constatar que $60 \%$ das escolas da amostra que se situam na região Sul, estão classificadas como aquelas que fazem um uso elevado ou muito elevado das TICs. Em outra perspectiva de análise e ainda seguindo os resultados apresentados neste estudo, foi possível observar que mais de $50 \%$ das escolas da amostra localizadas nas regiões Norte e Centro-Oeste, fazem uso moderado ou baixo das TICs.

Analisando os resultados a partir do tipo de dependência administrativa, foi possível concluir que as escolas particulares demonstraram diferenças significativas quando comparadas com as escolas municipais e estaduais. Foi possível observar que 80,10\% das escolas particulares da amostra estão classificadas como fazendo uso elevado ou muito elevado das TICs.

Por fim, analisando os resultados a partir do índice de desenvolvimento humano municipal, a pesquisa demonstrou que as escolas localizadas na menor faixa de IDHM possuem nível médio de TIC significantemente diferente se comparado com todas as outras faixas. Foi possível constatar que apenas 15,7\% das escolas analisadas que se encontram na menor faixa de IDH-M, demonstraram um nível de uso das TICs elevado, além disso, 40,5\% demonstraram baixo nível de uso. Comparativamente, apenas $21 \%$ das escolas localizadas na segunda pior faixa do IDH-M apresentam baixo uso das TICs, demonstrando uma diferença positiva de 19,5 pontos percentuais para o menor nível de IDH-M.

Assim, a partir dos resultados discutidos foi possível atingir o objetivo de explorar o índice e suas dimensões de forma a reforçar a importância de políticas públicas que desenvolvam regiões menos favorecidas e com menor índice de desenvolvimento humano, afinal, a partir de um uso elevado das TICs será possível ver uma transformação significativa da educação atual, da simples transmissão de conhecimento à aprendizagem criativa, por meio da convergência entre a educação e as TICs. 


\subsection{Analisando fatores que contribuem para uso das TICs em escolas}

A partir de um conjunto de variáveis utilizadas no desenvolvimento do índice, avaliou-se como o uso elevado das TICs é mediado por fatores ligados a: capacitação de professores e alunos; uso da Internet pelos professores em atividades de ensinoaprendizagem com os alunos; oferta de aulas específicas de informática, que ensinem a usar computador e Internet como parte da grade curricular; integração do computador e a Internet às práticas de ensino-aprendizagem; disponibilidade de computadores para uso pedagógico.

Os resultados demonstraram que uma escola fará melhor uso das TICs, a partir do momento em que é possível ter uma direção que suporte o uso, isto é, que enxergue a importância da capacitação de professores e alunos quanto ao uso das TICs. Além disso, é importante que a escola oferte uma infraestrutura que traga a maior disponibilidade de computadores para uso pedagógico possível, bem como propicie aulas específicas de informática. Por fim, integrar o computador e a Internet às práticas pedagógicas, também demonstrou-se um fator importante para que haja um elevado uso das TICs.

A partir dos resultados discutidos, foi possível atingir o objetivo de trazer fatores que poderão subsidiar pesquisadores e gestores públicos a compreenderem aspectos que influem positivamente no uso das TICs dentro do contexto escolar.

\subsection{Sugestões para a pesquisa TIC Educação}

Como último objetivo deste trabalho, foi possível explorar em detalhes os microdados da pesquisa TIC Educação e suas análises. É válido ressaltar que o trabalho realizado pela pesquisa é fundamental para que o governo brasileiro possa monitorar e desenhar melhores políticas de incentivo ao uso das tecnologias no ambiente educacional. Além disso, pesquisadores interessados em aprofundar-se no tema podem ter acesso a um conjunto de dados de qualidade e rico em detalhes.

No que diz respeito à unidade de análise "Diretores", sugere-se que sejam criadas questões que explicitem as atividades de gestão da escola que são suportadas pelas TICs, bem como quais funções administrativas da escola se encontram informatizadas. 
No que diz respeito às unidades de análise "Professores" e "Alunos", sugere-se que seja possível, de alguma maneira, extrair indicadores que informem proporcionalmente, dentro das escolas, o percentual de alunos e professores. Tal constatação se dá, pois não foi possível avaliar neste estudo, por exemplo, dentro de cada escola, o percentual de alunos que usam computador ou o percentual de professores que receberam capacitação em TIC. Cabe ressaltar que o índice proposto nesta dissertação seria extremamente enriquecido se tal tipo de informação pudesse ter sido extraído.

A fim de avaliar os casos identificados como extremos na análise realizada em cada uma das dimensões propostas neste estudo, sugere-se a exploração e análise de tais escolas a partir de estudos de caso. Uma exploração in loco, permitirá avaliar em profundidade a realidade de tais instituições de ensino.

Por fim, sugere-se que o índice proposto por este estudo seja replicado e utilize questões referentes ao desenho amostral, a fim de gerar uma estatística nacional que possa trazer uma perspectiva para o universo de escolas brasileiras.

\subsection{Limitações da pesquisa}

Uma das dimensões do índice proposto neste trabalho dizia respeito ao uso das TICs por professores e alunos, porém, ao analisar a possibilidade de incorporar as opiniões de tais públicos no índice, foi constatada a impossibilidade da extrapolação das opiniões das amostras para as respectivas populações. Foram analisadas isoladamente as bases de microdados de alunos e professores e percebeu-se que o número de escolas que tiveram mais de 05 respondentes para os dois públicos, simultaneamente, gerou um conjunto limitado de 62 observações. Sendo assim, para a construção do índice, tal dimensão levou em consideração as opiniões referentes ao uso das TICs por professores e alunos, a partir da visão dos Coordenadores Pedagógicos.

Mesmo estando a distribuição da amostra deste estudo alinhada com o desenho amostral da pesquisa TIC Educação, não foi possível generalizar os resultados apresentados, dado que não houve um processo de reponderação. Os achados deste estudo estão coerentes com o contexto das escolas analisadas e podem servir como um indicativo da realidade do universo das escolas brasileiras. 


\subsection{Conclusão e recomendações para estudos futuros}

A pergunta problema que gerou a pesquisa aqui descrita foi: qual é o nível de uso das Tecnologias da Informação e Comunicação em escolas brasileiras? As análises empreendidas nesta dissertação demonstraram que medir o nível de uso das TICs vai além das perspectivas da quantidade de software e hardware disponíveis para uso dentro das escolas. Além disso, os resultados do estudo demonstraram que a região, a dependência administrativa e o índice de desenvolvimento humano municipal, diferenciam o nível de uso das TICs nas escolas. Por fim, foi possível observar que o apoio da gestão, a oferta de infraestrutura e a apropriação das tecnologias no processo de ensino-aprendizagem, impactam positivamente um maior uso das TICs.

Em termos de implicação para a prática, este estudo investigou o cenário de algumas escolas brasileiras no que diz respeito ao uso das tecnologias da informação e comunicação. Neste sentido, sugere-se ao governo que observe tais resultados, a fim de avaliar o impacto das políticas públicas de inclusão digital.

Para organizações de tecnologia do setor privado, os resultados apresentados pelo estudo demonstraram que escolas de algumas regiões do país ainda carecem de uso efetivo das TICs. Além disso, este trabalho mostrou que, para que as escolas passem a utilizar as TICs de forma integrada, as organizações que oferecerem serviços de tecnologia, precisarão engajar os principais atores das escolas e precisarão capacitar seus usuários.

Em termos de contribuição teórica, a referida dissertação trouxe, além de uma revisão sobre o contexto TIC dentro do ambiente escolar, um conjunto de trabalhos acadêmicos desenvolvidos que visaram demonstrar formas de se medir o uso das TICs no contexto escolar. Sendo assim, esta pesquisa compartilha resultados nacionais a cerca da temática TIC na Educação que poderão ser utilizados por pesquisadores da área de informática na educação, a fim de aprimorar o instrumento neste trabalho desenvolvido.

Em termos metodológicos, este estudo demonstrou, através da inclusão de aspectos relevantes, a possibilidade de desenvolvimento de um índice que levou em consideração o rigor dos pressupostos das técnicas estatísticas aplicadas.

Por fim, a seguir, serão listadas recomendações para estudos futuros: 
1. Classificação das escolas e criação de um modelo de maturidade quanto ao uso das TICs.

2. Desenvolvimento do índice a partir das informações do plano amostral da pesquisa TIC Educação 2013.

3. Realização do cálculo do índice de uso das TICs para as próximas edições da pesquisa TIC Educação.

4. Análise temporal do desempenho do índice de uso nas escolas que estão na amostra da pesquisa TIC Educação desde 2010.

5. Análise do impacto do índice de uso das TICs em avaliações de desempenho escolar.

6. Evolução do modelo a fim de se trazer perspectivas pedagógicas para o índice. 


\section{REFERÊNCIAS}

ALBERTA EDUCATION. Bring your own device: A guide for schools. 2012.

Disponível em: 〈http://education.alberta.ca/admin/technology/research.aspx $\rangle$.

ALMEIDA, M. E. B. Informática e formação de professores. PROINFO, Secretaria de Educação a Distância, v.1. Brasil: MEC, SEED. 2000.

Tecnologias para gestão democrática - Gestão de tecnologias na escola: Possibilidades de uma prática democrática. Boletim do Salto para o Futuro. 2005

ALMEIDA, M E. B.; RUBIM, L. O papel do gestor escolar na incorporação das TICs na escola: experiências em construção e redes colaborativas de aprendizagem. São Paulo: PUC-SP, 2004.

ALTOÉ, A. O desenvolvimento histórico das novas tecnologias e seu emprego na educação. Educação e Novas Tecnologias. Maringá: EDUEM, p.13-25. 2005.

ANGRIST, J. D.; LAVY, V. New Evidence on Classroom Computers and Pupil Learning. Economic Journal, n.112, p. 735-765,.2002.

AOKI, H.; KIM, J.; LEE, W. Propagation \& level: Factors influencing in the ICT composite index at the school level. Computers \& Education, v. 60, p. 310-324. 2013.

ARAUJO, M. H. Análise de fatores que influenciam o uso de serviços de governo eletrônico no Brasil. 2013. Dissertação (Mestrado em Administração) - Faculdade de Economia, Administração e Contabilidade, Universidade de São Paulo, São Paulo, 2013. Disponível em: <http://www.teses.usp.br/teses/disponiveis/12/12139/tde05122013-185015/>.

ATKINSON, L. The measurement statistics controversy: Factor analysis and subinterval data. Bulletin of the Psychonomic Society, v. 26, p. 361-364. 1988.

ATLAS DO DESENVOLVIMENTO HUMANO BRASILEIRO. Download. Disponível em http://www.atlasbrasil.org.br/2013/pt/download/. 2015.

BACH, T. M.; DOMINGUES, M. J. C. S.; WALTER, S. A. Tecnologias da informação e comunicação no ensino: um estudo bibliométrico e sociométrico de 1997-2011. Avaliação, v.18, n. 2, p. 393-416. 2013. Disponível em : <

http://dx.doi.org/10.1590/S1414-40772013000200009). Acesso em: 14 março 2014.

BARBOSA, A.F.; BARBOSA, E.F.; MOURA, D.G. Inclusão das tecnologias de informação e comunicação na educação através de projetos. Congresso anual de 
Tecnologia da Informação - CATI, São Paulo. Anais do Congresso Anual de Tecnologia da Informação, v. 1, p. 1-13. 2004. Disponível em: < http://www.tecnologiadeprojetos.com.br/arts/inclus\%C3\%A3o\%20das\%20tecnologia s.pdf >. Acesso em: 1 março 2014 .

BARTHOLOMEW, D.; STEELE, F.; MOUSTAKI, I.; GALBRAITH, J. The Analysis and Interpretation of Multivariate Data for Social Scientists. 1 edição. London: Chapman and Hall/CRC Press. 2002.

BELLONI, M. L. O que é mídia-educação? 3 ed. Campinas, SP: Autores Associados, 2009.

BEZERRA, F. A. Análise Fatorial. Em: CORRAR, L. J.; PAULO, E.; DIAS FILHO, J. M. (Coord.). Análise multivariada para cursos de Administração, Ciências Contábeis e Economia. São Paulo: Atlas, p. 73-130. 2012.

BIAGI, F.; LOI, M. Measuring ICT Use and Learning Outcomes: evidence from recent econometric studies. European Journal of Education, v. 48, p. 28-42. 2013.

BIELSCHOWSKY, C. E. Tecnologia da Informação e Comunicação das Escolas Públicas Brasileiras: o programa PROINFO integrado. Revista e-curriculum, São Paulo v.5 n.1. 2009.

BISTAFFA, B. C. Incorporação de indicadores categóricos ordinais em modelos de equações estruturais. 2010. Dissertação (Mestrado em Estatística) - Instituto de Matemática e Estatística, Universidade de São Paulo, São Paulo, 2010. Disponível em: <http://www.teses.usp.br/teses/disponiveis/45/45133/tde-09022011-110229/>.

BORGES, M. F. V. Inserção da Informática no Ambiente Escolar: inclusão digital e laboratórios de informática numa rede municipal de ensino. XXVIII Congresso da Sociedade Brasileira de Computação (SBC), Workshop de Informática na Escola (WIE). 2008.

BRASIL. Ministério da Educação e do Desporto. PROINFO - Diretrizes para o Programa nacional de informática na educação. Brasília, 1997.

Presidência da Republica. Casa Civil. Subchefia para Assuntos

Jurídicos. Decreto no 6.300, de 12 de dezembro de 2007. Dispõe sobre o Programa Nacional de Tecnologia Educacional - ProInfo. Disponível em: <http://www.planalto.gov.br/ccivil_03/_Ato2007- 2010/2007/Decreto/D6300.htm>. Acesso em: 12 junho 2014.

LDB: Lei de Diretrizes e Bases da Educação Nacional: lei n ${ }^{\circ} 9.394$, de 20 de dezembro de 1996, que estabelece as diretrizes e bases da educação nacional. 5. ed. - Brasília: Câmara dos Deputados, Coordenação Edições Câmara, 2010. 
Disponível em:

<http://bd.camara.gov.br/bd/bitstream/handle/bdcamara/2762/ldb_5ed.pdf > . Acesso em: 02 maio 2014.

Acesso, permanência, aprendizagem e conclusão da Educação Básica na idade certa - Direito de todas e de cada uma das crianças e dos adolescentes /Fundo das Nações Unidas para a Infância. - Brasília: UNICEF, 2012. Disponível em: <http://www.uis.unesco.org/Education/Documents/OOSCI Reports/brazil-ooscireport-2012-pr.pdf>. Acesso em: 02 maio 2014.

BRIGNOL, S. M. S. Novas tecnologias de informação e comunicação nas relações de aprendizagem da estatística no ensino médio. Faculdade Jorge Amado, Salvador, 2004. Disponível em: 〈http://www.redeabe.org.br/Monografia.pdf >. Acesso em 02 maio 2015.

BYROM, E., BINGHAM, M. Factors influencing the effective use of technology for teaching and learning: Lessons learned from the SEIR*TEC intensive site schools. Greensboro, N.C.: University of North Carolina at Greensboro. 2001.

CHAVES, E. O. C. Tecnologia e Educação: o futuro da escola na sociedade da Informação. Campinas: Mindware, 1998.

CHAVES, S.; SOUZA, C. A. Benefícios Potenciais Associados à Computação em Nuvem: Um Estudo Delphi Envolvendo Profissionais e Acadêmicos Brasileiros. 2012. Anais do XV SemeAd. Disponível em:

<http://www.ead.fea.usp.br/semead/15semead/resultado/trabalhosPDF/919.pdf $>$. Acesso em: 05 janeiro 2015.

CGI. TIC Educação 2013. Pesquisa sobre uso das tecnologias da informação e da comunicação nas escolas brasileiras. São Paulo: Comitê Gestor da Internet no Brasil, 2014. Disponível em < http://cetic.br/media/docs/publicacoes/2/tic-educacao2013.pdf>. Acesso em: 1 dezembro 2014.

DUTRA, A. F. O Professor Orientador de Informática Educativa - POIE das escolas do município de São Paulo. 2010. Dissertação (Mestrado em Educação) Faculdade de Educação, Universidade de São Paulo, São Paulo, 2010. Disponível em: <http://www.teses.usp.br/teses/disponiveis/48/48134/tde-16092010-141502/>. Acesso em: 23 junho 2014.

DWYER, T.; WAINER, J.; DUTRA, R. S.; COVIC, A.; MAGALHÃES V. B.; FERREIRA L. R. R.; PIMENTA V. A.; CLAUDIO K. Desvendando mitos: os computadores e o desempenho no sistema escolar. Educação \& Sociedade, v. 28, n. 101, p.1303-1328, 2007.

ELIA, M. F. O papel do professor diante das Inovações Tecnológicas. XXVIII Congresso da Sociedade Brasileira de Computação. 2008. 
FAGUNDES, L. C.; VALENTINI, C. B.; SOARES, E. M. S. Linguagem, educação e recursos midiáticos: quem mexeu na minha escola? Em: PESCADOR, $\mathrm{C}$.; SOARES, E. M. S.; NODARI, P. C. (Org.). Ética, Educação e Tecnologia: pensando alternativas para os desafios da educação na atual idade. Curitiba: CRV, 2010.

FÁVERO, L. P.; BELFIORE, P.; SILVA, F. L.; CHAN, B. L. Dados: modelagem multivariada para tomada de decisões. Rio de Janeiro: Elsevier, 2009.

FIGUEIREDO FILHO, D. B.; SILVA JÚNIOR, J. A. da. Visão além do alcance: uma introdução à análise fatorial. Opinião Pública, v. 16, n. 1. 2010.

FIRPO, S. P.; DE PIERI, R. G. Avaliando os efeitos da introdução de computadores em escolas públicas brasileira. Revista Brasileira de Inovação, v. 11, p. 153-190, jul. 2012. Disponível em:

<http://www.ige.unicamp.br/ojs/index.php/rbi/article/view/528>.

FONSECA, J. J. S. Metodologia da pesquisa científica. Fortaleza: UEC, 2002.

FU, J. S. ICT in education: a critical literature review and its implications. International Journal of Education and Development using Information and Communication Technology, v. 9, p. 112-125. 2013.

GEPHART, R. Paradigms and Research Methods. Research Forum, v.4.1999.

GIL, A. C. Como elaborar projetos de pesquisa. 4. ed. São Paulo: Atlas, 2007.

GIMENEZ, M. C. A utilização do computador na educação, Revista da Educação, vol. 1, n. 2, jul.-dez. 2001.

Análise de uma proposta de capacitação para professores em informática educacional por meio de grupos de pesquisa desenvolvida no NTE de Cascavel - PR. Dissertação de mestrado, Universidade Federal de Santa Catarina. 2004. Disponível em:

<http://www.bibvirt.futuro.usp.br/content/download/3317/22949/file/PDF>. Acesso em 14 julho 2014.

GOSLING, M.; GONÇALVES, C. A. Modelagem por Equações Estruturais: conceitos e aplicações. Revista FACES - Revista de Administração, v. 2., n.2, p.8395. 2003.

GUIMARÃES, J. R. S.; JANNUZZI, P. M. IDH, indicadores sintéticos e suas aplicações em políticas públicas: uma análise crítica. Revista Brasileira de Estudos Urbanos e Regionais, vol. 7, p. 73-90. 2011. 
HAIR Jr, J. F.; BLACK, W. C.; BABIN, B. J.; ANDERSON, R. E. Multivariate

Data Analysis. 7 edição. Pearson Prentice Hall. 2010.

HANUSHEK, E. A.; KIMKO, D. Schooling, Labor-Force Quality, and the Growth of Nations. American Economic Review, American Economic Association, v. 90, n. 5, p. 1184-1208, dez. 2000. Disponível em < http://www2.econ.iastate.edu/classes/econ520/Huffman/documents/SchoolingLaborF orceQualityandtheGrowthofNations.pdf>. Acesso em: 2 maio 2014.

HARRISON, C.; COMBER, C.; FISHER, T.; HAW, K.; LEWIN, C.; LUNZER, E., ... \& WATLING, R. ImpaCT2: The impact of information and communication technologies on pupil learning and attainment. British Educational Communications and Technology Agency (BECTA). 2003.

HEIDE, A.; STILBORNE, L. Guia do professor para a Internet Completo e Fácil. Porto Alegre: Artes Médicas Sul. 2000.

IBGE. Pesquisa Nacional por Amostra de Domicílios - PNAD. Rio de Janeiro : 2012. Disponível em <http://www.ibge.gov.br/home/estatistica/populacao/trabalhoerendimento/pnad2012/ default.shtm>. Acesso em: 5 setembro 2014.

IDIE. Indicadores qualitativos da integração das TICs na educação: proposições. Documento para debate, dez. 2008. Disponível em: < http://www.ibertic.org/evaluacion/sites/default/files/biblioteca/3a_integraciontic_idie _documento_previo.pdf >. Acesso em: 14 julho 2014.

INTERVOZES. Contribuições para a construção de indicadores do direito à comunicação. 1a. ed. São Paulo: Intervozes - Coletivo Brasil de Comunicação Social, 2010 .

JANNUZZI, P. D. M. Indicadores para diagnóstico, monitoramento e avaliação de programas sociais no Brasil. Revista do Serviço Público, Brasília, v. 56, n. 2, p. 137-160, abril/junho. 2005.

KENSKI, V. M. Tecnologias e o tempo docente. Campinas, São Paulo: Papirus, 2013.

KIM, J.,;LEE W. An analysis of educational informatization level of students, teachers, and parents: in Korea. Computers \& Education, v. 56, n. 3, p. 760-768, abr. 2011a. 
Assistance and possibilities: analysis of learning-related factors affecting the online learning satisfaction of underprivileged students. Computers \& Education, v.57, n. 4, p. 2395-2405, dez. 2011 b.

KLUVER, R. Globalization, informatization, and intercultural communication. American Communication Journal, v. 3, jun. 2000.

KOZMA, R.; ANDERSON, R. E. Qualitative case studies of innovative pedagogical practices using ICT. Journal of Computer Assisted Learning, v. 18, n. 4, p. 387-394, 2002.

KUBO, S. H.; GOUVEA, M. A. Análise de fatores associados ao significado do trabalho. Rev. Adm. (São Paulo), São Paulo, v. 47, n. 4, dezembro. 2012.

LAVINAS, L.; VEIGA, A. Desafios do modelo brasileiro de inclusão digital pela escola. Cadernos de pesquisa, v.43, n.149, p. 542-569. 2013.

LEITE, W. S. S.; RIBEIRO, C. A. N. A inclusão das TICs na educação brasileira: problemas e desafios. Revista Internacional de Investigación En Educación, Javeriana, Colombia, v. 5, n. 10, p.173-187, 2012.

LÉVY, P. As Tecnologias da Inteligência - O Futuro do Pensamento na era da Informática. Rio de Janeiro: Editora 34. 1998.

Cibercultura. Rio de Janeiro: Editora 34. 1999.

LINDEN, L., BANERJEE, A.; DUFLO, E. Computer-Assisted Learning: Evidence from a Randomized Experiment. Poverty Action Lab Paper, n. 5, out. 2003.

LIRA, S. A.; Análise de correlação: abordagem teórica e de construção dos coeficientes com aplicações. 2004. Dissertação (mestrado). Setores de Ciências Exatas e de Tecnologia, UFPR, Curitiba, 2004.

LOBLER, M. L.; VISENTINI, S. V; CORSO, K. B; SANTOS, D. L. D. Acesso e uso da Tecnologia da Informação em escolas públicas e privadas de ensino médio: o impacto nos resultados do ENEM. Revista Eletrônica Sistemas \& Gestão, v. 5, n.2, p. 67-84. 2010. Disponível em:

<http://www.uff.br/sg/index.php/sg/article/viewFile/V5N2A1/V5N2A>. Acesso em: 10 julho 2014.

LOPES, J. J. A introdução da informática no ambiente escolar. 2002. Disponível em: <http://www.clubedoprofessor.com.br/artigos/artigojunio.htm>. Acesso em: 23 de junho 2013. 
LOPES, R. D. ; FICHEMAN, I. K. ; MARTINAZZO, A. A. G. ; CORREA, A. G. D. ; VENANCIO, V. ; BIAZON, L.C. ; YIN, H. T . O uso dos computadores e da Internet em escolas públicas de capitais brasileiras. Estudos e Pesquisas Educacionais, v. 1, p. 275-335, 2010. Disponível em: <http://www.fvc.org.br/estudose-pesquisas/avulsas/estudos1-7-uso-computadores.shtml>. Acessado em: 20 de junho 2014.

LÓPEZ, A., FÓRTIZ, M. J., ALMENDROS, M. L., SEGURA, M. J. Mobile learning technology based on iOS devices to support students with special education needs. Computers \& Education, v. 61, p.77-90, 2013. Disponível em: $<$ http://www.sciencedirect.com/science/article/pii/S0360131512002199>. Acesso em: 20 junho 2014

MACGIBBON, A. Smarter use of home devices. The Sydney Morning Herald. 2012. Disponível em: < http://www.smh.com.au/technology/technologynews/smarter-use-of-home-devices-20120527-1zcry.html>. Acesso em: 7 setembro 2014.

MAIA, D. L., BARRETO, M. C. Tecnologias digitais na educação: uma análise das políticas públicas brasileiras. Educação, Formação \& Tecnologias, v.5, n.1, p. 47-61. 2012.

MALHOTRA, N. Pesquisa de marketing: uma orientação aplicada. $3^{\mathrm{a}}$ edição. Porto Alegre: Bookman, 2001.

MAMEDE-NEVES, M. A.; ROSADO, L. A. S.; MARTINS, T. M. O. Mídias digitais na escola: a "eterna" fase de transição? Apropriações e perspectivas encontradas entre estudantes e professores. Revista e-curriculum, v. 11, n. 2, p. 515-536, ago. 2013.

MARTIN, F., ERTZBERGER, J. Here and now mobile learning: An experimental study on the use of mobile technology. Computers \& Education, v. 68, p. 76-85, 2013. Disponível

em:<http://www.sciencedirect.com/science/article/pii/S0360131513001140>. Acesso em: 20 de junho 2014.

MASETTO, M.T. Mediação pedagógica e o uso da tecnologia. Em: MORAN, J. M.; MASETTO, M. T.; BEHRENS, M. A. Novas tecnologias e mediação pedagógica. Campinas : Papirus. 2010.

MCAFFE, A. P. Mastering the three worlds of information technology. Harvard Business Review, v. 84,p.141-149, 2006.

MELL, P; GRANCE, T. The NIST definition of cloud computing. US National Institute of Science and Technology. 2011. Disponível em : < 
http://csrc.nist.gov/publications/nistpubs/800-145/SP800-145.pdf >. Acesso em: 10 dezembro 2014.

MINTZ, J.; BRANCH, C.;MARCH, C.;LERMAN, S. Key factors mediating the use of a mobile technology tool designed to develop social and life skills in children with Autistic Spectrum Disorders. Computers \& Education, v.58,p.53-62, 2012. Disponível em:

<http://www.sciencedirect.com/science/article/pii/S0360131511001710>. Acesso em: 20 junho 2014.

MIRANDA, G. L. Limites e possibilidades das TICs na educação. Sísifo. Revista de Ciências da Educação, n. 03, p. 41-50, maio/agosto. 2007. Disponível em: <http://www.scribd.com/doc/407971/Limites-e-possibilidades-das-TIC-na-Educacao> Acesso em: 20 junho 2014.

MORAES, M. C. Informática educativa no Brasil: uma história vivida, algumas lições aprendidas. Revista Brasileira de Informática Educativa, n.1, abril. 1997.

MORAN, J. M. Desafios na Comunicação Pessoal. 3a Ed. São Paulo: Paulinas, 2007.

MORENO JUNIOR, V. A.; CAVAZOTTE, F. S. C. N.; ARRUDA, R. R.. Conhecimento compartilhado, recursos de TI e desempenho de processos de negócios. Rev. adm. empres., São Paulo, v. 54, n. 2, abril. 2014 . Disponível em: $<$ http://www.scielo.br/scielo.php?script=sci_arttext\&pid=S0034-

$75902014000200005 \& \operatorname{lng}=$ en\&nrm=iso>. Acesso em: 10 dezembro 2014.

NEGROPONTE, N. A vida digital. São Paulo: Companhia das Letras, 1995.

NEITZEL, L. C. Novas Tecnologias e Práticas Docentes: o hipertexto no processo de construção do conhecimento (uma experiência vivenciada na rede pública estadual de Santa Catarina). 2001. Dissertação (Mestrado em Mídia e Conhecimento), Universidade Federal de Santa Catarina, Florianópolis.

NERI, M. Mapa da inclusão digital. Rio de Janeiro: FGV/CPS, 2012. Disponível em <http://www.cps.fgv.br/cps/telefonica/>. Acesso em 20 junho 2014.

NITZKE, J.A.; CARNEIRO, M. L.; FRANCO, S.R.K. Ambientes de Aprendizagem Cooperativa Apoiado pelo Computador e sua Epistemologia. Informática na educação: teoria \& prática, v. 5, n.1, maio. 2002.

OCDE. Programme for International Student Assessment - PISA. 2012.

Disponível em 〈http://www.oecd.org/pisa/keyfindings/PISA-2012-results-brazil.pdf>. Acesso em: 5 setembro 2014. 
OZCELIK, E., ACARTURK, C. Reducing the spatial distance between printed and online information sources by means of mobile technology enhances learning: Using 2D barcodes. Computers \& Education, v.57,p.2077-2085,2011. Disponível em:

<http://www.sciencedirect.com/science/article/pii/S0360131511001254>. Acesso em: 20 junho 2014. Acesso em: 5 setembro 2014.

PAPERT, S. A máquina das crianças: repensando a escola na era da informática. Porto Alegre: Artes Médicas, 1994.

PERRENOUD, P. 10 novas competências para ensinar. Porto Alegre: Artes Médicas,2000.

PIRES, E. S.. Coordenador pedagógico: o alcance da sua ação e aspectos de seu fortalecimento e legitimidade no contexto escolar. 2014. Dissertação (Mestrado em Educação)—Universidade de Brasília, Brasília, 2014.

PONTES, A.C.F; CORRENTE J.E. Comparações múltiplas não-paramétricas para o delineamento com um fator de classificação simples. Rev. Mat. Estat. v.19, p. 179-197. 2001.

POZO, J. I. A sociedade da aprendizagem e o desafio de converter informação em conhecimento. Revista Pedagógica, v. 8, p. 34-36, ago. 2004.

PRENSKY, M.Digital Natives Digital Immigrants. Em: PRENSKY, M. On the Horizon. NCB University Press, v. 9, n. 5. 2001.

RICHARDSON, R. J. Pesquisa social: métodos e técnicas. São Paulo: Atlas,1989.

RIPPER, A. V. O preparo do professor para as novas tecnologias. Em:

OLIVEIRA, V.B. Informática em Psicopedagogia. São Paulo: SENAC São Paulo. 1996.

ROCKINSON-SZAPKIW, A., COURDUFF, J., CARTER, K., BENNETT, D. Electronic versus traditional print textbooks: A comparison study on the influence of university students' learning. Computers \& Education, v.63,p.259-266, 2013. Disponível em:

<http://www.sciencedirect.com/science/article/pii/S0360131512002953>. Acesso em: 14 junho 2014.

RODRIGUES, A.; PAULO, E. Introdução à Análise Multivariada. Em: CORRAR, L. J.; PAULO, E.; DIAS FILHO, J. M. (Coord.). Análise multivariada para cursos de Administração, Ciências Contábeis e Economia. São Paulo: Atlas, 2012. p. 1-72. 
ROSALEN, M.; MAZILLI, S. Formação de professores para o uso da Informática nas escolas: evidências da prática. REUNIÃO ANUAL DA ASSOCIAÇÃO NACIONAL DE PÓS-GRADUAÇÃO E PESQUISA EM EDUCAÇẪO, 28, 2005, Caxambu. Anais ANPEd, p. 1-17. 2005.

SACCOL, A. Z. Um retorno ao básico: compreendendo os paradigmas de pesquisa e sua aplicação na pesquisa em Administração. Revista de Administração da UFSM , v. 2, p. 277-300, 2009.

SAMPAIO, C. E. M.; OLIVEIRA, L. A.; NESPOLI, V. A informática no suporte ao desenvolvimento do processo ensino-aprendizagem na educação básica no Brasil. Revista Brasileira de Estudos Pedagógicos. Brasília, v. 86, n. 213/214, p. 121-141, maio/dez. 2005.

SAMPIERI, R. H.; COLLADO, C. F.; LUCIO, P. B. Metodologia de pesquisa. 3. ed. São Paulo: McGraw-Hill Interamericana do Brasil Ltda. 2006.

SANCHEZ, O. P.; CAPPELLOZZA, A. Antecedentes da adoção da computação em nuvem: efeitos da infraestrutura, investimento e porte. Rev. adm. contemp., Curitiba, v. 16, n. 5, outubro. 2012. Disponível em:

$<$ http://www.scielo.br/scielo.php?script=sci_arttext\&pid=S1415-

65552012000500002\&lng=en\&nrm=iso>. Acesso em: 10 dezembro 2014.

SANCHO, J. M.; HERNÁNDEZ, F. Tecnologias para transformar a educação. Tradução Valério Campos. Porto Alegre: Artmed, 2006.

SANTAELLA, L. Da cultura das mídias à cibercultura: o advento do póshumano. Famecos, Porto Alegre, n. 22, 23-32, dez. 2003.

SANTOS, E. G. Padrões de adoção de tecnologias de informação e comunicação em empresas brasileiras: uma análise dos gastos em TI, dos impactos de TI e de seus reflexos no desempenho organizacional. 2013. Dissertação (Mestrado em Engenharia de Produção) - Escola Politécnica, Universidade de São Paulo, São Paulo, 2013. Disponível em: <http://www.teses.usp.br/teses/disponiveis/3/3136/tde21102013-101522/>.

SCHILLER, J. Working with ICT Perceptions of Australian principals. Journal of Educational Administration, v. 41, n. 2, p.171-185. 2003.

SCHMIDT, S.; PRADO, P.; NEVES A. Infraestrutura de TI e tecnologias emergentes, Em: PRADO, E.; DE SOUZA, C. (org.). Fundamentos de Sistemas de Informação. 2014.

SHARMA, S. K.; KITCHENS, F. L. Web services architecture for M-learning. Electronic Journal on E-Learning, v.2, n. 1, p. 203-216, fev. 2004. 
SILVA, J. S. F. Modelagem de Equações Estruturais: apresentação de uma metodologia. 2006. Dissertação (Mestrado), Programa de Pós-Graduação em Engenharia de Produção, Universidade Federal do Rio Grande do Sul, Porto Alegre, 2006.

SILVA, S. C.; CAMPOS, M. F. H. A melhoria da qualidade da educação na escola pública: desafios ao uso das TICs. Revista Estudos IAT, Salvador, v. 1, n. 3, p. 138154, dez. 2010.

SIQUEIRA, E. S. Exclusão digital de pequenas e médias empresas brasileiras e os fatores que influenciam a adoção das TICs nessas organizações: um estudo exploratório dos dados da pesquisa TIC empresas. 2014. Dissertação (Mestrado em Administração) - Faculdade de Economia, Administração e Contabilidade, Universidade de São Paulo, São Paulo, 2014. Disponível em: <http://www.teses.usp.br/teses/disponiveis/12/12139/tde-09122014-151046/>. Acesso em: 5 março 2015.

SOARES, T. M. Influência do professor e do ambiente em sala de aula sobre a proficiência alcançada pelos alunos avaliados no SIMAVE-2002. Estudos em Avaliação Educacional, São Paulo, n. 28, p. 103-124. 2003.

Utilização da Teoria da Resposta ao Item na Produção de Indicadores Socioeconômicos. Pesquisa Operacional, Rio de Janeiro, v. 25, n. 1, p. 83-112. 2005.

SOLAR, M.; SABATTIN, J.; PARADA, V. A Maturity Model for Assessing the Use of ICT in School Education. Educational Technology \& Society, v.16, n.1, p. 206-218. 2013.

SOUZA A. G.; LINHARES R. N. Políticas Pública de Educação e Tecnologia: O histórico das TICs no processo Educativo. V Colóquio Internacional de Educação e Contemporaneidade, p.1-15. 2011. Disponível em: < http://www.geppc.org.br/sites/default/files/uploads/evento/192/anais/gt05.pdf $>$. Acesso em: 5 julho 2014.

SOUZA, C. A. Uso organizacional da tecnologia de informação: um estudo sobre a avaliação do grau de informatização de empresas industriais paulistas. 2004. Tese (Doutorado em Administração) - Faculdade de Economia, Administração e Contabilidade, Universidade de São Paulo, São Paulo, 2004. Disponível em: $<$ http://www.teses.usp.br/teses/disponiveis/12/12139/tde-17042006-193159/>. Acesso em: 1 fevereiro 2015.

TAJRA, S. Informática na Educação: novas ferramentas pedagógicas para o professor da atualidade. $3^{\text {a }}$ ed. São Paulo: Editora Érica. 2004. 
THOMPSON, A. C. A. Computer Education Manifest. 2007. Disponível em : < http://www.acthompson.net/ComputerEd.htm>. Acesso em: 1 março 2014.

TRINDADE, E. S. C. Contribuições da formação de professores para o uso das TICS na escola: um estudo de caso no Curso de Graduação - Licenciatura em Pedagogia a Distância da Universidade Federal do Rio Grande do Sul. 2010. Dissertação (Mestrado em Educação) - Programa de Pós-Graduação em Educação, Universidade Federal do Rio Grande Do Sul, Porto Alegre, 2010. Disponível em: < http://www.lume.ufrgs.br/handle/10183/26302 >. Acesso em: 1 março 2014.

UNESCO BRASIL. Computador na escola - o futuro anunciado, Revista TIC nas Escolas, vol. 3, n. 1. 2008a.

. Computador na escola - tecnologia e aprendizagem, Revista TIC nas Escolas, vol. 3, n, 3. 2008b.

UIS. Global education digest 2009: Comparing education statistics across the world. Montreal: UIS. 2009.

VALDIVIA, I. J. Las políticas de tecnología para escuelas en América Latina y el mundo: visiones y lecciones, Santiago de Chile, Naciones Unidas. 2008. Disponível em $:<$ http://www.ceppe.cl/images/stories/recursos/publicaciones/Ignacio\%20Jara/Laspoliticas-de-tecnologia-para-escuelas-en-America-Latina-y-el-mundo.-.pdf $>$. Acesso em: 1 março 2014.

VALENTE, J. A. Por quê o Computador na Educação? Em: Valente, José Armando (org.), Computadores e Conhecimento: repensando a educação, p. 24-44. Campinas, SP: Gráfica da UNICAMP. 1993.

. Informática na Educação no Brasil: análise e contextualização histórica. Em: Valente, José Armando (org.), O computador na sociedade do conhecimento. 2008.

. Um laptop para cada aluno: promessas e resultados. Em: ALMEIDA, M. E. B. de; PRADO, M. E B. B. O computador portátil na escola: mudanças e desafios nos processos de aprendizagem. São Paulo: Avercamp. 2011.

VALENTE, J. A.; BUSTAMANTE, S. B. V. Educação a distância: prática e formação do profissional reflexivo. São Paulo: Avercamp. 2009.

VIEIRA, V. A. As tipologias, variações e características da pesquisa de marketing. Revista da FAE, Curitiba, v. 5, n. 1, p. 61-70, jan/abr. 2002.

WANG, Y-S.; WU, M-C.; WANG H-Y. Investigating the determinants and age and gender differences in the acceptance of mobile learning. British Journal of 
Educational Technology, v. 40, n.1, p. 92-118, jan. 2009.

WASTIAU, P.; BLAMIRE, R.; KEARNEY, C.; QUITTRE, V.; VAN DE GAER, E.; MONSEUR, C. The Use of ICT in Education: a survey of schools in Europe.

European Journal of Education, v.48, p. 11-27. 2013.

WETZELS, M.; ODEKERKEN-SCHRODER, G.; VAN OPPEN, C. Using PLS path modeling for assessing hierarchical construct models: guidelines and empirical illustration. Management Information Systems Quarterly, v.33, n.1, p. 177-195. 2009.

ZWICKER, R.; SOUZA, C. A. de; VIDAL, A. G. da R.; SIQUEIRA, J. de O. Grau de informatização de empresas: um modelo estrutural aplicado ao setor industrial do estado de São Paulo. RAE-eletrônica, v. 6, n. 2, art. 13, julho/dezembro. 2007.

ZWICKER, R.; SOUZA, C. A.; BIDO, D. S. Uma revisão do Modelo do Grau de Informatização de Empresas: novas propostas de estimação e modelagem usando PLS (partial least squares). XXXII Encontro da Associação Nacional dos Programas de Pós-Graduação em Administração, 2008, Rio de Janeiro, Anais. Rio de Janeiro: ANPAD, 2008. 


\section{ANEXOS}

\section{ANEXO A}

TIC PISA 2009: questões utilizadas no estudo de Biagi e LOI (2013)

Q1 Are any of these devices available for you to use at home?

(Please tick one box on each row)

\begin{tabular}{lccc}
\hline & Yes, and & Yes, but I & No \\
& I use it & don't use it & \\
\hline a) Desktop computer & $\square$ & $\square$ & $\square$ \\
b) Portable laptop computer & $\square$ & $\square$ & $\square$ \\
c) Internet connection & $\square$ & $\square$ & $\square$ \\
d) <Video games console>, e.g. <Sony PlayStationTM> & $\square$ & $\square$ & $\square$ \\
e) Cell phone & $\square$ & $\square$ & $\square$ \\
f) Mp3/Mp4 player, iPod or similar & $\square$ & $\square$ & $\square$ \\
g) Printer & $\square$ & $\square$ & $\square$ \\
h) Usb (memory) stick & $\square$ & $\square$ & $\square$ \\
\hline
\end{tabular}

Q2 Are any of these devices available for you to use at school?

(Please tick one box on each row)

\begin{tabular}{lccc}
\hline & Yes, and I use it & Yes, but I don't use it & No \\
\hline a) Desktop computer & $\square$ & $\square$ & $\square$ \\
b) Portable laptop computer & $\square$ & $\square$ & $\square$ \\
c) Internet connection & $\square$ & $\square$ & $\square$ \\
d) Printer & $\square$ & $\square$ & $\square$ \\
e) Usb (memory) stick & $\square$ & $\square$ & $\square$ \\
\hline
\end{tabular}

Q4 How often do you use a computer for the following activities at home? (Please tick one box on each row)

\begin{tabular}{|c|c|c|c|c|}
\hline & $\begin{array}{l}\text { Never or } \\
\text { hardly } \\
\text { ever }\end{array}$ & $\begin{array}{l}\text { Once or } \\
\text { twice a } \\
\text { month }\end{array}$ & $\begin{array}{l}\text { Once or } \\
\text { twice a } \\
\text { week }\end{array}$ & $\begin{array}{l}\text { Every day } \\
\text { or almost } \\
\text { every day }\end{array}$ \\
\hline a) Play one-player games & $\square$ & $\square$ & $\square$ & $\square$ \\
\hline b) Play collaborative online games & $\square$ & $\square$ & $\square$ & $\square$ \\
\hline c) Doing homework on the computer & $\square$ & $\square$ & $\square$ & $\square$ \\
\hline d) Use e-mail & $\square$ & $\square$ & $\square$ & $\square$ \\
\hline e) $<$ Chat online $>$ (e.g. MSN $^{8}$ ) & $\square$ & $\square$ & $\square$ & $\square$ \\
\hline $\begin{array}{l}\text { f) Browse the internet for fun (such as watching } \\
\text { videos, e.g. }\left\langle\text { YouTube }^{\mathrm{TM}}>\text { ) }\right.\end{array}$ & $\square$ & $\square$ & $\square$ & $\square$ \\
\hline $\begin{array}{l}\text { g) Download music, films, games or software } \\
\text { from the internet }\end{array}$ & $\square$ & $\square$ & $\square$ & $\square$ \\
\hline $\begin{array}{l}\text { h) Publish and maintain a personal website, } \\
\text { weblog or blog }\end{array}$ & $\square$ & $\square$ & $\square$ & $\square$ \\
\hline $\begin{array}{l}\text { i) Participate in online forums, virtual } \\
\text { communities or spaces (e.g. }<\text { Second Life } \\
\text { or MySpace }{ }^{\mathrm{TM}}>\text { ) }\end{array}$ & $\square$ & $\square$ & $\square$ & $\square$ \\
\hline
\end{tabular}


Q5 How often do you do the following at home?

(Please tick one box on each row)

\begin{tabular}{lcccc}
\hline & $\begin{array}{c}\text { Never or } \\
\text { hardly } \\
\text { ever }\end{array}$ & $\begin{array}{c}\text { Once or } \\
\text { twice a } \\
\text { month }\end{array}$ & $\begin{array}{c}\text { Once or } \\
\text { twice a } \\
\text { week }\end{array}$ & $\begin{array}{c}\text { Every day } \\
\text { or almost } \\
\text { every day }\end{array}$ \\
\hline $\begin{array}{l}\text { a) Browse the internet for schoolwork (e.g. preparing } \\
\text { and essay or a presentation) }\end{array}$ & $\square$ & $\square$ & $\square$ & $\square$ \\
$\begin{array}{c}\text { b) Use e-mail for communication with other students } \\
\text { about schoolwork }\end{array}$ & $\square$ & $\square$ & $\square$ & $\square$ \\
$\begin{array}{c}\text { c) Use e-mail for communication with teachers and } \\
\text { submission of homework or other schoolwork }\end{array}$ & $\square$ & $\square$ & $\square$ & $\square$ \\
$\begin{array}{l}\text { d) Download, upload or browse material from your } \\
\text { school's website (e.g. time table or course materials) }\end{array}$ & $\square$ & $\square$ & $\square$ & $\square$ \\
e) Check school's website for announcements, e.g. & $\square$ & $\square$ & $\square$ & $\square$ \\
absence of teachers & & & & $\square$ \\
\hline
\end{tabular}

Q6 How often do you use a computer for the following activities at school? (Please tick one box on each row)

\begin{tabular}{lcccc}
\hline & $\begin{array}{c}\text { Never or } \\
\text { hardly } \\
\text { ever }\end{array}$ & $\begin{array}{c}\text { Once or } \\
\text { twice a } \\
\text { month }\end{array}$ & $\begin{array}{c}\text { Once or } \\
\text { twice a } \\
\text { week }\end{array}$ & $\begin{array}{c}\text { Every day } \\
\text { or almost } \\
\text { every day }\end{array}$ \\
\hline a) <Chat on line > at school & $\square$ & $\square$ & $\square$ & $\square$ \\
b) Use e-mail at school & $\square$ & $\square$ & $\square$ & $\square$ \\
c) Browse the internet for schoolwork & $\square$ & $\square$ & $\square$ & $\square$ \\
d) Download, upload or browse material from your & $\square$ & $\square$ & $\square$ & $\square$ \\
$\begin{array}{l}\text { school's website (e.g. <intranet>) } \\
\text { e) Post your work on the school's website }\end{array}$ & $\square$ & $\square$ & $\square$ & $\square$ \\
f) Play simulations at school & $\square$ & $\square$ & $\square$ & $\square$ \\
g) Practice and drilling, such as for foreign language & $\square$ & $\square$ & $\square$ & $\square$ \\
learning or mathematics & & $\square$ & $\square$ & $\square$ \\
h) Doing individual homework on a school computer & $\square$ & $\square$ & $\square$ \\
i) Use school computers for group work and & $\square$ & $\square$ & $\square$ & $\square$ \\
communication with other students & & & & \\
\hline
\end{tabular}




\section{ANEXO B}

\section{Dicionário das variáveis contidas no questionário aplicado aos diretores} entrevistados pela pesquisa TIC Educação

\begin{tabular}{|c|c|c|c|}
\hline ID da variável & Descrição da variável & Tipo & Código e rótulo da variável \\
\hline COD_ESCOLA & Código da Escola & Numérico & \\
\hline QUEST & $\begin{array}{l}\text { Número de identificação do } \\
\text { questionário }\end{array}$ & Numérico & \\
\hline LOTE & Numero do lote & Numérico & \\
\hline INICIO & Horário de início de entrevista & Numérico & \\
\hline TERMINO & Horário de término da entrevista & Numérico & \\
\hline N_ESCOLA & Número de identificação da Escola & Numérico & \\
\hline$\overline{U F}$ & Código da Unidade Federativa & Numérico & $\begin{array}{l}11=" \mathrm{RO} \\
12=" A C " \\
13=" A M " \\
14=" R R " \\
15=" P A " \\
16=" A P " \\
17=" T O " \\
21=" M A " \\
22=" P I " \\
23=" C E " \\
24=" R N " \\
25=" P B " \\
26=" P E " \\
27=" A L " \\
28=" S E " \\
29=" B A " \\
31=" M G " \\
32==" E S " \\
33=" R J " \\
35=" S P " \\
41=" P R " \\
42=" S C " \\
43=" R S " \\
50=" M S " \\
51=" M T " \\
52=" G O " \\
53=" D F "\end{array}$ \\
\hline REG & Nome da Região & Numérico & $\begin{array}{l}\text { 1="NORTE" } \\
2=" N O R D E S T E " \\
3=" S U D E S T E " \\
\text { 4="SUL" } \\
\text { 5="CENTRO OESTE" }\end{array}$ \\
\hline DEPEND & Dependência administrativa & Numérico & $\begin{array}{l}\text { 1="Municipal" } \\
\text { 2="Estadual" } \\
\text { 3="Particular" }\end{array}$ \\
\hline ESTADO & Estado & Texto & \\
\hline MUNICIPIO & Município & Texto & \\
\hline MUNIC_OUT & Código do Município & Numérico & \\
\hline NOME_ESCOLA & Nome da Escola & Texto & \\
\hline SERIE & Série cursada & Numérico & $\begin{array}{l}1=" 5^{\mathrm{a}} \text { ano do Ens. Fundamental" } \\
2=" 9^{\mathrm{a}} \text { ano do Ens. Fundamental" } \\
3=" 2^{\circ} \text { ano Ens. Médio" }\end{array}$ \\
\hline SEXO & Sexo & Numérico & $\begin{array}{l}\text { 1="Feminino" } \\
2=\text { ="Masculino" }\end{array}$ \\
\hline $\mathrm{P} 2$ & Idade & Numérico & \\
\hline
\end{tabular}




\begin{tabular}{|c|c|c|c|}
\hline P2_FX & Faixa Etária & Numérico & $\begin{array}{l}1=" 18 \text { a } 24 \text { anos" } \\
2==25 \text { a } 34 \text { anos" } \\
3=" 35 \text { a } 44 \text { anos" } \\
4=" 45 \text { a } 59 \text { anos" } \\
5=" 60 \text { anos ou mais" }\end{array}$ \\
\hline $\mathrm{P} 3$ & Cor ou raça & Numérico & $\begin{array}{l}\text { 1="Branca" } \\
2=\text { ="Preta" } \\
\text { 3="Parda" } \\
\text { 4="Amarela" } \\
\text { 5="Indígena" }\end{array}$ \\
\hline P401 A P407 & Nível máximo de escolaridade & Numérico & 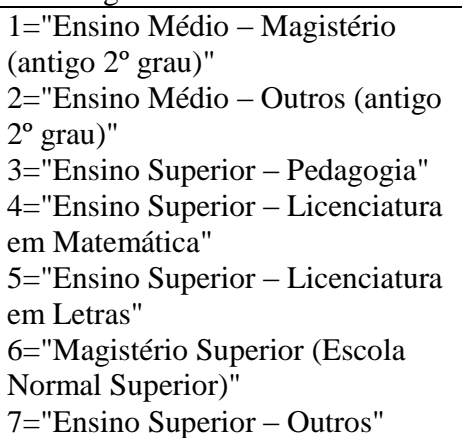 \\
\hline P5 & $\begin{array}{l}\text { Curso de mais alta titulação } \\
\text { completado }\end{array}$ & Numérico & $\begin{array}{l}\text { 1="Não fez ou ainda não completou } \\
\text { nenhum curso de pós-graduação" } \\
2=\text { ="Especialização (mínimo de } 360 \\
\text { horas)" } \\
3=\text { ="Mestrado" } \\
\text { 4="Doutorado" }\end{array}$ \\
\hline P6_ANOS & $\begin{array}{l}\text { Tempo de exercício da função de } \\
\text { Diretor } \\
\text { (em anos) }\end{array}$ & Numérico & \\
\hline P6_MES & $\begin{array}{l}\text { Tempo de exercício da função de } \\
\text { Diretor } \\
\text { (em meses) }\end{array}$ & Numérico & \\
\hline P6X & $\begin{array}{l}\text { Tempo de exercício da função de } \\
\text { Diretor }\end{array}$ & Numérico & $\begin{array}{l}2=\text { ="Até } 2 \text { anos" } \\
5==\text { De } 3 \text { a } 5 \text { anos" } \\
10=" D e \text { a } 10 \text { anos" } \\
11=" 11 \text { anos ou mais" }\end{array}$ \\
\hline P7 & $\begin{array}{l}\text { Quantidade de alunos matriculados } \\
\text { na Escola }\end{array}$ & Numérico & \\
\hline P7_FAIXA & $\begin{array}{l}\text { Quantidade de alunos matriculados } \\
\text { na } \\
\text { (Faixas) }\end{array}$ & Numérico & $\begin{array}{l}250=\text { ="Até } 250 \text { alunos" } \\
500=" \text { De } 251 \text { a } 500 \text { alunos" } \\
1000=" D e \text { 501 a } 1000 \text { alunos" } \\
1500=" D e 1001 \text { a } 1500 \text { alunos" } \\
1501=\text { ="Mais de } 1501 \text { alunos" }\end{array}$ \\
\hline P8_FAIXA & $\begin{array}{llll}\text { Quantidade } & \text { de } & \text { Professores } & \text { de } \\
\text { Informática } & & & \end{array}$ & Numérico & $\begin{array}{l}1=" \text { Até } 15 \text { professores" } \\
2=\text { ="De } 16 \text { a } 30 \text { professores" } \\
3=\text { ="De } 31 \text { a } 50 \text { professores" } \\
4=" 51 \text { e mais professores" }\end{array}$ \\
\hline P901_FAIXA & $\begin{array}{l}\text { Quantidade de Turmas de Educação } \\
\text { Infantil }\end{array}$ & Numérico & $\begin{array}{l}5=" \text { Até } 5 \text { turmas" } \\
10=" 6 \text { a } 10 \text { turmas" } \\
15=" 11 \text { a } 15 \text { turmas" } \\
20=" 16 \text { a } 20 \text { turmas" } \\
21=" 21 \text { turmas ou mais" } \\
99=" \text { ão há turmas deste nível" }\end{array}$ \\
\hline P902_FAIXA & $\begin{array}{l}\text { Quantidade de Turmas de Ensino } \\
\text { Fundamental I }\end{array}$ & Numérico & $\begin{array}{l}5=" \text { Até } 5 \text { turmas" } \\
10=" 6 \text { a } 10 \text { turmas" } \\
15=" 11 \text { a } 15 \text { turmas" } \\
20=" 16 \text { a } 20 \text { turmas" } \\
21=" 21 \text { turmas ou mais" } \\
99=" \text { ão há turmas deste nível" }\end{array}$ \\
\hline P903_FAIXA & $\begin{array}{l}\text { Quantidade de Turmas de Ensino } \\
\text { Fundamental II }\end{array}$ & Numérico & $\begin{array}{l}5=" \text { Até } 5 \text { turmas" } \\
10=" 6 \text { a } 10 \text { turmas" } \\
15=" 11 \text { a } 15 \text { turmas" } \\
20=" 16 \text { a } 20 \text { turmas" } \\
21=" 21 \text { turmas ou mais" }\end{array}$ \\
\hline
\end{tabular}




\begin{tabular}{|c|c|c|c|}
\hline & & & 99="Não há turmas deste nível" \\
\hline P904_FAIXA & $\begin{array}{l}\text { Quantidade de Turmas do Ensino } \\
\text { Médio }\end{array}$ & Numérico & $\begin{array}{l}5=" \text { Até } 5 \text { turmas" } \\
10=" 6 \text { a } 10 \text { turmas" } \\
15=" 11 \text { a } 15 \text { turmas" } \\
20=" 16 \text { a } 20 \text { turmas" } \\
21=" 21 \text { turmas ou mais" } \\
99=" \text { ão há turmas deste nível" }\end{array}$ \\
\hline P1001_FAIXA & $\begin{array}{l}\text { Quantidade média de alunos na } \\
\text { turma de educação infantil }\end{array}$ & Numérico & $\begin{array}{l}100=" \text { Até } 25 \text { alunos" } \\
200=" 26 \text { a } 30 \text { alunos" } \\
300=" 31 \text { a } 35 \text { alunos" } \\
400=" 36 \text { alunos ou mais" } \\
999=" \text { Não há turmas deste nível" }\end{array}$ \\
\hline P1002_FAIXA & $\begin{array}{l}\text { Quantidade média de alunos na } \\
\text { turma de ensino fundamental I }\end{array}$ & Numérico & $\begin{array}{l}100=" \text { Até } 25 \text { alunos" } \\
200=" 26 \text { a } 30 \text { alunos" } \\
300=" 31 \text { a } 35 \text { alunos" } \\
400=" 36 \text { alunos ou mais" } \\
999=" \text { Não há turmas deste nível" }\end{array}$ \\
\hline P1003_FAIXA & $\begin{array}{l}\text { Quantidade média de alunos na } \\
\text { turma de ensino fundamental II }\end{array}$ & Numérico & $\begin{array}{l}100=" \text { Até } 25 \text { alunos" } \\
200=" 26 \text { a } 30 \text { alunos" } \\
300=" 31 \text { a } 35 \text { alunos" } \\
400=" 36 \text { alunos ou mais" } \\
999=" \text { Não há turmas deste nível" }\end{array}$ \\
\hline P1004_FAIXA & $\begin{array}{l}\text { Quantidade média de alunos na } \\
\text { turma do ensino médio }\end{array}$ & Numérico & $\begin{array}{l}100=" \text { Até } 25 \text { alunos" } \\
200=" 26 \text { a } 30 \text { alunos" } \\
300=" 31 \text { a } 35 \text { alunos" } \\
400=" 36 \text { alunos ou mais" } \\
999=" \text { Não há turmas deste nível" }\end{array}$ \\
\hline P1101 A P1104 & $\begin{array}{l}\text { Períodos de funcionamento da } \\
\text { escola }\end{array}$ & Numérico & $\begin{array}{l}\text { 1="Manhã" } \\
2=\text { ="Tarde" } \\
3=\text { ="Noite" } \\
\text { 4="Integral" }\end{array}$ \\
\hline P12 & Escola dispõe de energia elétrica & Numérico & $\begin{array}{l}1=" \text { Sim" } \\
\text { 2="Não" } \\
8=" N a ̃ o \text { sabe" }\end{array}$ \\
\hline P13 & $\begin{array}{l}\text { Energia elétrica adequada para o uso } \\
\text { simultâneo de todos os } \\
\text { equipamentos elétricos da escola }\end{array}$ & Numérico & $\begin{array}{l}1=\text { ="Sim" } \\
\text { 2="Não" } \\
8=\text { ="Não sabe" }\end{array}$ \\
\hline P14 & Possui de computador em casa & Numérico & $\begin{array}{l}\text { 1="Sim" } \\
\text { 2="Não" }\end{array}$ \\
\hline P15 & Tipo de computador em casa & Numérico & $\begin{array}{l}\text { 1="Computador de mesa" } \\
2=\text { "Computador portátil (notebook / } \\
\text { laptop / netbook)" } \\
3=\text { "Tablet" }\end{array}$ \\
\hline P16 & $\begin{array}{l}\text { Levou o seu computador portátil } \\
\text { para a escola alguma vez }\end{array}$ & Numérico & $\begin{array}{l}\text { 1="Sim" } \\
\text { 2="Não" }\end{array}$ \\
\hline P17 & Acesso à Internet na residência & Numérico & $\begin{array}{l}\text { 1="Sim" } \\
\text { 2="Não" } \\
8=" N a ̃ o ~ s a b e "\end{array}$ \\
\hline P18 & Acesso à Internet pelo celular & Numérico & $\begin{array}{l}\text { 1="Sim" } \\
\text { 2="Não" }\end{array}$ \\
\hline P1901 & $\begin{array}{l}\text { O computador e a Internet são } \\
\text { habitualmente utilizados pelos } \\
\text { funcionários da escola para escrever } \\
\text { documentos, relatórios } \\
\text { comunicados? }\end{array}$ & Numérico & $\begin{array}{l}\text { 1="Sim" } \\
\text { 2="Não" } \\
\text { 8="Não sabe" } \\
\text { 9="Não respondeu" }\end{array}$ \\
\hline P1902 & $\begin{array}{l}\text { O computador e a internet são } \\
\text { habitualmente utilizados pelos } \\
\text { funcionários da escola para fazer } \\
\text { orçamentos e controle de gastos? }\end{array}$ & Numérico & $\begin{array}{l}\text { 1="Sim" } \\
\text { 2="Não" } \\
\text { 8="Não sabe" } \\
\text { 9="Não respondeu" }\end{array}$ \\
\hline
\end{tabular}




\begin{tabular}{|c|c|c|c|}
\hline P1903 & $\begin{array}{lccr}\text { O computador } & \text { e a internet } & \text { são } \\
\text { habitualmente } & \text { utilizados } & \text { pelos } \\
\text { funcionários da } & \text { escola } & \text { para } \\
\text { comunicarem-se } & \text { com } & \text { os } \\
\text { professores? } & & \\
\end{array}$ & Numérico & $\begin{array}{l}\text { 1="Sim" } \\
\text { 2="Não" } \\
\text { 8="Não sabe" } \\
\text { 9="Não respondeu" }\end{array}$ \\
\hline P1904 & $\begin{array}{l}\text { O computador e a internet são } \\
\text { habitualmente utilizados pelos } \\
\text { funcionários da escola para } \\
\text { comunicarem-se com os pais de } \\
\text { alunos? }\end{array}$ & Numérico & $\begin{array}{l}\text { 1="Sim" } \\
\text { 2="Não" } \\
\text { 8="Não sabe" } \\
\text { 9="Não respondeu" }\end{array}$ \\
\hline P1905 & $\begin{array}{l}\text { O computador e a Internet são } \\
\text { habitualmente utilizados pelos } \\
\text { funcionários da escola para buscar } \\
\text { informações? }\end{array}$ & Numérico & $\begin{array}{l}\text { 1="Sim" } \\
\text { 2="Não" } \\
\text { 8="Não sabe" } \\
\text { 9="Não respondeu" }\end{array}$ \\
\hline P1906 & $\begin{array}{l}\text { O computador e a Internet são } \\
\text { habitualmente utilizados pelos } \\
\text { funcionários da escola para preparar } \\
\text { e fazer apresentações? }\end{array}$ & Numérico & $\begin{array}{l}\text { 1="Sim" } \\
\text { 2="Não" } \\
\text { 8="Não sabe" } \\
\text { 9="Não respondeu" }\end{array}$ \\
\hline P1907 & $\begin{array}{l}\text { O computador e a Internet são } \\
\text { habitualmente utilizados pelos } \\
\text { funcionários da escola para fazer } \\
\text { cronogramas/grade de horários? }\end{array}$ & Numérico & $\begin{array}{l}\text { 1="Sim" } \\
\text { 2="Não" } \\
\text { 8="Não sabe" } \\
\text { 9="Não respondeu" }\end{array}$ \\
\hline P1908 & $\begin{array}{l}\text { O computador e a Internet são } \\
\text { habitualmente utilizados pelos } \\
\text { funcionários da escola para } \\
\text { administrar compromissos pessoais } \\
\text { (agenda)? }\end{array}$ & Numérico & $\begin{array}{l}\text { 1="Sim" } \\
\text { 2="Não" } \\
\text { 8="Não sabe" } \\
\text { 9="Não respondeu" }\end{array}$ \\
\hline P20 & $\begin{array}{l}\text { Existência de projeto/programa de } \\
\text { capacitação dos professores para o } \\
\text { uso de computador e Internet para } \\
\text { fins pedagógicos }\end{array}$ & Numérico & $\begin{array}{l}\text { 1="Sim" } \\
\text { 2="Não/ ainda não" }\end{array}$ \\
\hline P21 & $\begin{array}{l}\text { Instituição que implementa e } \\
\text { mantem o programa de capacitação } \\
\text { de professores }\end{array}$ & Numérico & $\begin{array}{l}\text { 1="Pela própria escola" } \\
2=\text { =Pelo governo federal" } \\
3=\text { =Pelo governo estadual" } \\
\text { 4="Pelo governo municipal/ } \\
\text { Prefeitura" } \\
\text { 5="Pela iniciativa privada" } \\
6=" P o r \text { uma organização não } \\
\text { governamental (ONG)" } \\
\text { 9="6 OUTROS" }\end{array}$ \\
\hline P2201 & $\begin{array}{l}\text { Esta escola conta com professor de } \\
\text { informática, que dê aulas específicas } \\
\text { de informática? }\end{array}$ & Numérico & $\begin{array}{l}1=" S i m " \\
\text { 2="Não" }\end{array}$ \\
\hline P2202 & $\begin{array}{l}\text { Esta escola conta com monitor no } \\
\text { laboratório de informática na escola? }\end{array}$ & Numérico & $\begin{array}{l}\text { 1="Sim" } \\
\text { 2="Não" }\end{array}$ \\
\hline P2203 & Coordenador pedagógico na escola & Numérico & $\begin{array}{l}\text { 1="Sim" } \\
\text { 2="Não" }\end{array}$ \\
\hline P23 & $\begin{array}{l}\text { Responsabilidades de monitor do } \\
\text { laboratório de informática }\end{array}$ & Numérico & $\begin{array}{l}\text { 1="É responsável somente pelo } \\
\text { laboratório" } \\
2=\text { ="Exerce outras funções na escola } \\
\text { relacionadas à informática ou ao uso } \\
\text { de outras tecnologias" } \\
3=\text { ="Exerce outras funções na escola, } \\
\text { mas não somente relacionadas à } \\
\text { informática ou ao uso de outras } \\
\text { tecnologias" }\end{array}$ \\
\hline P2401 & $\begin{array}{l}\text { Computadores instalados ou não na } \\
\text { escola }\end{array}$ & Numérico & $\begin{array}{l}\text { 1="Sim. Quantos no total?" } \\
\text { 2="Não" }\end{array}$ \\
\hline P2402 & $\begin{array}{l}\text { Quantidade de computadores na } \\
\text { escola }\end{array}$ & Numérico & \\
\hline P2402_FAIXA & $\begin{array}{l}\text { Quantidade de computadores na } \\
\text { escola }\end{array}$ & Numérico & $\begin{array}{l}5=" \text { Até } 5 \text { computadores" } \\
15=" \text { De } 6 \text { a } 15 \text { computadores" } \\
20=" \text { De } 16 \text { a } 20 \text { computadores" } \\
30=" \text { e } 21 \text { a } 30 \text { computadores" } \\
40=" \text { De } 31 \text { a } 40 \text { computadores" } \\
200=" 41 \text { computadores ou mais" }\end{array}$ \\
\hline
\end{tabular}




\begin{tabular}{|c|c|c|c|}
\hline P2501 A P2504 & Tipo de computador na escola & Numérico & $\begin{array}{l}\text { 1="Computador de mesa" } \\
2=\text { ="Computador portátil } \\
\text { (notebook/laptop/netbook)" } \\
3=\text { ="Computador de mão/ palmtop" } \\
\text { 4="Tablet" }\end{array}$ \\
\hline P2601_FAIXA & $\begin{array}{l}\text { Quantidade de computadores de } \\
\text { mesa na escola }\end{array}$ & Numérico & $\begin{array}{l}5=" \text { Até } 5 " \\
15=" \text { De } 6 \text { a } 15 " \\
20=" \text { De } 16 \text { a } 20 " \\
30=" \text { De } 21 \text { a } 30 " \\
40=" D e \text { a } 40 " \\
200=" 41 \text { ou mais" }\end{array}$ \\
\hline P2602_FAIXA & $\begin{array}{l}\text { Quantidade de computadores } \\
\text { portáteis na escola }\end{array}$ & Numérico & $\begin{array}{l}1=" 1 " \\
2=" 2 " \\
89=" 3 \text { ou mais" }\end{array}$ \\
\hline P2603_FAIXA & $\begin{array}{l}\text { Quantidade de computadores de } \\
\text { mão na escola }\end{array}$ & Numérico & $\begin{array}{l}1=" 1 " \\
2=" 2 " \\
89=" 3 \text { ou mais" }\end{array}$ \\
\hline P2604_FAIXA & Quantidade de tablet na escola & Numérico & $\begin{array}{l}1=" 1 " \\
2=" 2 " \\
89=" 3 \text { ou mais" }\end{array}$ \\
\hline $\mathrm{P} 2701$ & $\begin{array}{l}\text { Quantos computadores de mesa } \\
\text { estão funcionando? }\end{array}$ & Numérico & \\
\hline $\mathrm{P} 2702$ & $\begin{array}{l}\text { Quantos computadores de portáteis } \\
\text { estão funcionando? }\end{array}$ & Numérico & \\
\hline P2703 & $\begin{array}{l}\text { Quantos computadores de mão estão } \\
\text { funcionando? }\end{array}$ & Numérico & \\
\hline P2704 & $\begin{array}{l}\text { Quantos computadores do tipo tablet } \\
\text { estão funcionando? }\end{array}$ & Numérico & \\
\hline $\mathrm{P} 2705$ & $\begin{array}{l}\text { Total de computadores } \mathrm{em} \\
\text { funcionamento da escola. }\end{array}$ & Numérico & \\
\hline P2701_FAIXA & $\begin{array}{l}\text { Quantidade de computadores de } \\
\text { mesa em funcionamento na escola }\end{array}$ & Numérico & $\begin{array}{l}0=" \text { Nenhum" } \\
5=" \text { Até } 5 " \\
15=" \text { De } 6 \text { a } 15 " \\
20=" \text { De } 16 \text { a } 20 " \\
30=" \text { De } 21 \text { a } 30 " \\
40=" \text { De } 31 \text { a } 40 " \\
200=" 41 \text { ou mais" }\end{array}$ \\
\hline P2702_FAIXA & $\begin{array}{l}\text { Quantidade } \mathrm{de} \text { computadores } \\
\text { portáteis em funcionamento na } \\
\text { escola }\end{array}$ & Numérico & $\begin{array}{l}0=" N e n h u m " \\
1=" 1 " \\
2=" 2 " \\
89=" 3 \text { ou mais" }\end{array}$ \\
\hline P2703_FAIXA & $\begin{array}{l}\text { Quantidade de computadores de } \\
\text { mão em funcionamento na escola }\end{array}$ & Numérico & $\begin{array}{l}0=" N e n h u m " \\
1=" 1 " \\
2=" 2 " \\
89=" 3 \text { ou mais" }\end{array}$ \\
\hline
\end{tabular}




\begin{tabular}{|c|c|c|c|}
\hline P2704_FAIXA & $\begin{array}{lll}\text { Quantidade de tablets } & \text { em } \\
\text { funcionamento na escola } & \end{array}$ & Numérico & $\begin{array}{l}0=" \text { Nenhum" } \\
1=" 1 " \\
2=" 2 " \\
89=" 3 \text { ou mais" }\end{array}$ \\
\hline P2801_FAIXA & $\begin{array}{l}\text { Quantidade de computadores de } \\
\text { mesa com acesso a Internet }\end{array}$ & Numérico & $\begin{array}{l}5=" \text { Até } 5 " \\
15=" D e \text { a } 15 " \\
20=" D e \text { e } 16 \text { a } \\
30=" D e \text { a } 30 " \\
40=" D e \text { e } 31 \text { a } 40 " \\
200=" 41 \text { ou mais" }\end{array}$ \\
\hline P2802_FAIXA & $\begin{array}{l}\text { Quantidade de computadores } \\
\text { portáteis com acesso a Internet }\end{array}$ & Numérico & $\begin{array}{l}1=" 1 " \\
2=" 2 " \\
89=" 3 \text { ou mais" }\end{array}$ \\
\hline P2803_FAIXA & $\begin{array}{l}\text { Quantidade de computadores de } \\
\text { mão com acesso a Internet }\end{array}$ & Numérico & $\begin{array}{l}1=" 1 " \\
2=" 2 " \\
89=" 3 \text { ou mais" }\end{array}$ \\
\hline P2804_FAIXA & $\begin{array}{l}\text { Quantidade de tablets com acesso a } \\
\text { Internet }\end{array}$ & Numérico & $\begin{array}{l}1=" 1 " \\
2=" 2 " \\
89=" 3 \text { ou mais" }\end{array}$ \\
\hline P2901 & $\begin{array}{l}\text { Quantos computadores de mesa que } \\
\text { estão instalados e funcionando estão } \\
\text { disponíveis para o uso pedagógico } \\
\text { dos alunos, ou seja, para realização } \\
\text { de atividades educacionais? }\end{array}$ & Numérico & \\
\hline P2902 & $\begin{array}{l}\text { Quantos computadores portáteis } \\
\text { (como notebook, netbook, laptop) } \\
\text { que estão instalados e funcionando } \\
\text { estão disponíveis para o uso } \\
\text { pedagógico dos alunos, ou seja, para } \\
\text { realização de atividades } \\
\text { educacionais? }\end{array}$ & Numérico & \\
\hline P2903 & $\begin{array}{l}\text { Quantos computadores de mão que } \\
\text { estão instalados e funcionando que } \\
\text { estão disponíveis para o uso } \\
\text { pedagógico dos alunos, ou seja, para } \\
\text { realização de atividades } \\
\text { educacionais? }\end{array}$ & Numérico & \\
\hline P2904 & $\begin{array}{l}\text { Quantos computadores do tipo tablet } \\
\text { que estão instalados e funcionando } \\
\text { que estão disponíveis para o uso } \\
\text { pedagógico dos alunos, ou seja, para } \\
\text { realização de atividades } \\
\text { educacionais? }\end{array}$ & Numérico & \\
\hline P2905 & $\begin{array}{l}\text { Total de computadores instalados e } \\
\text { funcionando que estão disponíveis } \\
\text { para uso pedagógico dos alunos. }\end{array}$ & Numérico & \\
\hline P2901_FAIXA & $\begin{array}{l}\text { Quantidade de computadores de } \\
\text { mesa para uso pedagógico }\end{array}$ & Numérico & $\begin{array}{l}5=" \text { Até } 5 " \\
15=" \text { De } 6 \text { a } 15 " \\
20=" \text { De } 16 \text { a } 20 " \\
30=" \text { De } 21 \text { a } 30 " \\
40=" \text { De } 31 \text { a } 40 " \\
200=" 41 \text { ou mais" }\end{array}$ \\
\hline P2902_FAIXA & $\begin{array}{l}\text { Quantidade de computadores } \\
\text { portáteis para uso pedagógico }\end{array}$ & Numérico & $\begin{array}{l}1=" 1 " \\
2=" 2 " \\
89=" 3 \text { ou mais" }\end{array}$ \\
\hline P2903_FAIXA & $\begin{array}{l}\text { Quantidade de computadores de } \\
\text { mão para uso pedagógico }\end{array}$ & Numérico & $\begin{array}{l}1=" 1 " \\
2=" 2 " \\
89=" 3 \text { ou mais" }\end{array}$ \\
\hline
\end{tabular}




\begin{tabular}{|c|c|c|c|}
\hline P2904_FAIXA & $\begin{array}{l}\text { Quantidade de tablets para uso } \\
\text { pedagógico }\end{array}$ & Numérico & $\begin{array}{l}1=" 1 " \\
2=" 2 " \\
89=" 3 \text { ou mais" }\end{array}$ \\
\hline P30 & $\begin{array}{l}\text { Tempo médio de existência de } \\
\text { computadores na escolas }\end{array}$ & & $\begin{array}{l}1=\text { ="Há menos de } 6 \text { meses" } \\
2=\text { ="Mais de } 6 \text { meses até } 1 \text { ano" } \\
3=\text { ="Mais de } 1 \text { até } 2 \text { anos" } \\
4=" \text { Mais de } 2 \text { até } 5 \text { anos" } \\
5=\text { ="Mais de } 5 \text { até } 10 \text { anos" } \\
6=" H a ́ \text { mais de } 10 \text { anos" } \\
8=\text { ="Não sabe" }\end{array}$ \\
\hline P31 & $\begin{array}{lllr}\begin{array}{l}\text { Recebimento } \\
\text { computadores } \\
\text { substituição }\end{array} & \text { na } & \text { escola } & \text { para } \\
\end{array}$ & & $\begin{array}{l}\text { 1="Sim" } \\
\text { 2="Não" } \\
\text { 8="Não sabe" }\end{array}$ \\
\hline P32 & $\begin{array}{l}\text { Atualização de computadores da } \\
\text { escola }\end{array}$ & & $\begin{array}{l}\text { 1="Sim" } \\
\text { 2="Não" } \\
\text { 8="Não sabe" }\end{array}$ \\
\hline P3301 A P3303 & $\begin{array}{l}\text { Sistema operacional utilizado no } \\
\text { computador }\end{array}$ & Numérico & $\begin{array}{l}\text { 1="Microsoft/ Windows" } \\
\text { 2="Linux" } \\
\text { 3="Macintosh/ OS" } \\
\text { 98="Não sabe/ Não lembra" }\end{array}$ \\
\hline P3401 A P3406 & $\begin{array}{l}\text { Responsável pela manutenção dos } \\
\text { computadores }\end{array}$ & Numérico & $\begin{array}{l}\text { 1="Professor de Informática" } \\
2=\text { ="Monitor no laboratório de } \\
\text { informática" } \\
3=\text { " Coordenador pedagógico" } \\
4=\text { " Prestadores de serviço } \\
\text { contratados pela escola" } \\
\text { 5="Prestadores de serviço } \\
\text { contratados pela Secretaria de } \\
\text { Educação" } \\
6=\text { ="Voluntários" } \\
996=\text { " OUTROS" } \\
\text { 999="Ninguém se responsabiliza } \\
\text { pela manutenção dos equipamentos" }\end{array}$ \\
\hline P3501 A P3508 & $\begin{array}{l}\text { Medidas adotadas com relação ao } \\
\text { uso dos equipamentos de } \\
\text { informática e comunicação }\end{array}$ & Numérico & $\begin{array}{l}\text { 1="Uso de senha para acesso dos } \\
\text { alunos aos computadores" } \\
2=\text { ="Restrição ao número de horas } \\
\text { que um aluno pode usar o } \\
\text { computador" } \\
\text { 3="Permissão para que os alunos } \\
\text { utilizem os computadores fora de } \\
\text { seu horário de aula, mas dentro do } \\
\text { horário de funcionam" } \\
\text { 4="Permissão para que os alunos } \\
\text { utilizem os computadores fora do } \\
\text { horário de funcionamento da escola } \\
\text { (ex: finais de semana)" } \\
\text { 5="Proibição de acesso a sites com } \\
\text { conteúdo adulto (violência, } \\
\text { pornografia)" } \\
\text { 6="Restrição a jogos eletrônicos nos } \\
\text { computadores da escola } \\
\text { (videogames, etc.)" } \\
\text { 7="Existência do conhecimento } \\
\text { obrigatório de informática e } \\
\text { habilidades para os alunos no } \\
\text { currículo escolar" } \\
\text { 8="Necessidade dos professores } \\
\text { agendarem horário para utilizar o } \\
\text { laboratório de informática" }\end{array}$ \\
\hline P36 & Acesso à Internet & Numérico & $\begin{array}{l}\text { 1="Sim" } \\
\text { 2="Não/ Ainda não" }\end{array}$ \\
\hline P37 & Tipo de conexão da Internet & Numérico & $\begin{array}{l}\text { 1="Conexão discada" } \\
2=\text { ="Outro tipo de conexão" } \\
3=" \text { Ambas (Espontânea)" } \\
8=" \text { Não sabe (Espontânea)" } \\
9=" \text { ão respondeu (Espontânea)" }\end{array}$ \\
\hline
\end{tabular}




\begin{tabular}{|c|c|c|c|}
\hline P3801 A P3806 & $\begin{array}{l}\text { Tipo de conexão, exceto discada, } \\
\text { utilizada para acessar a Internet }\end{array}$ & Numérico & 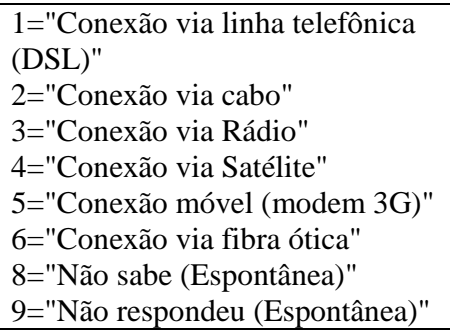 \\
\hline P39 & Principal tipo de conexão à Internet & Numérico & $\begin{array}{l}\text { 1=" Conexão via linha telefônica } \\
\text { (DSL)" } \\
\text { 2="Conexão via cabo" } \\
3=\text { ="Conexão via Rádio" } \\
\text { 4="Conexão via Satélite" } \\
\text { 5="Conexão móvel (modem 3G)' } \\
\text { 6="Conexão via fibra ótica" } \\
\text { 8="Não sabe (Espontânea)" } \\
\text { 9="Não respondeu (Espontânea)" }\end{array}$ \\
\hline P4001 A P4010 & Velocidade da conexão à Internet & Numérico & 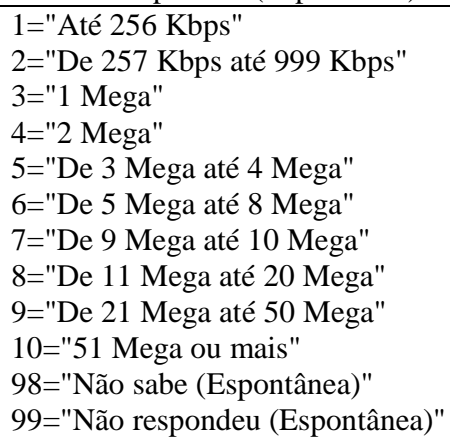 \\
\hline P41 & $\begin{array}{l}\text { Velocidade da conexão à Internet } \\
\text { mais utilizada }\end{array}$ & Numérico & 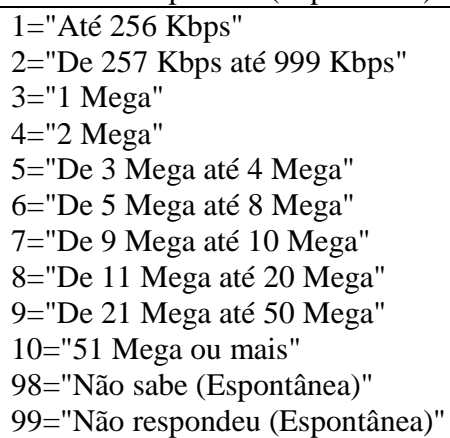 \\
\hline $\mathrm{P} 42$ & $\begin{array}{l}\text { Posse de Internet sem fio (wireless/ } \\
\text { wi-fi ou conexão via modem } 3 \mathrm{G} \text { ) }\end{array}$ & Numérico & $\begin{array}{l}1=\text { ="Sim" } \\
2=" N a ̃ o " \\
8=" N a ̃ o \text { sabe" }\end{array}$ \\
\hline $\mathrm{P} 43$ & Tempo de instalação de Internet & Numérico & $\begin{array}{l}1=\text { ="Há menos de } 6 \text { meses" } \\
2=" \text { Mais de } 6 \text { meses até } 1 \text { ano" } \\
3=\text { ="Mais de } 1 \text { até } 2 \text { anos" } \\
4=" \text { Mais de } 2 \text { até } 5 \text { anos" } \\
5=" \text { Mais de } 5 \text { até } 10 \text { anos" } \\
6=" \text { Há mais de } 10 \text { anos" } \\
8=\text { ="Não sabe (Espontânea)" }\end{array}$ \\
\hline P44 & $\begin{array}{l}\text { A Internet da escola é utilizada pelos } \\
\text { professores em atividades de ensino- } \\
\text { aprendizagem com os alunos? }\end{array}$ & Numérico & $\begin{array}{l}\text { 1="Sim" } \\
\text { 2="Não" }\end{array}$ \\
\hline $\begin{array}{l}\text { P45_ALUN_FAIXA } \\
\text { E P45_NS }\end{array}$ & $\begin{array}{l}\text { Quantidade de alunos que utilizam a } \\
\text { Internet com os professores para fins } \\
\text { pedagógicos }\end{array}$ & Numérico & $\begin{array}{l}250=" \text { Até } 250 " \\
500=" \text { De } 251 \text { a } 500 " \\
1000=" D e \text { 501 a } 1000 " \\
1001=" 1001 \text { ou mais" } \\
9998=" N \text { ÂO SABE" } \\
\text { 9999="NÃO RESPONDEU" }\end{array}$ \\
\hline $\begin{array}{l}\text { P46_PROF_FAIXA } \\
\text { E P46_NS }\end{array}$ & $\begin{array}{l}\text { Quantidade de professores que } \\
\text { receberam capacitação para fazer } \\
\text { uso de computador e Internet em } \\
\text { suas atividades de ensino- } \\
\text { aprendizagem }\end{array}$ & Numérico & $\begin{array}{l}20=" A t e ́ 20 " \\
40=" D e \quad 21 \text { a } 40 " \\
41=" 41 \text { ou mais" } \\
\text { 9998="NÃO SABE" } \\
\text { 9999="NÃO RESPONDEU" }\end{array}$ \\
\hline
\end{tabular}




\begin{tabular}{|c|c|c|c|}
\hline $\mathrm{P} 4701$ & $\begin{array}{l}\text { Existência de computador instalado } \\
\text { no laboratório de informática }\end{array}$ & Numérico & $\begin{array}{l}1=" \text { Sim" } \\
\text { 2="Não" }\end{array}$ \\
\hline $\mathrm{P} 4702$ & $\begin{array}{l}\text { Existência de computador instalado } \\
\text { na biblioteca ou sala de estudos para } \\
\text { os alunos }\end{array}$ & Numérico & $\begin{array}{l}1=" S i m " \\
2=" N a ̃ o "\end{array}$ \\
\hline $\mathrm{P} 4703$ & $\begin{array}{l}\text { Existência de computador instalado } \\
\text { na sala de aula }\end{array}$ & Numérico & $\begin{array}{l}\text { 1="Sim" } \\
\text { 2="Não" }\end{array}$ \\
\hline P4704 & $\begin{array}{l}\text { Existência de computador instalado } \\
\text { na sala dos professores ou sala de } \\
\text { reunião }\end{array}$ & Numérico & $\begin{array}{l}1=" S i m " \\
2=" N a ̃ o "\end{array}$ \\
\hline $\mathrm{P} 4705$ & $\begin{array}{l}\text { Existência de computador instalado } \\
\text { na sala do(a) coordenador(a) } \\
\text { pedagógico(a) ou do(a) Diretor(a) }\end{array}$ & Numérico & $\begin{array}{l}1=" \text { Sim" } \\
\text { 2="Não" }\end{array}$ \\
\hline $\mathrm{P} 4801$ & $\begin{array}{l}\text { Existência de acesso à Internet no } \\
\text { laboratório de informática }\end{array}$ & Numérico & $\begin{array}{l}\text { 1="Sim" } \\
\text { 2="Não" }\end{array}$ \\
\hline $\mathrm{P} 4802$ & $\begin{array}{l}\text { Existência de acesso à Internet na } \\
\text { biblioteca ou sala de estudos para os } \\
\text { alunos }\end{array}$ & Numérico & $\begin{array}{l}1=" \text { Sim" } \\
\text { 2="Não" }\end{array}$ \\
\hline P4803 & $\begin{array}{l}\text { Existência de acesso à Internet na } \\
\text { sala de aula }\end{array}$ & Numérico & $\begin{array}{l}\text { 1="Sim" } \\
\text { 2="Não" }\end{array}$ \\
\hline P4804 & $\begin{array}{l}\text { Existência de acesso à Internet na } \\
\text { sala dos professores ou sala de } \\
\text { reunião }\end{array}$ & Numérico & $\begin{array}{l}1=" S i m " \\
2=" N a ̃ o "\end{array}$ \\
\hline P4805 & $\begin{array}{l}\text { Existência de acesso à Internet na } \\
\text { sala do(a) coordenador(a) } \\
\text { pedagógico(a) ou do(a) Diretor(a) }\end{array}$ & Numérico & $\begin{array}{l}\text { 1="Sim" } \\
\text { 2="Não" }\end{array}$ \\
\hline P4901 & $\begin{array}{l}\text { Dia(s) de funcionamento do } \\
\text { laboratório de informática }\end{array}$ & Numérico & $\begin{array}{l}\text { 1="Apenas úteis" } \\
\text { 2="Apenas finais de semana" } \\
\text { 3="Dias úteis e Finais de semana" }\end{array}$ \\
\hline P4902 & $\begin{array}{l}\text { Dia(s) de funcionamento da } \\
\text { biblioteca ou sala de estudos para os } \\
\text { alunos }\end{array}$ & Numérico & $\begin{array}{l}1=\text { "Apenas úteis" } \\
2=\text { ="Apenas finais de semana" } \\
3=\text { =Dias úteis e Finais de semana" }\end{array}$ \\
\hline P4903 & $\begin{array}{l}\text { Dia(s) de funcionamento da sala de } \\
\text { aula }\end{array}$ & Numérico & $\begin{array}{l}1=\text { ="Apenas úteis" } \\
2=\text { ="Apenas finais de semana" } \\
3=\text { =Dias úteis e Finais de semana" }\end{array}$ \\
\hline P4904 & $\begin{array}{l}\text { Dia(s) de funcionamento da sala dos } \\
\text { professores ou sala de reunião }\end{array}$ & Numérico & $\begin{array}{l}\text { 1="Apenas úteis" } \\
2=\text { ="Apenas finais de semana" } \\
3=\text { =Dias úteis e Finais de semana" }\end{array}$ \\
\hline P4905 & $\begin{array}{l}\text { Dia(s) de funcionamento da sala } \\
\text { do(a) coordenador(a) pedagógico(a) } \\
\text { ou do(a) Diretor(a) }\end{array}$ & Numérico & $\begin{array}{l}\text { 1="Apenas úteis" } \\
\text { 2="Apenas finais de semana" } \\
\text { 3="Dias úteis e Finais de semana" }\end{array}$ \\
\hline P50A01 A P50A07 & $\begin{array}{l}\text { Quem utiliza computador no } \\
\text { laboratório de informática }\end{array}$ & Numérico & $\begin{array}{l}1=\text { ="Prof." } \\
2=\text { =Alunos" } \\
3=\text { ="Coord. Ped." } \\
\text { 4="Vice-diretor" } \\
\text { 5="Diretor" } \\
6=\text { ="Comunidade" } \\
7=\text { ="Outros func." }\end{array}$ \\
\hline P50B01 A P50B07 & $\begin{array}{l}\text { Quem utiliza computador na } \\
\text { biblioteca ou sala de estudos para os } \\
\text { alunos }\end{array}$ & Numérico & $\begin{array}{l}\text { 1="Prof." } \\
2=\text { ="Alunos" } \\
3=\text { =Coord. Ped." } \\
\text { 4="Vice-diretor" } \\
\text { 5="Diretor" } \\
6=\text { ="Comunidade" } \\
7=\text { ="Outros func." }\end{array}$ \\
\hline P50C01 A P50C07 & $\begin{array}{l}\text { Quem utiliza computador na sala de } \\
\text { aula }\end{array}$ & Numérico & $\begin{array}{l}\text { 1="Prof." } \\
2=\text { ="Alunos" } \\
3=\text { =Coord. Ped." } \\
\text { 4="Vice-diretor" } \\
\text { 5="Diretor" } \\
6=\text { ="Comunidade" } \\
7=\text { ="Outros func." }\end{array}$ \\
\hline
\end{tabular}




\begin{tabular}{|c|c|c|c|}
\hline P50D01 A P50D07 & $\begin{array}{l}\text { Quem utiliza computador na sala } \\
\text { dos professores ou sala de reunião }\end{array}$ & Numérico & $\begin{array}{l}\text { 1="Prof." } \\
2=\text { ="Alunos" } \\
3=\text { =Coord. Ped." } \\
\text { 4="Vice-diretor" } \\
\text { 5="Diretor" } \\
\text { 6="Comunidade" } \\
7=\text { ="Outros func." }\end{array}$ \\
\hline P50E01 A P50E07 & $\begin{array}{l}\text { Quem utiliza computador na sala } \\
\text { do(a) coordenador(a) pedagógico(a) } \\
\text { ou do(a) Diretor(a) }\end{array}$ & Numérico & $\begin{array}{l}1=\text { ="Prof." } \\
2=\text { ="Alunos" } \\
3=\text { ="Coord. Ped." } \\
4=\text { ="Vice-diretor" } \\
\text { 5="Diretor" } \\
6=\text { ="Comunidade" } \\
7=\text { ="Outros func." }\end{array}$ \\
\hline $\begin{array}{l}\text { P51_FAIXA } \quad \text { E } \\
\text { P51_N }\end{array}$ & $\begin{array}{l}\text { Quantidade de computadores no(s) } \\
\text { laboratório(s) de informática, } \\
\text { independente de } \\
\text { funcionando ou não }\end{array}$ & Numérico & $\begin{array}{l}5=" \text { Até } 5 " \\
15=" \text { De } 6 \text { a } 15 " \\
20=" \text { De } 16 \text { a } 20 " \\
\text { 30="De } 21 \text { a } 30 " \\
40=" \text { De } 31 \text { a } 40 " \\
41=" 41 \text { ou mais" } \\
\text { 998="Não sabe" } \\
\text { 999="Não respondeu" }\end{array}$ \\
\hline $\begin{array}{l}\text { P52_FAIXA } \\
\text { P52_N }\end{array}$ & $\begin{array}{l}\text { Quantidade de computadores no(s) } \\
\text { laboratório(s) de informática } \\
\text { instalados e funcionando }\end{array}$ & Numérico & $\begin{array}{l}5=" \text { Até } 5 " \\
15==\text { De } 6 \text { a } 15 " \\
20=" \text { De } 16 \text { a } 20 " \\
30=" \text { De } 21 \text { a } 30 " \\
40=" D e \text { a } 40 " \\
41=" 41 \text { ou mais" } \\
998=" N a ̃ o \text { sabe" } \\
\text { 999="Não respondeu" }\end{array}$ \\
\hline P53 & $\begin{array}{l}\text { Atualmente, o(s) laboratório(s) de } \\
\text { informática da escola está(ão) sendo } \\
\text { utilizado(s)? }\end{array}$ & Numérico & $\begin{array}{l}\text { 1="Sim" } \\
\text { 2="Não" } \\
\text { 3="Não sabe (Espontânea)" }\end{array}$ \\
\hline P54 & $\begin{array}{l}\text { Frequência com que o laboratório de } \\
\text { informática costuma ser utilizado } \\
\text { com finalidades pedagógicas }\end{array}$ & Numérico & $\begin{array}{l}1=\text { "Todos os dias ou quase todos os } \\
\text { dias" } \\
2=\text { ="Pelo menos uma vez por } \\
\text { semana" } \\
3=\text { ="Pelo menos uma vez por mês" } \\
4=\text { ="Menos do que uma vez por mês" } \\
8=\text { ="Não sabe (Espontânea)" }\end{array}$ \\
\hline P5501 A P5510 & Posse de equipamentos & Numérico & $\begin{array}{l}1=\text { "Aparelho de telefone celular (da } \\
\text { escola - excluir os pessoais)" } \\
2=" \text { Televisão" } \\
3=\text { ="Rádio" } \\
\text { 4="Aparelho de telefone fixo" } \\
\text { 5="Impressora" } \\
6=" \text { Filmadora" } \\
7=\text { ="Câmera digital" } \\
\text { 8="Videocassete/ DVD" } \\
\text { 9="Retroprojetor" } \\
\text { 10="Datashow" }\end{array}$ \\
\hline P5601_FAIXA & $\begin{array}{l}\text { Quantos aparelhos de telefone } \\
\text { celular (da escola - sem excluir os } \\
\text { pessoais) estão funcionando? }\end{array}$ & Numérico & $\begin{array}{l}1=" 1 " \\
100=" 2 \text { ou mais" }\end{array}$ \\
\hline P5602_FAIXA & $\begin{array}{l}\text { Quantas televisões } \\
\text { funcionando? }\end{array}$ & Numérico & $\begin{array}{l}1=" 1 " \\
2=" 2 " \\
3=" 3 " \\
4=" 4 " \\
5=" 5 " \\
6=" 6 \text { ou mais" }\end{array}$ \\
\hline P5603_FAIXA & Quantos rádios estão funcionando? & Numérico & $\begin{array}{l}1=" 1 " \\
2=" 2 " \\
3=" 3 " \\
4=" 4 " \\
5=" 5 " \\
6=" 6 "\end{array}$ \\
\hline
\end{tabular}




\begin{tabular}{|c|c|c|c|}
\hline & & & $7=" 7$ ou mais" \\
\hline P5604_FAIXA & $\begin{array}{l}\text { Quantos aparelhos de telefone fixo } \\
\text { estão funcionando? }\end{array}$ & Numérico & $\begin{array}{l}1=" 1 " \\
2=" 2 " \\
3=" 3 " \\
4=" 4 \text { ou mais" }\end{array}$ \\
\hline P5605_FAIXA & $\begin{array}{l}\text { Quantas impressoras estão } \\
\text { funcionando? }\end{array}$ & Numérico & $\begin{array}{l}1=" 1 " \\
2=" 2 " \\
3=" 3 " \\
4=" 4 " \\
5=" 5 " \\
6=" 6 " \\
7=" 7 \text { ou mais" }\end{array}$ \\
\hline P5606_FAIXA & $\begin{array}{l}\text { Quantas filmadoras estão } \\
\text { funcionando? }\end{array}$ & Numérico & $\begin{array}{l}1=" 1 " \\
2=" 2 \text { ou mais" }\end{array}$ \\
\hline P5607_FAIXA & $\begin{array}{l}\text { Quantas câmeras digitais estão } \\
\text { funcionando? }\end{array}$ & Numérico & $\begin{array}{l}1=" 1 " \\
2=" 2 " \\
3=" 3 \text { ou mais" }\end{array}$ \\
\hline P5608_FAIXA & $\begin{array}{l}\text { Quantos videocassetes/ DVDs estão } \\
\text { funcionando? }\end{array}$ & Numérico & $\begin{array}{l}1=" 1 " \\
2=" 2 " \\
3=" 3 " \\
4=" 4 " \\
5=" 5 \text { ou mais" }\end{array}$ \\
\hline P5609_FAIXA & $\begin{array}{l}\text { Quantos retroprojetores estão } \\
\text { funcionando? }\end{array}$ & Numérico & $\begin{array}{l}1=" 1 " \\
2=" 2 " \\
3=" 3 \text { ou mais" }\end{array}$ \\
\hline P5610_FAIXA & $\begin{array}{l}\text { Quantos datashows estão } \\
\text { funcionando? }\end{array}$ & Numérico & $\begin{array}{l}1=" 1 " \\
2=" 2 " \\
3=" 3 \text { ou mais" }\end{array}$ \\
\hline P5701 a P5703 & $\begin{array}{l}\text { Utilização de equipamentos para fins } \\
\text { pedagógicos }\end{array}$ & Numérico & $\begin{array}{l}\text { 1="Aparelho de telefone celular (da } \\
\text { escola - excluir os pessoais)" } \\
\text { 2="Televisão" } \\
\text { 3="Rádio" }\end{array}$ \\
\hline P5801 A P5805 & $\begin{array}{l}\text { Participação de programas que } \\
\text { disponibilizam computadores } \mathrm{e} \\
\text { acesso à Internet para as escolas }\end{array}$ & Numérico & $\begin{array}{l}\text { 1="Sim, do PROINFO" } \\
\text { 2="Sim, do GESAC" } \\
\text { 3="Sim, do Programa Banda Larga } \\
\text { nas Escolas" } \\
\text { 4="Sim, da iniciativa privada" } \\
\text { 5="Sim, de organizações não } \\
\text { governamentais" } \\
\text { 95="PROGRAMAS DA } \\
\text { SECRETÁRIA ESTADUAL DA } \\
\text { EDUCAÇÃO" } \\
\text { 96="OUTROS" } \\
\text { 98="Não respondeu/ Recusou } \\
\text { responder" } \\
\text { 99="Não" }\end{array}$ \\
\hline P5901 & $\begin{array}{l}\text { Posse de website/ blog/ própria } \\
\text { página na Internet }\end{array}$ & Numérico & $\begin{array}{l}1=" S i m " \\
\text { 2="Não" }\end{array}$ \\
\hline P5902 & $\begin{array}{l}\text { Posse de e-mail institucional/ e-mail } \\
\text { da própria escola }\end{array}$ & Numérico & $\begin{array}{l}\text { 1="Sim" } \\
\text { 2="Não" }\end{array}$ \\
\hline P6001 A P6017 & $\begin{array}{l}\text { Conteúdos oferecidos no website ou } \\
\text { blog }\end{array}$ & Numérico & $\begin{array}{l}1=\text { ="A proposta pedagógica da } \\
\text { Escola" } \\
2=\text { ="A grade das disciplinas que serão } \\
\text { oferecidas/ período letivo/ semestre/ } \\
\text { trimestre/ bimestre" } \\
3=\text { ="Galeria de fotos" } \\
4=\text { "Sugestões de atividades/ } \\
\text { exercícios/ leituras para pais ou } \\
\text { alunos" } \\
5=\text { ="Alimentação/ cardápio oferecido } \\
\text { pela Escola" }\end{array}$ \\
\hline
\end{tabular}




\begin{tabular}{|c|c|c|c|}
\hline & & & 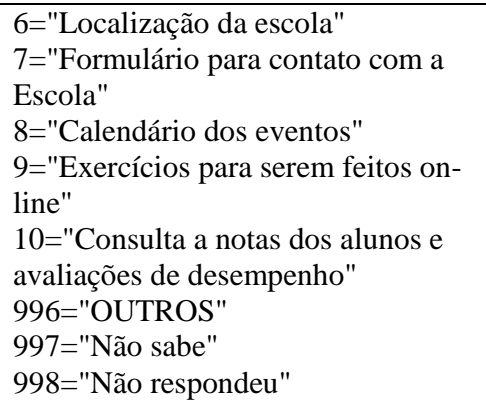 \\
\hline P6101 A P6111 & $\begin{array}{l}\text { Ações consideradas prioritárias para } \\
\text { a escola, considerando a alocação de } \\
\text { recursos }\end{array}$ & Numérico & 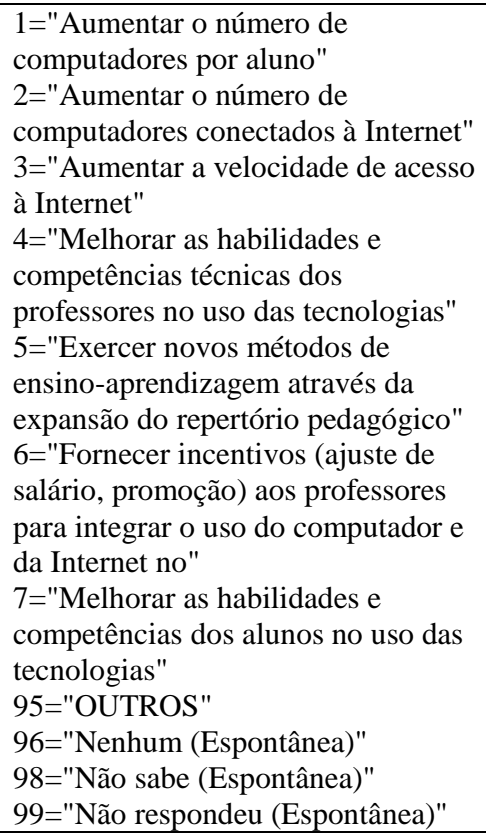 \\
\hline P62 & $\begin{array}{l}\text { Principal prioridade para a escola, } \\
\text { considerando a alocação de recursos }\end{array}$ & Numérico & $\begin{array}{l}\text { 1="Aumentar o número de } \\
\text { computadores por aluno" } \\
\text { 2="Aumentar o número de } \\
\text { computadores conectados à Internet" } \\
\text { 3="Aumentar a velocidade de acesso } \\
\text { à Internet" } \\
\text { 4="Melhorar as habilidades e } \\
\text { competências técnicas dos } \\
\text { professores no uso das tecnologias" } \\
\text { 5="Exercer novos métodos de } \\
\text { ensino-aprendizagem através da } \\
\text { expansão do repertório pedagógico" } \\
\text { 6="Fornecer incentivos (ajuste de } \\
\text { salário, promoção) aos professores } \\
\text { para integrar o uso do computador e } \\
\text { da Internet no" } \\
\text { 7="Melhorar as habilidades e } \\
\text { competências dos alunos no uso das } \\
\text { tecnologias" } \\
\text { 95="OUTROS" } \\
\text { 96="Nenhum (Espontânea)" } \\
\text { 98="Não sabe (Espontânea)" } \\
\text { 99="Não respondeu (Espontânea)" }\end{array}$ \\
\hline P6301 & $\begin{array}{l}\text { Grau de concordância com a } \\
\text { afirmação de que os alunos da escola } \\
\text { sabem mais sobre o computador e a } \\
\text { Internet do que o professor }\end{array}$ & Numérico & $\begin{array}{l}1=\text { ="Discordo Totalmente" } \\
2=\text { ="Discordo em parte" } \\
3=" \text { Nem concordo, nem discordo" } \\
4=\text { ="Concordo em parte" } \\
5=\text { ="Concordo totalmente" } \\
7=" \text { Nessa escola isso não acontece } \\
\text { (Espontânea)" } \\
\text { 8="Não sabe (Espontânea)" }\end{array}$ \\
\hline
\end{tabular}




\begin{tabular}{|c|c|c|c|}
\hline P6302 & $\begin{array}{l}\text { Grau de concordância com a } \\
\text { afirmação de que com a Internet, os } \\
\text { alunos } \\
\text { sobrecarregados de informação }\end{array}$ & Numérico & $\begin{array}{l}\text { 1="Discordo Totalmente" } \\
2==" \text { Discordo em parte" } \\
3=\text { "Nem concordo, nem discordo" } \\
4=\text { ="Concordo em parte" } \\
5=\text { ="Concordo totalmente" } \\
7=" \text { Nessa escola isso não acontece } \\
\text { (Espontânea)" } \\
\text { 8="Não sabe (Espontânea)" }\end{array}$ \\
\hline P6303 & $\begin{array}{l}\text { Grau de concordância com a } \\
\text { afirmação de que com a Internet, os } \\
\text { alunos acabam perdendo o contato } \\
\text { com a realidade }\end{array}$ & Numérico & $\begin{array}{l}\text { 1="Discordo Totalmente" } \\
2==" \text { Discordo em parte" } \\
3=\text { "Nem concordo, nem discordo" } \\
4=\text { ="Concordo em parte" } \\
5=\text { ="Concordo totalmente" } \\
7=\text { ="Nessa escola isso não acontece } \\
\text { (Espontânea)" } \\
\text { 8="Não sabe (Espontânea)" }\end{array}$ \\
\hline P6304 & $\begin{array}{l}\text { Grau de concordância com a } \\
\text { afirmação de que não confia nas } \\
\text { informações contidas na Internet }\end{array}$ & Numérico & $\begin{array}{l}\text { 1="Discordo Totalmente" } \\
2=\text { ="Discordo em parte" } \\
3=\text { ="Nem concordo, nem discordo" } \\
4=\text { ="Concordo em parte" } \\
5=\text { ="Concordo totalmente" } \\
7=" \text { Nessa escola isso não acontece } \\
\text { (Espontânea)" } \\
\text { 8="Não sabe (Espontânea)" }\end{array}$ \\
\hline P6305 & $\begin{array}{l}\text { Grau de concordância com a } \\
\text { afirmação de que acredita mais nos } \\
\text { métodos tradicionais de ensino }\end{array}$ & Numérico & $\begin{array}{l}\text { 1="Discordo Totalmente" } \\
2=\text { ="Discordo em parte" } \\
3=\text { "Nem concordo, nem discordo" } \\
4=\text { ="Concordo em parte" } \\
5=\text { ="Concordo totalmente" } \\
7=" \text { Nessa escola isso não acontece } \\
\text { (Espontânea)" } \\
\text { 8="Não sabe (Espontânea)" }\end{array}$ \\
\hline P6306 & $\begin{array}{l}\text { Grau de concordância com a } \\
\text { afirmação de que não sabe de que } \\
\text { forma/ para que atividades pode usar } \\
\text { o computador e a Internet na escola }\end{array}$ & Numérico & $\begin{array}{l}\text { 1="Discordo Totalmente" } \\
2=\text { ="Discordo em parte" } \\
3=\text { "Nem concordo, nem discordo" } \\
4=\text { ="Concordo em parte" } \\
5=\text { ="Concordo totalmente" } \\
7=\text { ="Nessa escola isso não acontece } \\
\text { (Espontânea)" } \\
\text { 8="Não sabe (Espontânea)" }\end{array}$ \\
\hline P6307 & $\begin{array}{lrr}\text { Grau de } & \text { concordância com a } \\
\text { afirmação de que os professores } \\
\text { tornam-se } & \text { educadores } & \text { menos } \\
\text { eficazes } & & \end{array}$ & Numérico & $\begin{array}{l}1=\text { ="Discordo Totalmente" } \\
2=\text { ="Discordo em parte" } \\
3=\text { "Nem concordo, nem discordo" } \\
4=\text { ="Concordo em parte" } \\
5=\text { ="Concordo totalmente" } \\
7=\text { ="Nessa escola isso não acontece } \\
\text { (Espontânea)" } \\
\text { 8="Não sabe (Espontânea)" }\end{array}$ \\
\hline P6308 & $\begin{array}{l}\text { Grau de concordância com a } \\
\text { afirmação de que os professores não } \\
\text { sabem ao certo como lidar com o } \\
\text { computador e a Internet }\end{array}$ & Numérico & $\begin{array}{l}\text { 1="Discordo Totalmente" } \\
2=\text { ="Discordo em parte" } \\
3=\text { "Nem concordo, nem discordo" } \\
4=\text { ="Concordo em parte" } \\
5=\text { ="Concordo totalmente" } \\
7=\text { ="Nessa escola isso não acontece } \\
\text { (Espontânea)" } \\
\text { 8="Não sabe (Espontânea)" }\end{array}$ \\
\hline P6401 & $\begin{array}{l}\text { Impacto da ausência de suporte } \\
\text { técnico para o uso do computador e } \\
\text { Internet para fins pedagógicos }\end{array}$ & Numérico & $\begin{array}{l}\text { 1="Dificulta muito" } \\
2==" \text { Dificulta" } \\
3=\text { ="Dificulta um pouco" } \\
\text { 4="Não dificulta nada" } \\
7=\text { ="Nessa escola isso não acontece } \\
\text { (Espontânea)" } \\
9=\text { ="Não respondeu (Espontânea)" }\end{array}$ \\
\hline
\end{tabular}




\begin{tabular}{|c|c|c|c|}
\hline P6402 & $\begin{array}{l}\text { Impacto da falta de apoio } \\
\text { pedagógico para o uso do } \\
\text { computador e Internet para o uso do } \\
\text { computador e Internet para fins } \\
\text { pedagógicos }\end{array}$ & Numérico & $\begin{array}{l}\text { 1="Dificulta muito" } \\
2==" \text { Dificulta" } \\
3=\text { ="Dificulta um pouco" } \\
\text { 4="Não dificulta nada" } \\
7=" \text { Nessa escola isso não acontece } \\
\text { (Espontânea)" } \\
9=" N a ̃ o \text { respondeu (Espontânea)" }\end{array}$ \\
\hline P6403 & $\begin{array}{l}\text { Impacto do número insuficiente de } \\
\text { computadores conectados à Internet } \\
\text { para o uso do computador e Internet } \\
\text { para fins pedagógicos }\end{array}$ & Numérico & $\begin{array}{l}\text { 1="Dificulta muito" } \\
2==" \text { Dificulta" } \\
3=\text { ="Dificulta um pouco" } \\
\text { 4="Não dificulta nada" } \\
7=" N e s s a \text { escola isso não acontece } \\
\text { (Espontânea)" } \\
9=" N a ̃ o \text { respondeu (Espontânea)" }\end{array}$ \\
\hline P6404 & $\begin{array}{l}\text { Impacto da baixa velocidade na } \\
\text { conexão de Internet para o uso do } \\
\text { computador e Internet para fins } \\
\text { pedagógicos }\end{array}$ & Numérico & $\begin{array}{l}\text { 1="Dificulta muito" } \\
2==" \text { Dificulta" } \\
3=\text { ="Dificulta um pouco" } \\
\text { 4="Não dificulta nada" } \\
7=\text { ="Nessa escola isso não acontece } \\
\text { (Espontânea)" } \\
9=" N a ̃ o \text { respondeu (Espontânea)" }\end{array}$ \\
\hline P6405 & $\begin{array}{l}\text { Impacto do número insuficiente de } \\
\text { computadores por aluno para o uso } \\
\text { do computador e Internet para fins } \\
\text { pedagógicos }\end{array}$ & Numérico & $\begin{array}{l}\text { 1="Dificulta muito" } \\
2==" \text { Dificulta" } \\
3=\text { ="Dificulta um pouco" } \\
\text { 4="Não dificulta nada" } \\
7=\text { ="Nessa escola isso não acontece } \\
\text { (Espontânea)" } \\
9=\text { ="Não respondeu (Espontânea)" }\end{array}$ \\
\hline P6406 & $\begin{array}{l}\text { Impacto de equipamentos obsoletos/ } \\
\text { ultrapassados para o uso do } \\
\text { computador e } \text { Internet para fins } \\
\text { pedagógicos }\end{array}$ & Numérico & $\begin{array}{l}\text { 1="Dificulta muito" } \\
2==" \text { Dificulta" } \\
3=\text { ="Dificulta um pouco" } \\
\text { 4="Não dificulta nada" } \\
7=\text { ="Nessa escola isso não acontece } \\
\text { (Espontânea)" } \\
9=\text { ="Não respondeu (Espontânea)" }\end{array}$ \\
\hline P6407 & $\begin{array}{l}\text { Impacto da pressão/ falta de tempo } \\
\text { para cumprir com o conteúdo } \\
\text { previsto (grade curricular) para o } \\
\text { uso do computador e Internet para } \\
\text { fins pedagógicos }\end{array}$ & Numérico & $\begin{array}{l}\text { 1="Dificulta muito" } \\
2==" D i f i c u l t a " \\
3=" D i f i c u l t a ~ u m ~ p o u c o " \\
\text { 4="Não dificulta nada" } \\
7=" N e s s a \text { escola isso não acontece } \\
\text { (Espontânea)" } \\
9=\text { ="Não respondeu (Espontânea)" }\end{array}$ \\
\hline P6408 & $\begin{array}{l}\text { Impacto da pressão para conseguir } \\
\text { boas notas nas avaliações de } \\
\text { desempenho para o uso do } \\
\text { computador e } \text { Internet para fins } \\
\text { pedagógicos }\end{array}$ & Numérico & $\begin{array}{l}\text { 1="Dificulta muito" } \\
2==" \text { Dificulta" } \\
3=\text { ="Dificulta um pouco" } \\
\text { 4="Não dificulta nada" } \\
7=\text { ="Nessa escola isso não acontece } \\
\text { (Espontânea)" } \\
9=" N a ̃ o \text { respondeu (Espontânea)" }\end{array}$ \\
\hline P6501 & $\begin{array}{l}\text { Grau de concordância com a } \\
\text { afirmação de que os professores } \\
\text { passaram a ter maior domínio do uso } \\
\text { do computador e da Internet }\end{array}$ & Numérico & 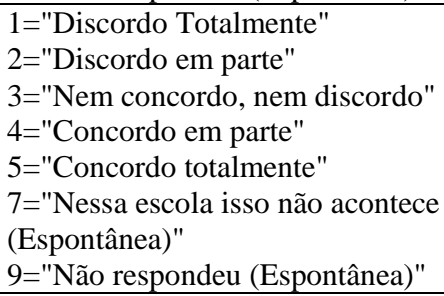 \\
\hline P6502 & $\begin{array}{l}\text { Grau de concordância com a } \\
\text { afirmação de que os professores } \\
\text { passaram a adotar novos métodos } \\
\text { pedagógicos para a escola }\end{array}$ & Numérico & $\begin{array}{l}\text { 1="Discordo Totalmente" } \\
2=\text { ="Discordo em parte" } \\
3=\text { "Nem concordo, nem discordo" } \\
\text { 4="Concordo em parte" } \\
5=\text { ="Concordo totalmente" } \\
7=\text { ="Nessa escola isso não acontece } \\
\text { (Espontânea)" } \\
\text { 9="Não respondeu (Espontânea)" }\end{array}$ \\
\hline
\end{tabular}




\begin{tabular}{|c|c|c|c|}
\hline P6503 & $\begin{array}{l}\text { Grau de concordância com a } \\
\text { afirmação de que os professores } \\
\text { passaram a fazer uma avaliação mais } \\
\text { individualizada dos alunos }\end{array}$ & Numérico & $\begin{array}{l}\text { 1="Discordo Totalmente" } \\
2==" \text { Discordo em parte" } \\
3=\text { "Nem concordo, nem discordo" } \\
4=\text { ="Concordo em parte" } \\
5=\text { ="Concordo totalmente" } \\
7=" \text { Nessa escola isso não acontece } \\
\text { (Espontânea)" } \\
\text { 9="Não respondeu (Espontânea)" }\end{array}$ \\
\hline P6504 & $\begin{array}{l}\text { Grau de concordância com a } \\
\text { afirmação de que os professores } \\
\text { passaram a ter acesso a materiais } \\
\text { mais diversificados/ de melhor } \\
\text { qualidade }\end{array}$ & Numérico & $\begin{array}{l}1=" \text { Discordo Totalmente" } \\
2==\text { Discordo em parte" } \\
3=" \text { Nem concordo, nem discordo" } \\
\text { 4="Concordo em parte" } \\
5=" \text { Concordo totalmente" } \\
7=\text { ="Nessa escola isso não acontece } \\
\text { (Espontânea)" } \\
\text { 9="Não respondeu (Espontânea)" }\end{array}$ \\
\hline $\mathrm{P} 6505$ & $\begin{array}{l}\text { Grau de concordância com a } \\
\text { afirmação de que os professores } \\
\text { passaram a colaborar mais com } \\
\text { outros colegas da escola }\end{array}$ & Numérico & $\begin{array}{l}\text { 1="Discordo Totalmente" } \\
2==" \text { Discordo em parte" } \\
3=\text { "Nem concordo, nem discordo" } \\
\text { 4="Concordo em parte" } \\
5=\text { ="Concordo totalmente" } \\
7=" \text { Nessa escola isso não acontece } \\
\text { (Espontânea)" } \\
\text { 9="Não respondeu (Espontânea)" }\end{array}$ \\
\hline P6506 & $\begin{array}{l}\text { Grau de concordância com a } \\
\text { afirmação de que os professores } \\
\text { passaram a ter contato com } \\
\text { educadores de outras escolas e com } \\
\text { especialistas de fora da escola }\end{array}$ & Numérico & $\begin{array}{l}\text { 1="Discordo Totalmente" } \\
2=" \text { Discordo em parte" } \\
3=" \text { Nem concordo, nem discordo" } \\
4=" \text { Concordo em parte" } \\
\text { 5="Concordo totalmente" } \\
7=" \text { Nessa escola isso não acontece } \\
\text { (Espontânea)" } \\
9=" N a ̃ o \text { respondeu (Espontânea)" }\end{array}$ \\
\hline P6507 & $\begin{array}{l}\text { Grau de concordância com a } \\
\text { afirmação de que os professores } \\
\text { passaram a cumprir suas } \\
\text { administrativas com } \\
\text { facilidade }\end{array}$ & Numérico & 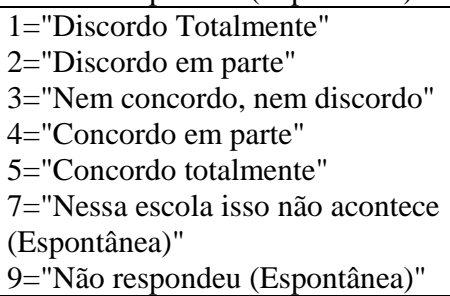 \\
\hline P6508 & $\begin{array}{l}\text { Grau de concordância com a } \\
\text { afirmação de que a quantidade de } \\
\text { trabalho dos professores aumentou }\end{array}$ & Numérico & 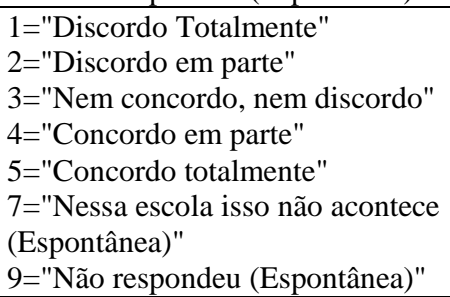 \\
\hline SIMET_1 & $\begin{array}{l}\text { Aceitação de teste para medição de } \\
\text { real velocidade da Internet }\end{array}$ & Numérico & $\begin{array}{l}\text { 1="Sim" } \\
\text { 2="Não" }\end{array}$ \\
\hline SIMET_2 & $\begin{array}{l}\text { Aceitação de teste para medição de } \\
\text { real velocidade da Internet com } \\
\text { acompanhamento do entrevistador }\end{array}$ & Numérico & $\begin{array}{l}\text { 1="Sim" } \\
\text { 2="Não" }\end{array}$ \\
\hline SIMET_3_VEL & $\begin{array}{l}\text { Sucesso do término do teste/ } \\
\text { velocidade real da Internet }\end{array}$ & Numérico & \\
\hline $\begin{array}{l}\text { SIMET_3 } \\
\text { SIMET_3_NOVA }\end{array}$ & $\begin{array}{l}\text { Sucesso do término do teste/ } \\
\text { velocidade real da Internet }\end{array}$ & Numérico & $\begin{array}{l}\text { 0="Sim" } \\
\text { 1="Até } 256 \text { Kbps" } \\
\text { 2="256 a 512 Kbps" } \\
\text { 3="512 Kbps a } 1 \text { Megabit" } \\
\text { 4="De } 1 \text { até } 2 \text { Megabits" } \\
\text { 5="De } 2 \text { até } 4 \text { Megabits" } \\
\text { 6="De } 4 \text { até } 8 \text { Megabits" } \\
\text { 7="Acima de } 8 \text { Megabits" } \\
\text { 98="Não respondeu" } \\
\text { 995="Não, pois não funcionou" } \\
\text { 996="Não, por outros motivos" }\end{array}$ \\
\hline
\end{tabular}




\begin{tabular}{|c|c|c|c|}
\hline LAB & $\begin{array}{l}\text { Computador instalado no laboratório } \\
\text { de informática }\end{array}$ & Numérico & $\begin{array}{l}1=" T e m " \\
2=" N a ̃ o \text { tem" } \\
9=" \text { Sem informação" }\end{array}$ \\
\hline LAB_INTERNET & $\begin{array}{l}\text { Internet instalada no laboratório de } \\
\text { informática }\end{array}$ & Numérico & $\begin{array}{l}1=" \text { Tem" } \\
2=" \text { Não tem" } \\
\text { 9="Sem informação" }\end{array}$ \\
\hline COMP_ALUNO & Alunos tem acesso a computadores & Numérico & $\begin{array}{l}\text { 1="Tem acesso" } \\
2=" \text { Não tem acesso" } \\
9=" \text { Sem informação" }\end{array}$ \\
\hline COMP_PROF & 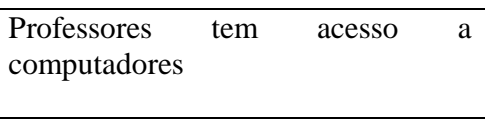 & Numérico & $\begin{array}{l}1=" \text { Tem acesso" } \\
2=" \text { Não tem acesso" } \\
9=" \text { Sem informação" }\end{array}$ \\
\hline REND1 & Renda pessoal & Numérico & 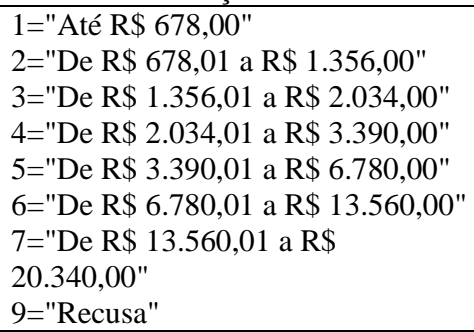 \\
\hline REND2 & Renda familiar & Numérico & 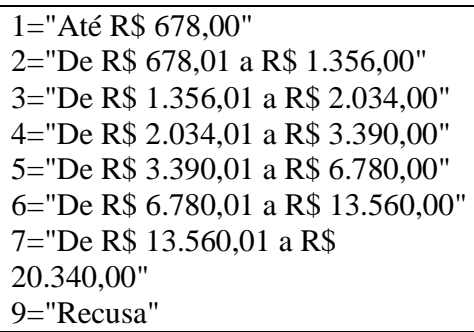 \\
\hline RENDCR_1 & $\begin{array}{l}\text { Renda pessoal } \quad \text { (em } \quad \text { salários } \\
\text { mínimos) }\end{array}$ & Numérico & $\begin{array}{l}\text { 3="ATÉ } 3 \text { SM" } \\
\text { 4="MAIS DE } 3 \text { ATÉ } 5 \text { SM" } \\
\text { 5="MAIS DE } 5 \text { SM" } \\
\text { 9="RECUSA" }\end{array}$ \\
\hline RENDCR_2 & $\begin{array}{l}\text { Renda familiar } \quad \text { (em salários } \\
\text { mínimos) }\end{array}$ & Numérico & $\begin{array}{l}\text { 3="ATÉ } 3 \text { SM" } \\
\text { 4="MAIS DE } 3 \text { ATÉ } 5 \text { SM" } \\
\text { 5="MAIS DE } 5 \text { SM" } \\
\text { 9="RECUSA" }\end{array}$ \\
\hline
\end{tabular}


ANEXO C

Dicionário das variáveis contidas no questionário aplicado aos coordenadores pedagógicos entrevistados pela pesquisa TIC Educação

\begin{tabular}{|c|c|c|c|}
\hline ID da variável & Descrição da variável & Tipo & Código e rótulo da variável \\
\hline QUEST & $\begin{array}{l}\text { Número de identificação do } \\
\text { questionário }\end{array}$ & Numérico & \\
\hline PESO & Fator de Expansão & Numérico & \\
\hline PESO_NORMALIZADO & Fator de Ponderação & Numérico & \\
\hline LOTE & Numero do lote & Numérico & \\
\hline N_ESCOLA & Número da escola & Numérico & \\
\hline N_TIT & Número titular & Numérico & \\
\hline REG & Região & Numérico & $\begin{array}{l}1=\text { "NORTE" } \\
2=\text { "NORDESTE" } \\
3=\text { "SUDESTE" } \\
4=\text { "SUL" } \\
5=\text { "CENTRO OESTE" }\end{array}$ \\
\hline MUNIC & Código do Município & Numérico & \\
\hline DEPEND & Dependência administrativa & Numérico & $\begin{array}{l}1 \text { = "Municipal" } \\
2 \text { = "Estadual" } \\
3 \text { = "Particular" } \\
\end{array}$ \\
\hline COD_ESCOLA & Código da Escola & Numérico & \\
\hline ESTADO & Estado & Texto & \\
\hline MUNICIPIO & Município & Texto & \\
\hline NOME_ESCOLA & Nome da Escola & Texto & \\
\hline SERIE_1 A SERIE_3 & Séries & Numérico & $\begin{array}{l}1=" 5^{\circ} \text { ano do Ensino } \\
\text { Fundamental (antiga } 4^{\mathrm{a}} \text { série)" } \\
2=" 9^{\circ} \text { ano do Ensino } \\
\text { Fundamental (antiga } 8^{\mathrm{a}} \text { série)" } \\
3=2^{\circ} \text { ano do Ensino Médio" }\end{array}$ \\
\hline SEXO & Sexo & Numérico & $\begin{array}{l}1=\text { "Feminino" } \\
2=\text { "Masculino" }\end{array}$ \\
\hline IDADE & Idade & Numérico & \\
\hline IDAD_FX & Faixa Etária & Numérico & $\begin{array}{l}1=\text { ="18 a } 24 \text { anos" } \\
2=\text { "25 a } 34 \text { anos" } \\
3=\text { "35 a } 44 \text { anos" } \\
4=\text { "45 a } 59 \text { anos" } \\
5=\text { "60 anos ou mais" }\end{array}$ \\
\hline IDADCR & Faixa Etária (novo agrupamento) & Numérico & $\begin{array}{l}1=\text { "Até } 30 \text { anos" } \\
2=\text { " } 31 \text { a } 45 \text { anos" } \\
3=\text { "46 anos ou mais" }\end{array}$ \\
\hline P3 & Cor ou raça & Numérico & $\begin{array}{l}1=\text { "Branca" } \\
2=\text { "Preta" } \\
3=\text { "Parda" } \\
4=\text { "Amarela" } \\
5=\text { "Indígena" }\end{array}$ \\
\hline P401 A P407 & Nível máximo de escolaridade & Numérico & $\begin{array}{l}1 \text { = "Ensino Médio - } \\
\text { Magistério (antigo } 2^{\circ} \text { grau)" } \\
2=\text { "Ensino Médio - Outros } \\
\text { (antigo } 2^{\circ} \text { grau)" } \\
3 \text { = "Ensino Superior - } \\
\text { Pedagogia" } \\
4 \text { = "Ensino Superior - } \\
\text { Licenciatura em Matemática" } \\
5=\text { "Ensino Superior - } \\
\text { Licenciatura em Letras" } \\
6=\text { "Magistério Superior } \\
\text { (Escola Normal Superior)" } \\
7 \text { = "Ensino Superior - Outros" }\end{array}$ \\
\hline
\end{tabular}




\begin{tabular}{|c|c|c|c|}
\hline P5 & $\begin{array}{l}\text { Curso de mais alta titulação } \\
\text { completado }\end{array}$ & Numérico & $\begin{array}{l}1 \text { = "Não fez ou ainda não } \\
\text { completou nenhum curso de } \\
\text { pós-graduação" } \\
2=\text { "Especialização (mínimo de } \\
360 \text { horas)" } \\
3 \text { = "Mestrado" } \\
4 \text { = "Doutorado" }\end{array}$ \\
\hline P6_ANOS & $\begin{array}{l}\text { Tempo de exercício da fundação de } \\
\text { Coordenador Pedagógico (em anos) }\end{array}$ & Numérico & \\
\hline P6_MES & $\begin{array}{l}\text { Tempo de exercício da fundação de } \\
\text { Coordenador Pedagógico (em meses) }\end{array}$ & Numérico & \\
\hline P6X & $\begin{array}{l}\text { Tempo de exercício da fundação de } \\
\text { Coordenador Pedagógico }\end{array}$ & Numérico & $\begin{array}{l}2=\text { "Até } 2 \text { anos" } \\
5=\text { "De } 3 \text { a } 5 \text { anos" } \\
10=\text { "De } 6 \text { a } 10 \text { anos" } \\
11=\text { "11 anos ou mais" }\end{array}$ \\
\hline P701 A P704 & $\begin{array}{l}\text { Outras atividades, além de } \\
\text { Coordenador Pedagógico }\end{array}$ & Numérico & $\begin{array}{l}1=\text { "Sim, como diretor" } \\
2=\text { "Sim, como professor" } \\
3=\text { "Sim, como coordenador } \\
\text { pedagógico" } \\
4=\text { "Sim, Outra" } \\
5=\text { "Não" }\end{array}$ \\
\hline P8 & $\begin{array}{l}\text { Uso de Internet nos últimos } 3 \text { meses } \\
\text { independente do local }\end{array}$ & Numérico & $\begin{array}{l}1=\text { = "Sim" } \\
2=\text { "Não" }\end{array}$ \\
\hline P9 & $\begin{array}{l}\text { Frequência média de uso de Internet, } \\
\text { independente do local }\end{array}$ & Numérico & $\begin{array}{l}1=\text { "Todos os dias ou quase } \\
\text { todos os dias" } \\
2=\text { "Pelo menos uma vez por } \\
\text { semana" } \\
3=\text { "Pelo menos uma vez por } \\
\text { mês" } \\
4=\text { "Menos do que uma vez por } \\
\text { mês" }\end{array}$ \\
\hline P10 & Posse de computador na moradia & Numérico & $\begin{array}{l}1=\text { "Sim" } \\
2=\text { "Não" }\end{array}$ \\
\hline P1101 A P1103 & Tipo de computador da moradia & Numérico & $\begin{array}{l}1 \text { = "Computador de mesa" } \\
2 \text { = "Computador portátil } \\
\text { (notebook / laptop / netbook)" } \\
3 \text { = "Tablet" } \\
8 \text { = "Não sabe" }\end{array}$ \\
\hline P1201 & $\begin{array}{l}\text { Forma de aquisição do computador } \\
\text { de mesa }\end{array}$ & Numérico & $\begin{array}{l}1 \text { = "Recursos pessoais } \\
\text { próprios" } \\
2=\text { "Recursos de algum } \\
\text { membro da família" } \\
3 \text { = "Recursos subsidiados por } \\
\text { programas do governo" } \\
4=\text { "Outros" } \\
\end{array}$ \\
\hline P1202 & $\begin{array}{l}\text { Forma de aquisição do computador } \\
\text { portátil }\end{array}$ & Numérico & $\begin{array}{l}1 \text { = "Recursos pessoais } \\
\text { próprios" } \\
2 \text { = "Recursos de algum } \\
\text { membro da família" } \\
3 \text { = "Recursos subsidiados por } \\
\text { programas do governo" } \\
4=\text { "Outros" }\end{array}$ \\
\hline P1203 & Forma de aquisição do tablet & Numérico & $\begin{array}{l}1 \text { = "Recursos pessoais } \\
\text { próprios" } \\
2=\text { "Recursos de algum } \\
\text { membro da família" } \\
3=\text { "Recursos subsidiados por } \\
\text { programas do governo" } \\
4=\text { "Outros" } \\
\end{array}$ \\
\hline P13 & $\begin{array}{l}\text { Levou o computador portátil para a } \\
\text { escola alguma vez }\end{array}$ & Numérico & $\begin{array}{l}1 \text { = "Sim" } \\
2 \text { = "Não" }\end{array}$ \\
\hline P14 & $\begin{array}{l}\text { Acesso à Internet na residência, } \\
\text { independente de ser utilizada ou não }\end{array}$ & Numérico & $\begin{array}{l}1=\text { "Sim" } \\
2=\text { "Não" } \\
8=\text { "Não sabe" }\end{array}$ \\
\hline
\end{tabular}




\begin{tabular}{|c|c|c|c|}
\hline $\mathrm{P} 1501$ & Uso da Internet em casa & Numérico & $\begin{array}{l}1 \text { = "Sim" } \\
2=\text { "Não" }\end{array}$ \\
\hline $\mathrm{P} 1502$ & Uso da Internet na escola & Numérico & $\begin{array}{l}1=\text { "Sim" } \\
2 \text { = "Não" }\end{array}$ \\
\hline P1503 & $\begin{array}{l}\text { Uso da Internet em algum outro } \\
\text { estabelecimento (faculdade, curso, } \\
\text { etc.) }\end{array}$ & Numérico & $\begin{array}{l}1=\text { "Sim" } \\
2=\text { "Não" }\end{array}$ \\
\hline P1504 & $\begin{array}{l}\text { Uso da Internet na casa de outra } \\
\text { pessoa (amigo, colega, parente, } \\
\text { vizinho, etc.) }\end{array}$ & Numérico & $\begin{array}{l}1=\text { = "Sim" } \\
2=\text { "Não" }\end{array}$ \\
\hline $\mathrm{P} 1505$ & $\begin{array}{l}\text { Uso da Internet em local público de } \\
\text { acesso gratuito (como biblioteca } \\
\text { externa à escola, centro comunitário, } \\
\text { Correios, SESC, etc.) }\end{array}$ & Numérico & $\begin{array}{l}1=\text { "Sim" } \\
2=\text { "Não" }\end{array}$ \\
\hline P1506 & $\begin{array}{l}\text { Uso da Internet em local de acesso } \\
\text { pago (lan house, Internet café, } \\
\text { hotspot) }\end{array}$ & Numérico & $\begin{array}{l}1=\text { "Sim" } \\
2=\text { "Não" }\end{array}$ \\
\hline P1507 & Uso da Internet em algum outro local & Numérico & $\begin{array}{l}1 \text { = "Sim" } \\
2=\text { "Não" }\end{array}$ \\
\hline $\begin{array}{l}\text { P1507_cod_1 } \\
\text { P1507_cod_2 }\end{array}$ & Outros locais aonde usou Internet & Numérico & $\begin{array}{l}17=\text { "Aeroporto" } \\
19=\text { "Gabinete do Senador" } \\
20=\text { "No trabalho" } \\
22=\text { "Trabalho do marido" } \\
23=\text { "Hotéis" } \\
27=\text { "Restaurante" } \\
28=\text { "Shopping" } \\
36=\text { "Consultório médico" } \\
99=\text { "Nao respondeu" }\end{array}$ \\
\hline $\begin{array}{ll}\text { P1501_RES } & \text { TO } \\
\text { P15_NAO } & \end{array}$ & Locais onde utilizaram a Internet & Numérico & $\begin{array}{l}1 \text { = "Em casa" } \\
2=\text { "Na escola" } \\
3 \text { = "Em algum outro } \\
\text { estabelecimento de ensino } \\
\text { (faculdade, curso, etc.)" } \\
4 \text { = "Na casa de outra pessoa } \\
\text { (amigo, colega, parente, } \\
\text { vizinho, etc.)" } \\
5=\text { "Local público de acesso } \\
\text { gratuito (como biblioteca } \\
\text { externa à escola, centro } \\
\text { comunitário, Correios, SESC, } \\
\text { etc.)" } \\
6=\text { "Local de acesso pago } \\
\text { (lanhouse, Internet café, } \\
\text { hotspot)" } \\
7 \text { = "Outros locais" } \\
8=\text { "Não utilizou" } \\
\end{array}$ \\
\hline P16 & $\begin{array}{l}\text { Local onde utiliza a Internet mais } \\
\text { frequentemente }\end{array}$ & Numérico & $\begin{array}{l}1 \text { = "Em casa" } \\
2=\text { "Na escola" } \\
3 \text { = "Em algum outro } \\
\text { estabelecimento de ensino } \\
\text { (faculdade, curso, etc.)" } \\
5 \text { = "Local público de acesso } \\
\text { gratuito (como biblioteca } \\
\text { externa à escola, centro } \\
\text { comunitário, Correios, SESC, } \\
\text { etc.)" } \\
6=\text { "Local de acesso pago } \\
\text { (lanhouse, Internet café, } \\
\text { hotspot)" } \\
96=\text { "Em algum outro local" } \\
999=\text { "Não utilizou Internet } \\
\text { nos últimos } 3 \text { meses" }\end{array}$ \\
\hline P17 & $\begin{array}{l}\text { Acesso à Internet através do telefone } \\
\text { celular }\end{array}$ & Numérico & $\begin{array}{l}1 \text { = "Sim" } \\
2=\text { "Não" }\end{array}$ \\
\hline
\end{tabular}




\begin{tabular}{|c|c|c|c|}
\hline P1801 A P1809 & $\begin{array}{l}\text { Aç̃oes que consideram prioritárias em } \\
\text { relação ao projeto pedagógico da } \\
\text { escola }\end{array}$ & Numérico & $\begin{array}{l}1 \text { = "Aumentar o número de } \\
\text { computadores por aluno" } \\
2 \text { = "Aumentar o número de } \\
\text { computadores conectados à } \\
\text { Internet" } \\
3 \text { = "Aumentar a velocidade de } \\
\text { acesso à Internet" } \\
4=\text { "Melhorar as habilidades e } \\
\text { competências técnicas dos } \\
\text { professores no uso das } \\
\text { tecnologias" } \\
5=\text { = "Exercer novos métodos de } \\
\text { ensino-aprendizagem através da } \\
\text { expansão do repertório } \\
\text { pedagógico" } \\
6=\text { "Fornecer incentivos (ajuste } \\
\text { de salário, promoção) aos } \\
\text { professores para integrar o uso } \\
\text { do computador e da Internet } \\
\text { no" } \\
7=\text { "Melhorar as habilidades e } \\
\text { competências dos alunos no uso } \\
\text { das tecnologias" } \\
96=\text { "Nenhum (Espontânea)" } \\
97=\text { "Outras prioridades" } \\
99=\text { "Não respondeu } \\
\text { (Espontânea)" }\end{array}$ \\
\hline P19 & $\begin{array}{l}\text { Principal prioridade considerando o } \\
\text { projeto pedagógico }\end{array}$ & Numérico & $\begin{array}{l}1 \text { = "Aumentar o número de } \\
\text { computadores por aluno" } \\
2 \text { = "Aumentar o número de } \\
\text { computadores conectados à } \\
\text { Internet" } \\
3 \text { = "Aumentar a velocidade de } \\
\text { acesso à Internet" } \\
4 \text { = "Melhorar as habilidades e } \\
\text { competências técnicas dos } \\
\text { professores no uso das } \\
\text { tecnologias" } \\
5=\text { = Exercer novos métodos de } \\
\text { ensino-aprendizagem através da } \\
\text { expansão do repertório } \\
\text { pedagógico" } \\
6=\text { = "Fornecer incentivos (ajuste } \\
\text { de salário, promoção) aos } \\
\text { professores para integrar o uso } \\
\text { do computador e da Internet } \\
\text { no" } \\
7 \text { = "Melhorar as habilidades e } \\
\text { competências dos alunos no uso } \\
\text { das tecnologias" } \\
96=\text { = Nenhum (Espontânea)" } \\
97 \text { = "Outras prioridades" } \\
99=\text { = Não respondeu } \\
\text { (Espontânea)" }\end{array}$ \\
\hline P2001 & 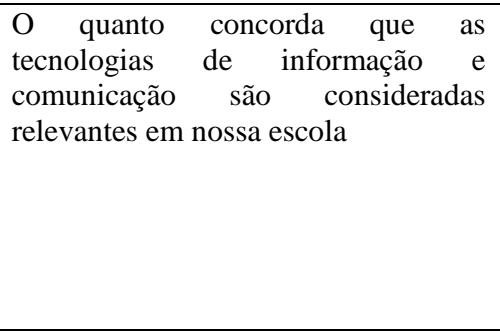 & Numérico & $\begin{array}{l}1=\text { = "Discordo totalmente" } \\
2=\text { "Discordo em parte" } \\
3=\text { ="Nem concordo, nem } \\
\text { discordo" } \\
4=\text { = "Concordo em parte" } \\
5=\text { "Concordo totalmente" } \\
7=\text { "Nessa escola isso não } \\
\text { acontece" } \\
9=\text { "Não respondeu" }\end{array}$ \\
\hline
\end{tabular}




\begin{tabular}{|c|c|c|c|}
\hline P2002 & $\begin{array}{l}\text { O quanto concorda que nossa escola } \\
\text { integrou o computador e a Internet às } \\
\text { práticas de ensino-aprendizagem }\end{array}$ & Numérico & $\begin{array}{l}1 \text { = "Discordo totalmente" } \\
2=\text { "Discordo em parte" } \\
3=\text { "Nem concordo, nem } \\
\text { discordo" } \\
4=\text { "Concordo em parte" } \\
5=\text { "Concordo totalmente" } \\
7 \text { = "Nessa escola isso não } \\
\text { acontece" } \\
9=\text { "Não respondeu" }\end{array}$ \\
\hline P2003 & $\begin{array}{l}\text { O quanto concorda que nossa escola } \\
\text { começou recentemente a usar o } \\
\text { computador e a Internet no ensino- } \\
\text { aprendizagem dos conteúdos } \\
\text { escolares }\end{array}$ & Numérico & $\begin{array}{l}1 \text { = "Discordo totalmente" } \\
2=\text { "Discordo em parte" } \\
3=\text { "Nem concordo, nem } \\
\text { discordo" } \\
4=\text { "Concordo em parte" } \\
5 \text { = "Concordo totalmente" } \\
7=\text { "Nessa escola isso não } \\
\text { acontece" } \\
9=\text { "Não respondeu" }\end{array}$ \\
\hline P2004 & $\begin{array}{l}\text { O quanto concorda que ainda não } \\
\text { sabemos quais ferramentas do } \\
\text { computador e da Internet são úteis } \\
\text { para a nossa escola }\end{array}$ & Numérico & $\begin{array}{l}1 \text { = "Discordo totalmente" } \\
2 \text { = "Discordo em parte" } \\
3=\text { "Nem concordo, nem } \\
\text { discordo" } \\
4 \text { = "Concordo em parte" } \\
5 \text { = "Concordo totalmente" } \\
7 \text { = "Nessa escola isso não } \\
\text { acontece" } \\
9=\text { "Não respondeu" }\end{array}$ \\
\hline P2005 & $\begin{array}{l}\text { O quanto concorda que há limitações } \\
\text { de infraestrutura que eliminam a } \\
\text { possibilidade de usar o computador e } \\
\text { a Internet em nossa escola }\end{array}$ & Numérico & $\begin{array}{l}1=\text { "Discordo totalmente" } \\
2=\text { "Discordo em parte" } \\
3=\text { "Nem concordo, nem } \\
\text { discordo" } \\
4=\text { "Concordo em parte" } \\
5=\text { "Concordo totalmente" } \\
7=\text { "Nessa escola isso não } \\
\text { acontece" } \\
9=\text { "Não respondeu" }\end{array}$ \\
\hline P2101 A P2105 & $\begin{array}{l}\text { Iniciativas ocorridas na escola nos } \\
\text { últimos dois anos por conta da } \\
\text { introdução do computador e Internet }\end{array}$ & Numérico & $\begin{array}{l}1 \text { = "Discutir com os } \\
\text { professores sobre novas } \\
\text { metodologias" } \\
2 \text { = "Consultar os professores } \\
\text { sobre suas expectativas em } \\
\text { termos de mudanças no projeto } \\
\text { pedagógico da escola" } \\
3 \text { = "Monitoramento da } \\
\text { implementação de novas } \\
\text { iniciativas" } \\
4 \text { = "Apresentação e debate } \\
\text { com os alunos sobre as } \\
\text { mudanças que estão ocorrendo } \\
\text { no processo de ensino- } \\
\text { aprendizagem da esco" } \\
5=\text { "Debate com os pais sobre } \\
\text { as mudanças que estão } \\
\text { ocorrendo no processo de } \\
\text { ensino-aprendizagem da } \\
\text { escola" }\end{array}$ \\
\hline P2201 A P2205 & $\begin{array}{l}\text { Atividades que consideram } \\
\text { importantes de ocorrer ainda no ano } \\
\text { letivo corrente }\end{array}$ & Numérico & $\begin{array}{l}1=\text { "Discutir com os } \\
\text { professores sobre novas } \\
\text { metodologias" } \\
2 \text { = "Consultar os professores } \\
\text { sobre suas expectativas em } \\
\text { termos de mudanças no projeto } \\
\text { pedagógico da escola" } \\
3=\text { "Monitoramento da } \\
\text { implementação de novas } \\
\text { iniciativas" } \\
4=\text { "Apresentação e debate }\end{array}$ \\
\hline
\end{tabular}




\begin{tabular}{|c|c|c|c|}
\hline & & & $\begin{array}{l}\text { com os alunos sobre as } \\
\text { mudanças que estão ocorrendo } \\
\text { no processo de ensino- } \\
\text { aprendizagem da esco" } \\
5 \text { = "Debate com os pais sobre } \\
\text { as mudanças que estão } \\
\text { ocorrendo no processo de } \\
\text { ensino-aprendizagem da } \\
\text { escola" }\end{array}$ \\
\hline $\mathrm{P} 2301$ & $\begin{array}{l}\text { O projeto pedagógico da escola } \\
\text { estimula ou requer os professores a } \\
\text { integração do uso da Internet em suas } \\
\text { práticas? }\end{array}$ & Numérico & $\begin{array}{l}1 \text { = "Estimula" } \\
2=\text { "Requer" } \\
3=\text { "Não requer nem estimula" }\end{array}$ \\
\hline $\mathrm{P} 2302$ & $\begin{array}{l}\text { O projeto pedagógico da escola } \\
\text { estimula ou requer os professores a } \\
\text { adoção de novas formas de } \\
\text { avaliação? }\end{array}$ & Numérico & $\begin{array}{l}1=\text { "Estimula" } \\
2=\text { "Requer" } \\
3=\text { "Não requer nem estimula" }\end{array}$ \\
\hline P2303 & $\begin{array}{l}\text { O projeto pedagógico da escola } \\
\text { estimula ou requer os professores a } \\
\text { utilização dos computadores para } \\
\text { monitorar o desempenho dos alunos? }\end{array}$ & Numérico & $\begin{array}{l}1=\text { "Estimula" } \\
2=\text { "Requer" } \\
3=\text { "Não requer nem estimula" }\end{array}$ \\
\hline P2304 & $\begin{array}{l}\text { O projeto pedagógico da escola } \\
\text { estimula ou requer os professores a } \\
\text { atualização quanto ao uso de } \\
\text { computador e Internet no processo de } \\
\text { ensino-aprendizagem? }\end{array}$ & Numérico & $\begin{array}{l}1=\text { "Estimula" } \\
2=\text { "Requer" } \\
3 \text { = "Não requer nem estimula" }\end{array}$ \\
\hline $\mathrm{P} 2305$ & $\begin{array}{l}\text { O projeto pedagógico da escola } \\
\text { estimula ou requer os professores a } \\
\text { utilização de programas de } \\
\text { computador (softwares) específicos } \\
\text { para o ensino de determinados } \\
\text { conteúdos? }\end{array}$ & Numérico & $\begin{array}{l}1=\text { "Estimula" } \\
2=\text { "Requer" } \\
3=\text { "Não requer nem estimula" }\end{array}$ \\
\hline $\begin{array}{l}\text { P2301_RES } \\
\text { P2305_RES }\end{array}$ & $\begin{array}{l}\text { O projeto pedagógico estimula ou } \\
\text { requer os professores a que tipo de } \\
\text { atividades }\end{array}$ & Numérico & $\begin{array}{l}1 \text { = "Integração do uso da } \\
\text { Internet em suas práticas" } \\
2 \text { = "Adoção de novas formas } \\
\text { de avaliação" } \\
3 \text { = "Utilização dos } \\
\text { computadores para monitorar o } \\
\text { desempenho dos alunos" } \\
4 \text { = "Atualização quanto ao uso } \\
\text { de computador e Internet no } \\
\text { processo de ensino- } \\
\text { aprendizagem" } \\
5=\text { "Utilização de programas } \\
\text { de computador (softwares) } \\
\text { específicos para o ensino de } \\
\text { determinados conteúdos" } \\
6=\text { "Não requer nem estimula" }\end{array}$ \\
\hline P24 & $\begin{array}{l}\text { Adoção de metodologias de ensino } \\
\text { com uso de apostilas e outros } \\
\text { materiais didáticos de sistemas de } \\
\text { ensino }\end{array}$ & Numérico & $\begin{array}{l}1=\text { "Sim" } \\
2=\text { "Não" }\end{array}$ \\
\hline P25 & $\begin{array}{l}\text { O sistema adotado promove } \\
\text { realização de atividades que } \\
\text { envolvam material digital, através de } \\
\text { computador e/ou Internet }\end{array}$ & Numérico & $\begin{array}{l}1 \text { = "Sim" } \\
2=\text { "Não" }\end{array}$ \\
\hline P26 & $\begin{array}{l}\text { Esta escola proporciona aulas } \\
\text { específicas de informática, que } \\
\text { ensinem a usar computador e Internet } \\
\text { como parte da grade curricular? }\end{array}$ & Numérico & $\begin{array}{l}1=\text { = "Sim" } \\
2=\text { "Não" } \\
3=\text { "Está previsto/ em fase de } \\
\text { projeto" }\end{array}$ \\
\hline P2701 A P2704 & $\begin{array}{l}\text { Níveis de ensino que são ou serão } \\
\text { beneficiados em atividades com } \\
\text { utilização de material digital }\end{array}$ & Numérico & $\begin{array}{l}1 \text { = "Educação Infantil" } \\
2 \text { = "Ensino Fundamental I" } \\
3 \text { = "Ensino Fundamental II" } \\
4 \text { = "Ensino Médio" }\end{array}$ \\
\hline
\end{tabular}




\begin{tabular}{|c|c|c|c|}
\hline P2801 & $\begin{array}{l}\text { Grau de dificuldade em utilizar } \\
\text { computador e Internet por ausência } \\
\text { de suporte técnico }\end{array}$ & Numérico & $\begin{array}{l}1=\text { "Dificulta muito" } \\
2=\text { "Dificulta" } \\
3=\text { "Dificulta um pouco" } \\
4 \text { = "Não dificulta em nada" } \\
7=\text { "Nessa escola isso não } \\
\text { acontece" } \\
9=\text { = Não respondeu" }\end{array}$ \\
\hline $\mathrm{P} 2802$ & $\begin{array}{l}\text { Grau de dificuldade em utilizar } \\
\text { computador e Internet por falta de } \\
\text { apoio pedagógico aos professores } \\
\text { para o uso do computador e Internet }\end{array}$ & Numérico & $\begin{array}{l}2=\text { "Dificulta muito" } \\
2=\text { "Dificulta" } \\
3 \text { = "Dificulta um pouco" } \\
4 \text { = "Não dificulta em nada" } \\
7 \text { = "Nessa escola isso não } \\
\text { acontece" } \\
9=\text { = Não respondeu" }\end{array}$ \\
\hline P2803 & $\begin{array}{l}\text { Grau de dificuldade em utilizar } \\
\text { computador e Internet por número } \\
\text { insuficiente de computadores } \\
\text { conectados à Internet }\end{array}$ & Numérico & $\begin{array}{l}3=\text { "Dificulta muito" } \\
2=\text { "Dificulta" } \\
3=\text { "Dificulta um pouco" } \\
4 \text { = "Não dificulta em nada" } \\
7=\text { "Nessa escola isso não } \\
\text { acontece" } \\
9=\text { = Não respondeu" }\end{array}$ \\
\hline P2804 & $\begin{array}{l}\text { Grau de dificuldade em utilizar } \\
\text { computador e Internet por baixa } \\
\text { velocidade na conexão de Internet }\end{array}$ & Numérico & $\begin{array}{l}4=\text { "Dificulta muito" } \\
2=\text { "Dificulta" } \\
3=\text { "Dificulta um pouco" } \\
4 \text { = "Não dificulta em nada" } \\
7=\text { "Nessa escola isso não } \\
\text { acontece" } \\
9=\text { = Não respondeu" }\end{array}$ \\
\hline P2805 & $\begin{array}{l}\text { Grau de dificuldade em utilizar } \\
\text { computador e Internet por número } \\
\text { insuficiente de computadores por } \\
\text { aluno }\end{array}$ & Numérico & $\begin{array}{l}5=\text { "Dificulta muito" } \\
2=\text { "Dificulta" } \\
3=\text { "Dificulta um pouco" } \\
4 \text { = "Não dificulta em nada" } \\
7=\text { "Nessa escola isso não } \\
\text { acontece" } \\
9=\text { =Não respondeu" }\end{array}$ \\
\hline P2806 & 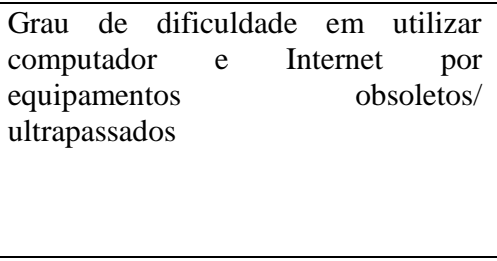 & Numérico & $\begin{array}{l}6=\text { "Dificulta muito" } \\
2=\text { "Dificulta" } \\
3=\text { "Dificulta um pouco" } \\
4 \text { = "Não dificulta em nada" } \\
7=\text { "Nessa escola isso não } \\
\text { acontece" } \\
9=\text { =Não respondeu" }\end{array}$ \\
\hline P2807 & $\begin{array}{l}\text { Grau de dificuldade em utilizar } \\
\text { computador e Internet por pressão/ } \\
\text { falta de tempo para cumprir com o } \\
\text { conteúdo previsto (grade curricular) }\end{array}$ & Numérico & $\begin{array}{l}7=\text { "Dificulta muito" } \\
2 \text { = "Dificulta" } \\
3 \text { = "Dificulta um pouco" } \\
4 \text { = "Não dificulta em nada" } \\
7 \text { = "Nessa escola isso não } \\
\text { acontece" } \\
9=\text { = Não respondeu" }\end{array}$ \\
\hline P2808 & $\begin{array}{l}\text { Grau de dificuldade em utilizar } \\
\text { computador e Internet por pressão } \\
\text { para conseguir boas notas nas } \\
\text { avaliações de desempenho }\end{array}$ & Numérico & $\begin{array}{l}8=\text { = Dificulta muito" } \\
2=\text { "Dificulta" } \\
3=\text { "Dificulta um pouco" } \\
4 \text { = "Não dificulta em nada" } \\
7 \text { = "Nessa escola isso não } \\
\text { acontece" } \\
9=\text { =Não respondeu" }\end{array}$ \\
\hline P2901 & $\begin{array}{l}\text { Grau de concordância com a } \\
\text { afirmação de que a escola integrou o } \\
\text { computador e a Internet às práticas de } \\
\text { ensino-aprendizagem }\end{array}$ & Numérico & $\begin{array}{l}1=\text { "Discordo Totalmente" } \\
2=\text { "Discordo em parte" } \\
3=\text { "Nem concordo, nem } \\
\text { discordo" } \\
4=\text { "Concordo em parte" } \\
5=\text { "Concordo totalmente" } \\
7=\text { "Nessa escola isso não } \\
\text { acontece" } \\
9=\text { "Não respondeu" }\end{array}$ \\
\hline
\end{tabular}




\begin{tabular}{|c|c|c|c|}
\hline P2902 & $\begin{array}{lcrr}\text { Grau de concordância com a } & \text { a } \\
\text { afirmação de } & \text { que esta escola faz } \\
\text { manutenção } & \text { regular } & \text { nos } \\
\text { computadores } & & \end{array}$ & Numérico & $\begin{array}{l}1=\text { "Discordo Totalmente" } \\
2=\text { "Discordo em parte" } \\
3=\text { "Nem concordo, nem } \\
\text { discordo" } \\
4=\text { "Concordo em parte" } \\
5=\text { "Concordo totalmente" } \\
7=\text { "Nessa escola isso não } \\
\text { acontece" } \\
9=\text { "Não respondeu" }\end{array}$ \\
\hline P2903 & $\begin{array}{l}\text { Grau de concordância com a } \\
\text { afirmação de que nesta escola, há } \\
\text { treinamento para os alunos, de como } \\
\text { se usa computador e Internet. }\end{array}$ & Numérico & $\begin{array}{l}1=\text { "Discordo Totalmente" } \\
2=\text { "Discordo em parte" } \\
3=\text { "Nem concordo, nem } \\
\text { discordo" } \\
4=\text { "Concordo em parte" } \\
5=\text { "Concordo totalmente" } \\
7=\text { "Nessa escola isso não } \\
\text { acontece" } \\
9=\text { "Não respondeu" }\end{array}$ \\
\hline P2904 & $\begin{array}{l}\text { Grau de concordância com a } \\
\text { afirmação de que nesta escola, há } \\
\text { treinamento para os professores, de } \\
\text { como se usa computador e Internet. }\end{array}$ & Numérico & $\begin{array}{l}1=\text { "Discordo Totalmente" } \\
2=\text { "Discordo em parte" } \\
3=\text { "Nem concordo, nem } \\
\text { discordo" } \\
4=\text { "Concordo em parte" } \\
5=\text { "Concordo totalmente" } \\
7=\text { "Nessa escola isso não } \\
\text { acontece" } \\
9=\text { "Não respondeu" }\end{array}$ \\
\hline P2905 & $\begin{array}{l}\text { Grau de concordância com a } \\
\text { afirmação de que nesta escola, há } \\
\text { treinamento para os coordenadores, } \\
\text { de como se usa computador e Internet }\end{array}$ & Numérico & $\begin{array}{l}1=\text { "Discordo Totalmente" } \\
2=\text { "Discordo em parte" } \\
3=\text { "Nem concordo, nem } \\
\text { discordo" } \\
4=\text { "Concordo em parte" } \\
5=\text { "Concordo totalmente" } \\
7=\text { "Nessa escola isso não } \\
\text { acontece" } \\
9=\text { "Não respondeu" }\end{array}$ \\
\hline P2906 & $\begin{array}{l}\text { Grau de concordância com a } \\
\text { afirmação de que os alunos desta } \\
\text { escola sabem mais sobre o } \\
\text { computador e a Internet do que o } \\
\text { Professor }\end{array}$ & Numérico & $\begin{array}{l}1=\text { "Discordo Totalmente" } \\
2=\text { "Discordo em parte" } \\
3=\text { "Nem concordo, nem } \\
\text { discordo" } \\
4=\text { "Concordo em parte" } \\
5=\text { "Concordo totalmente" } \\
7=\text { "Nessa escola isso não } \\
\text { acontece" } \\
9=\text { "Não respondeu" }\end{array}$ \\
\hline P2907 & $\begin{array}{l}\text { Grau de concordância com a } \\
\text { afirmação de que com a Internet, os } \\
\text { alunos acabam perdendo o contato } \\
\text { com a realidade }\end{array}$ & Numérico & $\begin{array}{l}1=\text { "Discordo Totalmente" } \\
2=\text { "Discordo em parte" } \\
3=\text { "Nem concordo, nem } \\
\text { discordo" } \\
4=\text { "Concordo em parte" } \\
5=\text { "Concordo totalmente" } \\
7=\text { "Nessa escola isso não } \\
\text { acontece" } \\
9=\text { "Não respondeu" }\end{array}$ \\
\hline P2908 & $\begin{array}{l}\text { Grau de concordância com a } \\
\text { afirmação de que não confio nas } \\
\text { informações contidas na Internet }\end{array}$ & Numérico & $\begin{array}{l}1=\text { = Discordo Totalmente" } \\
2=\text { "Discordo em parte" } \\
3=\text { "Nem concordo, nem } \\
\text { discordo" } \\
4=\text { "Concordo em parte" } \\
5=\text { "Concordo totalmente" } \\
7=\text { "Nessa escola isso não } \\
\text { acontece" } \\
9=\text { "Não respondeu" }\end{array}$ \\
\hline
\end{tabular}




\begin{tabular}{|c|c|c|c|}
\hline P2909 & $\begin{array}{l}\text { Grau de concordância com a } \\
\text { afirmação de que os professores desta } \\
\text { escola não têm tempo suficiente para } \\
\text { preparar aulas com o computador e a } \\
\text { Internet }\end{array}$ & Numérico & $\begin{array}{l}1=\text { = "Discordo Totalmente" } \\
2=\text { "Discordo em parte" } \\
3=\text { ="Nem concordo, nem } \\
\text { discordo" } \\
4=\text { ="Concordo em parte" } \\
5=\text { "Concordo totalmente" } \\
7=\text { "Nessa escola isso não } \\
\text { acontece" } \\
9=\text { "Não respondeu" }\end{array}$ \\
\hline REND1 & Renda pessoal & Numérico & 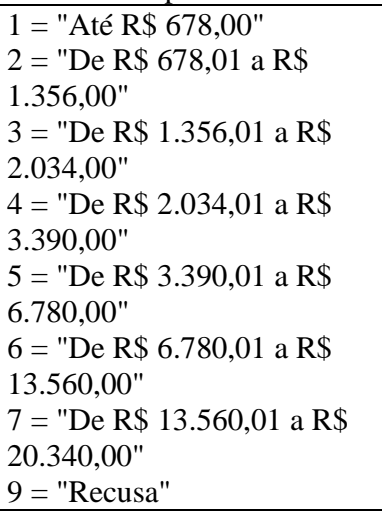 \\
\hline REND2 & Renda familiar & Numérico & $\begin{array}{l}=\text { = Até } \mathrm{R} \$ 678,00 " \\
2=\text { "De } \mathrm{R} \$ 678,01 \text { a } \$ \\
1.356,00 " \\
3=\text { "De } \mathrm{R} \$ 1.356,01 \text { a } \mathrm{R} \$ \\
2.034,00 " \\
4=\text { "De } \mathrm{R} \$ 2.034,01 \text { a } \mathrm{R} \$ \\
3.390,00 " \\
5=\text { "De } \mathrm{R} \$ 3.390,01 \text { a } \mathrm{R} \$ \\
6.780,00 " \\
6=\text { "De } \mathrm{R} \$ 6.780,01 \text { a } \mathrm{R} \$ \\
13.560,00 " \\
7=\text { "De } \mathrm{R} \$ 13.560,01 \text { a } \$ \\
20.340,00 " \\
9=\text { "Recusa" }\end{array}$ \\
\hline RENDCR_1 & Renda pessoal (em salários mínimos) & Numérico & $\begin{array}{l}3 \text { = "ATÉ } 3 \text { SM" } \\
4=\text { "MAIS DE } 3 \text { ATÉ } 5 \text { SM" } \\
5=\text { "MAIS DE } 5 \text { SM" } \\
9=\text { "RECUSA" }\end{array}$ \\
\hline RENDCR_2 & Renda familiar (em salários mínimos) & Numérico & $\begin{array}{l}3 \text { = "ATÉ } 3 \text { SM" } \\
4=\text { "MAIS DE } 3 \text { ATÉ } 5 \text { SM" } \\
5=\text { "MAIS DE } 5 \text { SM" } \\
9=\text { "RECUSA" }\end{array}$ \\
\hline LAB & $\begin{array}{l}\text { Computador instalado no laboratório } \\
\text { de informática }\end{array}$ & Numérico & $\begin{array}{l}1=\text { "Tem" } \\
2=\text { "Não tem" } \\
9=\text { "Sem informação" }\end{array}$ \\
\hline COMP_ALUNO & Alunos tem acesso a computadores & Numérico & $\begin{array}{l}1=\text { "Tem acesso" } \\
2=\text { "Não tem acesso" } \\
9=\text { "Sem informação" }\end{array}$ \\
\hline COMP_PROF & $\begin{array}{llll}\begin{array}{l}\text { Professores } \\
\text { computadores }\end{array} & \text { tem } & \text { acesso } & \text { a } \\
\end{array}$ & Numérico & $\begin{array}{l}1=\text { "Tem acesso" } \\
2=\text { "Não tem acesso" } \\
9=\text { "Sem informação" }\end{array}$ \\
\hline LAB_INTERNET & $\begin{array}{l}\text { Internet instalada no laboratório de } \\
\text { informática }\end{array}$ & Numérico & $\begin{array}{l}1 \text { = "Tem" } \\
2=\text { "Não tem" } \\
9=\text { "Sem informação" }\end{array}$ \\
\hline
\end{tabular}

